\title{
CONTRIBUCIÓN AL ESTUDIO DE LA LIQUENOBIOTA DEL PATRIMONIO EDILICIO DE LA PROVINCIA DE BUENOS AIRES (ARGENTINA)
}

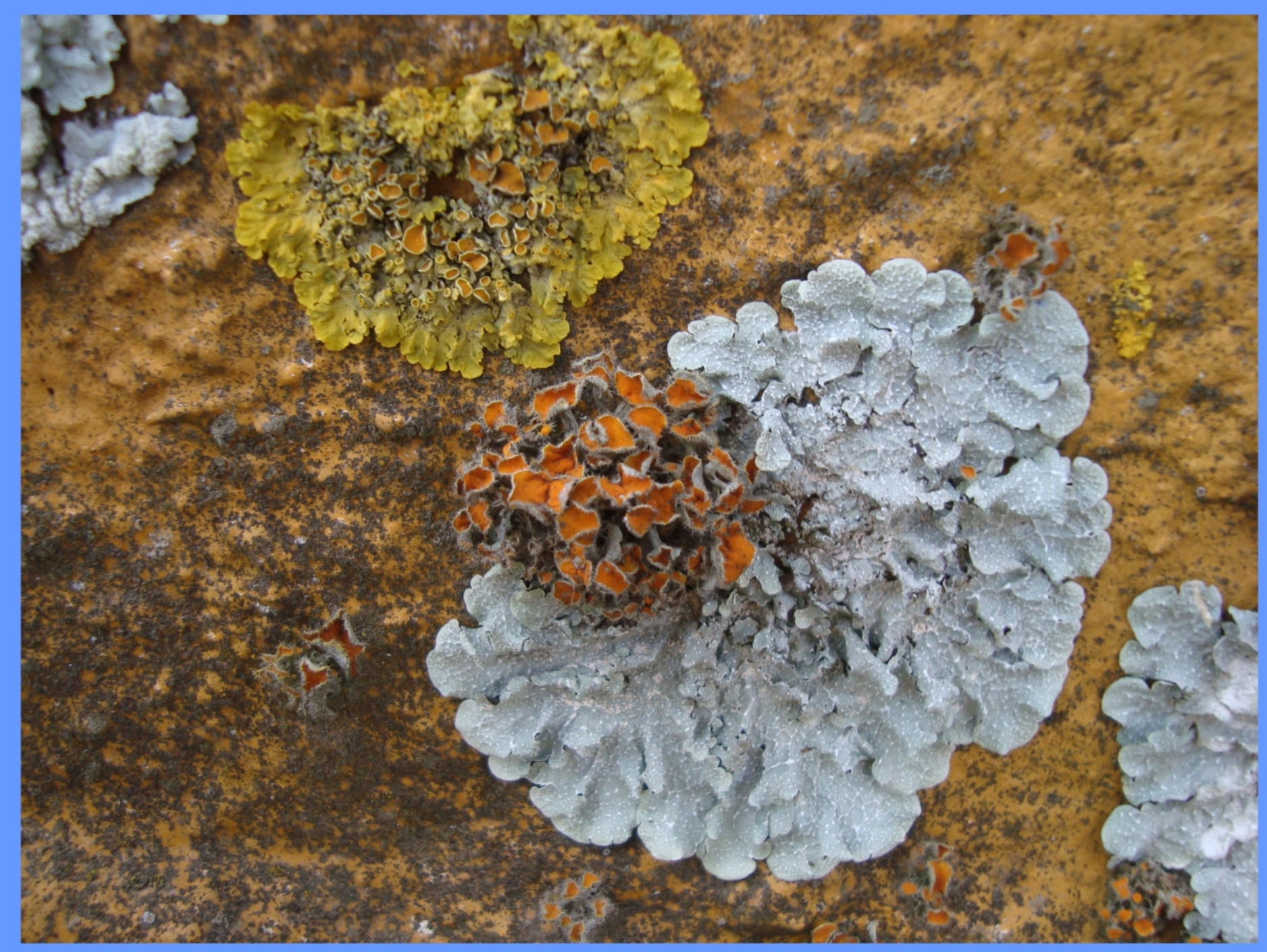

Renato Andrés García 


\section{UNIVERSIDAD NACIONAL DE LA PLATA \\ FACULTAD DE CIENCIAS NATURALES Y MUSEO \\ DOCTORADO EN CIENCIAS NATURALES}

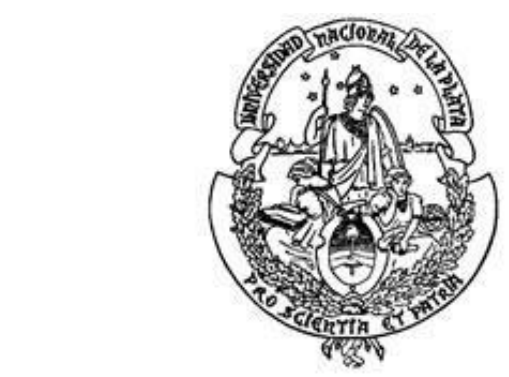

Universidad Nacional de La Plata

TESIS DOCTORAL

CONTRIBUCIÓN AL ESTUDIO DE LA LIQUENOBIOTA DEL PATRIMONIO EDILICIO DE LA PROVINCIA DE BUENOS AIRES (ARGENTINA)

Lic. Renato Andrés García

Tesista

Dra. María Julia Kristensen

Dra. Vilma Gabriela Rosato

Co-Directora

Directora

Año 2017 
"Los monumentos pueden soportar una flora liquénica extermadamente rica y especial, y no deben ser ignoradas en relevamientos florísticos solo porque se encuentren fuera de reservas naturales".

Aptroot \& James (2002) 


\section{Agradecimientos}

A mi familia quienes me ayudaron económica y emocionalmente para que pudiera estudiar la carrera de grado y posgrado.

A Vilma y Julia mis directoras, quienes han sabido ayudarme, motivarme y orientarme en cada momento de esta tesis.

A Mechi mi novia y ayudante de campo ocasional, quien me apoyo durante toda esta experiencia.

A Alexandra Elbakyan la creadora y directora del proyecto Sci-hub, el cual permitió que pudiera acceder a bibliografía.

A mis amigos Ale, Chule, Jere, Kique, Mairo y al resto del Centro Cultural García por los asados, discusiones de fútbol, taxonomía, ecología y campañas.

A los liquenólogos argentinos Juan Manuel Lavornia, Edith Filippini, Juan Manuel Rodríguez, Cecilia Estrabou, Juan Martín Hernández, Alfredo Passo, Andrea Michling, Lidia Ferraro y Nadia de la Rosa quienes siempre estuvieron dispuestos a dar su opinión, sugerencias y compartir bibliografía.

A Ulf Arup, Kerry Knused, Andre Aptroot quienes de forma desinteresada me han dado una mano en determinación de especies y con bibliografía.

A la OPDS por los permisos de colecta otorgados. A los guardaparques que facilitaron las colectas en las áreas protegidas y en especial al Cuerpo de Guardaparques de la Reserva Natural de Punta Lara quienes siempre se han mostrado interesados en mi trabajo.

Al Ing. Luis Traversa por el lugar de trabajo en el Laboratorio de Estudios Multidisciplinarios para la Investigación Tecnológica.

Al personal del Laboratorio de Estudios Multidisciplinarios para la Investigación Tecnológica, en especial a la Dra. Anahí Lopez por los mates y las charlas.

A la Comisión de Investigaciones Científicas de La Provincia de Buenos Aires y al CONICET por las becas otorgadas, que posibilitaron la realización de ésta tesis. 
Índice

Resumen

Abstract

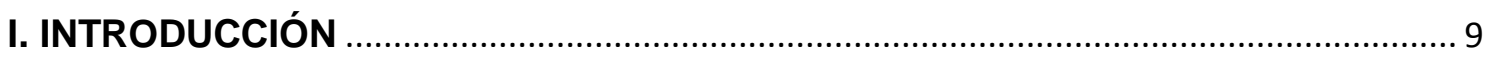

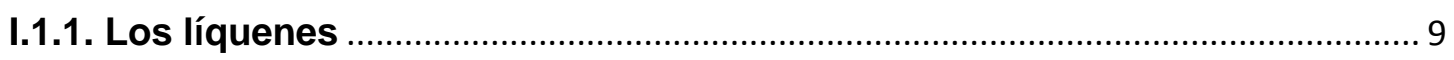

I.1.2. Los líquenes en el ambiente .......................................................................... 11

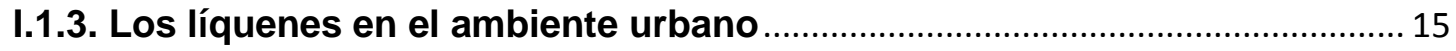

I.1.4. Sucesión y el cambio en la comunidad......................................................... 21

I.1.5. La competencia y el rol en la estructura de las comunidades..................... 24

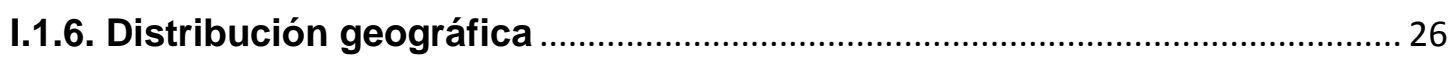

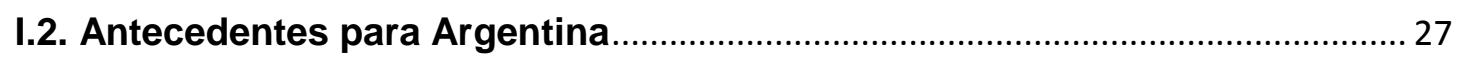

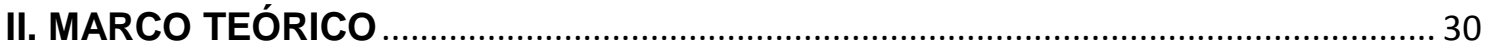

II.1.1. La comunidad ecológica ............................................................................ 30

II.1.2. El efecto de las condiciones ambientales en la estructura de la

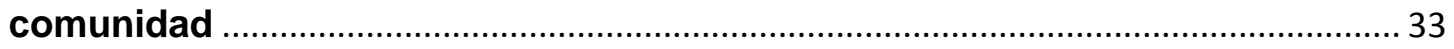

II.1.3. Factores que operan en la dispersión de los líquenes ............................... 36

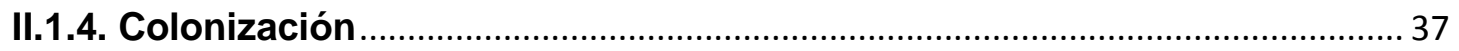

II.1.5. La sucesión de las comunidades .................................................................. 39

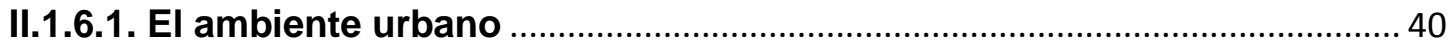

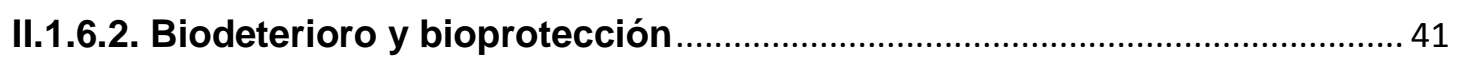

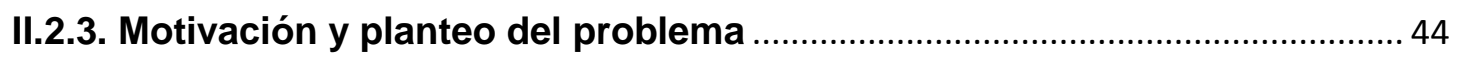

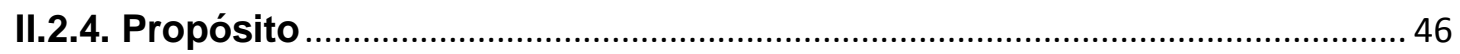

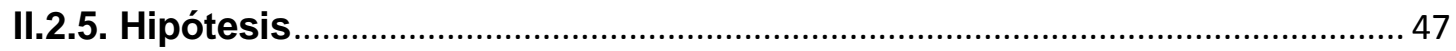

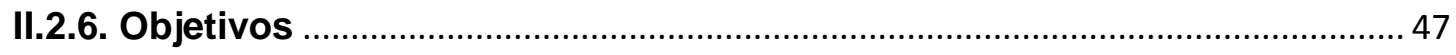

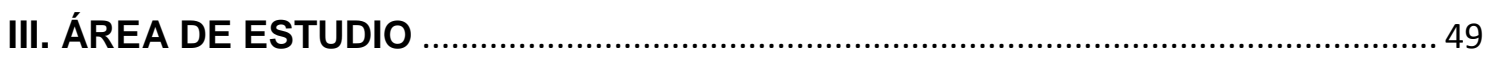

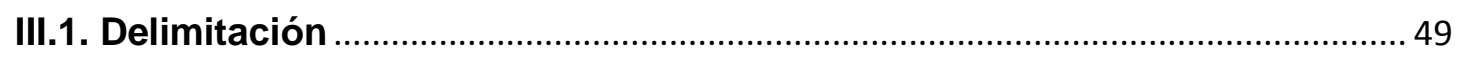

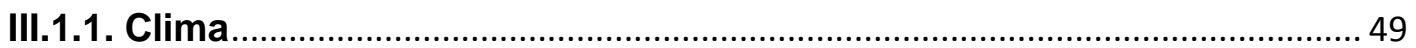

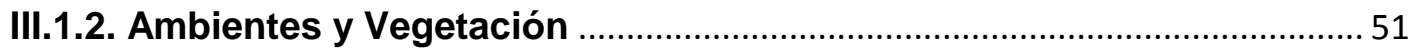

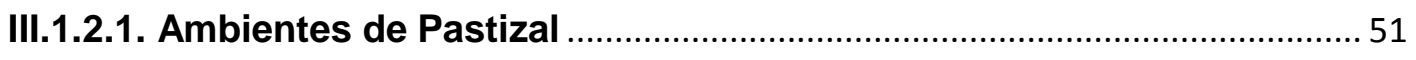

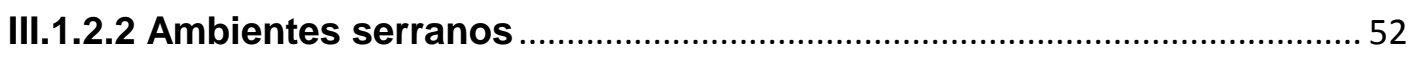

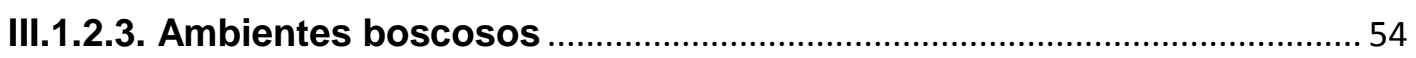

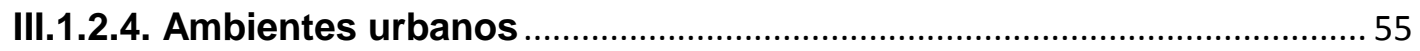

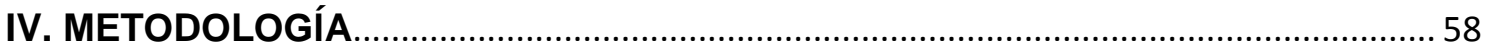

IV.1. Liquenobiota de ambientes urbanos y naturales de la provincia de Buenos Aires y sus preferencias ambientales ......................................................... 58

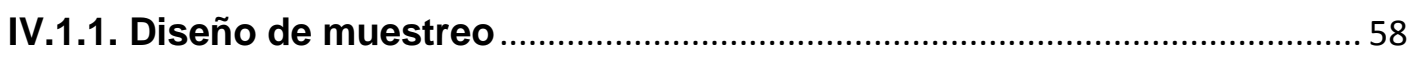

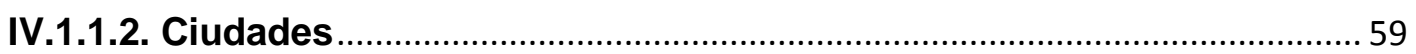

IV. 1.1.2.1. Características de las localidades y los sitios relevados ...............61 


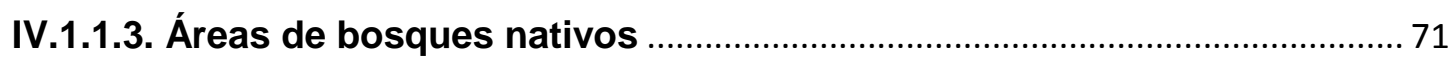

IV. 1.1.3.1. Características de las localidades y los sitios relevados ............... 72

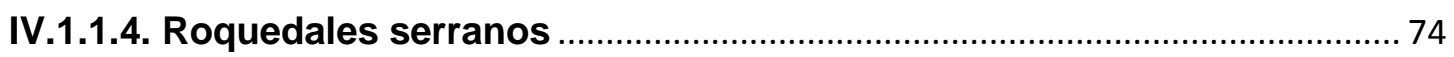

IV. 1.1.4.1. Características de las localidades y los sitios relevados ............... 75

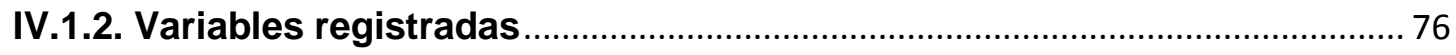

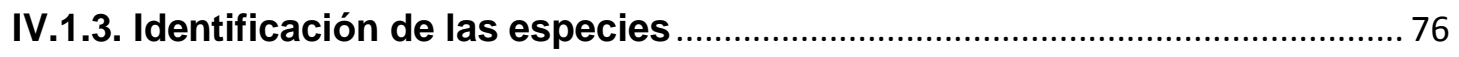

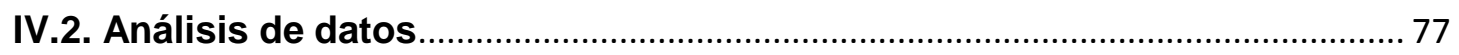

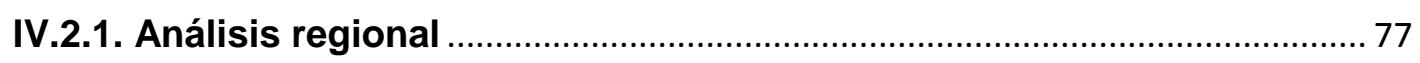

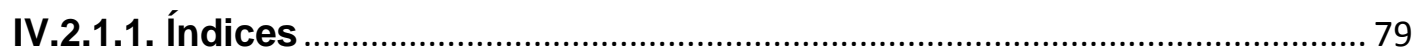

IV.2.2. Relación entre comunidades y variables ambientales ............................... 81

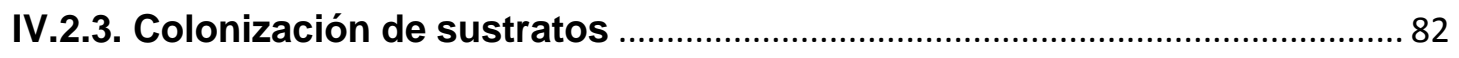

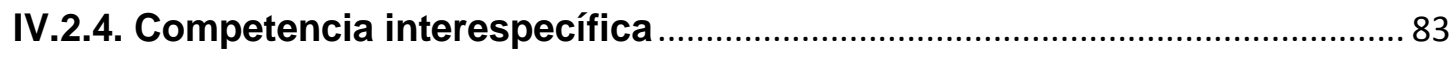

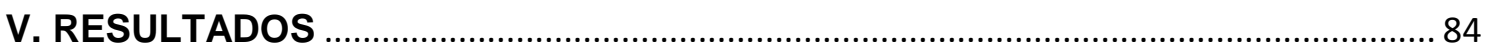

V.1. Liquenobiota de ambientes urbanos y naturales de la provincia de Buenos

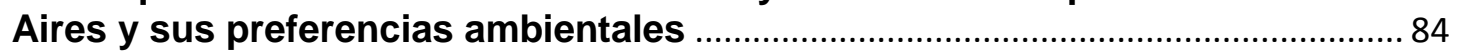

V.1.1. Biota liquénica de ambientes urbanos ................................................. 84

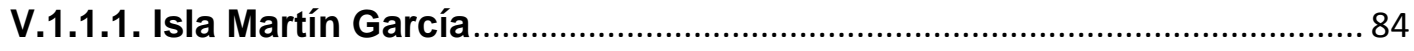

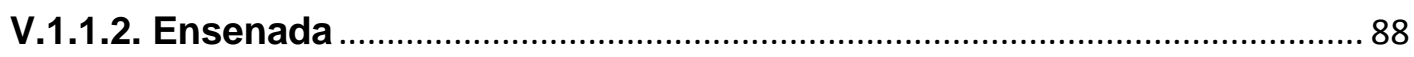

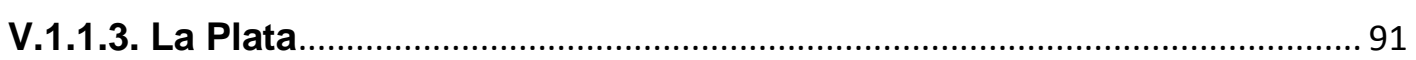

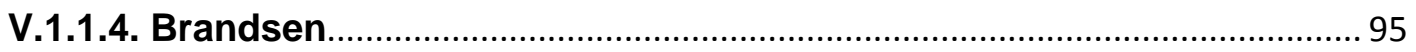

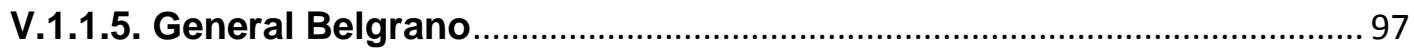

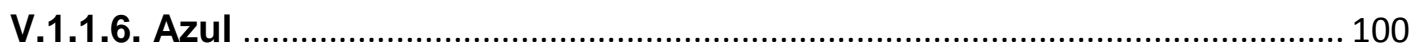

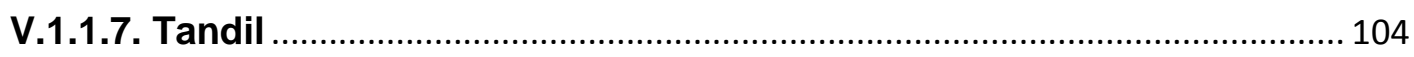

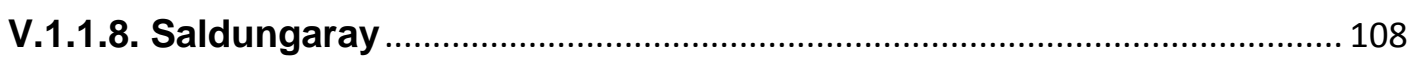

V.1.1.9. Parque Provincial Ernesto Tornquist .................................................... 111

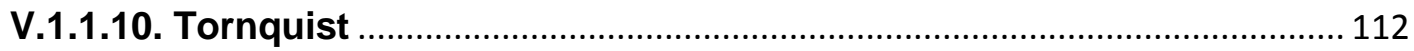

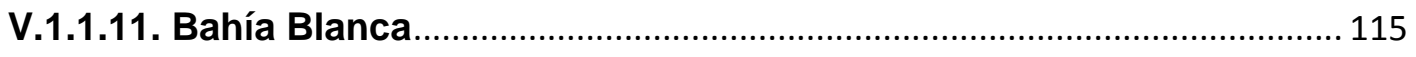

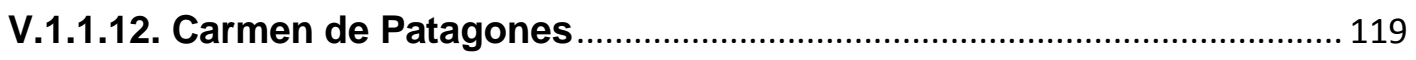

V.1.2. Liquenobiota de ambientes naturales...................................................... 122

V.1.2.1. Reserva Natural de Uso Múltiple Isla Martín García (RNIMG)............ 122

V.1.2.2. Reserva Natural Integral Punta Lara (RNPL) ...................................... 125

V.1.2.3. Sierras de Tandil (ST) ...................................................................... 128

V.1.2.4. Parque Provincial Ernesto Tornquist (PPET) ................................... 131

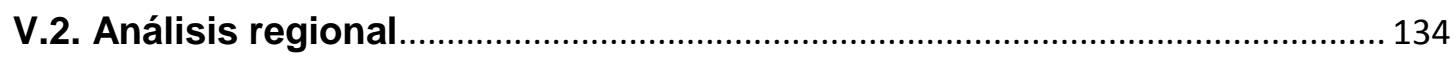

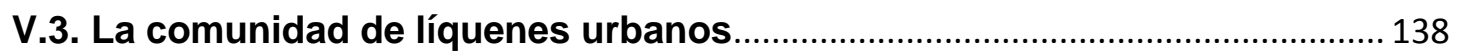

V. 3.1. Análisis de la variabilidad geográfica .................................................... 148

V.3.2. Preferencias ambientales de las especies urbanas .............................. 151

V.3.3. Procesos vinculados a la colonización .................................................... 155 


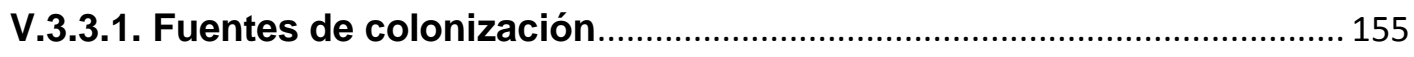

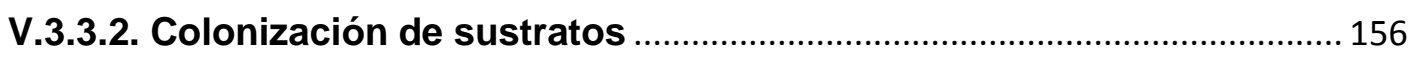

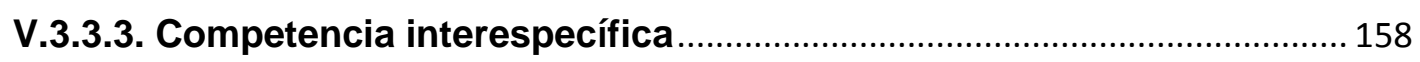

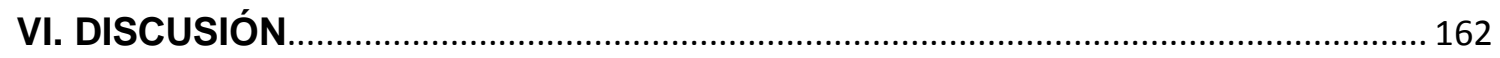

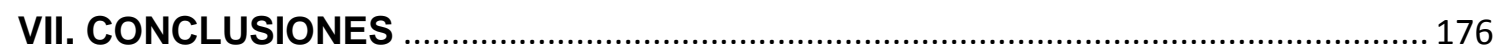

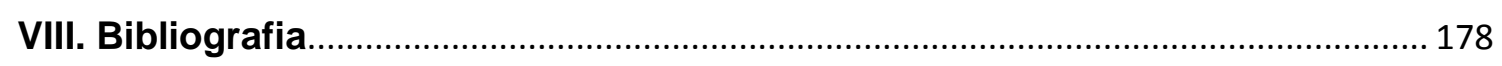

ANEXO I. Recomendaciones para la conservación del patrimonio.......................... 207

ANEXO II. Diversidad de familias y especies de líquenes registrados.................. 210 


\section{Resumen}

Los líquenes constituyen una asociación simbiótica mutualista entre un hongo o micobionte y un alga o fotobionte y de cuya interacción se origina un talo estable, con estructura y fisiología específicas. Son capaces de colonizar una amplia gama de sustratos: además de las superficies naturales proporcionadas por las rocas, el suelo, corteza, maderas, hojas y caparazones de animales; también pueden desarrollarse sobre materiales de origen industrial tales como plásticos, gomas, metales, vidrio, cementos y pinturas. Con el crecimiento de las ciudades, la edificación y la creación de monumentos, el ambiente urbano ha pasado a constituir un importante proveedor de sustratos y refugios para los líquenes saxícolas. Los muros proporcionan hábitats secundarios para los organismos colonizadores de rocas naturales, sin embargo, los mismos pueden estar constituídos por diferentes materiales, con lo cual, dependiendo cual sea su composición, pueden promover el crecimiento de diferentes organismos. Desde el punto de vista ecológico, la urbanización puede tener efectos favorables y adversos en las comunidades bióticas. Por un lado, las ciudades crean y mantienen una variedad de hábitats que no se producen en otros lugares, las especies exitosas en el ambiente urbano son generalistas, con alta fecundidad y alta capacidad dispersiva. Por otro lado, la urbanización es una amenaza para muchas especies que viven en hábitats naturales, y para las que no soporten las condiciones ambientales urbanas.

En Argentina los estudios en las urbes relacionados con líquenes y patrimonio edilicio son escasos. La mayoría de ellos son listas de especies encontradas sobre sustrato antrópico, o estudios relacionados al biodeterioro. Las superficies construidas constituyen un nuevo sustrato para el asentamiento de comunidades liquénicas. En el caso del Patrimonio edificado perteneciente a la provincia de Buenos Aires se trata de un sustrato que está disponible para colonizar desde hace más de un siglo. Dado que las sustancias que liberan, la penetración de hifas y ricines, pueden deteriorar el sustrato que colonizan, y suelen constituir un problema en la preservación de las obras de arte y de los edificios. 
Vale preguntarse cuáles son las características de las comunidades liquénicas desarrolladas sobre construcciones en Buenos Aires, si se diferencian de las naturales en su composición específica, si existen variaciones geográficas en su distribución dentro de la provincia, qué importancia en su diferenciación tienen la naturaleza y/o la antigüedad del sustrato y las condiciones microambientales locales y cómo son las características de colonización de estos "nuevos" sustratos. Esta tesis buscó profundizar en el conocimiento de las comunidades de líquenes en general y urbanas en particular y responder cuestiones de cómo las construcciones interactúan con la liquenobiota local, cuál es el origen biogeográfico de las especies, cómo se organizan sus comunidades, cuáles son los factores abióticos que condicionan la presencia de unas u otras especies, cómo son las interrelaciones entre especies durante el proceso de colonización de muros y qué característica tiene la sucesión sobre estos sustratos. No se pretende profundizar en temas de biodeterioro pero sí pensamos que la información generada será básica para evaluar la gestión y control de las superficies ocupadas por líquenes y contribuir al mantenimiento y conservación de patrimonio. El objetivo general de esta tesis fue conocer la composición y estructura de las comunidades liquénicas presentes en las construcciones edilicias y monumentos de la provincia de Buenos Aires, determinar las condiciones ambientales que influyen en estas asociaciones y analizar procesos vinculados con la colonización de estos neoecosistema.

El área de estudio abarcó la provincia de Buenos Aires: se trazó una transecta desde el NE (Isla Martín García) al SW (Carmen de Patagones) de $845 \mathrm{~km}$ de longitud sobre la que se seleccionaron 12 localidades de muestreo en ambientes urbanos y 4 localidades que representaron los ambientes naturales próximos. En las mismas se seleccionaron sustratos que presentaran líquenes, de los cuales se registró su cobertura promedio con cuadrados de20 x $20 \mathrm{~cm}$, sobre distintas orientaciones, inclinaciones, alturas y materiales. análisis de los datos se realizó mediante métodos de clasificación y ordenación para identificar las distintas asociaciones conformadas por los líquenes por localidad, se analizaron todas las unidades de muestreo junto con las variables ambientales registradas en cada una de ellas, y se caracterizaron las 
localidades mediante riqueza, índices de diversidad y equitatividad. Para reconocer las relaciones entre las especies y los factores ambientales que pueden estar actuando sobre sus distribuciones se realizaron análisis multivariados, y se realizaron test estadísticos entre las especies y sus preferencias sobre variables de orientación, inclinación y altura sobre los muros. También se realizaron test estadísticos para encontrar asociaciones entre las variables ambientales y las variables de la comunidad. Se utilizaron índices de similitud y disimilitud para comparar las biotas de ambientes urbanos con ambientes naturales y de ambientes urbanos entre si. Se realizó un análisis para encontrar posibles patrones geográficos mediante técnicas de agrupamiento. Para conocer los procesos vinculados a la colonización se realizó una limpieza de los muros y se observo la colonización de las especies. También se analizó la competencia por el espacio que se da en el seno de la misma, como proceso dentro de la sucesión.

Se relevaron 12 localidades con sustrato antrópico y 4 con sustrato nativo. Se registraron un total de 132 especies, 48 de ellas en sustrato antrópico, de estas, Caloplaca teicholyta, Myriolecis dispersa, Lecania erysibe y Staurothele monosporoides aparecieron en la mayoría de las localidades y Flavoplaca austrocitrina fue la única que se encontró en todas ellas. Entre las localidades con sustrato antrópico Ensenada presentó la mayor riqueza (16), presentando una gran cantidad de especies corticícolas únicas de esta localidad, por otro lado la localidad con menor riqueza fue el Parque Provincia Ernesto Tornquist (3). En cuanto a las localidades con sustratos naturales todas mostraron una riqueza más alta que los ambientes urbanos, destacandoce el Parque Provincial Ernesto Tornquist como la localidad con mayor riqueza. El $83,3 \%$ de las localidades urbanas no compartieron ninguna especie con las áreas naturales boscosas. El 16,7\% restante sí compartió al menos una especie con las áreas naturales arboladas (Ensenada y Isla Martín García), en ambos casos Ensenada fue el sitio que compartió más especies con los ambientes naturales próximos; con la Reserva Natural de Punta Lara compartió 11 especies mientras que con la Reserva Natural Isla Martín García compartió 6. En cambio el $100 \%$ de los sitios compartieron al menos una especie con las áreas naturales con roquedales, las localidades de Azul y 
Bahía Blanca fueron las que compartieron más especies (4) con el Parque Provincia Ernesto Tornquist y Ensenada, Bahía Blanca y Tandil compartieron 3 especies con las Sierra de Tandil, siendo estas las que compartieron más especies. El sustrato que presentó mayor riqueza de especies fue el mortero (24) seguido de la pintura (20) y el granito (16). En cuanto a la inclinación la horizontal presentó una mayor riqueza (40) que la vertical (25), dentro de las alturas 1,50 m sobre el suelo presentó una mayor riqueza (22) seguida por $1 \mathrm{~m}$ sobre el suelo (20) y por último $0,50 \mathrm{~m}$ sobre el suelo (19). El 52,08\% del total de especies crecieron sobre un solo tipo de sustrato, mientras que el 47,92\% se observaron en al menos 2 tipos de sustratos. La mayor riqueza se encontró al W (15), seguidas en orden de importancia por el E, SE y N (13).

Se puede concluir que la comunidad urbana se diferencian de las comunidades de ambientes naturales por la composición de especies y por la abundancia de las mismas. La comunidad presenta una fisonomía crustosa con predominancia de especies crustosas, en menor medida especies foliosas y raramente fruticulosas, con una baja riqueza y especies con una dominancia marcada. Éstas especies son especies generalistas, con una amplia tolerancia y muchas de estas pioneras, pero no son reemplazadas, sino que son capaces de competir por el espacio que ocupan. El conjunto de especies no mostraró diferencias latitudinales, las diferencias entre las localidades se dio por el tipo de sustrato que existe entre ellas y por las posibilidades de dispersión de cada especie. Las construcciones antrópicas permiten que los líquenes "escapen" de los ambientes naturales en donde se encontraban y se expandan hasta donde sus preferencias ambientales se lo permitan. 


\section{Abstract}

Lichens constitute a mutualistic symbiotic association between a fungus or mycobiont and an algae or photobiont and from whose interaction a stable thallus it is develops, with specific structure and physiology. They are able to colonize a wide range of substrates: in addition to the natural surfaces provided by the rocks, the soil, bark, wood, leaves and shells of animals; they can also be developed on materials of industrial origin such as plastics, rubber, metals, glass, cements and paints.

With the growth of cities, the building and the creation of monuments, the urban environment has become an important provider of substrates and shelters for saxicolous lichens. The walls provide secondary habitats for colonizing organisms of natural rocks, however, they can be constituted by different materials, which, depending on their composition, can promote the growth of different species. From the ecological point of view, urbanization can have favorable and adverse effects on biotic communities. On the one hand, cities create and maintain a variety of habitats that do not occur elsewhere, successful species in the urban environment are generalists, with high fertility and high dispersive capacity. On the other hand, urbanization is a threat to many species that live in natural habitats, and for those that do not support urban environmental conditions.

In Argentina, studies in cities related to lichen and building heritage are scarce. Most of them are lists of species found on anthropic substrate, or studies related to biodeterioration. The constructed surfaces constitute a new substrate for the settlement of lichen communities. In the case of the built heritage belonging to the province of Buenos Aires, it is a substrate that has been available to colonize for more than a century. Since the substances that release, the penetration of hyphae and ricines, can deteriorate the substrate they colonize, and usually constitute a problem in the preservation of art and buildings.

Worth asking what are the characteristics of lichen communities developed on buildings in Buenos Aires, if they differ from natural in their specific composition, if there are geographic variations in distribution within the 
province, how important in their differentiation have the nature and / or the age of the substrate and the local micro-environmental conditions and how are the characteristics of colonization of these "new" substrates. This thesis sought to deepen the knowledge of lichen communities in general and urban in particular and answer questions of how buildings interact with local lichenbiota, what is the biogeographical origin of the species, how are their communities organized, what are the factors abiotic that condition the presence of some or other species, how are the interrelations between species during the process of colonization of walls and what feature has the succession on these substrates. We do not intend to delve deeper into biodeterioration issues, but we do think that the information generated will be basic to evaluate the management and control of surfaces occupied by lichens and contribute to the maintenance and conservation of heritage. The general objective of this thesis was to know the composition and structure of the lichen communities present in the buildings and monuments of the province of Buenos Aires, determine the environmental conditions that influence these associations and analyse processes related to the colonization of these neo-ecosystems.

The study area encompassed the province of Buenos Aires: a transect was drawn from the NE (Martín García Island) to SW (Carmen de Patagones) of $845 \mathrm{~km}$ in length, on which 12 sampling localities were selected in urban environments and 4 localities which represented the next natural environments. In them, substrates were selected that presented lichens, of which their coverage was recorded with squares of $20 \times 20 \mathrm{~cm}$, on different orientations, inclinations, heights and materials. The analysis of the data was carried out by classification and ordering methods to identify the different associations formed by the lichens by locality, all the sampling units were analysed together with the environmental variables registered in each of them, and the localities were characterized by richness, diversity and evenness index. In order to recognize the relationships between the species and the environmental factors that may be acting on their distributions, multivariate analyses were performed, and statistical tests were carried out among the species and their preferences on orientation, inclination and height variables on the walls. Statistical tests were also performed to find associations between environmental variables and 
community variables. Similarity and dissimilarity index were used to compare the biota of urban environments with natural environments and urban environments. An analysis was performed to find possible geographic patterns by grouping techniques. To know the processes linked to colonization, the walls were cleaned and the colonization of the species was observed. The competition for the space that occurs within it, as a process within the succession, was also analysed.

Twelve localities with anthropic substrate and 4 with native substrate were surveyed. A total of 132 species were recorded, 48 of them in anthropic substrate, of these, Caloplaca teicholyta, Myriolecis dispersa, Lecania erysibe and Staurothele monosporoides appeared in most localities and Flavoplaca austrocitrina was the only one found in all of them. Among the locations with anthropic substrate Ensenada presented the greatest richness (16), presenting a many of unique corticolous species of this locality, on the other hand the town with the least wealth was the Parque Provincial Ernesto Tornquist (3). As for the locality with natural substrates, all showed a higher wealth than urban environments, highlighting among these the Parque Provincia Ernesto Tornquist as the locality with the greatest richness. The $83.3 \%$ of the urban localities did not share any species with the forested natural areas. The remaining $16.7 \%$ did share at least one species with the arboreal natural areas (Ensenada and Isla Martín García), in both cases, Ensenada was the site that shared more species with the nearby natural environments; with the Reserva Natural de Punta Lara shared 11 species while with the Reserva Natural Isla Martín García shared 6. On the other hand, $100 \%$ of the sites shared at least one species with the natural areas with rocks, the localities of Azul and Bahía Blanca shared the most species (4) with the Parque Provincial Ernesto Tornquist and Ensenada, Bahía Blanca and Tandil shared 3 species with the Sierra de Tandil, these being the ones that shared more species. The substrate that presented the highest species richness was the mortar (24) followed by the paint (20) and the granite (16). As for the inclination, the horizontal one presented a greater wealth (40) than the vertical one (25), inside the heights $1.50 \mathrm{~m}$ above the ground it presented a greater wealth (22) followed by $1 \mathrm{~m}$ above the ground (20) and finally $0.50 \mathrm{~m}$ above the ground (19). $52.08 \%$ of the total species grew on a 
single type of substrate, while $47.92 \%$ were observed on at least 2 types of substrates. The greatest wealth was found at W (15), followed in order of importance by E, SE and N (13).

It can be concluded that urban community differ from communities of natural environments due to the composition of species and the abundance of them. It presents a crustose appearance with predominance of crustose species, less foliose and rarely fruticose species, with a low richness and species with a marked dominance. These species are generalist species, with a wide tolerance and many of these pioneers, but they are not replaced, but they are able to compete for the space they occupy. The set of species did not show latitudinal differences, the differences between the localities was given by the type of substrate that exists between them and by the dispersal possibilities of each species. The anthropic constructions allow the lichens to "escape" from the natural environments where they were and expand as far as their environmental preferences allow. 


\section{INTRODUCCIÓN}

\section{I.1.1. Los líquenes}

Los líquenes constituyen una simbiosis mutualista obligada entre un hongo o micobionte y un simbionte fotosintético o fotobionte (algas 0 cianobacterias), de cuya interacción se origina un talo estable, con estructura y fisiología específicas. Se clasifican dentro del Reino Fungi y se han descripto alrededor de 20000 especies. La simbiosis apareció de forma independiente varias veces dentro de la filogenia de Basidiomycota y Ascomycota, por lo que conforman un grupo polifilético (Gargas et al., 1995; Honegger, 1997; Sipman \& Aptroot, 2001; Tehler \& Wedin, 2008). La variedad de especies es alta y no todas poseen relación filogenética cercana, por ello es difícil hacer generalizaciones dentro de este grupo.

Aunque la naturaleza dual de los líquenes es ampliamente reconocida, no es raro encontrar individuos formados por tres o más componentes (Nash, 2008; Rambold \& Triebel, 1992). Tal es así que Spribille et al. (2016) y Kachalkin et al. (2017) encontraron que en diversas familias de Ascomycota liquenizados existian levaduras (Ascomycota y Basidiomycota) como micobiontes que formaban parte de la simbiosis, los cuales mostraron participación en la formación de metabolitos secundarios, poniendo de manifiesto que la relación simbiótica es mucho más compleja de lo que se pensaba.

Los líquenes son capaces de colonizar una amplia gama de sustratos: además de las superficies naturales también pueden desarrollarse sobre materiales de origen industrial (Brightman \& Seaward, 1977; Lücking, 1998; Rosato, 2003, 2006). Según el tipo de sustrato específico sobre el que se desarrolla, se los denomina como saxícolas (rocas), corticícolas (corteza), muscícolas (musgo), terrícolas (suelo) y folícolas (hojas). Para los que crecen sobre materiales antrópicos también recibieron denominaciones tales como: murícolas (muros), plasticícolas (plástico), ferrícolas (metales) y vehiculícolas 
(automóviles) entre otros (Brightman \& Seaward, 1977; Lücking, 1998; Aptroot et al., 2014).

En cuanto a su morfología externa se pueden separar en distintas formas de crecimiento, divididas en:

1. Crustosas: aquellas donde toda la superficie inferior del talo se encuentra adherida al sustrato y son difícilmente separables de él. Dentro de este grupo podemos encontrar formas epilíticas que crecen sobre el sustrato sujeándose a éste a través de hifas y formas endolíticas que crecen dentro del sustrato y solo exponen sus estructuras reproductivas (Büdel \& Scheidegger, 2008; Lakatos et al., 2006).

2. Foliosas: se caracterizan por su forma laminar, con una simetría dorsiventral con una corteza superior fotosintética y una corteza inferior especializada en la sujeción al sustrato. Poseen una tasa de crecimiento mayor que las crustosas y pueden formar talos de gran tamaño (Büdel \& Scheidegger, 2008; Barreno \& Rico, 1984).

3. Fruticulosas: el talo se desarrolla de forma perpendicular al sustrato y se sujeta a este por una pequeña parte del talo (disco), puede ser erecto o péndulo, con simetría radial o dorsiventral. Este grupo es el que posee las especies de mayor tamaño, con altas tasas de crecimiento (Büdel \& Scheidegger, 2008; Barreno \& Rico, 1984). Al igual que los talos foliosos los fruticulosos presentan una estratificación interna, donde las hifas forman un pseudoparénquima hidrofílico y zonas llenas de gas formadas por sistemas de hifas laxamente dispuestas, con aire entre ellas e hifas con paredes hidrofóbicas (Honegger, 1993).

4. Mixtas: esta forma presenta una etapa vegetativa con morfología crustosa o foliosa y una etapa reproductiva con morfología fruticosa donde se encuentran los apotecios. El talo vegetativo puede o no ser efímero (Barreno \& Rico, 1984).

5. Filamentosas: se caracterizan por su morfología sencilla, su talo se conforma por algas filamentosas envueltas en una vaina más o menos cerrada del hongo. La ausencia de corteza les permite 
absorber rápidamente agua pero los hace muy sensibles a la desecación, por ello son casi exclusivos de ambientes selváticos (Barreno \& Rico, 1984; Lakatos et al., 2006).

\section{I.1.2. Los líquenes en el ambiente}

Este diverso grupo es capaz de crecer en casi todos los hábitats terrestres, desde los trópicos hasta las regiones polares y algunos ambientes acuáticos (Barreno, 1998; Aptroot \& Seaward, 2003; Galloway, 2008). En ecosistemas polares y subpolares, los líquenes son los autótrofos dominantes (Longton, 1988), en ambientes áridos o semiáridos son un componente importante de la costra de criptógamas (Evans \& Johansen, 1999; Belnap \& Lange, 2003), y en ecosistemas boscosos pueden conformar una biomasa que sobrepasa los $100 \mathrm{~kg} / \mathrm{ha}$ (Coxson \& Nadkarni, 1995). El grupo ha sido clasificado por varios autores como extremófilo por encontrarse en ambientes con rangos de humedad y temperatura poco convencionales para organismos fotosintéticos -polos y desiertos- (Sancho et al., 2007; Kappen, 2000; Green, 2009; Kappen \& Valladares, 2007).

Entre las adaptaciones más relevantes se encuentran:

1. Protección UV: los líquenes producen una gran cantidad de compuestos secundarios que han demostrado su utilidad al momento de evitar el daño por una alta radiación UV entre estos se mencionan compuestos aromáticos, por ejemplo, las xantonas, derivados del ácido pulvínico, atranorina, pannarina, ácido úsnico, parietina, entre otros. Muchos de estos compuestos dan colores amarillos, rojos y naranjas que son típicos de los líquenes que viven en una alta exposición a la radiación directa (Rundel, 1978; Nguyen et al., 2013; Rojas-Fernández et al., 2008).

2. Presencia de cefalodios: es una estructura diferenciada (surgida de una simbiosis tripartita) en la cual se encuentran cianobacterias, mientras que en el resto del talo hay algas verdes. Esta estructura está encargada de fijar nitrógeno directamente 
desde la atmósfera, mientras que las algas verdes se ocupan de la fotosíntesis (Bermúdez de Castro et al., 1990; Nash, 2008).

3. Forma de crecimiento: algunos autores sugieren que el morfotipo crustoso está mejor adaptado a climas extremos debido a su buena economía del agua y a su baja resistencia al viento, ambos factores comunes en ambientes muy expuestos. Sin embargo no son exclusivas solo de este tipo de ambientes, a la vez que tampoco las otras formas de crecimiento están excluidas de ellos (Rogers, 1977). Las especies fruticulosas por otro lado absorben el agua de rocío o bruma que se condensa sobre ellas (del Prado Millán, 2002).

4. Forma de vida endolítica: algunos autores han propuesto que esta es una forma de escape de la competencia habitando un nicho diferente (Tretiach, 1995). Sin embargo en ambientes donde no existe una alta competencia como los desiertos, esta estrategia de vida se relacionaría a evitar los efectos dañinos de la alta radiación solar y la rápida pérdida de agua que sufren los líquenes epilíticos (Bungartz et al., 2004).

Al considerar a cada especie según sus necesidades ecológicas, esto es, sus requerimientos de $\mathrm{pH}$ (acidófilos, neutrófilos, basófilos), de concentración de nutrientes (oligotróficos, eutróficos, hipertróficos) y de calidad del aire (Wirth, 2001; Seaward \& Coppins, 2004; Hauck \& Wirth, 2010), muchas trascienden más de una categoría. En cuanto a sus requerimientos de nitrógeno los líquenes utilizan principalmente amonio, nitrato o nitrógeno orgánico, y en el caso de los cianolíquenes, nitrógeno inorgánico gaseoso (Hyvarinen \& Crittenden, 1998a,b; Ellis et al., 2004). Las deyecciones de las aves pueden tener un efecto que en algunos casos favorece el crecimiento de algunas especies (Armstrong, 1984).

Entre los factores limitantes se puede mencionar al agua, los líquenes son organismos poiquilohídricos, por lo que no tienen forma de controlar el contenido de agua del talo, están sujetos a drásticas fluctuaciones de agua causadas por las condiciones ambientales de su entorno. Sobreviven a un fuerte estrés de sequía sin daños en un estado de latencia ya que poseen 
mecanismos que permiten una rápida restauración de las membranas plasmáticas que se deterioran durante la desecación con acumulación de solutos en el aploplasto, pero restablecen sus actividades metabólicas muy rápidamente tras la rehidratación (Honegger, 1998).

Los líquenes presentan diferencias en cuanto a la preferencia en la cantidad de luz que reciben, aunque algunas especies son plásticas y se adaptan a diferentes grados de insolación e incluso están adaptadas, como ya se ha señalado, a concentraciones altas de radiación UV. La familia Teloschistaceae posee un pigmento cortical rojo, la parietina, que le permite continuar realizando fotosíntesis bajo condiciones de alta exposición solar. Así las especies de Caloplaca s.l., Teloschistes y Xanthoria s.I. son características de ambientes altamente insolados, en algunos desiertos Caloplaca s.l. es el único líquen saxícola presente (Barkman, 1958; Rundel, 1978). Si la especie no se encuentra expuesta a la luz solar directa puede no generar este pigmento y mostrar una coloración grisácea, como se ha visto en formas de Xanthoria parietina (Scutari, 1992a). Anstett (2009) encontró en Barcroft Station (USA), que la cobertura de los líquenes fue mayor en rocas protegidas del viento y más expuestas a la radiación, y disminuyó en sitios poco protegidos del viento y sombreados. Esto se debería a la desecación en los talos producida por el viento que provoca una alta tasa de respiración y una baja fotosíntesis.

En los líquenes, al igual que otros grupos de organismos, las especies que se ensamblan para formar una comunidad están determinadas por la capacidad de dispersión de cada especie, las limitaciones ambientales y la dinámica interna de la comunidad (Begon et al., 2006). Las comunidades de líquenes pueden variar en áreas pequeñas respondiendo a la heterogeneidad propia de los sustratos que ocupan, tipos de roca o suelo, características del forófito y de su corteza. También se ha comprobado que la variación en la diversidad es influenciada por las condiciones microclimáticas determinadas por la humedad, la exposición a la radiación y al viento, entre otros. Se ha observado que existen una gran cantidad de especies de líquenes cosmopolitas. Esta distribución se explica por una capacidad de dispersión a larga distancia o por constituir poblaciones relictuales de lento cambio evolutivo, presentes antes de la separación de Pangea (Kärnefelt, 1990; 
Galloway, 2008). Por otro lado hay que tener en cuenta que la actividad humana también puede tener un efecto en la distribución de las especies de líquenes, no solo afectándola de forma negativa, sino también en la expansión de su área de distribución. Si bien es difícil poder asegurar la expansión de las especies ocasionada por el hombre debido a la falta de conocimiento a nivel mundial sobre el grupo, existen algunos casos donde se ha comprobado. Tal es el caso de lo observado por Osyczka (2010) quien analizando los materiales de construcción para una base en Antártida encontró 24 especies de líquenes de los cuales solo 3 habían sido previamente registradas para el continente. Essl \& Lambdon (2009) comentan que Parmelia submontana está asociada al arbolado exótico en Europa y podría haber llegado con las importaciones de los jardines.

Los líquenes son considerados como especies pioneras capaces de colonizar sustratos nuevos, y conformarían las primeras etapas serales en muchas sucesiones primarias. Una vez instalados comienzan un proceso de deterioro, acumulación de materia orgánica y sedimentos sobre el sustrato sobre el cual se encuentran permitiendo que otros organismos posteriormente puedan instalarse en el lugar (Topham, 1977; Seaward, 2008). Tal es así, que han sido utilizados en algunos casos para la medir la antigüedad de superficies expuestas como morenas de glaciares, deslizamientos de rocas, fluctuaciones en el nivel del agua y para datar la edad de los petroglifos y las estatuas de la Isla de Pascua (Seaward, 2008). La dispersión eficiente de los propágulos de ninguna manera garantiza un exitoso establecimiento y desarrollo. Los sustratos deben ser bioreceptivos (materiales con propiedades que contribuyen a la colonización, establecimiento y desarrollo de biota), y estar protegidos de la sedimentación, la gravitación y el lavado por la lluvia que impactan sobre las superficies limitando la colonización (Guillitte, 1995).

En el caso de las comunidades de líquenes crustosos, la disponibilidad de espacio y el acceso a la luz son recursos por los que las especies compiten (Oksanen 1984; Stone, 1989; Hilmo, 1994; Ruchty et al., 2001; Armstrong, 2002; Armstrong \& Welch, 2007). Estudios descriptivos y experimentales sobre comunidades de líquenes han provisto evidencia de que la competencia condiciona la distribución de las especies, determina la estructura de las 
comunidades y es un factor clave dentro de la sucesión (Barkman, 1958; James et al., 1977; Armstrong, 1982; Oksanen, 1984; Woolhouse et al., 1985; Welch, 2002). Lawrey (1981) propone que la superioridad competitiva de algunas especies de líquenes sobre otras es responsable de la creación de patrones comunitarios relativamente estables en hábitats no perturbados. Por otro lado también se ha sugerido que la competencia puede variar su intensidad en relación al estrés ambiental (Bertness \& Callaway, 1994), y que en las comunidades de líquenes existe una intransitividad competitiva, por lo que no existiría una jerarquía competitiva estricta en la comunidad (Bowker et al., 2010; Bowker \& Maestre, 2012).

\section{I.1.3. Los líquenes en el ambiente urbano}

Los ambientes urbanos son aquellos en los que la gente vive en altas densidades, o cuando la infraestructura construida cubre una gran parte de la superficie terrestre. En un sentido más amplio, los ecosistemas urbanos comprenden áreas suburbanas, periurbanas, poblados pequeños conectados por corredores, por servicios públicos e influencia del núcleo urbano (Pickett et al., 2008). Podemos decir que en casi todos los ecosistemas de la Tierra el hombre ha dejado su huella, y los líquenes, en algunos casos, los han seguido. Un claro ejemplo de estos son los líquenes que se han encontrado creciendo sobre los edificios y restos de vidrio en Antártida (Lindsay, 1973; Schroeter \& Sancho, 1996; Osyczka, 2010). Desde el punto de vista ecológico, la urbanización puede tener efectos favorables y adversos en las comunidades. Por un lado, las ciudades crean y mantienen una variedad de hábitats que no se producen en otros lugares. Esta riqueza de tipos de hábitat a menudo es compatible con una gran diversidad de especies, las especies exitosas en el ambiente urbano son generalistas, con alta fecundidad y alta capacidad dispersiva. Por otro lado, la urbanización es una amenaza para otras especies que viven en hábitats naturales (McKinney \& Lockwood, 1999; Niemelä, 2002; Motiejûnaitë, 2005).

Con el crecimiento de las ciudades, la edificación y la creación de monumentos, el ambiente urbano ha pasado a constituir un importante 
proveedor de sustratos y refugios para varias formas de vida, entre ellas, los líquenes saxícolas (Hill, 2010). Los muros proporcionan hábitats secundarios para los organismos colonizadores de rocas naturales (Kolbek, 1997), sin embargo, difieren en muchas características que determinan la composición de las especies que los ocupan (Duchoslav, 2002).

En Alemania, Holanda e Inglaterra, donde los afloramientos de roca naturales son raros, los edificios antiguos, paredes y lápidas representan un santuario esencial y hábitat compensatorio para líquenes saxícolas (Weber \& Büdel, 2001). En las ciudades, al igual que en el medio natural, los factores ecológicos más influyentes que determinan la distribución y crecimiento de la liquenobiota en edificaciones son: la orientación, la exposición, la luminosidad, el fotoperíodo, la temperatura, la humedad relativa, el tipo de sustrato, su composición química, pH, textura (Brightman \& Seaward, 1977; Egea, 1985; Gaylarde \& Morton, 1999; Laso, 2001; Souza-Egipsy \& García Zancho, 2001; Johansson et al., 2005).

Los cementerios a menudo proporcionan un hábitat muy diverso para líquenes, debido a los variados tipos de rocas y materiales empleados para la construcción de las tumbas, los caminos de los alrededores y muros, por estas condiciones la exposición, la pendiente y las condiciones hídricas presentan una alta variación (Aptroot \& James, 2002). La biodiversidad de los cementerios puede ser muy alta: a pesar de su pequeño tamaño, y pueden constituir hotspots. Por ejemplo en el Reino Unido varios cementerios albergan entre 150 y 180 especies, y en la totalidad de ellos se han encontrado 630 especies, que es un tercio del total de los líquenes británicos (Purvis, 2000). En el cementerio judío de Białystok (Polonia) Matwiejuk (2008) registró 56 especies de las cuales 4 estaban bajo protección legal Peltigera rufescens, Stereocaulon condensatum, S. tomentosum y Evernia prunastri. Pocas especies están restringidas a los cementerios, pero algunas son mucho más frecuentes en este hábitat que en otros lugares, por ej. Acarospora moenium y Sarcopyrenia gibba, que prefieren las tapas expuestas a la luz solar de tumbas de piedra caliza dura (Aptroot et al., 1998).

Ariño et al. (1995) relevaron las comunidades presentes sobre el piso de un foro romano y encontraron 22 especies entre las que predomina el morfotipo 
crustoso, y reconocieron 2 ensambles de especies diferentes, uno ubicado en los desagües y otro en el resto de las rocas que forman el piso. Atribuyen estas diferencias a la disponibilidad de agua y al grado de erosión de las rocas, ya que los desagües aún son funcionales y además al fluir el agua por estos, la superficie de estas rocas muestra un grado de erosión mayor. En cambio en el resto del piso la disponibilidad de agua es menor y las rocas presentan un grado menor de erosión.

En edificios romanos de España, Ariño et al. (1997) registraron un total de 38 especies de líquenes, en su mayoría crustosas. Notaron una variación de la composición específica entre diferentes edificios y dentro de los mismos edificios. Esta variación es atribuida a la diferencia del sustrato sobre los que crecían los líquenes y la antigüedad de este, ya que las especies encontradas sobre la parte del edificio restaurada (con materiales modernos) eran diferentes a las que se encontraban sobre las partes originales (materiales antiguos). Por lo que concluyen que existía una preferencia de las especies por el tipo de sustrato.

Martin et al. (2011), en su relevamiento de líquenes de la península Pakri en Estonia, relevó construcciones militares, algunas de las cuales tenían hasta 100 años de antiguedad. Si bien sugieren que el concreto es similar a la piedra caliza por sus características físicas y químicas, su riqueza de especies fue menor y solo aparecieron especies comunes (e.g. Acarospora moenium, Flavoplaca citrina, Calogaya decipiens, Candelariella aurella, Myriolecis albescens, Protoblastenia rupestris).

Prieto et al. (1999) estudiaron y compararon la composición de la flora liquénica de dos construcciones diferentes en Galicia, España. Encontraron diferencias florísticas entre las iglesias y los dólmenes.Los dólmenes parecen favorecer especies más acidófilas, mientras que las iglesias concentraron especies más neutrófilas y nitrofílicas. La asociación con preferencias de humedad y luminosidad fue menos clara, aunque las especies de algunas iglesias fueron más xerófilas que las encontradas en los dólmenes y el resto de las iglesias. Que las iglesias alberguen especies menos acidófilas puede deberse a la presencia de morteros de piedra caliza en su estructura. Su colonización por nitrófilos moderados sugiere que existe un suministro de 
nitrógeno más abundantes que en los dólmenes. Esto podría estar relacionado con las actividades de los visitantes humanos y animales, las aves, especialmente.

Carballal et al. (2001) realizaron un estudio sobre iglesias de granito en las costas de Galicia, España, y las compararon con estudios realizados sobre iglesias que no estaban en la costa. Encontraron entre 28 a 49 especies de líquenes por iglesia, y pudieron reconocer 3 grupos, uno con preferencias por las rocas graníticas sin importar la cercanía al mar, otro con especies asociadas a los ambientes costeros y otro que prefería ambientes alejados de las costas. Las especies que se encontraron creciendo en las rocas graníticas también fueron observadas en roquedales cercanos, aunque su presencia fue mayor en edificios que en estos roquedales, mientras que las que se encontraban creciendo sobre mortero no fueron encontradas sobre roquedales, al menos en Galiccia.

Christensen (2004) estudió los líquenes sobre los techos de fibrocemento en Copenhagen (Dinamarca) y registró 22 especies, todas encontradas también sobre sustratos antrópicos en las ciudades aledañas. Propuso que la distribución de las especies sobre el techo está dada por la topografía de este, observó que las especies foliosas como Xanthoria parietina, Oxneria fallax y especies de la familia Physciaceae eran más comunes en las zonas por donde el agua de lluvia escurría, mientras que especies del grupo Lecanora se encontraban en las zonas de crestas, como así también existían especies que estaban en ambos sitios. Una de las observaciones, que no se comprobó analíticamente, es que las especies ubicadas en la zona por donde escurre el agua podrían estar ahí por la mayor concentración de nutrientes los cuales estarían siendo arrastrados por el agua y no necesariamente por el agua.

Weber \& Büdel (2001) relevaron las iglesias medievales del NE de Alemania y analizaron las especies de líquenes con respecto a las características de los muros, material, orientación e inclinación. Propusieron que las superficies verticales se humedecen solo por fuertes lluvias combinadas con fuertes vientos, las superficies muy inclinadas son propensas a estar húmedas, y las superficies más o menos horizontales, por el lento 
escurrimiento del agua están casi siempre humedecidas por más tiempo. Estas diferencias mostraron relacionarse a especies como Porina chlorotica que se asoció a muros verticales o con una fuerte inclinación. También se pudo notar que de las 99 especies encontradas, 25 preferían zonas oceánicas o suboceánicas. Enterographa zonata crece principalmente en los muros $\mathrm{N}$ en piedra y superficies de ladrillo. Otras especies tal como Caloplaca saxícola se encontró en todas las orientaciones, tipos de roca y alturas, con una frecuencia similar. Además comprobaron que muchas de las especies halladas se encontraban dentro de la lista roja de especies para Alemania por lo que también sugieren que al no existir roquedales cercanos los muros de las iglesias se han convertido en un sustrato de suma importancia para la conservación de los líquenes de la región.

Laso (2001) relevó monumentos y edificios patrimoniales en Salamanca y encontró un total de 52 especies, 2 de ellas citadas por primera vez para España. Separó grupos de especies por las condiciones que prefieren, el tipo de sustrato, la orientación, la humedad y la exposición a la luminosidad, y concluyó que había un mayor desarrollo liquénico (cobertura y riqueza) en sustratos horizontales que en verticales, debido a que el agua de lluvia en estas últimas escurre rápidamente y la roca se deseca antes. La humedad del aire, niebla o lluvia, se deposita sobre las superficies horizontales, aunque varía en función de la porosidad del sustrato. Nimis \& Monte (1988) coincidieron con que estos son los factores de mayor importancia para el desarrollo de los líquenes. También observaron que muchas especies nitrófilas crecen en sectores donde el sustrato tiene bajo contenido en nitrógeno, lo que relacionaron con la eutrofización del mismo provocado por la acumulación de excrementos de aves que habitan en los edificios.

Sparrius et al. (2007) relevaron los líquenes en las paredes de iglesias medievales y renacentistas en Los Países Bajos. Registraron 194 especies, varias de las cuales están casi confinadas a este hábitat en el país. También observaron diferencias regionales en la composición de especies, algunas de las cuales atribuyeron a diferencias en las rocas de construcción, con lo que proponen 4 tipos de comunidades dependiendo de la exposición y del tipo de roca. También proponen que los líquenes sobre sustratos básicos no son 
susceptibles a los cambios en la contaminación del aire, en contraste con los epífitos en rocas ácidas. En general, los cambios de la biodiversidad son una función de la edad de la superficie expuesta. La colonización de una superficie de piedra fresca comienza con unas pocas especies comunes, ninguna de las cuales son especies pioneras reales ya que no desaparecen con la maduración de la comunidad.

Nascimbene et al. (2009) realizó un seguimiento de las comunidades sobre una estatua de mármol que se había "limpiado" (por segunda vez) hacía 12 años, con el fin de conocer el proceso de recolonización, ya que la misma se había estudiado 20 años antes (primera limpieza) con el mismo motivo (Nimis \& Salvadori, 1997). Observaron que el restablecimiento de los líquenes estuvo influenciado por las líneas del flujo de agua de lluvia que transporta propágulos y esporas, y también proporciona la humedad para su desarrollo posterior. Áreas que están protegidas por estructuras emergentes, o que tienen una forma cóncava están libres de la recolonización de los líquenes. Además la riqueza de líquenes aumentó con el tiempo. Algunas especies se asociaron significativamente a una etapa seral, como el caso de Bacidina delicata que fue pionera o Verrucaria nigrescens que apareció años después y terminó dominando varios sitios. Sin embargo, las comunidades difirieron de las encontradas por Nimis y Salvadori (1997), por lo que los autores supusieron que la comunidad aún estaba en una etapa temprana de sucesión.

Es conocida la sensibilidad de los líquenes a la contaminación atmosférica, en tanto que las ciudades son un foco de contaminantes, ya sea por fábricas o por el parque automotor (Carrera \& Carreras, 2011; Monna et al., 2012; Słaby \& Lisowska, 2012; Chaparro et al., 2013; Evju \& Bruteig, 2013). Por ello hay que tener en cuenta que existe el "efecto ciudad" no solo por la contaminación sino por la alta temperatura y la baja humedad, según el cual el efecto negativo de la urbe disminuye al alejarnos del centro de ésta (Brodo, 1966; Brightman \& Seaward, 1977). Brodo (1966), quien realizó una transecta desde el centro de la ciudad de New York hasta los bosques de las cercanías, encontró que en el centro de la ciudad solo crecía Myriolecis dispersa sobre mortero, especie que ya había sido categorizada como resistente a la ciudad por Erichsen (1957). Propuso una escala de tolerancia a la ciudad según la 
morfología de las especies, que en orden de tolerancia creciente sería: fruticosa-foliosa-crustosa-leprosa. Determinó además que las especies saxícolas y terrícolas son más resistentes a la ciudad, mientras que las corticícolas son más sensibles. Sin embargo, en los últimos años muchos centros urbanos han experimentado una recuperación de las poblaciones de líquenes debido al cambio generalizado a combustibles más limpios y mayores esfuerzos para controlar, o al menos reducir, las emisiones de algunas de las fuentes de contaminación más dañinas (Seaward, 1997). En Londres se notó un efecto similar: el centro de la ciudad era un desierto de líquenes (Laundon, 1973), en tanto que varias especies sobreviven en los cementerios posiblemente debido a la capacidad buffer de $\mathrm{pH}$ de las rocas calcáreas y el mortero (Laundon, 1967). También hay que tener en cuenta que estos desiertos de líquenes pueden ser producidos por la limpieza de las superficies como así también el vandalismo, que afectan la estabilidad del sustrato (Seaward, 1997). Hill (2010) registró sobre los muros de una iglesia una diferenciación vertical de la diversidad y de la composición de las comunidades de líquenes, y la relacionó con la contaminación a la que estaba expuesto el edificio, dado que fue en la parte inferior donde predominaron los más resistentes a la contaminación mientras en la superior también aparecieron especies sensibles.

\section{I.1.4. Sucesión y el cambio en la comunidad}

La sucesión en las comunidades de líquenes es un proceso lento que en algunos casos puede llegar a tardar décadas o posiblemente centurias (Hale 1974; Woolhouse et al., 1985; Armstrong \& Welch, 2007). De las interacciones que se producen entre las especies durante la sucesión, la competencia es propuesta como la interacción más común y de mayor influencia en la estructura de la comunidad (Topham, 1977; Seaward, 2008; Bowker et al., 2010).

La sucesión ha sido estudiada por diversos autores en distintas partes del mundo, tanto sobre rocas como sobre troncos, dentro de estos podemos mencionar las contribuciones realizadas por los siguientes autores: 
Orwin (1970) estudió morenas glaciares en Nueva Zelanda y logró realizar mediante líquenes una datación de las rocas expuestas que habrían quedado libres de hielo de 5 hasta 40 años. Esta autora comprobó que durante la sucesión no existe una desaparición de especies pioneras, sino que éstas se perpetúan en el ambiente pero con una cobertura y frecuencia mucho menor que en las primeras etapas. Durante las primeras etapas la comunidad saxícola está dominada por especies crustosas (Placopsis perrugosa y Rhizocarpon geographicum) posteriormente aparece Stereocaulon, una especie fruticulosa capaz de fijar nitrógeno gracias a sus cefalodios. En etapas tardías aparecen especies foliosas como Parmelia adpicta Zahlbr. que domina en su cobertura por sobre las otras especies.

Ketner-Oostra \& Sýkora (2000) analizaron la sucesión primaria sobre las dunas de la costa de la isla de Terschelling (Holanda) y encontraron que los colonizadores primarios eran líquenes. La comunidad es dominada principalmente por especies del género Cladonia, y observaron que muchas especies que crecen sobre la corteza de los árboles también eran capaces de hacerlo sobre las dunas. Con el paso del tiempo los líquenes eran reemplazados por musgos y gramíneas en su cobertura, pero esto solo se lleva a cabo gracias a la consolidación de las dunas y la acidificación de las mismas.

Woolhouse et al. (1985) estudió la sucesión sobre rocas en Canadá: propuso la ocurrencia de 5 etapas serales, de las cuales la inicial solo contó con 2 especies foliosas. En las etapas subsiguientes éstas no volvieron a aparecer, fueron reemplazadas por otras especies foliosas y crustosas; estas últimas dominaron las comunidades. En las etapas tardías apareció una especie fruticosa, descendió la riqueza, varias especies antes presentes desaparecieron y la cobertura entre especies foliosas y crustosa se volvió similar.

Ellis \& Choppins (2006) estudiaron las relaciones entre los patrones de sucesión de una comunidad liquénica corticícola y la disponibilidad de humedad en bosques de Aspen (Escocia). Encontraron un patrón para lugares secos donde las especies crustosas aparecen en etapas tempranas y son reemplazadas por especies foliosas en los árboles viejos. En los ambientes húmedos, en tanto, las especies crustosas son reemplazadas por especies 
foliosas con cianobacterias (gelatinosas) y briofitas. Estos autores comentan la discrepancia entre la sucesión de líquenes con respecto a la sucesión de plantas vasculares en las que las especies fijadoras de nitrógeno aparecen en etapas tempranas mientras que en esta sucesión de líquenes las especies fijadoras de nitrógeno (gelatinosas) aparecen en etapas tardías. Complementando esto Ellis \& Choppins (2007) notaron que las especies pioneras en este caso presentaban una tendencia a tener reproducción asexual mientras que las especies de etapas tardías presentaban estructuras reproductivas asexuales, por lo que sugieren que el remplazo de las especies no es solo condicionada por el tiempo o el sustrato, sino también por las estrategias reproductivas de cada especie.

Fos et al. (2001) analizaron la sucesión secundaria después de un incendio en los bosques de Quercus suber en España. Compararon los troncos afectados por el fuego con sectores que no lo han sido y encontraron que los primeros estadios de la sucesión está dominada por especies con una amplia tolerancia ecológica y que poseen estructuras de multiplicación vegetativa. Las especies Hyperphyscia adglutinata, Physcia adscendens, P. tenella y Scoliciosporum chlorococcum aparecen más tempranamente y son las más ampliamente representadas. Otras, como Evernia prunastri, Parmelia tiliacea, Flavoparmelia soredians, Punctelia subrudecta, Ramalina farinacea, aparecen con mayor frecuencia y desarrollo en los alcornocales que sufrieron un incendio menos intenso y con clima subhúmedo. Esto los autores lo relacionan al hecho de que en los sectores menos dañados los líquenes que estaban previo al disturbio pudieron mantenerse, mientras que en donde el fuego tuvo una alta intensidad no dejó rastro de la antigua comunidad.

Nascimbene et al. (2017) estudiando la dinámica espacio-temporal de la sucesión primaria después de la desglaciación en comunidades de líquenes, en los Alpes europeos. Encontraron que existían diferentes conjuntos de comunidades a lo largo de las etapas de sucesión, las etapas sucesionales anteriores albergaban un subconjunto de las especies ya establecidas en etapas sucesionales más antiguas, no se producia un desplazacioneto total de las especies. Además encontraron patrones contrastantes en relación al tiempo transcurrido desde la deglaciación: la incidencia de especies con 
cianobacterias y aquellas que se reproducen por esporas disminuyó, mientras que la de especies que se reproducen por propágulos vegetativos aumentó. Los rasgos funcionales que reflejan la capacidad de dispersión y adaptación de la especie sustentan el éxito de la colonización de los líquenes.

\section{I.1.5. La competencia y el rol en la estructura de las comunidades}

La competencia interespecífica es una relación que resulta por la limitación de uno o varios recursos y de la interacción entre los nichos ecológicos de las especies (Begon et al., 2006). La simplificación de la comunidad que a menudo resulta de una perturbación pone a disposición los recursos a las especies tolerantes que antes no estaban disponibles debido a la intensa competencia. Como resultado, las especies resistentes a la perturbación son capaces de acceder a recursos por los que serían incapaces de competir con éxito en comunidades complejas.

Según Crowley et al. (2005) la competencia local por el espacio a través de una amplia gama de taxones implica tres mecanismos: la expansión (difusión en hábitat desocupado), el azar (reemplazo de los competidores muertos), y el sobrecrecimiento (invadir competidores a lo largo de zonas de contacto).

En comunidades de líquenes saxícolas, se ha sugerido que las especies con las tasas de crecimiento radiales más rápidas tenderán a ser los mejores competidores por el espacio (Armstrong, 1991). La interacción entre especies crustosas resulta en el contacto entre los bordes de los talos, donde una especie puede crecer sobre la otra o impedir su crecimiento por medio de sustancias alelopáticas (Dale, 1985), aunque las especies pioneras tienden a no invertir energía en el desarrollo de defensas químicas (Rogers, 1990). Pentecost (1980) propone tres tipos de interacciones que se producen en el contacto entre este tipo de talo: una especie crece sobre la otra (sobrecrecimiento), una especie se retrae o es eliminada por el contacto (derrota), ninguna de las especies crece en el punto de contacto (empate). El resultado real de contacto puede depender de la forma de crecimiento de los 
líquenes; por ejemplo los contactos entre las especies crustosas es más probable que resulten en condición de empate que entre especies foliosas. A pesar de la prevalencia del sobrecrecimiento en comunidades de líquenes, es posible que tal interacción no conduzca inevitablemente a la eliminación de especies (Armstrong, 1982). La convivencia de múltiples especies se debe a que las especies con mayor habilidad competitiva no pueden ocupar todos los sitios al mismo tiempo, dejando espacios para que otras especies puedan ocuparlos. Muchos talos, degeneran las porciones centrales creando espacios o "ventanas", que son ocupados por líquenes de la misma u otra especie, por lo tanto, la exclusión de un competidor débil es evitada si es capaz de colonizar estas ventanas (Pentecost, 1980; Armstrong, 1982; Armstrong \& Smith, 1997).

Lawrey (1984) lista los atributos competitivos importantes de los líquenes: tasa de crecimiento, forma de crecimiento, química del líquen, tamaño del talo y palatabilidad. Topham (1977) y posteriormente Rogers (1990) sugieren que los propágulos vegetativos de mayor tamaño tienden a ser de especies más competitivas con una estrategia de tipo $K$, mientras que los que cuentan con propágulos pequeños (soredios o esporas) tienden a ser tolerantes al estrés o ruderales y relacionados a una estrategia de tipo $r$. El desplazamiento local nunca es permanente por lo que, cuando los mejores competidores mueren por senescencia, factores ambientales, o factores bióticos (Seaward, 2008), los sitios quedan disponibles para ser colonizados por competidores menos hábiles (Armstrong, 1982).

Armstrong (2002) evalúa la posible exclusión competitiva del líquen crustoso Rhizocarpon geographicum de los afloramientos rocosos expuestos al $\mathrm{N}$, en el norte de Gales. En su estudio pudo observar que hay cuatro especies comunes de líquenes foliosos presentes en estos sitios con tasas de crecimiento significativamente más altos y con la capacidad de crecer sobre $R$. geographicum, que podrían ser competidores potenciales. Sobre los roquedales con otras orientaciones pudo observar la presencia de esta especie con talos bien desarrollados, pero las especies foliosas no se encontraban. El autor sugiere que $R$. geographicum puede sobrevivir sobre ciertas superficies orientadas hacia el $\mathrm{N}$, donde convive con un gran número de especies competidoras pero éstas presentan una baja frecuencia, no llegando a tener la 
misma capacidad competitiva que sobre las otras orientaciones, en las cuales presentan una frecuencia mucho más alta.

\section{I.1.6. Distribución geográfica}

Hay estudios que han demostrado que los factores locales tienen más importancia sobre la distribución que la latitud, o al menos no condicen con un aumento de diversidad en un gradiente latitudinal (N-S) propuestos para otros organismos (Hawkins, 2001): en USA lo comprobó Holt et al. (2015) para una amplia gama de especies y en Polonia Szczepańska et al. (2015) para especies del género Xanthoparmelia.

Con respecto a la zona austral de América del Sur, Lücking et al. (2003) analizan la flora liquénica de la selva Valdiviana y comprueban que existe una conexión con las de Australia y Nueva Zelanda, aunque remarcaron que presenta características propias como para considerarla un área diferente. No obstante, la falta de evidencia fósil, la naturaleza polifilética de los líquenes, los registros incompletos en muchos territorios y la continua discusión taxonómica en el seno de numerosos grupos dificultan el estudio y la interpretación biogeográfica (Jørgensen, 1983).

Aun así, en diversos estudios se ha propuesto que la distribución espacial de los líquenes está asociada a gradientes ecológicos (Kappen, 1988; van Herk et al., 2002; Brunialti \& Giordani, 2003). Entre ellos la precipitación ha sido considerada como el factor de mayor relevancia (Nash, 2008; Jovan \& McCune, 2004; Geiser \& Neitlich, 2007; Marini et al., 2011); el clima local juega un papel muy importante dado que son organismos en cuyos talos el nivel de agua varía pasivamente con las condiciones ambientales que lo rodean (poiquilohídricos).

Calatayud et al. (1994) analizaron la fitogeografía de líquenes en las sierras de Espadán (España), donde encontraron que las especies se reúnen en cuatro grandes grupos: especies de amplia distribución, con áreas que abarcan normalmente varios continentes, especies mesógeas que viven en clima mediterráneos o en microclimas de altas temperaturas, especies de 
distribución mediterráneo-atlántica consideradas oceánicas, cuya presencia en el territorio se restringe a aquellos enclaves más húmedos, y especies con área disyunta que incluyen especies mediterráneas compartidas con América.

\section{I.2. Antecedentes para Argentina}

Para Argentina podemos enumerar los siguientes trabajos en los que se han analizado las comunidades de líquenes:

Estrabou \& García (1995) estudiaron las comunidades de líquenes sobre Lithraea ternifolia en bosques de la provincia de Córdoba discriminando cuatro grupos de especies. La distribución de los grupos tuvo poca relación con factores externos; el diámetro a la altura de pecho sugirió una relación entre la distribución de las especies liquénicas y la edad de los forófitos. El grupo 1 fue indiferente a los factores externos, aunque presentaron una tendencia a aparecer sobre forófitos jóvenes. Las especies del grupo 2 se establecieron con preferencia en la parte basal de los forófitos jóvenes, mientras que las especies del grupo 3 mostraron una tendencia a seleccionar forófitos de mayor edad, presentes en el bosque maduro. Las especies del grupo 4 se distribuyeron preferentemente sobre forófitos de edad media.

Estrabou (2007b) realizó una comparación entre las especies de líquenes que crecían sobre 3 forófitos diferentes en el bosque chaqueño, encontró que la comunidad liquénica presente en los tres forófitos estudiados fue similar en cuanto al número y diversidad de especies. Las especies dominantes presentaron una preferencia marcada por un sustrato, mientras las especies secundarias no tienen preferencia por uno u otro forófito.

Estrabou et al. (2005) realizaron un relevamiento de los líquenes epífitos en 4 ecosistemas diferentes de Córdoba, de estos 3 fueron bosques nativos y uno fue el arbolado urbano de la capital de la provincia. Encontraron que Candelaria concolor fue la única presente en los 4 ecosistemas. Observaron diferencias entre el bosque chaqueño oriental y el bosque serrano que atribuyeron a las condiciones ambientales y las diferencias de los forófitos disponibles, mientras que en Salinas Grandes y en la ciudad de Córdoba se 
encontraron similitudes en cuanto a las especies dominantes, con variaciones en su cobertura, reproducción, anatomía y morfología.

Quiroga et al. (2008) con el fin de conocer la respuesta de las comunidades liquénicas a la fragmentación del bosque realizaron inventarios en dos unidades boscosas con distinta situaciones de manejo. Reconocieron una comunidad diferente en cada bosque, una dominada por Parmotrema crozalsiana en situación de poco disturbio y otra dominada por Parmotrema reticulatum en la zona con mayor degradación. Contrario a lo que otros autores han propuesto, existió una mayor presencia de especies con reproducción asexual en el bosque menos degradado.

Lavornia (2015) analizó las comunidades sobre roquedales de las sierras próximas a la ciudad de Tandil (Buenos Aires) en relación a diferentes variables ambientales. Encontró que las variables que condicionan la distribución de las comunidades operan en la escala espacial de sitio (exposición y posición topográfica de las laderas), aunque también existe cierta influencia de la pendiente general y la rocosidad. El autor pudo identificar tres grupos florísticos: la comunidad de Caloplaca cinnabarina-Flavoplaca austrocitrina en roquedales altos o bajos, granitoide y miloníticos, con exposiciones que reciben insolación plena todo el día; otra comunidad definida por Usnea amblyocladaHaemmatoma montevidensis en roquedales altos, granitoides al SW, y una tercera comunidad de Parmotrema tandilense- $P$. cetratum en roquedales bajos, miloníticos expuestos al $\mathrm{S}$.

Liberatore et al. (2002) analizaron la diversidad y distribución de los líquenes en Argentina mediante técnicas multivariadas, sin embargo, al no contar con información detallada de las distribuciones (solo el $30 \%$ de los datos les era fiable), no les fue posible establecer relaciones con las unidades fitogeográficas de la vegetación, como patrones previos de comparación. Por ello utilizaron la división política de Argentina para analizar las distribuciones. Ferraro (1995), en cambio, pudo relacionar la diversidad de los líquenes de la provincia de Corrientes con las unidades fitogeográficas y constató algunas correlaciones entre éstas y la distribución de líquenes corticícolas. Estrabou (2000) utilizó técnicas de ordenación multivariada para analizar los patrones de distribución de las Parmeliaceae s.s. en la provincia de Córdoba (Argentina). 
Remarcó que la disponibilidad de sustratos sería uno de los factores más importantes para explicar los patrones de distribución de las especies de la familia. Un ejemplo de esto es que en el ambiente de pastizal no se encuentran especies, pero no debido a las condiciones ambientales (que si son favorables) sino a la falta de sustratos útiles.

Rodríguez (2011) realizó una descripción de los patrones de distribución del género Usnea para todo el país y obtuvo correlaciones positivas solo para las especies corticícolas, entre la presencia de ciertas especies y las zonas fitogeográficas propuestas por Cabrera (1971). Las especies saxícolas en cambio, forman un arco "peripampásico" delimitado por las montañas que rodean a territorios de llanura. Estas sierras y montañas funcionan como islas favoreciendo la dispersión.

En Argentina los estudios en las urbes relacionados con líquenes son escasos. La mayoría de ellos son listas de especies encontradas sobre sustrato antrópico, o estudios relacionados al biodeterioro (Rosato, 2006, 2010; Estrabou, 2007a; Guiamet et al., 2012, Rosato \& García, 2014; García et al., 2015). Solo se pueden nombrar los trabajos de Rosato et al. (2009) y García et al. (2014) donde se han realizado algunos análisis ecológicos de los líquenes presentes sobre edificios. 


\section{MARCO TEÓRICO}

\section{II.1.1. La comunidad ecológica}

La comunidad biótica es un conjunto de poblaciones que viven en un área o en un hábitat físico determinado en un mismo tiempo (Begon et al., 2006); es una unidad laxamente organizada, hasta el punto que posee características complementarias de las de sus componentes individuales y funciona como unidad mediante transformaciones metabólicas acopladas; es la parte viva del ecosistema (Odum \& Barrett, 2008). En términos generales, las especies que se ensamblan para formar una comunidad son determinadas por: constantes de dispersión, dinámica interna y constantes ambientales (Belyea \& Lancaster, 1999). Clements (1916) concibió a la comunidad como un superorganismo donde sus especies componentes están fuertemente unidas entre sí, tanto ahora como en su historia evolutiva común. Por lo tanto, los individuos, las poblaciones y las comunidades llevaban una relación entre sí que se asemeja a la que existe entre las células, los tejidos y organismos. Entre estas entidades se puede observar en el paisaje la presencia de otras unidades de transición que son denominadas ecotonos (Perelman et al., 2005). En contraste, Gleason (1926) consideraba a las especies vegetales distribuidas como un continuum. Propone una visión individualista, donde el ensamblaje de organismos que habitan en un lugar dado no es solo el resultado de las condiciones ambientales, sino que también de la migración de especies; cualquier área está recibiendo continuamente propágulos de especies. El éxito de estas especies depende de la combinación de los factores ambientales en el lugar y de los rangos de tolerancia de las especies invasoras. Tomando este punto de vista, los límites de la comunidad no tienen que ser bruscos, y las asociaciones de especies serían mucho menos predecibles de lo que cabría esperar del concepto de super organismo.

Dentro de la comunidad ecologíca podemos encontrar características que la separan de otros niveles de organización y que son propias de este nivel (Begon et. al, 2006; Odum \& Barrett, 2008). 
- Riqueza de especies (S): se refiere al número de especies que conforman una comunidad, también se le denomina riqueza o riqueza específica.

- Estructura: es la forma en que están organizadas las comunidades en el espacio, pudiendo ser:

- Estructura vertical: es la manera en que se distribuyen los componentes de la comunidad a lo largo del eje vertical, la altura sobre el suelo o la profundidad bajo la superficie del agua a la que se encuentran los organismos.

- Estructura horizontal: es la manera en la que se distribuyen los componentes de la comunidad en el terreno que ocupan.

- Estructura cuantitativa: se refiere al número de individuos o a la biomasa que aporta cada especie a su comunidad.

- Fisonomía: Es el aspecto externo de las comunidades y depende fundamentalmente de las características morfológicas de las especies que la conforman.

- Diversidad: Es la variedad de organismos que forman una comunidad y sus dos componentes son: la riqueza de especies y su abundancia.

- Dominancia y rareza: son atributos relacionados con la estructura cuantitativa y la diversidad de las comunidades. La dominancia se refiere a la proporción de especies que son muy abundantes en la comunidad. La rareza se refiere a la proporción de especies escasas en una comunidad.

- Fenología: se refiere al comportamiento estacional de la comunidad en su conjunto, como resultado de los procesos del ciclo de vida de las especies que la componen.

- Estado sucesional: es el grado de desarrollo de una comunidad en el proceso de recuperación después de un disturbio, el cual da lugar a la apertura de nuevas áreas de colonización.

- Tasa de recambio de especies: Es la velocidad a la que se lleva a cabo el proceso de pérdida (extinción local) y ganancia (colonización) de especies.

Las comunidades pueden nombrarse y clasificarse adecuadamente según sus características estructurales más importantes, como las especies dominantes, las formas o los indicadores de vida, el hábitat físico de la comunidad, o sus atributos funcionales, tales como el tipo de metabolismo de la 
comunidad. No se ha formulado regla precisa alguna para la denominación de las comunidades, como se ha hecho para nombrar o clasificar organismos. En efecto, las clasificaciones basadas en las características estructurales son más bien particulares de ciertos medios, y en cuanto a los intentos de establecer una clasificación universal sobre esta base, éstos han sido en gran parte poco satisfactorios. En cambio, los atributos funcionales proporcionan una base mejor para la comparación de todas las comunidades en hábitats muy distintos, como terrestres, marinos o de agua dulce (Odum \& Barrett, 2008).

Uno de los componentes más importantes y con mayor discusión es la medida de la diversidad que se puede separar en:

La diversidad alfa ( $\alpha$ ) es la variedad de especies de una comunidad particular a la que consideramos homogénea, la diversidad beta $(\beta)$ es el grado de cambio o reemplazo en la composición de especies entre diferentes comunidades en un paisaje, y la diversidad gamma ( $\mathrm{Y}$ ) es la riqueza de especies del conjunto de comunidades que integran un paisaje, resultante tanto de las diversidades alfa como de las diversidades beta (Whittaker, 1972).

Para diferenciar los distintos métodos en función de las variables biológicas que miden, los dividimos en dos grandes grupos (1) métodos basados en la cuantificación del número de especies presentes o riqueza específica (S); (2) métodos basados en la estructura de la comunidad, es decir, la distribución proporcional del valor de importancia de cada especie (abundancia relativa de los individuos, su biomasa, cobertura, productividad, u otro valor). Los métodos basados en la estructura pueden a su vez clasificarse según se basen en la dominancia (e.g. índices de Shannon-Wiener, de Simpson) o en la equidad de la comunidad tales como el índice de equitatividad o el de equidad (Moreno, 2001).

La diversidad $\beta$, o diversidad entre hábitats, es el grado de reemplazo de especies o cambio biótico a través de gradientes ambientales (Whittaker, 1972). La medición de la diversidad $\beta$ es de una dimensión diferente que las otras medidas de diversidad porque está basada en proporciones o diferencias. Estas proporciones pueden evaluarse con base en índices o coeficientes de similitud, de disimilitud o de distancia entre las muestras a partir de datos cualitativos (presencia-ausencia de especies) o cuantitativos (abundancia 
proporcional de cada especie medida como número de individuos, biomasa, densidad, cobertura), o bien con índices de diversidad $\beta$ propiamente dichos (Moreno, 2001; Magurran, 2013; Wilson \& Shmida, 1984).

La diversidad y como la riqueza en especies de un grupo de hábitats (un paisaje, un área geográfica, una isla) resulta como consecuencia de la diversidad a de las comunidades individuales y del grado de diferenciación entre ellas (Whittaker, 1972). Desgraciadamente, la mayoría de los esfuerzos realizados para medir la biodiversidad en áreas que incluyen más de un tipo de comunidad se limitan a presentar listas de especies de sitios puntuales (diversidad $\alpha$ ), describiendo la diversidad regional $(\gamma)$ únicamente en términos de números de especies, o bien con cualquier otra medida de diversidad a (Moreno, 2001; Magurran, 2013).

Del número total de las especies en un componente trófico o en una comunidad conjunta, un porcentaje relativamente pequeño suele ser abundante (esto es, estar representado por grandes números de individuos, por una biomasa grande, una gran productividad o alguna otra indicación de "importancia"), y un porcentaje grande es raro (posee pequeños valores de "importancia"). La diversidad de las especies suele ser baja en los ecosistemas controlados físicamente (esto es, sujetos a factores fisicoquímicos fuertemente limitativos) y alta, en cambio, en los ecosistemas controlados biológicamente (Odum \& Barrett, 2008).

\section{II.1.2. El efecto de las condiciones ambientales en la estructura de la comunidad}

En ambientes rocosos, las hendiduras llenas de arena y grietas reciben más agua que la superficie lisa de una roca expuesta, la insolación se reduce por el sombreado, la temperatura es menor, la caída de rocío más probable y el agua que gotea desde la roca se almacena en los intersticios. Un mejor suministro de agua parece ser la razón principal de la densa cobertura de líquenes en dichas hendiduras y grietas (Marton \& Galun, 1981; Insarov \& Insarova, 1995). En cuanto a los líquenes endolíticos, generalmente habitan 
afloramientos con una alta insolación y se cree que este tipo de crecimiento es una adaptación al clima extremo de estos hábitats (Kappen et al., 1980).

Hernández Gallego \& Muñoz Reinoso (2005) estudiaron las comunidades de líquenes psammófilos de Huelva (España), su composición, su relación con el medio físico y las comunidades de matorral con las que convivían. Encontraron seis comunidades liquénicas terrícolas asociadas a cinco comunidades vegetales. Las diferencias en la composición liquénica responderian al microambiente creado por las comunidades leñosas y no al pH o a la conductividad del suelo. Cada una de las unidades de vegetación (sabinar, monte blanco, monte intermedio, monte negro y pinar) presenta características propias en función de la estructura de la vegetación (cobertura y altura) y como resultado ofrecen distintos microambientes desde soleados y con poca hojarasca hasta muy sombreados con mucha hojarasca que influyen en la conformación de las comunidades de líquenes según las preferencias de cada especie.

Los patrones de distribución de los líquenes saxícolas en las cercanías de la estación Syowa en Antártida (Kanda \& Inoue, 1994) a gran escala es afectada por: las condiciones de nutrientes del sustrato, la presencia de sitios protegidos en valles o depresiones, la hidrología superficial (arroyos, estanques y lagos) la presencia de glaciares o por la dinámica de la caída de nieve. En cambio, la distribución a pequeña escala dentro de las comunidades se ve afectada por las características microclimáticas y micro-topográficos de cada sitio, que estarían influyendo sobre las características propias de las especies, como la cobertura y la tasa de crecimiento de los talos durante la temporada de crecimiento.

En el valle Kärkevagge (Suecia), Buschbom \& Kappen (1998) estudiaron las comunidades de líquenes crustosos sobre las rocas. Analizaron las condiciones microclimaticas que se producían sobre estas durante las cuatro estaciones. Ellos observaron que contrario a lo esperado los patrones de distribución eran coincidentes con las condiciones microambientales del otoño. Las especies de esta región tienen una preferencia por las precipitaciones y vientos del NW, por lo que interpretan en otoño es la época en que aumenta el metabolismo de los líquenes y se expanden sobre las rocas. 
Egea \& Llimona (1982) realizaron relevamientos fitosociológicos en Sierra del Cabo de Palo (España), relevan 61 especies entre las cuales encuentran 3 grupos: especies características para la región, especies típicas de pisos termo y meso mediterráneo y especies cosmopolitas. Además proponen diferentes comunidades basadas en las preferencias microambientales y el tipo de sustrato, estas son: comunidad dominante en la solana, sobre superficies poco inclinadas; comunidad relegada a los lugares más oligotróficos, en exposición abierta y muy soleados; comunidad en las paredes verticales, superverticales, interior de cuevas, generalmente en la umbría; comunidad sobre pizarras blandas, fisuras y rellenos con materiales pulverulentos.

En los roquedales del SE de España Egea \& Llimona (1987) relevaron los líquenes presentes con el fin de poder identificar la existencia de una o más comunidades. Encontraron dos comunidades definidas, una formada por 11 especies "mediterráneas" y otra formada por 15 especies. Los autores adjudican esta separación a diferencias en la intensidad de la luz que reciben, y a la desecación que ésta causa en los talos. La comunidad mediterránea es poco sensible a la desecación y por tal motivo habita sitios con una alta exposición, mientras que la otra comunidad solo se encuentra en lugares sombríos.

Egea \& Llimona (1997) realizaron un relevamiento de los líquenes que crecían sobre lavas básicas en el SE de España, encontrando 88 especies, las cuales describen como especies nitrófilas y calcícolas. En comparación con sus trabajos previos, en la misma zona pero sobre lavas síliceas (Egea \& Llimona, 1994), observaron en esta comunidad la ausencia de las numerosas especies típicas de las rocas silíceas ácidas de la región, aunque ambos tipos de rocas comparten especies nitrófilas cosmopolitas. Consideran que ambas son comunidades diferentes y que el tipo de roca está asociado a esta diferencia.

En un bosque húmedo bien conservado en el Sistema Central de Madrid (España) Molina Moreno \& Provanza (1992) diferenciaron tres comunidades de líquenes epífitos, las cuales atribuyen a la selección del forófito. Una tendió a asociarse a acebos (Ilex aquifolium) y avellanos (Corylus avellana), otra a robles (Quercus spp.), y otra que fue indiferente al forófíto. Estas preferencias 
son explicadas por las diferencias en las cortezas de los árboles y por la iluminación que recibe cada uno. El avellano forma rodales densos por lo que están más protegidos del viento y reciben menos cantidad de luz que los robles que crecen en forma aislada.

En selvas del NE de Brasil, para determinar el efecto del forófito y de los parámetros ambientales en la estructura de la comunidad de líquenes corticícolas Cáceres et al. (2007) midieron la presencia de látex, el pH de la corteza, la densidad, el tamaño de las lenticelas, la especie del forófito y la circunferencia del tronco. Ninguna de estas variables tuvo influencia sobre la estructura de las comunidades observadas; o sea que no hubo preferencias por el sustrato y la presencia de una especie sobre el forófito se debería a la probabilidad de un establecimiento exitoso de la diáspora. Medina et al. (2012) también llegaron a la misma conclusión para líquenes crustosos de las selvas de Colombia.

\section{II.1.3. Factores que operan en la dispersión de los líquenes}

Los propágulos de origen asexual están constituidos por pequeños trozos del talo, especializados para la dispersión por hidrocoria, anemocoria o zoocoria, formados por una masa de hifas que envuelven células algales, que pueden tener corteza (isidios) o carecer de ella (soredios). En cambio las esporas resultantes de la reproducción sexual del micobionte pueden estar asociadas a células algales, en este caso la espora con la célula algal asociada dará origen a un nuevo talo liquénico. En el caso de que la espora no tenga asociada una célula algal, después de la dispersión el hongo necesitará encontrar alguna especie de alga para formar la simbiosis (Barreno \& Rico, 1984; Chaparro de Valencia \& Ceballos, 2002; Galloway, 2008). Estos propágulos pueden ser dispersados por agentes abióticos como las ráfagas de viento que arrastran pequeños soredios, esporas y fragmentos de talo a grandes distancias, o el agua que en cambio actúa de forma local, las gotas que caen sobre la superficie del talo liberan y transportan los propágulos a cortas distancias (Bailey, 1966, 1976). Un ejemplo de esto sucede en las colonizaciones primarias, como es el caso de las coladas de lava de la isla 
Surtsey (Islandia) donde Kristinsson \& Heiômarsson (2009) realizaron un seguimiento del proceso durante 36 años. Ellos pudieron observar que los primeros colonizadores llegaron por diásporas traídas por las corrientes de viento y además que estas especies pioneras comenzaron a colonizar el resto de la isla también por el transporte de los propágulos por el viento.

Por otro lado los agentes bióticos como las aves, los mamíferos y los invertebrados actúan cuando los propágulos se adhieren a las plumas, las patas, la piel o el pelo, o mediante la recolección de material para su uso como alimento o la construcción de nidos (Galloway, 2008).

\section{II.1.4. Colonización}

Un número de factores determinan la colonización biológica, (Miller et al., 2009): (i) las propiedades intrínsecas del material a colonizar, tales como la porosidad, la rugosidad y la permeabilidad, que influyen fuertemente en la disponibilidad de agua para los microorganismos; (ii) las del ambiente (e.g. radiación solar, temperatura, régimen de agua, clima), y (iii) los parámetros microclimáticos específicos (e.g. la orientación, la exposición a la sombra, la humedad capilar permanente). Los microorganismos en las superficies de rocas expuestas raramente crecen como colonias que comprenden una sola especie, sino que forman comunidades que deben su supervivencia al microhábitat que se establece con ese crecimiento colectivo (Costerton et al., 1995; Gorbushina, 2007).

Armstrong (1988) ha demostrado la importancia de la textura de la superficie y de la microtopografía para la inserción exitosa y la supervivencia de los propágulos, tanto de origen asexual como sexual.

Las actividades humanas pueden desempeñar un papel significativo en la introducción accidental de las especies a una nueva área (e.g. transporte accidental a nuevas zonas en madera con corteza, leña, turba, o piedra), conduciendo en algunos casos a un aumento en el número de taxones cosmopolitas (Galloway, 2008). 
Entre los materiales de construcción, el mortero conformado por una mezcla de granos de arena unidos entre sí por un aglomerante plástico (cal, cemento, etc.), es un sustrato fácilmente colonizado por líquenes, debido a su composición y estructura (Saiz-Jiménez \& Ariño, 1995; Guillitte, 1995; Chen et al., 2000). Guillitte \& Dresen (1995) realizaron un estudio sobre materiales de construcción, 2 rocas naturales (granito y calcita) y 3 rocas manufacturadas (mortero aireado, mortero compacto y ladrillo), que se colocaron en una cámara con humedad e iluminación controlada y se les sembraron propágulos de algas, hongos y musgos. Al cabo de 6 meses todos los materiales fueron colonizados por los organismos sembrados, y pudieron corroborar que no importaba si el sustrato presentaba nutrientes ya que los estaban obteniendo del agua, por lo que proponen que las características importantes de la bioreceptividad son: la porosidad o rugosidad de la superficie, la capacidad de retener humedad y las características mineralógicas del material. Según estos valores proponen que el material más bioreceptivo fue el mortero aireado, seguido por el mortero compacto y el ladrillo y por último las 2 rocas naturales. Aunque por otro lado algunos investigadores han sugerido que tales factores climáticos y ambientales pueden tener una mayor influencia en el patrón de colonización de las superficies de piedra que la naturaleza de la propia roca (Urzì et al., 2001; Bellinzoni et al., 2003).

El crecimiento de los talos en materiales de construcción está estrechamente relacionado con los procesos de alteración química y física, debido a que la fijación de los líquenes en el sustrato por lo general implica la penetración de las hifas a través de los poros o disolución y disgregado de cristales minerales. En este proceso excretan compuestos, (principalmente ácidos orgánicos) que desempeñan un papel importante, no solo en el cambio de la composición química, sino también en las alteraciones microestructurales (Ascaso \& Wierzchos, 1994). 


\section{II.1.5. La sucesión de las comunidades}

Las comunidades están sujetas a procesos de sucesión en que se produce un reemplazo de comunidades en el tiempo que es determinado por un proceso de colonización y desaparición de especies en un determinado lugar, a lo largo de un período de tiempo. La sucesión primaria se produce cuando se coloniza un sustrato "nuevo" o cuando las comunidades anteriores no tienen ningún tipo de relación con la subsiguiente. Ejemplo de esto son la colonización de flujos de lava y piedra pómez, de llanuras causadas por erupciones volcánicas, de cráteres producto del impacto de meteoritos, de los sustratos expuestos tras el retroceso de un glaciar, o de dunas de arena recién formadas. La sucesión secundaria ocurre cuando la vegetación de un área se ha eliminado parcial o completamente y la comunidad subsiguiente está influenciada por la anterior al disturbio dado que el sustrato conserva propágulos, semillas y/o esporas de la comunidad anterior al disturbio (Begon et al., 2006).

Siguiendo las dos teorías de la comunidad antes expuestas se desprende que para la teoría organísmica, Clements (1928) asumió la sucesión como un proceso único y secuencial. Se considera que la dominancia secuencial surge de las especies dominantes que modifican su entorno (en particular el suelo y la luz) por lo que es menos favorable para ellos mismos, y tal vez más favorable a otras especies que pueden dominar de forma competitiva a los anteriores ocupantes. El resultado es unidireccional, a un clímax inevitable y fijo, pero solo en ausencia de perturbaciones.

Siguiendo las ideas de la comunidad individualista, Egler (1954) propone una hipótesis en la que la sucesión es consecuencia de las diferentes tasas de crecimiento de las diferentes especies que están presentes inicialmente en un sitio. Este punto de vista implica que la aparición de una serie de especies se debe al rápido crecimiento de algunas, que eclipsan el crecimiento de otras especies que dominan más tarde, debido al tamaño, longevidad y otros rasgos de historia de vida. Además puso en duda la generalidad de los procesos de sucesión; sugirió la posibilidad de efectos inhibitorios y sostuvo que el supuesto 
de un solo punto final, o el clímax estable para cualquier sitio no está comprobada.

Posterior a estos autores Margalef $(1968,1997)$ consideraba a la sucesión como un proceso de auto-organización, que conllevaba una disminución gradual de la entropía paralela a la paulatina disminución de la influencia del ambiente y al progresivo aumento de las interacciones bióticas. La cantidad de información, viva e inanimada, incrementa durante la sucesión. La información puede ser definida como energía, biomasa o estructura, y es transferida desde estadios iniciales de la sucesión a estadios posteriores a través de un proceso de explotación. La explotación se produce porque las fases tardías de la sucesión acumulan una mayor cantidad de información, gracias a un menor nivel de perturbación, que las iniciales. Paradójicamente, las fases tardías son más resistentes a la perturbación gracias al flujo de energía o transferencia de información. Una alteración en cualquier estadio provoca cambios rápidos, catastróficos, caracterizados por una disminución de la madurez (retrogresión).

\section{II.1.6.1. El ambiente urbano}

Los muros se consideran a menudo hábitats más extremos con fluctuaciones de temperatura más grandes debido a sus dimensiones más pequeñas y generalmente se encuentras expuestas directmente a la radiación solar. Además, tienen menos variabilidad en microhábitats por ser superficies regulares (Seaward, 1979; Aptroot \& James, 2002; Simonová, 2008a,b)

Seaward (1979) enumera las propiedades y los principales factores que operan sobre la flora criptogámica en habitas urbanos:

- Clima urbano. la precipitación (cantidad, duración, pH); humedad; temperatura; intensidad de luz; viento (dirección, velocidad); contaminación atmosférica.

- Efectos microclimáticos debidos a la proximidad de otras superficies (otros muros, bases, suelo, etc.). 
- Efectos microclimáticos de paredes con concavidades, que pueden contener agua.

- Efectos de la superficie. inclinación; química; textura (porosidad, capacidad de retención de agua); antigüedad; mantenimiento; absorción de calor (e.g. color); variación en la composición química, forma, etc.; influencia de las deposiciones de aves.

- El clima interno de la construcción (e.g. temperatura).

- La deposición de partículas de sedimento y formación del suelo.

Simonová, $(2008 a, b)$ por otro lado hace una simplificación de lo antes mencionado, postulando que sobre los muros se distinguen solamente dos microhábitats según la inclinación de las superficies, separándolas en horizontales y verticales.

\section{II.1.6.2. Biodeterioro y bioprotección}

Los líquenes han sido reconocido por varios autores como posibles agentes en la destrucción de estructuras de interés patrimonial (Seaward et al., 1989; Wierzchos \& Ascaso, 1996; Chen et al., 2000; St. Clair \& Seaward, 2004), dependiendo de las características de cada especie tendrán distintaspodemos separar los efectos que el liquen tiene sobre el sustrato en:

\section{- $\underline{\text { Físicos }}$}

- Penetración. Las hifas penetran la roca, tanto vertical como horizontalmente, por los poros intergranulares y por los planos de clivaje de algunos minerales, esto produce su ruptura en partes de menor tamaño y la movilización de las mismas. (Wessels \& Schoeman, 1988; Cooks \& Otto, 1990; Prieto et al., 1994; Prieto-Lamas et al., 1995).

o Expansión y contracción del talo. Fry $(1924 ; 1927)$ investigó sobre una variedad de sustratos colonizados y sugirió que la fuerza mecánica ejercida por la expansión y contracción de las sustancias gelatinosas y mucilaginosas de la médula, a través del humedecimiento y secado de los talos liquénicos, fue de importancia significativa en el proceso de desgaste físico de los sustratos. Se puede esperar, por lo tanto, que en 
sustratos donde el humedecimiento y secado alternados es frecuente, la erosión de las rocas será considerable, este mecanismo puede tener lugar en períodos de tiempo relativamente corto. Incorporación de fragmentos minerales al talo. Se ha demostrado que los fragmentos minerales que se desprenden del sustrato por acción del líquen pueden ser incorporados dentro del talo del mismo. Prieto Llamas et al. (1995) informó que los talos de cinco especies de líquenes contenían partículas, principalmente cuarzo, feldespato y mica, lo que confirma que estos granos minerales que forman rocas sueltas puede ser atrapados por el talo. García et al. (2015) observaron un caso similar en el que líquenes creciendo sobre metal pintado desprendian fragmentos de pintura y los incorporaban al talo.

- Químicos

Los líquenes producen una amplia variedad de compuestos químicos (Huneck \& Yoshimura, 1996). Jackson \& Keller (1970), Creveld (1981), Seaward et al. (1989) y Wierzchos \& Ascaso (1996) encontraron que el $\mathrm{CO}_{2}$, producto de la respiración de los líquenes, disuelto en agua puede bajar el pH localmente promoviendo la erosión de la roca. Además los líquenes secretan ácidos orgánicos simples (Huneck \& Yoshimura, 1996) que son capaces de degradar el sustrato sobre el que se encuentran, dentro de estos el más estudiado es el ácido oxálico (Eick et al., 1996a, b). Muchos líquenes crecen exclusivamente en sustratos con una determinada composición (calcícolas, silícolas, ferrícolas, etc.) estas sustancias que liberan les ayudan degradación del sustrato y a la posterior absorción de nutrientes y da lugar a la aceleración de la disolución y movilización de otros compuestos (Chisholm et al., 1987; Carcía-Rowe \& Saiz-Jímenez, 1991; Purvis \& Halls, 1996).

Dentro del proceso de pedogénesis los líquenes son organismos cuyo aporte radica ya sea en su capacidad de meteorizar rocas como de acumular sedimentos y materia orgánica durante la sucesión. Chen \& Blume (1999) proponen que los líquenes, sobre todos los endolíticos, son importantes para el desarrollo de los suelos en la Antártida, siendo organismos capaces de 
penetrar y degradar rocas en este tipo de ambientes extremos. De los Ríos et al. (2005) realizaron las mismas observaciones también sobre rocas de la Antártida con la especie endolítica Lecidea sp. y comprobaron a través de cortes delgados que era capaz de penetrar más de $2 \mathrm{~mm}$ en el granito. Esto mismo también fue propuesto para Verrucaria rubrocincta Breuss y su accionar sobre las rocas del desierto de Sonora (Bungartz et al., 2004).

Mohammadi \& Krumbein (2008) observaron el deterioro causado por especies de líquenes sobre monumentos de piedra en Persépolis (Irán), donde encontraron especies crustosas epilíticas y endolíticas y pudieron estudiar las perforaciones que éstas estaban causando sobre las rocas de las ruinas. $\mathrm{Si}$ bien reconocen que el efecto de los líquenes es pequeño, poniéndolo en contexto junto con otros factores y sumado al interés de la conservación del sitio, reconocen la importancia de éstos.

Jones et al. (1981) mediante microscopía electrónica de barrido y análisis con microsonda, observaron la meteorización de feldespatos, minerales ferromagnesianos, cuarzo y serpentina, por líquenes crustosos. Estos atribuyen tal meteorización a los efectos quelantes de ácido oxálico, aunque tampoco descartan la participación de otros ácidos.

Ariño et al. (1997) estudiaron morteros antiguos en España, y encontraron una variada comunidad de líquenes. Observaron las perforaciones causadas por éstos, y comprobaron la presencia de ácido oxálico que al atacar al carbonato de calcio forma oxalato de calcio. Estos daños son de importancia ya que el carbonato de calcio es una parte importante dentro de la composición del mortero, en el cual se afecta la apariencia del mismo pero con el paso del tiempo y la facilitación de la llegada de otros organismos de mayor tamaño pueden dañar la estructura de forma irreversible. Además de agentes de deterioro en estructuras de roca, los líquenes juegan un importante rol como colonizadores primarios debido a su capacidad de crecer sobre una variedad de sustratos y bajo un amplio rango de condiciones ambientales (Nimis et al., 1987; 1992; Nimis \& Monte, 1988; Seaward et al., 1989) y su presencia en los edificios y monumentos no tiene solo efectos de deterioro, sino también un lado positivo. La presencia o ausencia de una especie en particular en un sitio dado está condicionada por sus requisitos relativos a factores tales como la luz, la 
temperatura y la humedad, por lo tanto, las especies que colonizan un edificio pueden actuar como indicadores que ofrezcan la información ambiental que sea relevante para la conservación del edificio (Prieto et al., 1999).

Otro efecto de los líquenes es la bioprotección, este caso se da cuando el talo del liquen protege una superficie de un efecto ambiental destructivo y, el deterioro sería mayor en el caso de no existir esta capa protectora, como fue comprobado experimentalmente por Carter \& Viles (2003) quienes simularon el efecto de las fuertes lluvias sobre rocas con una cubierta de Verrucaria nigrescens y otras sin esta cubierta. Estos encontraron que la capa de liquen actúa reduciendo la amplitud de las fluctuaciones de temperatura interna y externa de la roca, disminuyendo las probabilidades de que aparezcan fracturas por la dilatación de esta. En otro caso Lázaro et al. (2008) comprobó que la capa de líquenes evitaba la rápida erosión de suelos pobres y ayudaba a la fijación de los mismos.

\section{II.2.3. Motivación y planteo del problema}

En la provincia de Buenos Aires existe un desarrollado patrimonio edilicio y monumental, dentro de estos son de renombre las obras creadas por los Arquitectos Bustillo, Benoit y Salamone entre otros. Además de la existencia de una gran variedad de estilos artísticos (neoclásico, neogótico, art nouveau, art deco), arquitectónicos (atemporal, significativo, hightech, de autor, hitos urbanos), y religioso. Esta se debe a la fuerte influencia del viejo continente, como así también a la moda reinante en la época de construcción de cada uno (Pernaut \& Casal, 2005; Traversa, 2010; Sempé \& Flores, 2011), si bien la gran diversidad no permite ubicarlos dentro de un estilo que represente a la sociedad local, forman parte del patrimonio bonaerense ya que son testimonios y "soportes" de la memoria viviente de la comunidad (Bonfil Batalla, 1997) y por ello son de interés como parte del paisaje cultural de Buenos Aires.

En los últimos años los cementerios han dejado de ser un mero lugar de descanso para los restos humanos llegando a ser atractivos turísticos, 
aprovechando las peculiaridades de sus construcciones y sus trasfondos históricos. Ejemplo de este nuevo atractivo turístico han sido los cementerios de La Isla Martín García, de Azul (www.azul.gov.ar/), Saldungaray (http://www.turismo.gba.gov.ar/accesible/pueblo-saldungaray.php?id=2), incluso llegando a realizar visitas guiadas como en la ciudad de La Plata (http://www.eldia.com/la-ciudad/nueva-visita-guiada-al-cementerio-local172616).

A pesar de ser Buenos Aires una de las provincias con mayor desarrollo urbano del país, el conocimiento de su liquenobiota es aún escaso, la mayoría de los estudios se han realizado principalmente en ambientes naturales: en las zonas serranas, donde abundan líquenes saxícolas en roquedales (Frangi, 1975; Osorio, 1980, 1987; Lavornia, 2015; Lavornia et al., 2016), y en los ecosistemas leñosos de la ribera platense, donde aparecen especies corticícolas y folícolas (Piergentili, 1947; Osorio, 1968, 1976, 1977a,b; Adler, 1988, 1992; Scutari, 1992a, 1995a,b; García \& Rosato, 2013,2015) y también son frecuentes en el arbolado nativo y exótico que rodea las urbes (Osorio \& Ranta, 1985; Osorio \& D'esposito, 1979; Scutari \& Therinhardt, 2001). Es de destacar que en los últimos años se ha incursionado en otro tipo de estudios en el ámbito provincial donde se pueden mencionar el trabajo de bioindicación de Chaparro et al. (2013) y la tesis doctoral de Lavornia (2015) quien realiza un análisis de las comunidades de las sierras de Tandil relacionando éstas a su posibilidad de usarlas en la bioindicación de la pureza atmosférica.

Las superficies construidas constituyen un nuevo sustrato donde los líquenes se asientan y constituyen comunidades. En el caso de Buenos Aires se trata de un sustrato que está disponible para colonizar desde hace un siglo. Dado que las sustancias que liberan, la penetración de hifas y ricines, pueden deteriorar sustrato que colonizan, suelen constituir un problema en la preservación de las obras de arte y de los edificios. Estas cuestiones son las que han conducido a varios autores a interesarse por las comunidades de líquenes urbanos (Rosato, 2006; Rosato et al. 2009; Guiamet et al. 2012; Rosato. \& García, 2012; García et al., 2014.Rosato \& García, 2014; García et al., 2015; Rosato et al. 2016). 
Sin embargo hay cuestiones sobre las que aún no se ha investigado y que se relacionan con aspectos que hacen al origen de la biota y a los procesos que llevan a colonizar los ambientes urbanos de la provincia de Buenos Aires. Vale preguntarse cuáles son las características de las comunidades liquénicas desarrolladas sobre construcciones en Buenos Aires, si se diferencian de las naturales en su composición específica, si existen variaciones geográficas en su distribución dentro de la provincia, qué importancia en su diferenciación tienen la naturaleza y/o la antigüedad del sustrato y las condiciones microambientales locales y cómo son las características de colonización de estos "nuevos" sustratos. Son estas cuestiones las que se abordan en este trabajo de tesis doctoral.

\section{II.2.4. Propósito}

El propósito es contribuir al conocimiento de las comunidades liquénicas que crecen sobre el patrimonio edilicio de la provincia de Buenos Aires. Además se busca profundizar en: el conocimiento de la interacción entre la superficie y la liquenobiota, la organización de las comunidades, la procedencia de las especies, los factores abióticos que condicionan la presencia de las especies, las interrelaciones entre especies y el patrón se observa durante los procesos de colonización y suseción sobre estos sustratos. Este conocimiento además de contribuir a la comprensión ecológica de los mecanismos y procesos que determinan la estructuración de las comunidades biológicas, también puede ofrecer información (sobre las especies capaces de crecer sobre las construcciones humanas) que podrá ser aplicada y servir de base a posteriores propuestas de control y preservación del patrimonio construido.

No se pretende profundizar en temas de biodeterioro pero sí pensamos que la información generada será básica para evaluar la gestión y control de las superficies ocupadas por líquenes y contribuir al mantenimiento y conservación de patrimonio, la misma es compendiada y discutida en el ANEXO I. 


\section{II.2.5. Hipótesis}

Se plantean las siguientes hipótesis:

1-La biota liquénica constituye sobre las construcciones humanas comunidades semejantes en abundancia y composición específica a las de las comunidades nativas propias de los ambientes naturales cercanos.

2-Las especies urbanas se disponen de forma indistinta en todos los tipos de sustratos y se comportan selectivamente respecto de las alturas, inclinaciones y orientaciones de los muros.

3-La distribución y abundancia de las especies de las comunidades liquénicas urbanas responden claramente al gradiente biogeográfico latitudinal de la provincia de Buenos Aires.

4-En los procesos sucesionales que se desencadenan sobre el sustrato antrópico las especies pioneras son remplazadas por nuevas especies.

\section{II.2.6. Objetivos}

El objetivo general de esta tesis fue conocer la composición y estructura de las comunidades liquénicas presentes en construcciones edilicias y monumentos de la provincia de Buenos Aires, determinar las condiciones ambientales que influencian estas asociaciones y analizar procesos vinculados con la colonización de estos nuevos ambientes o neoecosistemas.

Los objetivos específicos fueron:

1. Caracterizar las comunidades liquénicas de construcciones edilicias y monumentos de urbes y reconocer similitudes $y / 0$ diferencias con las comunidades nativas de la zona.

2. Establecer comparativamente la influencia de las condiciones microambientales y del sustrato, sobre la composición de las mismas.

3. Analizar diferencias biogeográficas latitudinales de las especies. 
4. Realizar una evaluación preliminar de los procesos de colonización, inicio de la sucesión y características de las interacciones interespecíficas en el seno de las comunidades de líquenes. 


\section{III. ÁREA DE ESTUDIO}

\section{III.1. Delimitación}

Abarca la provincia de Buenos Aires cuya capital es la ciudad de La Plata. Situada en la región centro-E del país, limita al $\mathrm{N}$ con las provincias de Entre Ríos y Santa Fe, al W con las provincias de Córdoba, La Pampa y Río Negro, al S y al E con el mar Argentino del océano Atlántico y al NE con el Río de la Plata. Con $307.571 \mathrm{~km}^{2}$ de extensión, ocupa el $11,06 \%$ de la superficie total del país. Se encuentra dividida en 135 municipios, denominados constitucionalmente partidos. El partido de Patagones es el más extenso, con 13.600 km², y el de Vicente López el menor, con 33 km².

\section{III.1.1. Clima}

La región pampeana pertenece al área de los climas templados del Dominio Atlántico. Este dominio se caracteriza por la convergencia periódica de diferentes masas de aire. La principal de ellas, una masa cálida y húmeda, proviene del anticiclón permanente del Atlántico Sur, sus mayores efectos se sienten durante el verano y por su condición de aire marítimo es causante del mayor monto de las precipitaciones. Otras masas de aire frío son de origen continental (SW), marítimo (SE) o también polar. Parte de los ingresos de aire polar que llegan a esta región se trasladan desde el océano Pacífico produciendo precipitaciones en la región andina, en Patagonia, y al descender hacia el E sufren un calentamiento adiabático que las deseca. Estas masas de aire frío y seco llegan a la provincia de Buenos Aires provenientes del SW con temperaturas superiores a las de origen (Burgos, 1968). Los climas templados se caracterizan por poseer temperaturas medias anuales entre 20 y $14{ }^{\circ} \mathrm{C}$ y una marcada estacionalidad térmica anual. Con respecto a la precipitación si bien no existe una estación seca definida, se registran mínimos a fines de verano y durante el invierno (Burgos, 1968). La incidencia del factor topográfico 
en la temperatura, determina distintos tipos climáticos, entre los cuales está el denominado subhúmedo serrano.

Según la clasificación de climas de Köppen, en la provincia de Buenos Aires hay 3 tipos diferentes de climas: el templado pampeano que abarca casi toda la provincia, el templado oceánico al SW y el templado de transición en el extremo S de la provincia (Kottek et al., 2006).

Por otro lado Czajkowski \& Rosenfeld (1992) clasifican el clima de la provincia de Buenos Aires en función de las variables: claridad atmosféricas, temperaturas (media, mínima, máxima, absoluta), humedad relativa, velocidad del viento, tensión de vapor y grados día con base $18^{\circ} \mathrm{C}$ y aplican análisis multivariados de agrupamiento Cluster para agrupar áreas similares. Estos autores proponen para la provincia la presencia de 6 zonas bioclimáticas diferentes (figura III.1).

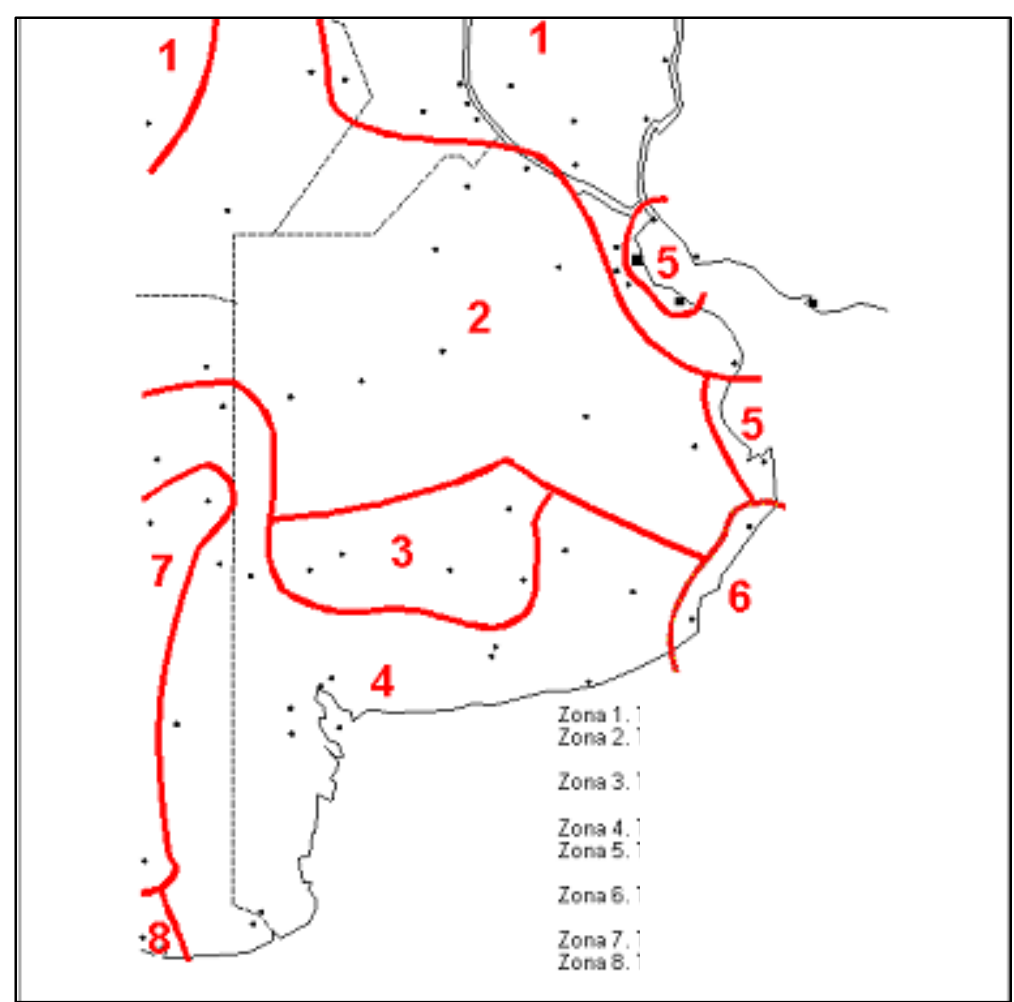

Figura III.1. Mapa de las zonas bioclimáticas de la provincia de Buenos Aires según Czajkowski \& Rosenfeld (1992). Zonas: 1- Templada cálida húmeda; 2- Templada cálida de transición; 3- Templada muy fría de transición; 4- Templada fría húmeda; 5- Templada cálida 
muy húmeda; 6-Templada fría muy húmeda; 7- Templada fría seca; 8- Templada muy fría húmeda.

\section{III.1.2. Ambientes y Vegetación}

Desde la perspectiva biogeográfica la provincia de Buenos Aires se encuentra dentro del dominio Chaqueño y en su gran mayoría es ocupada por la provincia Pampeana la cual está caracterizada por una estepa o subestepa de gramíneas y herbáceas, con algunos arbustos y subfrutices. El extremo $S$ de Buenos Aires es ocupado por sectores correspondientes a la provincia del Espinal, donde predominan especies arbóreas del género Prosopis y a la provincia del Monte donde la comunidad dominante es el matorral, con Larrea como elemento fundamental (Cabrera, 1971; Cabrera \& Wilink, 1973).Para esta tesis distinguimos el ambiente urbano y tres tipos de ambiente según fisonomía vegetal y tipo de sustrato.

\section{III.1.2.1. Ambientes de Pastizal}

La Provincia Pampeana se caracteriza por la predominancia absoluta de gramíneas cespitosas, especialmente de especies de los géneros Stipa (hoy mayormente incluidos en el género Nassella), Piptochaetium, Aristida, Melica, Briza, Bromus, Eragrostis, Poa, Paspalum y Panicum. Entre las matas de gramíneas se desarrollan una serie de géneros herbáceos o arbustivos, como Margyricarpus, Baccharis, Heimia, Alicropsis, Berroa, Chaptalia, Aster, Vicia, Oxalis, Adesmia, entre otras. Este paisaje predominantemente llano y de baja pendiente es interrumpido por la presencia de dos sistemas orográficos emplazados en el centro-SE y SW de la provincia. En el extremo $S$ de la provincia se encuentran se encuentra la provincia del Espinal, distrito del Caldén, donde los pastizales son un elemento dominante pero ingresan elemento arbóreos como: Prosopis caldenia, P. nigra, P. flexuosa, Geoffroea decorticans, Jodina rhombifolia, Schinus fasciculatus y Ximenia americana, que han sido muy explotados para obtener postes o leña, no quedando 
comunidades nativas representativas. Entre los arbustos son: Condalia microphylla, Atamisquea marginata, P. alpataco, Cassia aphylla, Prosopisdastrum globosum, Larrea divaricata, Lycium chilense, Ephedra triandra, E. ochreata entre otros (Cabrera, 1971; 1976).

Los biomas de la pradera pampeana son los que más transformaciones han sufrido a causa de la intervención humana, perdiendo su identidad debido a la continua expansión agrícola-ganadera. Los pocos relictos que se mantienen de estas comunidades de vegetación nativa se encuentran en áreas protegidas (Viglizzo et al., 2006; Miñarro et al., 2006).

\section{III.1.2.2 Ambientes serranos}

En el área pampeana correspondiente a la provincia de Buenos Aires, emergen dos sistemas orográficos, Tandilia y Ventania (figura III 2), que incorporan un nuevo tipo de sustrato, los roquedales, que son ocupados por comunidades saxícolas.

En rasgos generales, el Sistema de Tandilia, o sierras Septentrionales, se encuentra emplazado en medio de las planicies pampeanas, interrumpiendo abruptamente las suaves llanuras y está constituido por rocas graníticas meteorizadas. Este sistema tiene su eje mayor paralelo a los sistemas de fallas del estuario del Río de la Plata, de la Sierra de la Ventana y de los cursos inferiores de los ríos Colorado y Negro, lo cual responde a las características tectónicas de la provincia de Buenos Aires. Presenta un alineamiento discontinuo cuyo rumbo general es SE-NW y está conformado por cerros aislados o pequeñas sierras, con una altura máxima de $500 \mathrm{~m}$ s.n.m., que dejan entre sí amplios valles longitudinales y transversales que son objeto de intenso laboreo agrícola (Holmberg, 1972; Dalla Salda, 1999). En general el sistema de Tandilia tiene un solo estrato de vegetación, la estepa o pseudoestepa de gramíneas (dominada por la Fam. Poaceae), cuya altura no supera un metro de altura, alternando con una diversidad de otras familias de herbáceas y algunos subfrútices y arbustos. En las sierras, donde el hábitat rocoso determina la presencia de asociaciones casmofíticas de naturaleza 
xerofítica, es decir, adaptadas a la desecación, la asociación dominante es el flechillar con Stipa neesiana, Piptochaetum montevidense y Bothriochloa lagurioides (Cabrera \& Willink, 1980).

El Sistema de Ventania, o Sierras Australes, se dispone como una cadena montañosa de dirección general NW-SE de unos $180 \mathrm{~km}$ de largo y 60 $\mathrm{km}$ de ancho ubicados en el sector SW de la provincia de Buenos Aires. Estas montañas están compuestas principalmente por rocas paleozoicas acompañadas por afloramientos aislados de rocas graníticas y riolíticas milonitizadas, aunque también se encuentran rocas precámbricas. Se eleva de 400 a $1240 \mathrm{~m}$ snm emergiendo en la llanura pampeana siendo su punto de máxima altura el Cerro Tres Picos (Zárate \& Rabassa, 2005). Los afloramientos rocosos aparecen como pequeñas unidades dispersas entre el suelo serrano, y alcanzan áreas de mayor extensión en cumbres y faldeos, donde los pliegues constituyen farallones de difícil acceso, o forman grandes bloques con grietas profundas de difícil acceso. Kristensen (1992) y Kristensen y Frangi (1995, 1996) realizaron un estudio sobre las sierras del Parque Ernesto Tornquist y diferenciaron diversidad de mesoclimas condicionados principalmente por la altitud y la exposición.

Con respecto a la geoformas características de las serranías septentrionales, se distinguen tres unidades geomorfológicas que se corresponden con unidades de paisaje de características diferenciadas: (1) la base de los cerros, como un ecotono entre las comunidades de las planicies y de las laderas que se caracterizan por tener una pedregosidad del orden del $30 \%$, que es menor a la de las laderas y las cimas de los cerros, ya que los roquedales se presentan aislados en el pastizal y su extensión se incrementa con la proximidad a las laderas. Estas diferencias se traducen en un mayor régimen de humedad por poseer una cubierta edáfica más desarrollada que retiene el agua. (2) Otra unidad geomorfológica la constituye la propia ladera del cerro, con un mayor porcentaje de rocosidad, entre un 30 y un $60 \%$, y menor humedad que en la base. (3) Las cimas, con una rocosidad entre el $60 \mathrm{y}$ el $100 \%$, se presentan como una unidad geomórfica diferenciada por tener mayor exposición a los vientos, insolación constante, menor humedad y el mayor porcentaje de rocosidad (Sánchez et al., 1999). 
El Sistema Serrano de Tandilia así como el de Ventania, constituyen enclaves singulares en el entorno pampeano bonaerense. En ellos, el relieve condiciona una heterogeneidad de hábitats que no son propios de los ambientes de la planicie circundante, a los que se asocia una mayor diversidad de especies (Spegazzini, 1896; Spegazzini, 1901; Cabrera, 1971, 1976; Cabrera \& Willink, 1980; Kristensen \& Frangi, 1996).

\section{III.1.2.3. Ambientes boscosos}

Siguiendo las costas de los ríos Uruguay y Paraná se pueden encontrar comunidades de selva en galería o tropical (figura III 2), las cuales se van empobreciendo a medida que descienden latitudinalmente que también se comparten con las islas del delta del Paraná. Esta selva marginal, según Cabrera \& Dawson (1944), pertenece al distrito fitogeográfico de las selvas mixtas de la Provincia fitogeográfica Paranaense, aunque en sus posteriores trabajos fitogeográficos no las incluye en ésta (Cabrera, 1971; Cabrera \& Wilink, 1973; Ribichich, 2002). Antaño cubría los albardones de las islas del delta inferior del río Paraná, y algunos sectores restringidos de la costa bonaerense del estuario del Río de la Plata superior y las desembocaduras de los cursos de agua en el mismo. Actualmente, con el desarrollo de las urbes, estas comunidades selváticas han sido desmontadas quedando pocas hectáreas, algunas protegidas como reservas y otras en zonas poco accesibles.

La fisonomía de estas selvas está marcada por un estrato arbóreo integrado por el laurel negro (Ocotea acutifolia), el chal-chal (Allophylus edulis), el mata ojo (Pouteria salicifolia), el blanquillo (Sebastiania brasiliensis), el yerba del bugre (Lonchocarpus nitidus), el tarumá (Citharexylum montevidense), el palo amarillo (Terminalia australis), los canelones (Myrsine laetevirens y Myrsine parvula), y la anacahuita (Blepharocalyx salicifolius), siendo más raras otras especies, como el ingá (Inga uraguensis) y el timbó colorado (Enterolobium contortisiliquum). 
Bajo el estrato superior se desarrollan los estratos arbustivos y herbáceos compuestos por: yatevó o tacuara brava (Guadua trinii), las malvas (Pavonia malvaceae) y el tala gateador (Celtis iguanaea), así como una variada gama de helechos y epífitas (Cabrera \& Dawson, 1944; Lahite \& Hurrel, 1994).

En el S de la provincia de Buenos Aires, según Cabrera \& Wilink (1980), se encuentra la región $S$ de la provincia biogeográfica del Espinal, Distrito del Cálden, caracterizada por las especies arbóreas Prosopis caldenia, P. nigra, P. alba, Jodina rhombifolia, Scutia buxifolia, Acacia caven, Geoffroea decorticans y Celtis tala. También se encuentra la Provincia del Monte, Distrito de Llanuras y mesetas con una vegetación compuesta por los árboles Geoffroea decorticans, Bougainvillea spinosa, Mimozyganthus carinatus, Tricomaria usillo, las cactáceas Cereus aethiops, Opuntia sulphurea, Echinopsis leucantha, Ximena americana, y la presencia del género Larrea. Los cultivos provocaron grandes cambios en el paisaje con la desaparición de las formaciones leñosas en parches continuos de cientos de hectáreas. Sin ningún área protegida en esta zona (exceptuando alguna áreas protegidas costeras) no quedan áreas donde se conserven estos bosques en su forma original, pudiendo quedar algunos relictos en zonas sin importancia productiva o que han quedado en el desuso (Arturi, 2005).

\section{III.1.2.4. Ambientes urbanos}

La provincia de Buenos Aires es la más poblada de Argentina con 15.625.084 habitantes y una densidad de población de 50,8 hab/ $\mathrm{km}^{2}$ siendo la segunda para el país. Alrededor del $96,4 \%$ de la población de la provincia reside en áreas urbanas (figura III 2), el resto vive en localidades de menos de 2.000 habitantes, las cuales se consideran población rural. Sus principales centros urbanos son las ciudades de La Plata, Mar del Plata, Bahía Blanca, Tandil y el área metropolitana (gran Buenos Aires) que rodea a la Ciudad Autónoma de Buenos Aires.

En relación a los materiales de construcción utilizados en las ciudades, a lo largo de la historia el hombre ha utilizado materiales manufacturados para la confección de sus viviendas y más tarde, monumentos. Entre éstos, el cemento 
pórtland y sus derivados han sido siempre los más empleados en la construcción debido a su fácil aplicación y a su bajo costo, por estar formados de mezclas de caliza, arcilla y yeso que son minerales abundantes.

La provincia de Buenos Aires no es la excepción a esto, siendo el mortero uno de los elementos más utilizados (Sota et al., 2004; Traversa et al., 2007; Traversa, 2011; Traversa et al., 2011; Rosato et al., 2012; Traversa et al., 2013). En Argentina a fines de la década del '30 en el siglo XX, existió una corriente de construcción de mobiliario urbano prefabricado (entre los que se destaca el Arq. F. Salamone con su obra pública en la provincia de Buenos Aires), ejecutado en símil piedra y elaborado con mármol de color blanco triturado con un tratamiento superficial para alcanzar la exposición de las partículas del agregado (Traversa et al., 2003). 


\section{Capítulo III: Área de estudio}

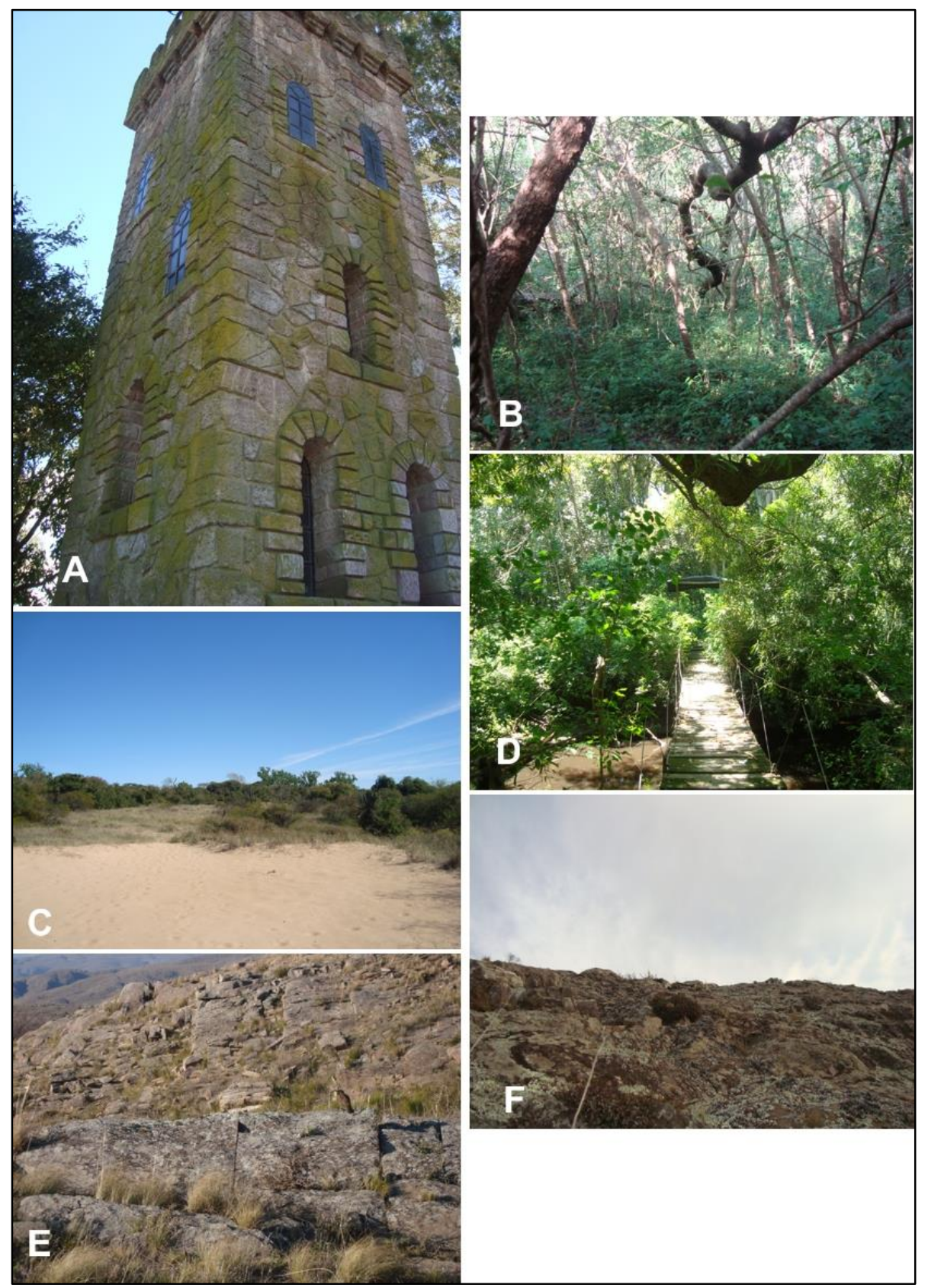

Figura. III.2. Áreas de estudio: $A=$ Ambiente urbano; $B=$ Ambiente boscoso, Isla Martín García; $\mathrm{C}=$ Ambiente boscoso, arenal Isla Martín García; $\mathrm{D}=$ Ambiente boscoso, Reserva Natural de Punta Lara; $E=$ Ambiente serrano, roquedales del Parque Provincial Ernesto Tornquist; $F=$ Ambiente serrano, roquedales Tandil. 


\section{METODOLOGÍA}

\section{IV.1. Liquenobiota de ambientes urbanos y naturales de la provincia de Buenos Aires y sus preferencias ambientales}

\section{IV.1.1. Diseño de muestreo}

Se trazó una transecta de $845 \mathrm{~km}$ de longitud desde el NE (Isla Martín García) al SW (Carmen de Patagones) de la provincia de Buenos Aires, abarcando climas húmedos en el extremo NE hasta climas secos en el extremo $\mathrm{SW}$, y pasando por selvas y roquedales. Sobre la transecta se seleccionaron 12 localidades de muestreo en ambientes urbanos y 4 localidades que representaron los ambientes naturales próximos (figura III.2). Las localidades urbanas fueron seleccionadas por su proximidad a la transecta, su disponibilidad de construcciones y la posibilidad de acceso a estas. Las localidades naturales fueron seleccionadas por la cercanía a las localidades urbanas, por su condición de reservas y su grado de conservación de los ecosistemas preexistentes a las ciudades.

Las localidades fueron: Isla Martín García, Ensenada, La Plata, Brandsen, General Belgrano, Azul, Tandil, Saldungaray, Parque Provincial Ernesto Tornquist, Tornquist, Bahía Blanca y Carmen de Patagones. Las 4 localidades con presencia de comunidades nativas que sirvieron para realizar el análisis comparativo con las urbanas próximas fueron: el Parque Provincial Ernesto Tornquist, Las sierras circundantes a Tandil, la Reserva Natural de Punta Lara y la Reserva Natural Isla Martín García. En ellos los sustratos fueron corteza, en bosques y roca en sierras. En ambas se seleccionaron sitios de muestreo al azar. En bosques cada árbol muestreado constituyó un sitio y en roquedales lo fue un punto seleccionado al azar.

Los muestreos se realizaron entre los años 2012 a 2016, no seleccionando meses específicos para los mismos sino que fueron realizados a conveniencia del tesista. Tanto en sitios naturales como antrópicos se realizaron las curvas de especie por área, para conocer el mínimo de cuadrados necesarios, en todos los casos se llego al mínimo de cuadrados, 
con la excepción de las sierras de Tandil, donde la curva no llegó a estabilizarse.

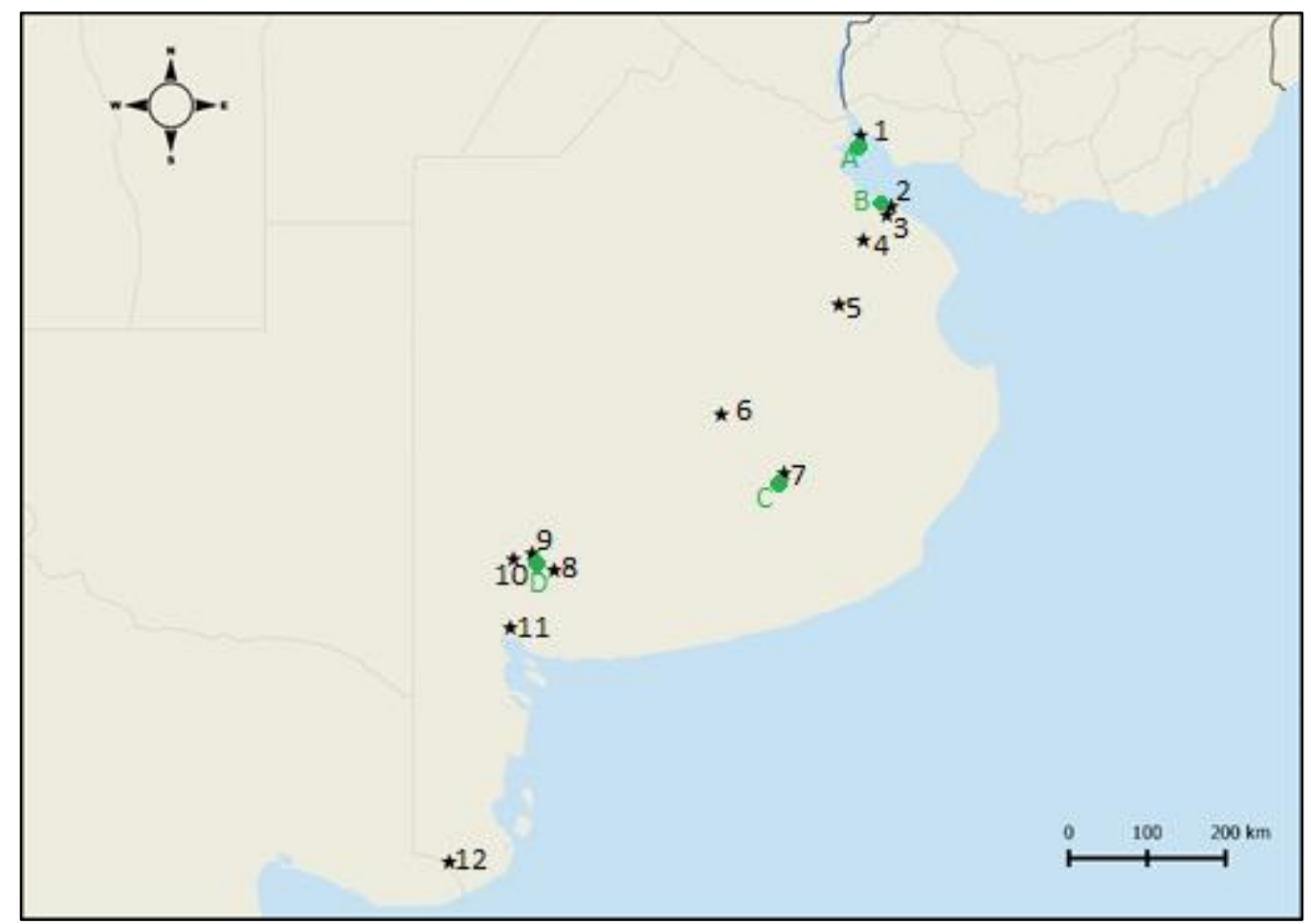

Figura IV.1. Mapa con las localidades donde se realizaron los muestreos. Localidades urbanas: 1= Isla Martín García; 2= Ensenada; 3= La Plata; 4=Brandsen; 5= General Belgrano; 6= Azul; 7= Tandil; $8=$ Saldungaray; $9=$ Parque Provincial E. Tornquist; $10=$ Tornquist; $11=$ Bahía Blanca; 12= Carmen de Patagones. Localidades naturales: $A=$ Reserva natural Isla Martín García; B= Reserva Natural Punta Lara; $C=$ Sierras de Tandil; D= Parque Provincial E. Tornquist

\section{IV.1.1.2. Ciudades}

En cada localidad, se establecieron sitios de muestreo sobre construcciones de distinta antigüedad. En cada uno de ellos se realizó un muestreo con cuadrados de $20 \times 20 \mathrm{~cm}$-unidades de muestreo- (Matteucci \& Colma, 1982; Nimis \& Monte 1988; Rosato et al., 2009). 
En el caso del muestreo sobre muros las unidades de muestreo se ubicaron regularmente (cada $40 \mathrm{~cm}$ ) sobre transectas ubicadas sobre superficies horizontales y verticales de los muros (Figura. IV.2). Sobre estas últimas se dispusieron transectas a tres alturas sobre el suelo: 50, 100 y 150 $\mathrm{cm}$. En cada localidad urbana se realizaron muestreos sobre construcciones cuyos muros estuvieran colonizados y cuyo acceso fuera posible, el número de sitios de muestreo estuvo condicionado por la cantidad de construcciones que cumplieran con esas condiciones, no siempre frecuentes. La cantidad de unidades de muestreo por edificio variaron dependiendo del tamaño de la construcción y la presencia de líquenes sobre cada muro, como así también por otros factores tales como la limpieza de los muros (hidrolavado), el uso los líquenes como grafitis, la presencia de herbívoros (figura IV.3). Por otro lado hay lugares tales como los cementerios que presentan una sensibilidad particular y para evitar molestar a los concurrentes se prefirió no realizar muestreos sobre algunas bóvedas y tumbas. Dentro de las ciudades no fueron tenidos en cuenta el arbolado urbano, ni los postes de madera, ya que no se los considera parte del patrimonio edilicio, tampoco fueron encontrados estructuras o edificios de madera que presentaran líquenes creciendo sobre estos.

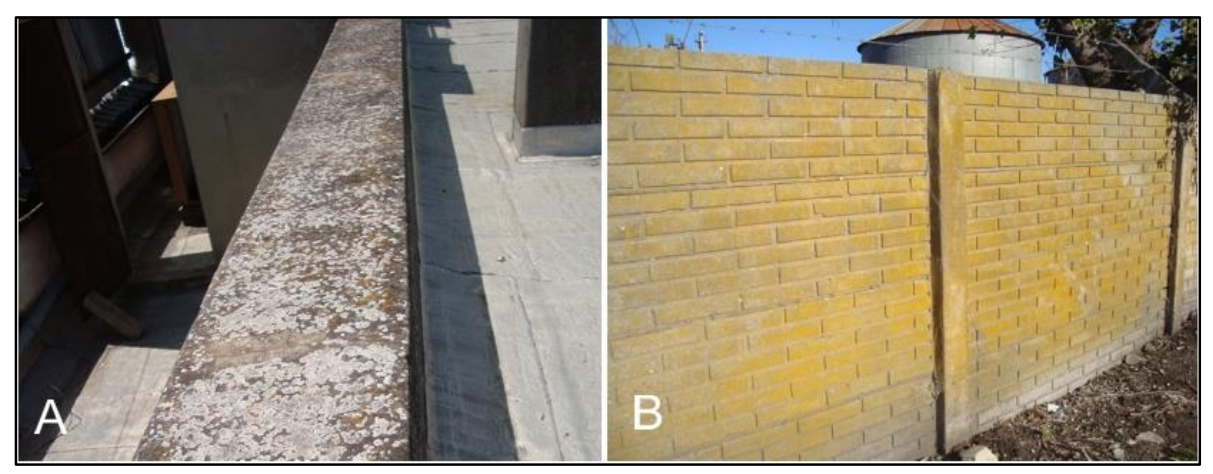

Figura. IV.2. A= muro horizontal colonizado por líquenes; $B=$ muro vertical colonizado por líquenes 


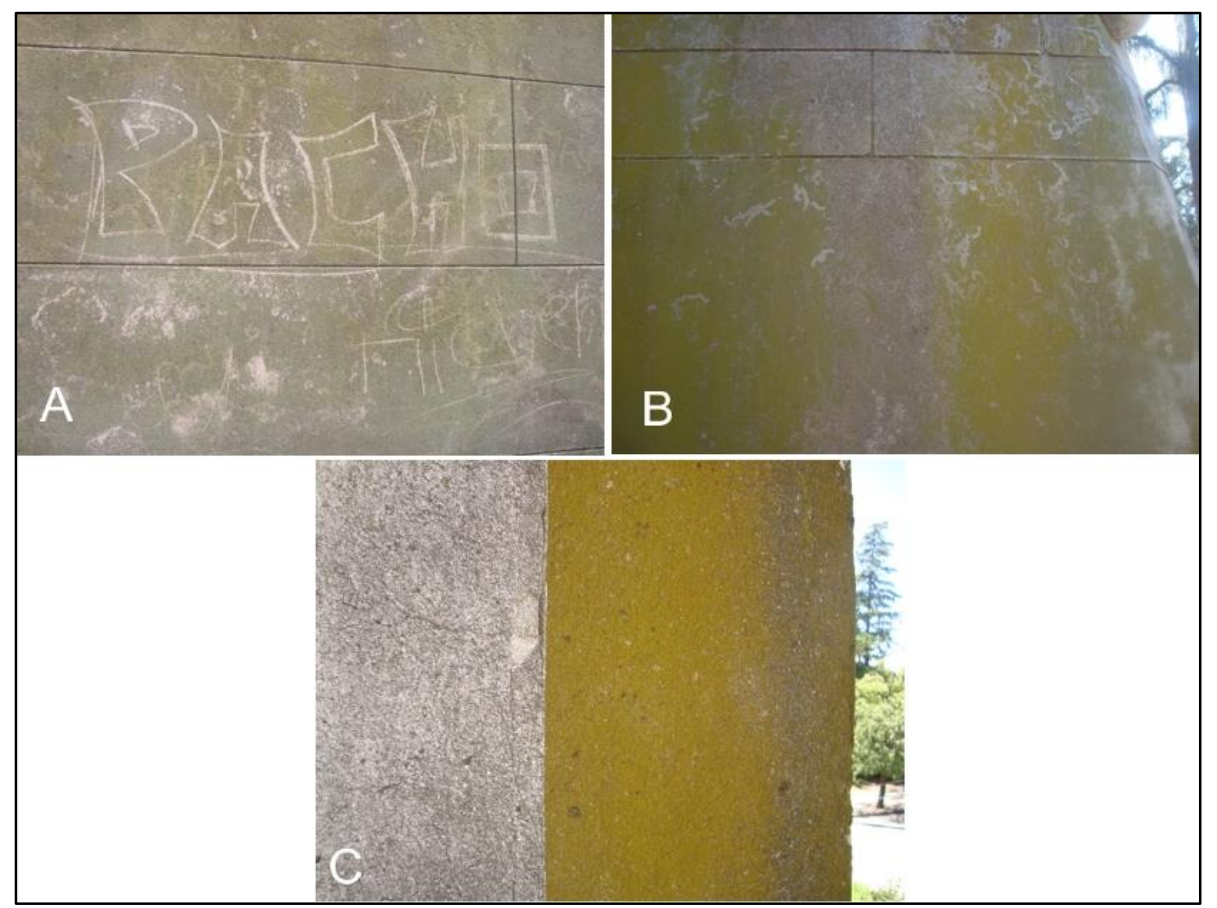

Figura IV.3. $A=$ muro donde se uso los especios dejados por la limpieza de líquenes como grafitis; $\mathrm{B}=$ Marcas de gasterópodos que se alimentaron de los líquenes; $\mathrm{C}=$ sector a la izquierda hidrolabado, sector a la derecha no hidrolavado

\section{1.1.2.1. Características de las localidades y los sitios relevados}

\section{Isla Martín García}

La isla Martín García está ubicada en el Río de La Plata en las coordenadas $34^{\circ} 11^{\prime} 00^{\prime \prime S} 58^{\circ} 15^{\prime} 10^{\prime \prime} \mathrm{W}$. No existen muchos datos sobre la construcción de los edificios de la isla, pero se sabe que las construcciones militares más antiguas datan de 1861, el faro data de 1897 (declarado Monumento Histórico Nacional en 2011), el cementerio es creado en 1899 y en 1900 se encontraban construidas la prisión y el lazareto (ambas en ruinas). Actualmente la isla alberga alrededor de 200 habitantes estables, en ella se encuentran pocos edificios dispersos (http://islamgarcia.com.ar). En la isla no hay industrias ni se realizan actividades agropecuarias, la principal actividad es el turismo y algunos comercios. La isla completa es una Reserva Natural de Usos Múltiples, cuenta con una zona intangible de selva marginal y se encuentra bajo la jurisdicción del Organismo Provincial para el Desarrollo Sostenible -OPDS- (Lahitte \& Hurrel, 1994). El clima es templado y húmedo con una temperatura media de alrededor de $17^{\circ} \mathrm{C}$ y una precipitación anual de 
$1000 \mathrm{~mm}$. El mes más cálido es enero con $29^{\circ} \mathrm{C}$ y el más frio es julio con una temperatura promedio de $8{ }^{\circ} \mathrm{C}$ (Lahitte \& Hurrel, 1994).

Características de los sitios muestreados:

Cementerio: fundado en 1899, actualmente en desuso, se conserva como sitio histórico de la isla siendo las tumbas con las cruces "torcidas" un atractivo al público, por lo que se les realiza una limpieza periódica. En este sitio se muestrearon superficies horizontales de mármol.

Edificio 1: se encuentra dentro de la zona selvática y consta de 2 pisos. Solo se muestreó el piso superior que se eleva por encima del nivel de los árboles circundantes. La envolvente del edificio es de un mortero de cemento. Se desconoce el año de construcción del mismo.

Faro: su construcción data de 1897, hace unos 10 años se realizó su puesta en valor limpiando su exterior. Este edificio presenta una envolvente de mortero de cemento. Fueron muestreadas sus paredes verticales externas.

Edificio 2: edificio militar abandonado dentro de la selva, presenta una gran cobertura arbórea a su alrededor, constituido por una envolvente de mortero de cemento. Se desconoce su año de construcción. Fue muestreada su superficie horizontal.

Mirador militar: resto de un edificio militar abandonado sobre la costa, se encuentra dentro del sector intangible de la reserva rodeado por una densa vegetación de selva ribereña, se relevó un sector horizontal constituido por hormigón armado. Esta estructura queda debajo del nivel del agua en los períodos de crecida del río.

\section{Ensenada}

La ciudad de Ensenada fue fundada en 1801 y se ubica en el noroeste de la provincia sobre la margen del Río de La Plata (34 $51^{\circ} \mathrm{S} 57^{\circ} 54 \mathrm{~W}$ ) en el partido homónimo (http://www.ensenada.gov.ar). El clima es clasificado como 
cálido y templado, de acuerdo con Köppen y Geiger se clasifica como Cfa. Hay precipitaciones durante todo el año, con un total de $932 \mathrm{~mm}$. La temperatura media anual es $16,5^{\circ} \mathrm{C}$. El mes más seco es agosto, con $48 \mathrm{~mm}$, mientras que el mes más húmedo es marzo con $109 \mathrm{~mm}$. El mes más caluroso del año con un promedio de $23,2^{\circ} \mathrm{C}$ es enero (https://es.climate-data.org/). El mes más frío del año es julio con $10,4^{\circ} \mathrm{C}$. Tiene una población de 56.729 habitantes. En el partido se encuentran industrias metalúrgica, siderúrgica, naval y portuaria (INDEC, 2010). Dentro de este partido se encuentra comprendida parte de la Reserva Natural Provincial de Punta Lara que protege la última estribación de las selvas marginales (www.opds.gba.gov.ar).

\section{Características de los sitios muestreados:}

Club universitario de La Plata (CULP): su construcción comenzó en 1930, es un edificio de líneas modernas ubicado sobre la costa del Río de la Plata. El mismo ha sido declarado como: Bien de Interés Arquitectónico Nacional por la Comisión Nacional de Monumentos, de Lugares y de Bienes Históricos. La envolvente del edificio es de mortero de cemento (símil piedra) y una capa de pintura sintética muy degradada que falta en partes. Los muestreos se realizaron en el sector de la terraza.

Murallón costero: esta estructura tiene aproximadamente 20 años, es una estructura de hormigón armado con una envolvente de mortero de cemento. Se encuentra sobre el borde del Río de La Plata, tiene la función de evitar que las crecientes del río entren al camino costero.

\section{La Plata}

La ciudad de La Plata $\left(34^{\circ} 56^{\prime} 00^{\prime \prime} S 57^{\circ} 57^{\prime} 00^{\prime \prime} \mathrm{W}\right)$ fue fundada en 1884 , pertenece al partido de La Plata, y es la capital de la provincia de Buenos Aires. La ciudad tiene una población de 799.523 habitantes, siendo la cuarta ciudad más poblada del país (INDEC, 2010). Es una ciudad administrativa, universitaria y cuenta con diversas industrias. La ciudad cuenta con una gran infraestructura edilicia en las que han participado personajes de renombre 
como Charles Le Corbusier y Pedro Benoit, y donde alberga una gran cantidad de edificios de interés patrimonial tales como La Catedral, el Museo de Ciencias Naturales, el Observatorio, la Gobernación, el Palacio Municipal entre otros que por su antigüedad o por sus características se han convertido en parte del patrimonio de la ciudad (https://www.laplata.gob.ar). El clima en la ciudad es templado, con precipitaciones durante todo el año, clasificado como Cfa por Köppen-Geiger. La temperatura media anual es $16,3{ }^{\circ} \mathrm{C}$ y la precipitación es de $946 \mathrm{~mm}$ al año. El mes más seco es agosto, con $52 \mathrm{~mm}$, mientras que el más húmedo es marzo con $111 \mathrm{~mm}$. Enero es el mes más caluroso del año con un promedio de $23,1^{\circ} \mathrm{C}$ y el mes más frío es julio, con temperaturas medias de $10,2^{\circ} \mathrm{C}$ (https://es.climate-data.org/).

\section{Características de los sitios muestreados:}

Museo de La Plata: construido en 1884, es uno de los edificios fundacionales de la ciudad de La Plata. Está designado como: Bien de Interés Arquitectónico Nacional por la Comisión Nacional de Monumentos, de Lugares y de Bienes Históricos. La envolvente del edificio es de mortero de cemento y hace 100 años que no se le realiza una limpieza. Se realizaron muestreos en el sector de terrazas, sobre una superficie horizontal.

Edificio donde se encuentra el Laboratorio de Entrenamiento Multidisciplinario para la Investigación Tecnológica (LEMIT): el edificio de dos pisos que se construyó en 1947 en el Paseo del Bosque. El muestreo se realizó sobre el sector de terrazas sobre el cual no se han realizado modificaciones, sobre muros verticales y horizontales. La envolvente es un mortero de cemento.

Cementerio: fue fundado en 1886, contiene tumbas, bóvedas y mausoleos de personajes ilustres como Florentino Ameghino. Se relevaron 3 tumbas que presentaban colonización de líquenes y aunque no se halló la fecha de construcción, se especula que por el tipo de construcción datan aproximadamente de 1950. Sobre las mismas se muestrearon los muros verticales. La envolvente de las tres es un mortero de cemento. 


\section{Brandsen}

La ciudad de Brandsen, fundada en 1876, se ubica en el noreste de la provincia $\left(35^{\circ} 09^{\prime} 00^{\prime \prime} S 58^{\circ} 16^{\prime} 00^{\prime \prime} \mathrm{O}\right)$; es cabecera del partido homónimo, con una población de 19.877 habitantes. La actividad predominante de la región es la agropecuaria, aunque también se puede encontrar curtiembres y algunas fábricas pequeñas (INDEC, 2010). El clima es templado y cálido con precipitaciones durante todo el año, es clasificado como Cfa por KöppenGeiger. La temperatura media anual es $16,0{ }^{\circ} \mathrm{C}$ y la precipitación media anual de $966 \mathrm{~mm}$. El mes más seco es agosto, con $55 \mathrm{~mm}$, mientras que el más húmedo es marzo con $104 \mathrm{~mm}$. El mes más caluroso del año es enero con $23,0{ }^{\circ} \mathrm{C}$ de promedio y el mes más frío del año es julio con $9,9{ }^{\circ} \mathrm{C}$ (https://es.climate-data.org/).

\section{Características de los sitios muestreados:}

Cementerio: la fundación del mismo fue en 1879, se encuentra alejado del casco urbano, aunque en la actualidad existen viviendas alrededor. En el mismo se relevaron 11 tumbas, con envolventes de mortero de cemento y de granito negro, de las cuales se relevaron sectores horizontales y verticales solamente 2 unidades de muestreo con orientación $\mathrm{E}$. Las tumbas tenían una antigüedad de 50 años, aunque la mayoría vandalizadas y no contaban con fechas.

\section{General Belgrano}

La ciudad de General Belgrano fue fundada en 1881, se ubica en el centro de la provincia $\left(35^{\circ} 45^{\prime} S 58^{\circ} 30^{\prime} \mathrm{O}\right)$; es la ciudad cabecera del partido homónimo, y cuenta con una población de 15.394 habitantes. La actividad predominante es la agropecuaria. El clima es templado y cálido, con precipitaciones durante todo el año; según la clasificación del clima de KöppenGeiger es Cfa. La temperatura media anual es $15,5^{\circ} \mathrm{C}$ y la precipitación media 
anual es de $951 \mathrm{~mm}$. El mes más seco es agosto, con $53 \mathrm{~mm}$ y el más húmedo es enero con $100 \mathrm{~mm}$. El mes más caluroso del año es enero con $22,8^{\circ} \mathrm{C}$ de promedio y el mes más frío del año es julio con $9,2{ }^{\circ} \mathrm{C}$ https://es.climatedata.org).

Características de los sitios muestreados:

Cementerio: el cementerio data de 1881 y se ubica en un área rural. Se relevaron bóvedas con una antigüedad de 50 años. Todos presentaban una envolvente de mortero de cemento.

Azul

La ciudad de Azul fue fundada en 1832 en el centro de la provincia ( $\left.36^{\circ} 47^{\prime} 00^{\prime \prime} \mathrm{S} 59^{\circ} 51^{\prime} 00^{\prime \prime} \mathrm{W}\right)$, es la cabecera del partido homónimo y cuenta con 55.728 habitantes. La actividad económica principal es la agropecuaria. En su patrimonio destacan las estructuras diseñadas por el Arquitecto Francisco Salomone tales como la portada del Cementerio local, el diseño del Parque Municipal Domingo F. Sarmiento, la Plaza San Martín y el edificio del Matadero Municipal. El clima es cálido, templado y lluvioso, incluso en el mes más seco. La clasificación según el sistema de Köppen-Geiger es Cfa. La temperatura media anual es $14,1{ }^{\circ} \mathrm{C}$ y la precipitación media es de $918 \mathrm{~mm}$. El mes más seco es agosto, con $40 \mathrm{~mm}$, mientras la mayor cantidad de precipitación ocurre en marzo, con un promedio de $122 \mathrm{~mm}$. El mes más caluroso es enero con un promedio de $22{ }^{\circ} \mathrm{C}$ y las temperaturas medias más bajas del año se producen en junio con $7,6^{\circ} \mathrm{C}$ (https://es.climate-data.org).

Características de los sitios muestreados:

Cementerio: Fundado en 1853, cuenta como un atractivo turístico la entrada del mismo diseñada por F. Salamone creada en 1938. Se relevaron tumbas y mausoleos de mortero de cemento, granito y mortero con agregado de conchilla (mortero 2), sobre muros verticales y horizontales 
Costanera: rodeando al arroyo Azul, se relevaron estructuras (bancos y otras construcciones) que forman parte del paseo costanero y muros de contención, todos ellos presentando una envolvente de mortero de cemento.

Estación de ferrocarril: un muro de construcción más reciente que la estación, probablemente de 20 años de antigüedad, que delimitaba parte del ingreso hacia los galpones ferroviarios, construido en mortero de cemento.

Edificio de la costanera: de construcción reciente, presentaba un revestimiento de mortero de cemento símil piedra, es un edificio de depósito caracterizado como una torre medieval.

\section{Tandil}

Tandil fue fundada en 1823 y es la ciudad cabecera del partido homónimo. Se ubica sobre las coordenadas $37^{\circ} 19^{\prime} 00^{\prime \prime S} 59^{\circ} 08^{\prime} 00^{\prime \prime} \mathrm{W}$ y posee una población de 116.916 habitantes (INDEC, 2010). La actividad predominante es la agropecuaria, aunque también se encuentran fábricas metalúrgicas y se realiza minería de rocas en la zona de sierras. El clima es cálido y templado y hay precipitaciones durante todo el año. Según el sistema Köppen-Geiger es clasificado como $\mathrm{Cfb}$. La temperatura media anual es de $13,4{ }^{\circ} \mathrm{C}$ con una precipitación anual de $847 \mathrm{~mm}$. El mes más seco es julio con $43 \mathrm{~mm}$, mientras que el mes más húmedo es marzo con $93 \mathrm{~mm}$. El mes más caluroso del año es enero con $20,8^{\circ} \mathrm{C}$ y el mes más frío del año es julio con 7,2 ${ }^{\circ} \mathrm{C}$ (https://es.climate-data.org).

\section{Características de los sitios muestreados:}

Cementerio: comienza a funcionar como tal en 1879, se encuentra en las afueras del casco urbano aunque en la actualidad ya hay viviendas cercanas. Se relevó una bóveda de granito no pulido ( $\sin$ fecha), una bóveda revestida de mortero de cemento (fechado en 1940) y un monumento de la asociación musical tandilense fechado en 1956. 
UNICEN: se relevaron muros a los que se accedió desde el techo de 2 edificios pertenecientes a la Universidad Nacional del Centro (UNICEN) sede Tandil, ubicados en el Campus universitario Paraje $\mathrm{A}^{\circ}$ Seco, los mismos tienen una antigüedad de 15 años aproximadamente, presentaron una envolvente de mortero de cemento.

\section{Saldungaray}

La localidad de Saldungaray $\left(38^{\circ} 12^{\prime} 00^{\prime \prime} \mathrm{S} 61^{\circ} 46^{\prime} 00^{\prime \prime} \mathrm{W}\right)$ fue fundada en 1900, está ubicada dentro del partido de Tornquist, actualmente tiene una población de 1.351 habitantes. La actividad económica predominante es la agropecuaria (INDEC, 2010). El cementerio de la localidad cuenta con un portal de entrada realizado por el arquitecto Francisco Salamone, reconocido por sus obras de edificios públicos en la provincia. El clima es cálido y templado, con precipitaciones durante todo el año. Es clasificada como $\mathrm{Cfb}$ en el sistema Köppen-Geiger. La temperatura media anual es $14,0{ }^{\circ} \mathrm{C}$ y la precipitación media anual es de $710 \mathrm{~mm}$. El mes más seco es agosto, con $24 \mathrm{~mm}$ y el más húmedo es marzo con $99 \mathrm{~mm}$. El mes más caluroso del año es enero con un promedio de $21,9{ }^{\circ} \mathrm{C}$, en tanto el mes más frío del año es junio con $7,3{ }^{\circ} \mathrm{C}$ (https://es.climate-data.org/).

\section{Características de los sitios muestreados:}

Cementerio: hoy en día además de ser un cementerio funcional también es un atractivo turístico por su portal diseñado por el Arq. Salamone. Se relevaron 3 bóvedas y tumbas de inclinación vertical y horizontal con una envolvente de mortero de cemento y 2 tumbas con inclinación horizontal construidas en aglomerado. La más antigua relevada data de 1918, mientras que la más moderna fue de 1974.

\section{Parque Provincial Ernesto Tornquist}


El Parque Provincial Ernesto Tornquist creado en 1958 se encuentra en el partido de Tornquist $\left(38^{\circ} 03^{\prime} 00^{\prime \prime} \mathrm{S} 62^{\circ} 02^{\prime} 00^{\prime \prime} \mathrm{W}\right)$. El clima es cálido y templado, con precipitaciones durante todo el año. Es clasificada como Cfb en el sistema Köppen-Geiger. La temperatura media anual es $13,3^{\circ} \mathrm{C}$ y la precipitación media anual es de $745 \mathrm{~mm}$. El mes más seco es agosto, con $26 \mathrm{~mm}$ y el más húmedo es marzo con $102 \mathrm{~mm}$. El mes más caluroso del año es enero con un promedio de $21,4{ }^{\circ} \mathrm{C}$, en tanto el mes más frío del año es junio con $6,5^{\circ} \mathrm{C}$ (https://es.climate-data.org/).

Características de los sitios muestreados:

Se muestrearon unos puentes que se utilizan para el paso sobre arroyos dentro del parque, construidos con una envolvente de mortero, inclinación horizontal y se desconoce su antigüedad, se especula que alrededor de 20 años.

\section{Tornquist}

La ciudad fue fundada en 1883 , se ubica en $38^{\circ} 06^{\prime} 00^{\prime \prime S} 62^{\circ} 14^{\prime} 00^{\prime \prime} \mathrm{W}$ y es la cabecera del partido homónimo, cuenta con una población de 6.473 habitantes, la actividad predominante es la agropecuaria (INDEC, 2010). El clima es templado y cálido con precipitaciones durante todo el año. Es clasificado como Cfa según el sistema de Köppen-Geiger La temperatura media anual es $13,9{ }^{\circ} \mathrm{C}$ y las precipitaciones de $727 \mathrm{~mm}$. El mes más seco es agosto, con $26 \mathrm{~mm}$ y el más húmedo es marzo con $100 \mathrm{~mm}$. El mes más caluroso del año con un promedio de $22,1^{\circ} \mathrm{C}$ de enero y el mes más frío del año es junio $6,9^{\circ} \mathrm{C}$ (https://es.climate-data.org/).

Características de los sitios muestreados:

Cementerio: Se relevaron 5 bóvedas y una tumba todas ellas con una envolvente de mortero de cemento. Se registró la fecha de solo una bóveda la cual fue construida en 1975. Todos los muros verticales de las bóvedas fueron limpiados con hidrolavadora aproximadamente 5 años antes del muestreo, por 
el personal de mantenimiento del cementerio para poder mantener una fachada limpia

\section{Bahía Blanca}

La ciudad de Bahía Blanca, ubicada al S de la provincia $\left(38^{\circ} 43^{\prime 00}\right.$ "S $\left.62^{\circ} 16^{\prime} 00^{\prime \prime} \mathrm{W}\right)$, fue fundada en 1828 y es cabecera del partido homónimo, con una población de 301.501 habitantes. Se desarrollan distintas actividades económicas entre las que se encuentran la industria petroquímica y la actividad portuaria (INDEC, 2010).

El clima es templado subhúmedo, con precipitaciones significativas incluso en el mes más seco. Este clima es considerado Cfa según la clasificación climática de Köppen-Geiger. La temperatura es en promedio 15,7 ${ }^{\circ} \mathrm{C}$, y la precipitación media es 597 mm por año. El mes más seco es agosto, con $23 \mathrm{~mm}$ de precipitación y el mes más húmedo es marzo promediando 88 $\mathrm{mm}$ (https://es.climate-data.org).

\section{Características de los sitios muestreados:}

Cementerio: fue fundado en 1885. Se relevaron 3 tumbas revestidas de mármol (fechada en 1917), aglomerado (1988) y laja (1972) y bóvedas revestidas con mortero de cemento donde la más antigua fue construida en 1893 y la más moderna en 1973, además de algunas que no estaban fechadas.

Parque de la independencia: es un parque municipal abierto al público, dentro del casco urbano de la ciudad, fundado en 1911. Se muestreó el muro perimetral confeccionado con laja.

Tanto la laja del cementerio y del Parque Independencia eran iguales, siendo esta roca originaria de la provincia de Neuquen (com. pers. Alejandro Ribot).

\section{Carmen de Patagones}


La localidad fue fundada en 1779, se ubica al extremo $S$ de la provincia $\left(40^{\circ} 47^{\prime} 00^{\prime \prime} \mathrm{S} 62^{\circ} 58^{\prime} 00^{\prime \prime} \mathrm{W}\right)$, es la ciudad cabecera del partido homónimo, cuenta con una población de 20.533 habitantes y la principal actividad económica que se desarrolla es la agroindustria (INDEC, 2010). El casco histórico de la ciudad ha sido declarado como "Bien de interés histórico nacional en su calidad de Poblado Histórico" (Decreto Nacional Nº401 del 21/07/2003).

El clima es seco, con pocas precipitaciones durante todo el año. De acuerdo con el sistema Köppen y Geiger se clasifica como BSk. La temperatura media anual es de $14,2^{\circ} \mathrm{C}$ ya precipitación anual es de $330 \mathrm{~mm}$. El mes más seco es junio, con un promedio de $19 \mathrm{~mm}$ y el más húmedo es marzo, con un promedio de $37 \mathrm{~mm}$. El mes más cálido es enero con una temperatura media de $21,7^{\circ} \mathrm{C}$, en tanto las temperaturas medias más bajas del año se producen en julio con $7,1^{\circ} \mathrm{C}$ (https://es.climate-data.org).

\section{Características de los sitios muestreados:}

Cementerio: no se conoce la fecha exacta de su construcción y se especula que data de mediados del siglo XIX. Se relevaron bóvedas y tumbas delimitadas por una envoltura de mortero de cemento.

Murallón costero: se relevaron secciones horizontales y verticales del murallón que se encuentra sobre la margen del Río Negro en el límite de la ciudad, acabado con una envoltura de mortero de cemento.

Estación de ferrocarril: actualmente en desuso, fue fundada en 1949. Es un edificio que se destaca del resto de las estaciones de la provincia de Buenos Aires, ya que tiene un estilo de construcción francés diferente al estilo inglés de la mayoría de ellas. La misma está delimitada por una envolvente de mortero de cemento con una capa de pintura blanca muy desgastada por la falta de mantenimiento. Se relevaron muros verticales de la misma.

\section{IV.1.1.3. Áreas de bosques nativos}


En las zonas boscosas nativas de la ribera platense se realizaron caminatas, por las zonas donde se tuviera acceso, en los cuales se realizo un muestreo al azar sobre árboles con un diámetro de tronco a la altura de pecho mayor a $10 \mathrm{~cm}$ y registrándose la especie de árbol. Sobre cada árbol se seleccionó la cara del tronco que presentó mayor cobertura de líquenes (Estrabou \& García 1995; Estrabou et al., 2005; Rodríguez et al., 2009), sobre esta se dispusieron unidades de muestreo delimitadas por cuadrados de $20 \mathrm{x}$ $20 \mathrm{~cm}$ ubicados a 50, 100 y $150 \mathrm{~cm}$ de altura del suelo. No se tomaron en cuenta las especies que crecieron sobre ramas de los árboles, ya que para el muestreo de las mismas es necesaria la utilización de aparataje que permita ascender a $15 \mathrm{~m}$ con el cual no se contaba.

\section{1.1.3.1. Características de las localidades y los sitios relevados}

\section{Reserva Natural de Uso Múltiple Isla Martín García (RNIMG)}

La Reserva Natural de Uso Múltiple Isla Martín García (RNIMG), declarada como tal en 1973, se encuentra dentro de la región fitogeográfica de las selvas Paranaenses, del dominio amazónico y de la región Neotropical (Cabrera y Dawson, 1944), la vegetación de la isla fue revisada por Lahitte y Hurrel (1994) quienes realizan una caracterización de toda la vegetación de la isla, y la dividen en 10 unidades vegetales que se diferencian por la fisonomía y la composición de especies de cada una, ellas son: selvas marginales, bosques xeromórficos, bosques periurbanos, bosques ribereños, asimetrías, matorral y césped ribereños, pajonales mixtos, juncales, área urbanas y arenales. En los estratos arbóreos las especies que se pueden encontrar son Erythrina cristagalli, Ocotea acutifolia, Lonchocarpus nitidus, Luehea divaricata, Citharexylum montevidense, Pouteria salicifolia, Salix humboldtiana, Ficus luschnathiana, Blepharocalyx tweediei, Inga uruguensis, Allophylus edulis, Sebastiana brasiliensis y Enterolobium contortisiliquum, Rapanea laetevirens, entre otras y en el estrato arbustivo: Diodia brasiliensis, Cordia bifurcata, Psychotria carthagenensis. 
Características de los sitios muestreados en la localidad:

Se realizó un muestreo en el sector, o sitio, de arenal donde se tomaron muestras sobre Sapium haematospermum (6), y en el sector de selva marginal, donde se muestreó sobrelas siguientes especies: Lonchocarpus nitidus (14), Ocotea acutifolia (16), Ligustrum Iucidum (2), Pouteria salicifolia (4), Sapium haematospermum (1), Blepharocalyx salicifolius (2), Poecilanthe parviflora (1), Zanthoxylum fagara (3), Citharexylum montevidens (2), Erythrina crista-galli (1), Myrsine laetevirens (2), Ficus luschnathiana (1). Estos sectores eran los que presentaban menores alteraciones a causa de las acciones humanas. Las muestras se tomaron a 3 alturas pero dado que la totalidad del tronco estaba recubierto de líquenes las exposiciones sobre este fueron tomadas al azar.

\section{Reserva Natural Integral Punta Lara (RNPL)}

La Reserva Natural Integral Punta Lara -RNPL- $\left(34^{\circ} 47^{\prime} 28^{\prime \prime S}\right.$ $\left.57^{\circ} 59^{\prime} 49^{\prime \prime} \mathrm{W}\right)$, fundada en 1943 es un área natural protegida enmarcada dentro del sistema de áreas protegidas de la provincia de Buenos Aires, bajo jurisdicción y administración provincial. Está a cargo del Organismo Provincial para el Desarrollo Sostenible (OPDS), y ha sido recientemente declarada como área núcleo de la Reserva de la Biósfera Pereyra Iraola. Se encuentra localizada entre los Partidos de La Plata, Ensenada, Berazategui y Florencio Varela y en el espacio costero del estuario del Río de La Plata, con el que mantiene una íntima conexión, ya que su presencia aporta condiciones subtropicales a latitudes templadas (Barbetti, 2008), las riadas e inundaciones son un factor de pulso sobre los ecosistemas ribereños, y propicia la existencia de distintas comunidades vegetales como pastizales inundables, pajonales, bosquecillos y la selva ribereña que constituye el exponente más austral de las "selvas en galería" que bordean los ríos Paraná y Uruguay. Fisonómicamente es una selva empobrecida, mantenida gracias a los factores edáficos y microclimáticos en una región donde la vegetación clímax es la estepa de gramíneas. Las especies arbóreas más comunes son Ocotea acutifolia, 
Allophylus edulis, Pouteria salicifolia y Sebastiania brasiliensis, además de la especie exótica Ligustrum lucidum (Cabrera \& Dawson, 1944).

\section{Características de los sitios muestreados:}

Se muestreó el sector de selva marginal cercano al destacamento de guardaparques de la reserva y a la pasarela de uso público. Se muestreó sobre las especies: Ocotea acutifolia (8), Ligustrum lucidum (8), Lonchocarpus nitidus (8), Pouteria salicifolia (4), y Terminalia australis (3).

\section{IV.1.1.4. Roquedales serranos}

En los ambientes con roquedales, se utilizó la misma unidad de muestreo $(20 \times 20 \mathrm{~cm})$, estos cuadrados fueron dispuestos sobre los roquedales de manera azarosa. Sobre los sitios muestreados se tomó la siguiente información adicional (Lavornia, 2015):

- Exposición: mediante el uso de brújula se registró la orientación de los roquedales seleccionados (N, NE, E, SE, S, SW, W y NW).

- Rocosidad: se estimó subjetivamente el porcentaje de rocosidad de la localidad.

- Posición topográfica: se utilizó la clasificación usada por Frangi (1973) en la descripción de las comunidades de plantas superiores del área.

i. Cumbre: parte más alta de un relieve positivo

ii. Ladera superior: parte de la pendiente cercana a la cumbre

iii. Ladera media: sector de la pendiente intermedio entre la ladera superior e inferior.

iv. Ladera inferior: porción más baja de la pendiente.

v. Fondo: parte más baja del relieve cóncavo.

- Tipo de roquedal: se consignó de acuerdo a la clasificación utilizada por (Frangi, 1973, 1975) que separa a los roquedales en:

i. Granitoides: formados por rocas plutónicas de grano grueso con cuarzo.

ii. Miloníticos: constituidos por rocas miloníticas de grano fino. 


\section{1.1.4.1. Características de las localidades y los sitios relevados}

\section{Sierras de Tandil (ST)}

El sistema de Tandilia se dispone como una cadena montañosa de dirección NW-SE de unos 300 km de largo, con un ancho máximo de 60 km y con una altura máxima de $524 \mathrm{~m}$ s.n.m. ubicados en el centro-E de Buenos Aires. El clima es templado-húmedo con heladas invernales y verano caluroso. La temperatura media anual es de $14^{\circ} \mathrm{C}$. Las precipitaciones se registran durante todo el año en forma de lluvia, con ocasionales granizadas durante el verano. El promedio es de unos $850 \mathrm{~mm}$ por año (https://es.climate-data.org/).

\section{Características de los sitios muestreados en ST:}

Se realizaron muestreos en el partido de Tandil $\left(37^{\circ} 19^{\prime} 00^{\prime \prime} S\right.$ $\left.59^{\circ} 08^{\prime} 00^{\prime \prime} \mathrm{W}\right)$, en los roquedales urbanos de la ciudad cabecera del partido, que se encuentran dentro del parque de la ciudad y en las sierras próximas (ST), más precisamente en el cerro Las Ánimas. Las rocas presentes en estos roquedales son graníticas metamórficas.

\section{Parque Provincial Ernesto Tornquist (PPET)}

El sistema de Ventania se dispone como una cadena montañosa de dirección NW-SE de unos $180 \mathrm{~km}$ de largo y $60 \mathrm{~km}$ de ancho ubicados en el sudoeste de la provincia de Buenos Aires. El Parque provincial Ernesto Tornquist -PPET- $\left(38^{\circ} 03^{\prime} 00^{\prime \prime S} 62^{\circ} 02^{\prime} 00^{\prime \prime} \mathrm{W}\right)$ es un área protegida creada en 1937, en el partido de Tornquist. El clima regional es húmedo sub-húmedo, mesotermal con pequeño a nulo déficit de agua (Burgos, 1968), con una temperatura media de $14,5^{\circ} \mathrm{C}$ y $896 \mathrm{~mm}$ de precipitación anual.

\section{Características de los sitios muestreados en PPET:}

Se realizó un relevamiento sobre roquedales el cerro Bahía Blanca (800 m s.n.m.) en un área poco frecuentada y alterada por el público que visita el parque. Las rocas presentes en estos roquedales son graníticas metamórficas. 


\section{IV.1.2. Variables registradas}

En todos los casos las variables de los líquenes que se registraron y calcularon fueron: cobertura por especie utilizando procentaje de cobertura que ocupaban dentro del cuadrado de muestreo. Se caracterizó la comunidad por la fisonomía de acuerdo a los tipos de talo, a la riqueza, la composición de especies.

La frecuencia absoluta (Fre) se considero como la cantidad de cuadrados de muestreo en los que la especie estuvo presente.

La frecuencia porcentual ( $\mathrm{Fr} \%$ ) es el porcentaje de presencia de la especie dentro del total de cuadrados.

La riqueza de especies (S) se consideró como el número de especies que se encuentran en un hábitat, ecosistema, paisaje, área o región determinado (Begon et al. 2009) y se calculó para cada localidad, para cada sitio y por cada variable ambiental.

\section{IV.1.3. Identificación de las especies}

Para la identificación se realizaron observaciones de las estructuras externas mediante lupa binocular, cortes a mano alzada de talo y de estructuras reproductivas los cuales fueron observados bajo microscopio óptico de cámara clara. Se realizaron reacciones puntuales de color, que se utilizan como carácter taxonómico y se aplican para una primera determinación de la composición química. Se utilizaron los siguientes reactivos:

-Reactivo K (hidróxido de potasio al 10\%): se aplicó una micro-gota de dicha sustancia en un sector de la médula, corteza, apotecio o himenio y se observó la variación de color, o la aparición de cristales bajo microscopio.

-Reactivo C (hipoclorito de sodio): se realizó el mismo procedimiento que con el reactivo anterior y se observó la posible variación de color. 
-Reactivo CK y KC: es una combinación de los dos reactivos anteriormente descriptos, cuyos resultados a su vez difieren según el orden de aplicación de los mismos.

-Reactivo I (solución de iodo iodurado): este se utilizó sobre el himenio y se observó el cambio en la coloración bajo miscoscopio.

-Reactivo Pd (Parafenilendiamina): se saturó en etanol para después colocar una micro-gota sobre la corteza o médula y se observó el cambio de coloración.

Además se realizó la reacción del talo bajo luz UV, con una lámpara de luz ultra violeta. En los casos que lo ameritaba se realizó una cromatografía de capa delgada (TLC) mediante la técnica de Culberson et al. (1981) y White \& James (1985).

Con estos datos se identificaron las especies de líquenes a través de las claves específicas de Malme (1927), Magnusson (1929), Poelt (1969), Ozenda \& Clauzade (1970), Osorio (1977a), Nimis et al. (1987), Moberg (1990), Adler (1988, 1992), Scutari (1992a,b), Marbach (2000), Rambold et al. (2001), Messuti \& Vobis (2002), Lumbsch \& Elix (2004), Rivas Plata et al. (2006), Cáceres (2007), Lücking et al. (2009), Messuti \& de la Rosa (2009), Rodríguez (2011), Rosato \& García (2012), de la Rosa et al. (2012), Mccune (2012), Lavornia et al. (2016).

El registro de las especies identificadas se encuentra en el ANEXO II.

\section{IV.2. Análisis de datos \\ IV.2.1. Análisis regional}

Para reconocer las relaciones entre las especies y los factores ambientales que pueden estar actuando sobre sus distribuciones se realizaron análisis multivariados utilizando Análisis de Correspondencia Canónico -CCA(Armesto \& Contreras, 1981; Begon et al., 2006; Moreno, 2001; McCune \& Grace, 2002; Estrabou et al., 2005; Martins, 2006; Estrabou, 2007b; Cáceres et al., 2007; Quiroga et al., 2008), previamente los datos de cobertura fueron transformados con el arco-seno de la cobertura $\left(b=2 / \pi\right.$ arcoseno $\left.X_{i j}\right)$, para 
ajustar los datos a una distribución cercana a la distribución normal. Se prefirió el análisis CCA ya que incorpora la relación entre los datos florísticos y factores ambientales dentro del propio análisis, mientras que otros métodos multivariados realizan el análisis por separado, además si bien el método es muy utilizado para la búsqueda de gradiente en variables continuas (McCune, 1997) también se ha demostrado que acepta variables de presencia-ausencia siendo de esta forma un análisis muy completo (Palmer, 1993; Øklan, 1996; Palmer, 2004). Se determinó mediante la prueba de permutaciones de Monte Carlo si los valores de las raíces características de los primeros ejes de la ordenación, de los valores de correlación entre las especies y de las variables ambientales obtenidos con el CCA eran estadísticamente significativos $(\alpha=$ 0,05 ), quitando las variables ambientales que no presentaban correlación con los datos de la matriz de líquenes. En los casos en que por la escasa cantidad de variables ambientales no permitió la utilización de un CCA se utilizaron otras metodologías de ordenación de gradiente indirecto, las cuales priorizan los datos florísticos y no los analizan en conjunto con las variables ambientales (por lo cual el análisis es independiente de estas), tales como NMS (No Metric Sistem) o PCA (Principal Component Analysis), eligiendo la metodología que pudiera resolver mejor la situación. Para todos los casos se utilizó el software PC-ORD 6.12 (McCune \& Grace, 2002). Siguiendo a Cáceres et al. (2007) las especies raras no fueron removidas de los análisis, como proponen otros autores (Greig-Smith 1983, Jongman et al. 1995, McCune \& Grace 2002), ya que fue demostrado que existen una gran cantidad de especies que aparecen como especies raras y brindan información básica de las comunidades que usando la metodología clásica se perdería.

En el análisis multivariado se utilizaron las variables de cobertura relativa de cada especie y las variables ambientales expresadas en valores absolutos y nominales según el caso. Las categorías de estas últimas fueron:

- Tipo de sustrato: mortero, mármol, granito, laja, aglomerado, ladrillo.

- Inclinación: horizontal y vertical.

- Altura desde el suelo: 0,5 m (alt 1), $1 \mathrm{~m}$ (alt 2) y 1,5 m (alt 3).

- Orientación: N, W, E, S, NE, NW, SE, SW. 
Con el promedio de cobertura por localidad de las especies urbanas se realizo un NMS, para poder reconocer posible agrupamientos de las especies. Además se realizó un análisis de agrupamiento de localidades en función de la presencia de especies (Cluster de dos vías) para el cual se utilizó el índice de la distancia de Jaccard.

Por otro lado se analizó cada localidad en función de las variables ambientales: temperatura promedio anual, precipitación promedio anual, temperatura mínima anual, temperatura máxima anual, precipitación mínima anual y precipitación máxima anual, con el fin de observar un patrón entre las variables ambientales de las localidades. Para ello se aplicó un análisis PCoA (Principal Coordinates Analysis), donde se utilizó la medida de distancia de Jaccard. Para ambos casos se utilizó el software PC-ORD 6.12 (McCune \& Grace, 2002).

\section{IV.2.1.1. Índices}

La diversidad se cuantificó mediante el índice de Shannon-Wiener, calculado según la fórmula:

$$
H^{\prime}=-\Sigma p_{i} \ln p_{i}
$$

Donde:

$H^{\prime}=$ índice de diversidad de Shannon-Wiener (bits/individuo) ó diversidad de especies observada.

$p_{i}=$ abundancia proporcional de la especie $i$, lo cual implica obtener el número de individuos de la especie $i$ dividido entre el número total de individuos de la muestra. Siendo que las especies en su mayoría son modulares, lo que imposibilita la diferenciación de individuos se utilizo la cobertura como medida de la abundancia (Gonzáles, 2006).

Entre los valores del índice de Shannon-Wiener se realizó un análisis de significancia propuesto por Magurran (1988) $\operatorname{con} \alpha=0,05$. 
El índice de Equidad de Pielou se calculó según la fórmula (Magurran, 2013):

$$
J^{\prime}=\frac{H^{\prime}}{H_{\max }^{\prime}}
$$

Donde:

J' = índice de equidad de Pielou.

$H_{\text {máx }}^{\prime}=\ln \mathrm{S}$.

En el análisis de la diversidad alfa ( $\alpha$ ) se compararon los sitios de muestreo según los índices riqueza de especies (S), diversidad de ShannonWiener $\left(H^{\prime}\right)$ y de Equidad de Pielou $\left(J^{\prime}\right)$. En esta parte del análisis su información se utilizó para dimensionar las variaciones en los diferentes sitios de muestreo, independientemente de las variaciones ambientales. Para dimensionar la diversidad beta $(\beta)$ se utilizaron índices de similitud/disimilitud o distancia, e índices de reemplazo de especies. Dentro del primer grupo se calculó el coeficiente de similitud de Jaccard (Magurran, 2013), mientras que en el segundo grupo se calculó el índice de Cody según la versión de 1975 (SosaEscalante, 2004). En ambos casos para la riqueza de las localidades naturales se contabilizaron no solo las especies encontradas en los muestreos, sino también la encontrada en bibliografía para cada uno, por lo que para Isla Martín García se uso García y Rosato (2015), para Punta Lara García y Rosato (2013), para las sierras de Tandil Lavornia et al. (2016) y para el Parque Provincial Ernesto Tornquist Osorio (1987).

El coeficiente de similitud de Jaccard $\left(l_{j}\right)$ se calculó según la fórmula:

$$
I_{j}=\frac{c}{a+b-c}
$$

Donde:

$a=$ número de especies en el sitio $\mathrm{A}$.

$b=$ número de especies en el sitio $\mathrm{B}$. 
$c=$ número de especies presentes en ambos sitios $\mathrm{A}$ y $\mathrm{B}$, es decir que están compartidas.

El rango de este índice va desde cero (0) cuando no hay especies compartidas, hasta uno (1) cuando los dos sitios comparten todas las especies. Este índice mide diferencias en la presencia o ausencia de especies.

El índice de Cody (1975) se calculó mediante la siguiente fórmula:

$$
\beta=\frac{g(H)+p(H)}{2}
$$

Donde:

$g(H)$ = número de especies ganadas; especies que están en el sitio 2 pero que no están en el sitio 1.

$p(H)=$ número de especies perdidas; especies del sitio 1 que no están en el sitio 2.

\section{IV.2.2. Relación entre comunidades y variables ambientales}

Se realizaron test estadísticos en cada localidad, sobre la altura y las distintas orientaciones para establecer si existía diferencia significativa en relación a la cobertura de los líquenes y se utilizó prueba de Kruskal-Wallis para determinar si existían diferencias, en los casos que este análisis mostró diferencias significativas se realizó una prueba pos hoc de Bonferrini Dunn. En cambio cuando solo se contó con 2 variables se realizó un test de $t$ el cual es más robusto, y da mejores resultados que su contraparte no paramétrica, aún no cumpliendo el supuesto básico de normalidad (Zimmerman, 1987; Faguerland \& Sandvik, 2009). Ambos análisis se realizaron con un nivel de confianza $\alpha=0,05$. Además para detectar qué especies presentaron preferencia por las variables ambientales se utilizó el análisis de especies indicadoras (ISA) de Dufrêne y Legendre (1997), este brinda un valor indicador (IV) al cual se le realiza un test de Monte Carlo para comprobar su significancia 
$(\alpha=0,05)$, este análisis se realizó con el programa PC-ORD 6.12. (McCune \& Grace, 2002).

\section{IV.2.3. Colonización de sustratos}

Para reconocer las especies pioneras que intervienen en la colonización de muros y obtener información relacionada al tiempo de propagación de la cobertura liquénicas se analizó un caso de estudio. Se realizó la limpieza de sectores de $10 \times 10 \mathrm{~cm}$ sobre muros de mortero de cemento que previamente estaban colonizados por líquenes en un edificio ubicado en la localidad de La Plata en el edificio donde se ubica el Laboratorio de Entrenamiento Multidisciplinario para la investigación Tecnológica (LEMIT), se seleccionó este sitio priorizando realizar un seguimiento constante de los parches, por lo que no se pudieron tener representadas todas las orientaciones. De estos parches 4 fueron sobre un muro horizontal, 3 sobre un muro vertical con orientación SE y 3 sobre muro vertical con orientación SW, de estos últimos uno se perdió por reformas edilicias. La remoción de los líquenes fue manual, para esto se utilizó un cepillo de cerdas duro de plástico sumado a la acción de lavandina comercial que es un biocida sin efecto residual $(\mathrm{NaClO})$. Después de la limpieza se realizó una observación de cada cuadrado con una lupa de mano (60x) para verificar que no quedaran restos. Posteriormente de la limpieza los cuadrados fueron observados con lupa de mano (60x) cada 3 meses para registrar la cobertura de las especies que recolonizaron la superficie. Estos parches fueron observados durante 3 años de forma periódica cada 3 meses (Figura. IV.4).

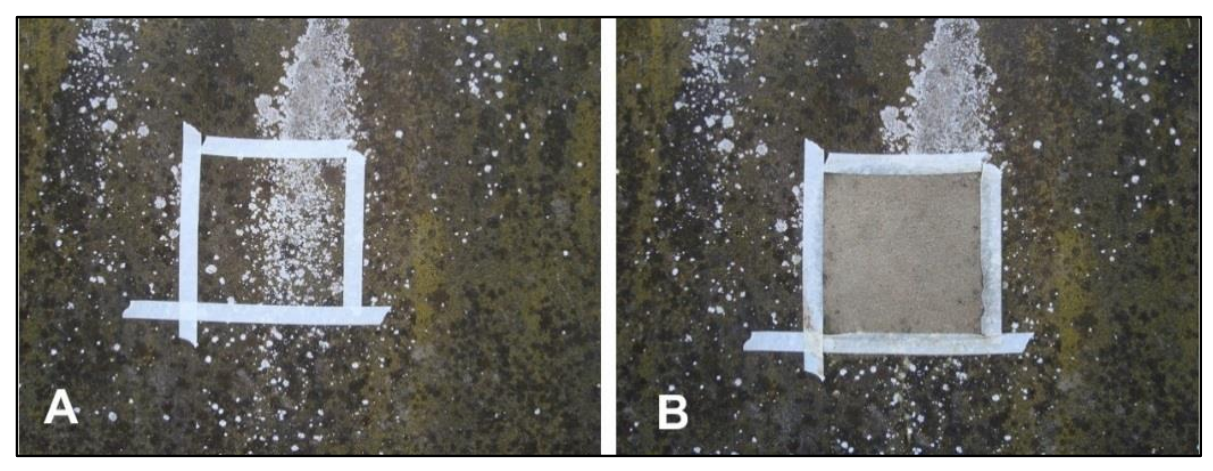


Figura. IV.4. $A=$ sector previo a la limpieza; $B=$ sector posterior a la limpíeza

\section{IV.2.4. Competencia interespecífica}

Para evaluar la competencia entre especies se realizó un relevamiento en los muros de un edificio de la ciudad de La Plata y se eligió la terraza del edificio ocupado por el Laboratorio de Entrenamiento Multidisciplinario para la Investigación Tecnológica (LEMIT) ubicado en el Paseo del Bosque (calle 52 $\mathrm{s} / \mathrm{n}$ entre 121 y 122). Esta construcción posee una antigüedad de 70 años, en la terrasa existen muros recubiertos por un mortero de cemento que no han sido retocados desde la fundación, colonizados por una densa capa de líquenes. Allí se trazaron transectas sobre muros horizontales y verticales sobre las que se colocaron las unidades de muestreo (cuadrados de $20 \mathrm{x}$ $20 \mathrm{~cm}$ ). Se registraron la cobertura por especie, y la naturaleza de la interacción cuando dos especies entraban en contacto. Se contabilizaron todas las zonas de contacto entre talos de distintas especies y los sobrecrecimientos de una especie sobre otra. Siguiendo la terminología empleada por Pentecost (1980), se consideraron tres tipos de contactos: "victoria" (+) cuando el talo de una especie creció sobre el talo de otra especie; "empate" (II) si hubo contacto entre el talo de dos especies diferentes pero ninguno de ambos crece sobre el otro; y "derrota" (-), cuando el talo de una especie fue tapado por el talo de otra especie (inversa de victoria). El tipo de interacción se constató mediante la observación de la zona de contacto de los líquenes. Para detectar si hubo una interacción predominante entre cada par de especies que entraron en contacto, se transformaron los datos para convertirlos de variables discreta a continua mediante $y=\sqrt{x+1}$ (Legendre \& Legendre, 1998). Posteriormente se utilizó una prueba no paramétrica, el test de Kruskal-Wallis. De este modo se pudo verificar si hubo diferencias significativas entre el número de victorias, empates y derrotas ocurridas entre dos especies dadas. En los casos de existir diferencias significativas se realizó una prueba pos hoc de Bonferrini Dunn (Sheskin, 2003). Ambas pruebas se realizaron mediante el programa Statgraphics 7.0. 


\section{RESULTADOS}

\section{V.1. Liquenobiota de ambientes urbanos y naturales de la provincia de Buenos Aires y sus preferencias ambientales}

\section{V.1.1. Biota liquénica de ambientes urbanos \\ V.1.1.1. Isla Martín García}

\section{Composición de especies}

Se registraron un total de 14 especies (tabla V.1), de las cuales 11 fueron de morfología crustosa y 4 foliosas. Dentro de las especies crustosas encontramos 3 especies endolíticas y 7 epilíticas. Flavoplaca austrocitrina presentó la mayor cobertura total y frecuencia, seguida de Athallia holocarpa y Staurothele monosporoides. De los 5 sitios relevados $F$. austrocitrina se encontró en 4 de estos, siendo la especie que se encontró en casi la totalidadad de los sitios. Fue la especie con mayor cobertura en los sitios: mirador, edificio 1 y faro, siendo la única especie presente en este último. Mientras que en cementerio y mirador las especies con mayor cobertura fueron A. holocarpa y Graphis virescens respectivamente. El sitio con mayor riqueza fue el edificio 1 (9), seguido por el mirador (5) el edificio (2) y el cementerio (2), por último el faro (1) (tabla V.2).

Tabla V.1. Especies encontradas en la Isla Martín García, cobertura (\%) promedio (Cob), frecuencia absoluta (Fre), frecuencia porcentual (Fre \%) y tipo morfológico. Unidades de muestreo $\mathrm{n}=185$.

\begin{tabular}{lcccc}
\hline & Cob & Fre & Fre \% & Morfología \\
\hline Flavoplaca austrocitrina & 18,62 & 115 & 61,8 & Crustosa \\
Athallia holocarpa & 4,18 & 39 & 21,0 & Crustosa \\
Staurothele monosporoides & 2,90 & 36 & 19,4 & Crustosa \\
Phaeophyscia hirsuta & 3,20 & 28 & 15,1 & Foliosa \\
Graphis virescens & 7,20 & 21 & 11,3 & Crustosa \\
Rinodina oxydata & 2,90 & 17 & 9,1 & Crustosa \\
Bacidina pallidocarnea & 0,81 & 13 & 7,0 & Crustosa
\end{tabular}




\begin{tabular}{lcccc} 
Lecania erysibe & 0,009 & 15 & 8,1 & Crustosa \\
Physcia tribacia & 0,02 & 3 & 0,0 & Foliosa \\
Sarcogyne regularis & 0,06 & 2 & 1,6 & Crustosa \\
Oxneria fallax & 0,01 & 2 & 1,1 & Foliosa \\
Endocarpon sp. & 0,05 & 2 & 1,1 & Crustosa \\
Crustoso $s p$. & 0,08 & 1 & 1,1 & Crustosa \\
Myriolecis dispersa & 0,03 & 1 & 0,5 & Crustosa \\
\hline
\end{tabular}

Tabla V.2. Cobertura relativa media (\%) de cada especie por sitio de muestreo, de la localidad Isla Martín García.

\begin{tabular}{lccccc}
\hline & $\begin{array}{c}\text { Faro } \\
(\mathrm{n}=37)\end{array}$ & $\begin{array}{c}\text { Cementerio } \\
(\mathrm{n}=24)\end{array}$ & $\begin{array}{c}\text { Mirador } \\
(\mathrm{n}=17)\end{array}$ & $\begin{array}{c}\text { Edificio 1 } \\
(\mathrm{n}=81)\end{array}$ & $\begin{array}{c}\text { Edificio 2 } \\
(\mathrm{n}=26)\end{array}$ \\
\hline Flavoplaca austrocitrina & 6,03 & 0,7 & 7,94 & 37,53 & - \\
Athallia holocarpa & - & 26,3 & 0,06 & - & - \\
Staurothele monosporoides & - & - & 31,76 & 4,44 & - \\
Phaeophyscia hirsuta & - & - & - & 7,36 & - \\
Lecania erysibe & - & - & - & 2,22 & - \\
Physcia tribacia & - & - & - & 0,04 & - \\
Sarcogyne regularis & - & - & - & 0,14 & - \\
Oxneria fallax & - & - & - & 0,02 & - \\
Crustoso sp.1 & - & - & - & 0,19 & - \\
Graphis virescens & - & - & - & - & 63,8 \\
Bacidina palidocarnea & - & - & - & - & 10,8 \\
Rinodina oxydata & - & - & 9,18 & - & - \\
Myriolecis dispersa & - & - & 0,29 & - & - \\
Endocarpon sp.1 & - & - & 0,59 & - & - \\
\hline
\end{tabular}

$\underline{\text { Relación con las variables ambientales }}$

Del análisis de los resultados de las unidades de muestreo agrupadas por altura sobre el suelo, tipo de sustrato e inclinación del mismo se observó que la mayor diversidad ( $H^{\prime}$ ) y riqueza $(\mathrm{S})$ se dieron a $0,5 \mathrm{~m}$ (altura 1), sobre la orientación $\mathrm{E}$, sobre el sustrato mortero y con la inclinación vertical. La mayor equitatividad se dió en la orientación horizontal, a 1,5 m (altura 3), sobre mortero y orientación W. Tanto en la orientación NW como en la NE solo se encontró la especie $F$. austrocitrina (tabla V.3). 
Tabla V.3. Riqueza(S), diversidad (H') y equitatividad

(J') de la localidad Isla Martín garcía sobre distintas orientaciones, inclinaciones, materiales, y alturas sobre el suelo $(1=0,5 ; 2=1$ y $3=1,5 \mathrm{~m})$.

\begin{tabular}{lccc}
\hline & S & $\mathbf{H}^{\prime}$ & $\mathbf{J}^{\prime}$ \\
\hline Mortero & 14 & 1,652 & 0,626 \\
Mármol & 2 & 0,398 & 0,574 \\
Horizontal & 6 & 1,0 & 0,71 \\
Vertical & 10 & 1,313 & 0,57 \\
Altura 1 & 11 & 1,394 & 0,605 \\
Altura 2 & 9 & 1,275 & 0,613 \\
Altura 3 & 7 & 1,232 & 0,633 \\
$\mathbf{N}$ & 5 & 0,977 & 0,607 \\
NE & 1 & - & - \\
NW & 1 & - & - \\
E & 8 & 1,20 & 0,579 \\
W & 4 & 0,902 & 0,650 \\
S & 6 & 1,139 & 0,634 \\
SE & 2 & 0,276 & 0,399 \\
Total & 14 & 1,757 & 0,665 \\
\hline
\end{tabular}

Se realizó la prueba de Kruskal-Wallis usando las coberturas de las especies, entre las alturas, las orientaciones, la inclinación y el tipo de material, en todos los casos el resultado de la prueba fue que no existía diferencia significativa $(p>0,05)$.

El Análisis de Especies Indicadoras (ISA) para la variable material inclinación que las especies $A$. holocarpa presento el mayor valor de indicación (IV) para el sustrato mármol y horizontal, mientras que $F$. austrocitrina lo presento para la variable mortero y vertical. En cuanto a la variable altura $F$. austrocitrina fue la única especie que mostro un valor de IV significativo, siendo este con alt 1. Para las variables de orientación las especie que presentaron un IV significativo fueron: $F$. austrocitrina para $N, G$. virescens para $S$ y $B$. pallidocarnea para $\mathrm{E}$.

En el análisis CCA (figura V.1) se observó una diferenciación sobre el eje 1 de las unidades de muestreo realizadas en las superficies horizontales respecto de las verticales. Mientras que en el eje 2 en la parte inferior se 
ubicaron las especies del mirador, en la parte superior las de los relevamientos realizados sobre mármol y en la sección central los restantes. Al analizar ambos ejes se forman 3 grupos, uno de estos formado por los relevamientos realizados sobre mármol, caracterizados por la especie $A$. holocarpa, otro grupo formado por los relevamientos en el mirador con las especies Rinodina oxydata, Myriolecis dispersa y Endocarpon sp. que se encontraron sobre sustrato mortero, por último se encuentran los restantes sitios (faro, edificio 1 y 2) con el resto de las especies excepto $S$. monosporoides que se encuentra asociada a la variable horizontal y sustrato mortero. Tanto la variable orientación (solamente se ven representadas $S$ y E) como altura no se separaron entre sí, sino que acompañaronn a la variable vertical que poseyó el mayor peso.

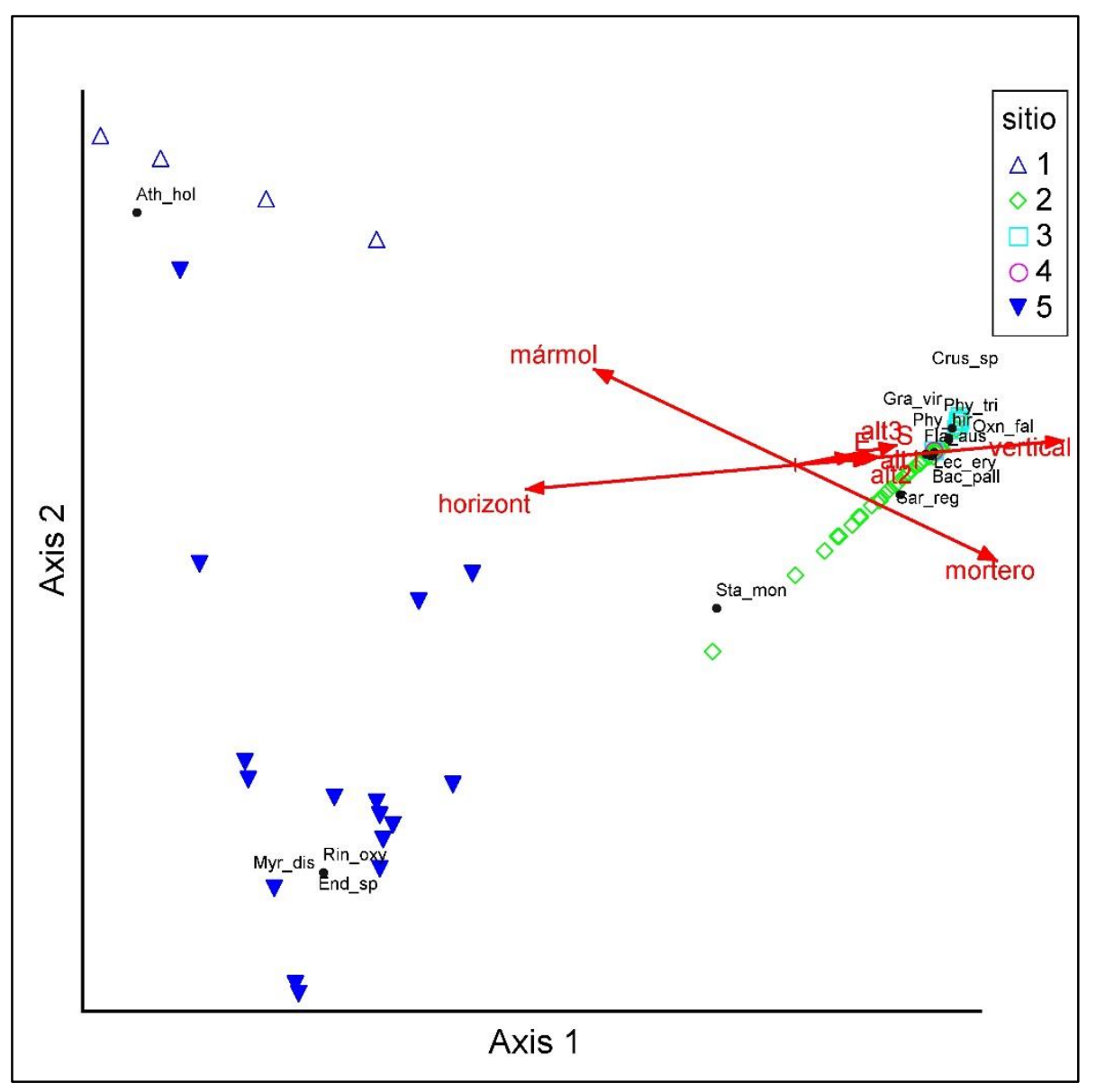


Figura V.1. Análisis de CCA de la localidad Isla Martín García. Sitios de muestreo: 1cementerio; 2- edificio 1; 3- faro; 4-edificio 2; 5- mirador militar. Referencias de especies de líquenes en Anexo II. Unidades de muestreo $\mathrm{n}=185$.

\section{V.1.1.2. Ensenada}

\section{Composición de especies}

Se encontraron un total de 21 especies, de las cuales 8 especies fueron crustosas, 10 foliosas y 3 fruticulosas. De estas especies $F$. austrocitrina presentó mayor cobertura promedio y frecuencias (tabla V.4). De los dos sitios muestreados el CULP presentó una riqueza mayor (21), y tres morfologías diferentes, mientras que en el sitio murallón la riqueza fue menor (6) y solo se encontró la morfología crustosa, estos sitios compartieron el $19 \%$ de las especies, en ambos casos $F$. austrocitrina fue la especie con mayor cobertura (tabla V.5).

Tabla V.4. Especies encontradas para Ensenada, cobertura (\%) promedio (Cob), frecuencia absoluta (Fre), frecuencia porcentual (Fre \%) y tipo morfológico. Unidades de muestreo $\mathrm{n}=98$

\begin{tabular}{lcccc}
\hline & Cobertura & Fre & Fre\% & Morfología \\
\hline Flavoplaca austrocitrina & 14,32 & 96 & 98,0 & Crustoso \\
Monoblastia echinulospora & 6,15 & 39 & 39,8 & Crustoso \\
Staurothele monosporoides & 3,39 & 33 & 33,7 & Crustoso \\
Caloplaca teicholyta & 1,41 & 23 & 23,5 & Crustoso \\
Athallia holocarpa & 0,32 & 10 & 10,2 & Crustoso \\
Physcia alba & 0,38 & 9 & 9,2 & Folioso \\
Ramalina celastri & 0,16 & 8 & 8,2 & Fruticoso \\
Ramalina aspera & 0,082 & 8 & 8,2 & Fruticoso \\
Caloplaca erythrantha & 0,16 & 8 & 8,2 & Crustoso \\
Physcia convexella & 0,11 & 6 & 6,1 & Folioso \\
Flavoparmelia exornata & 0,15 & 5 & 5,1 & Folioso \\
Myriolecis dispersa & 0,05 & 4 & 4,1 & Crustoso \\
Usnea strigosa & 0,06 & 4 & 4,1 & Fruticoso \\
Flavoparmelia soredians & 0,07 & 3 & 3,1 & Folioso
\end{tabular}




\begin{tabular}{lllll} 
Candelaria concolor & 0,02 & 2 & 2,0 & Folioso \\
Punctelia subpraesignis & 0,02 & 2 & 2,0 & Folioso \\
Sarcogyne regularis & 0,06 & 2 & 2,0 & Crustoso \\
Parmotrema pilosa & 0,01 & 1 & 1,0 & Folioso \\
Polycaulionacandelaria & 0,05 & 1 & 1,0 & Folioso \\
Phaeophyscia hirsuta & 0,01 & 1 & 1,0 & Folioso \\
Xanthoria parietina & 0,01 & 1 & 1,0 & Folioso \\
\hline
\end{tabular}

Tabal V.5. Cobertura relativa media (\%) de cada especie por sitio de muestreo, de la localidad Ensenada. CULP = Club universitario de La Plata.

\begin{tabular}{lcc}
\hline & CULP $(\mathrm{n}=26)$ & Murallón $(\mathrm{n}=72)$ \\
\hline Flavoplaca austrocitrina & 30,42 & 8,5 \\
Staurothele monosporoides & 7,53 & 1,9 \\
Caloplaca teicholyta & 4 & 0,47 \\
Monoblastia echinulospora & 0,62 & 8,2 \\
Physcia alba & 1,42 & - \\
Ramalina celastri & 0,62 & - \\
Caloplaca erythrantha & 0,62 & - \\
Flavoparmelia exornata & 0,58 & - \\
Physcia convexella & 0,42 & - \\
Ramalina aspera & 0,31 & - \\
Flavoparmelia soredians & 0,27 & - \\
Usnea strigosa & 0,23 & - \\
Myriolecis dispersa & 0,19 & - \\
Policaulonia candelaria & 0,19 & - \\
Candelaria concolor & 0,077 & - \\
Punctelia subpraesignis & 0,077 & - \\
Parmotrema pilosa & 0,038 & - \\
Phaeophyscia hirsuta & 0,038 & - \\
Xanthoria parietina & 0,038 & - \\
Athallia holocarpa & - & 0,43 \\
Sarcogyne regularis & - & 0,08 \\
\hline
\end{tabular}

$\underline{\text { Relación con las variables ambientales }}$

Los muestreos fueron realizados en ambos sitios sobre inclinación horizontal y sobre un sustrato de mortero de cemento, por lo que solo se diferenció el sustrato, en función de la presencia o ausencia de pintura. Sobre 
las superficies pintadas la riqueza, la diversidad y la equitatividad fueron mayores que sobre la superficie de mortero de cemento (tabla V.6). El test de $T$ no mostró diferencias significativas entre las coberturas sobre pintura y sobre mortero $(p>0,5)$.

El Analisis de especies indicadoras (ISA) para el tipo de sustrato mostro que para el sustrato mortero la especie con un IV significativo fue $M$. echinulospora, mientras que para el sustrato pintura fue la especie $P$. alba.

Tabla V.6. Riqueza (S), diversidad (H') y equitatividad (J') en Ensenada sobre los distintos sustratos con inclinación horizontal

\begin{tabular}{lccc}
\hline & S & H' & J' \\
\hline Mortero & 6 & 1,19 & 0,666 \\
Pintura & 18 & 1,96 & 0,679 \\
Total & 21 & 1,46 & 0,481 \\
\hline
\end{tabular}

Debido a la poca variabilidad de las variables ambientales no se pudo realizar CCA, por lo que se optó por un PCA que sí se pudo llevar a cabo. En el análisis de PCA (figura V.2) sobre el eje 1 se observó una clara separación entre la superficie de mortero y la superficie pintada, quedando 2 grupos claramente separados. Los resultados sobre las unidades de muestreo ubicadas sobre el CULP sobre mortero fueron similares a los realizados sobre el murallón costero formando un grupo compacto, mientras que los realizados sobre pintura se diferencian en gran medida por las especies que se encontraron sobre cada uno, siendo la riqueza de esta superficie mayor que sobre mortero solo. La especie $F$. austrocitrina fue encontrada sobre ambas superficies por lo que se posiciona en el gráfico entre estos 2 grupos. 


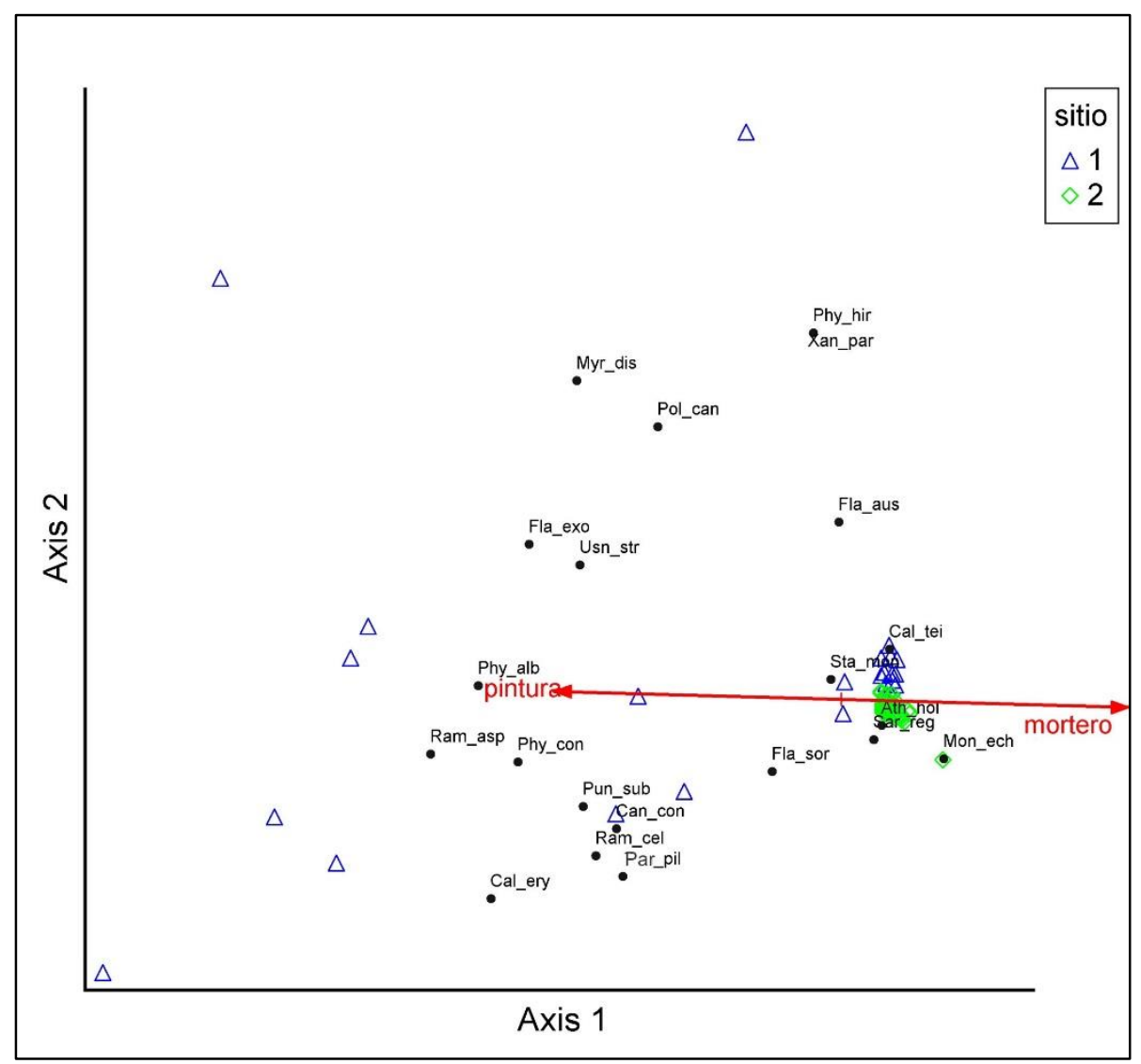

Figura V.2. Análisis de componentes principales (PCA) en la localidad Ensenada. Sitios: 1CULP; 2-murallón costero. Referencias de especies de líquenes en Anexo II. Unidades de muestreo $n=98$.

\section{V.1.1.3. La Plata}

\section{Composición de especies}

Se encontraron un total de 12 especies de líquenes (tabla V.7), 2 especies no han podido ser identificadas por falta de estructuras reproductivas. Tres de esas especies eran foliosas y 9 crustosas; entre éstas últimas 3 especies fueron endolíticas y 6 epilíticas. De todas las especies $F$. austrocitrina obtuvo los mayores porcentajes de cobertura y de frecuencia, seguida por Caloplaca teicholyta y $S$. monosporoides. De todas las especies listadas $A$. holocarpa, $C$. teicholyta, $S$. monosporoides y $F$. austrocitrina se encontraron en todos los sitios de muestreo (tabla V.8), además esta última es la especie con mayor cobertura promedio en 4 de los 5 sitios, siendo superada solo por $C$. 
teicholyta en el sitio Museo (tabla V.8). Dos especies no pudieron ser identificadas ni al nivel de género (crustoso sp) ya que no presentaban ninguna estructura, solamente eran un talo crustoso ambas de diferente color por lo que se interpretaron como distintas especies.

Tabla V.7. Especies encontradas en La Plata, cobertura (\%) promedio (Cob), frecuencia absoluta (Fre), frecuencia porcentual

(Fre \%) y tipo morfológico. Unidades de muestreo $n=243$.

\begin{tabular}{lcccc}
\hline & Cob & Fre & Fre\% & Morfología \\
\hline Flavoplaca austrocitrina & 16,31 & 222 & 91,4 & Crustoso \\
Caloplaca teicholyta & 11,94 & 206 & 84,8 & Crustoso \\
Staurothele monosporoides & 4,67 & 89 & 36,6 & Crustoso \\
Myriolecis dispersa & 2,07 & 79 & 32,5 & Crustoso \\
Athallia holocarpa & 0,77 & 47 & 19,3 & Crustoso \\
Oxneria fallax & 0,79 & 16 & 6,6 & Folioso \\
Monoblastia echinulospora & 0,55 & 11 & 4,5 & Crustoso \\
Lecania erysibe & 0,107 & 6 & 2,5 & Crustoso \\
Phaeophyscia chloantha & 0,025 & 2 & 0,8 & Folioso \\
Xanthoparmelia farinosa & 0,062 & 1 & 0,4 & Folioso \\
crustoso sp.2 & 0,017 & 4 & 1,6 & Crustoso \\
crustoso sp.3 & 0,115 & 12 & 4,9 & Crustoso \\
\hline
\end{tabular}

Tabla V.8. En la localidad La Plata, cobertura (\%) promedio de especies por sitio de muestreo

\begin{tabular}{lccc}
\hline & $\begin{array}{c}\text { LEMIT } \\
(\mathrm{n}=40)\end{array}$ & $\begin{array}{c}\text { Museo } \\
(\mathrm{n}=86)\end{array}$ & $\begin{array}{c}\text { Cementerio } \\
(\mathrm{n}=117)\end{array}$ \\
\hline Flavoplaca austrocitrina & 22,78 & 12,59 & 17,23 \\
Caloplaca teicholyta & 15,73 & 15,80 & 5,72 \\
Staurothele monosporoides & 6 & 4,91 & 3,29 \\
Athallia holocarpa & 0,03 & 1,08 & 0,78 \\
Myriolecis dispersa & 0,28 & 4,10 & 0,33 \\
Lecania erysibe & 0,13 & 0,15 & 0,08 \\
Monoblastia echinulospora & 3,33 & - & - \\
Oxneria fallax & - & - & 2,86 \\
Phaeophyscia chloantha & - & - & 0,17 \\
Oxneria farinosa & - & 0,13 & - \\
crustoso sp.2 & - & 0,03 & - \\
crustoso sp.3 & - & 0,24 & - \\
\hline
\end{tabular}




\section{$\underline{\text { Relación con las variables ambientales }}$}

En cuanto a las variables ambientales (tabla V.9) la mayor riqueza se encontró en la inclinación vertical, a 0,5 m sobre el suelo (altura1), SE y SW. La mayor diversidad $\left(H^{\prime}\right)$ y equitatividad $\left(J^{\prime}\right)$ se encontraron en muros de inclinación horizontal, a 0,5 m sobre el suelo (altura 1) y con orientación NE.

Se realizó la prueba de Kruskal-Wallis entre las alturas, las orientaciones, la inclinación y el tipo de material, usando las coberturas relativas de las especies. Se halló una diferencia significativa $(p<0,05)$ solo entre los valores de las orientaciones, por lo que se realizó un test de Bonferrini Dunn para identificar qué mostró que las orientaciones entre las que hubo diferencias fueron las NE y SW $(p<0,05)$.

EI ISA para la variable orientación, mostró que solo las $O$. fallax para SE y M. echinulospora para SO tuvieron valores de IV significativos. Mientras que para la varible inclinación las especies que presentaron un IV significativo fueron las especies $C$. teicholyta para horizontal y $M$. echinulospora para vertical. Para la variable altura no se encontró ninguna especie un IV significativo.

Tabla V.9. Riqueza (S), diversidad (H')

y equitatividad (J') sobre sustrato

mortero de cemento a distintas

orientaciones, alturas e inclinaciones, de La Plata. .

\begin{tabular}{lccc}
\hline & S & H' $^{\prime}$ & J' \\
\hline Horizontal & 8 & 1,353 & 0,651 \\
Vertical & 9 & 1,253 & 0,57 \\
Altura 1 & 9 & 1,4 & 0,568 \\
Altura 2 & 7 & 1,07 & 0,55 \\
Altura 3 & 8 & 0,898 & 0,491 \\
NE & 4 & 1,76 & 0,849 \\
NW & 2 & 0,523 & 0,754 \\
SE & 8 & 1,41 & 0,549 \\
SW & 8 & 1,28 & 0,614
\end{tabular}




\begin{tabular}{llll} 
Total & 11 & 1,451 & 0,605 \\
\hline
\end{tabular}

En el análisis de CCA (figura V.3) se observó sobre el eje 1 una separación muy fuerte de especies y sitios en 2 grupos asociados a las variables vertical y horizontal. Las especies Xanthoparmelia farinosa, $M$. dispersa, crustoso sp2 y crustoso sp3 son las más relacionadas a la variable horizontal y al sitio Museo, del que estas especies fueron exclusivas. En el eje 2 la separación se observó entre las orientaciones SW y SE; las especies Phaeophyscia chloantha y Oxneria fallax estuvieron relacionadas a la variable SE mientras que $M$. echinulospora se relacionó al SW. El resto de las especies no manifestó una tendencia marcada con alguna de las variables seleccionadas.

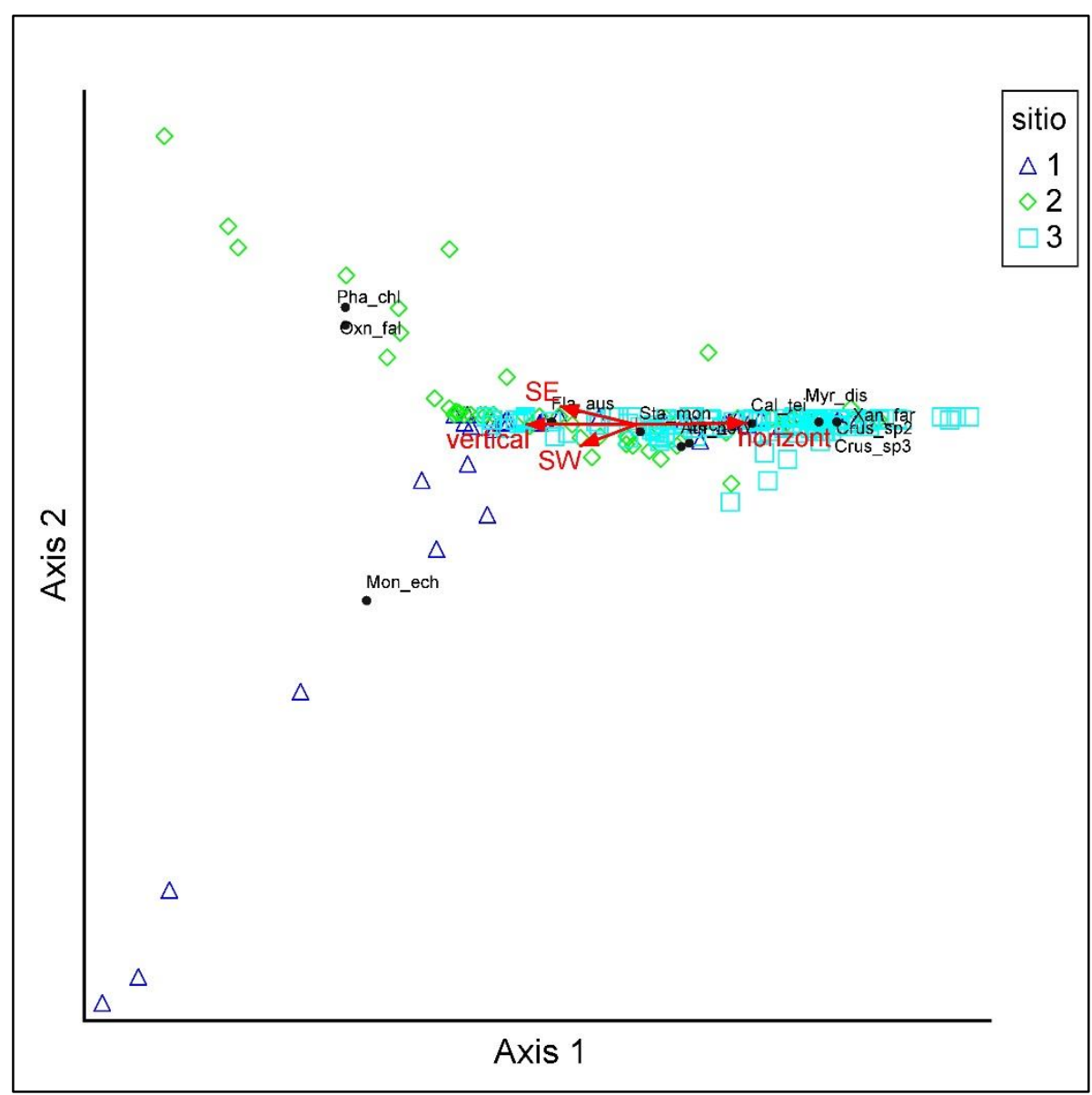

Figura V.3. Análisis CCA en la localidad La Plata. Sitios 1- LEMIT; 2- Cementerio; 3- Museo. Referencias de especies de líquenes en Anexo II. Unidades de muestreo $\mathrm{n}=243$. 


\section{V.1.1.4. Brandsen}

\section{$\underline{\text { Composición de especies }}$}

Se encontraron 5 especies de líquenes, de las cuales todas presentaron morfología crustosa, de estas 4 son especies epilíticas y 1 endolítica (tabla V.10), De estas especies $C$. teicholyta presentó la mayor frecuencia y cobertura, mientras las otras especies no superaron el $10 \%$ de cobertura. La especie C. teicholyta se encontró en 10 de los 11 sitios, de estos en 7 sitios fue la especie con mayor cobertura, de los restantes $F$. austrocitrina y $A$. holocarpa fueron las especies dominantes en 2 sitios cada una (tabla V.11).

Tabla V.10. Especies encontradas en Brandsen, cobertura (\%) promedio (Cob), frecuencia absoluta (Fre), frecuencia porcentual (Fre \%) y tipo morfológico. Unidades de muestreo $n=67$.

\begin{tabular}{lcccc}
\hline & Cob & Fec & Frec\% & Morfología \\
\hline Caloplaca teicholyta & 26,3 & 51 & 82,3 & Crustosa \\
Athallia holocarpa & 10,5 & 16 & 25,8 & Crustosa \\
Flavoplaca austrocitrina & 8,5 & 40 & 64,5 & Crustosa \\
Staurothele monosporoides & 2,2 & 8 & 12,9 & Crustosa \\
Lecania erysibe & 0,3 & 2 & 3,2 & Crustosa \\
\hline
\end{tabular}

Tabla V.11. En la localidad de Brandsen cobertura (\%) promedio de especies por sitio de muestreo.

\begin{tabular}{lccccc}
\hline & $\begin{array}{c}\text { Flavoplaca } \\
\text { austrocitrina }\end{array}$ & $\begin{array}{c}\text { Caloplaca } \\
\text { teicholyta }\end{array}$ & $\begin{array}{c}\text { Staurothele } \\
\text { monosporoides }\end{array}$ & $\begin{array}{c}\text { Lecania } \\
\text { eryvise }\end{array}$ & $\begin{array}{c}\text { Athallia } \\
\text { holocarpa }\end{array}$ \\
\hline Tumba 1 $(n=2)$ & 35 & 3 & 17,5 & - & - \\
Tumba 2 $(n=8)$ & - & - & - & 3,25 & 69,25 \\
Tumba 3 $(n=6)$ & 14,17 & 35,83 & 0,83 & - & - \\
Tumba 4 $(n=6)$ & 6,67 & 50,83 & - & - & - \\
Tumba 5 $(n=6)$ & 1,17 & 40 & - & - & - \\
Tumba 6 $(n=6)$ & 0,33 & 51,67 & - & - & - \\
Tumba 7 $(n=7)$ & 1 & 15 & - & - & - \\
Tumba 8 $(n=6)$ & 1,5 & 27,5 & - & 0,83 & -
\end{tabular}




\begin{tabular}{lccccc} 
Tumba $9(n=6)$ & 0,7 & 56,7 & - & - & - \\
Tumba 10 $(n=6)$ & 25,8 & 9,3 & 2,5 & - & - \\
Tumba 11 $(n=6)$ & 10 & - & 3,75 & - & 50,6 \\
\hline
\end{tabular}

\section{$\underline{\text { Relación con las variables ambientales }}$}

Se encontró mayor riqueza y diversidad sobre la superficie de granito mientras que sobre el sustrato cemento se encontró mayor equitatividad (tabla V.12). Se realizo un test de $T$ entre las coberturas de las variables granito y mortero no encontrándose diferencia significativa entre estas dos ( $p>0,5)$. La inclinación vertical solo contaba con 2 unidades de muestreo con orientación $\mathrm{E}$ y sustrato granito, y al no contar con un mínimo de 3 unidades no se la usó para este tipo de análisis.

EI ISA para la variable material mostro que las especies $C$. teicholyta para mortero y $A$. holocarpa para granito fueron las que obtuvieron IV significativos. Mientras que para la variable inclinación la especie $\mathrm{S}$. monosporoides fue la única que presento un IV significativo para vertical.

Tabla V.12. Riqueza (S), diversidad ( $\left.\mathrm{H}^{\prime}\right)$ y equitatividad $\left(J^{\prime}\right)$ sobre los distintos sustratos en la localidad de Brandsen.

\begin{tabular}{lccc}
\hline & S & H' $^{\prime}$ & J' \\
\hline Total & 5 & 1,09 & 0,675 \\
Granito & 5 & 0,568 & 0,352 \\
Mortero & 3 & 0,454 & 0,413 \\
\hline
\end{tabular}

El CCA con todas las unidades de muestreo relevadas no pudo realizarse por falta de variables ambientales mientras que el PCA no mostró una separación entre las unidades de muestreo por lo que se consideró no informativo. En el análisis de NMS (Non-metric multidimensional scaling) sí se observó una separación (figura V.4) de 2 grupos bien diferenciados sobre el eje 1. El primero, más relacionado a la especie $C$. teicholyta junto con la variable mortero ya que solo se presentó sobre este sustrato. Mientras que el otro grupo 
estaría asociado al sustrato granito y a la especie $A$. holocarpa que solo se encontró sobre este sustrato al igual que la especie L. erysibe aunque esta ultima con una cobertura mucho menor. Las especies $S$. monosporoides y $F$. austrocitrina se encontraban en ambos sustratos por lo que se las encuentran en la zona media entre ambas partes. Las variables de inclinación no se aprecian dentro del análisis por la baja variabilidad de las mismas, siendo que la variable vertical contaba con solo 2 unidades de muestreo.

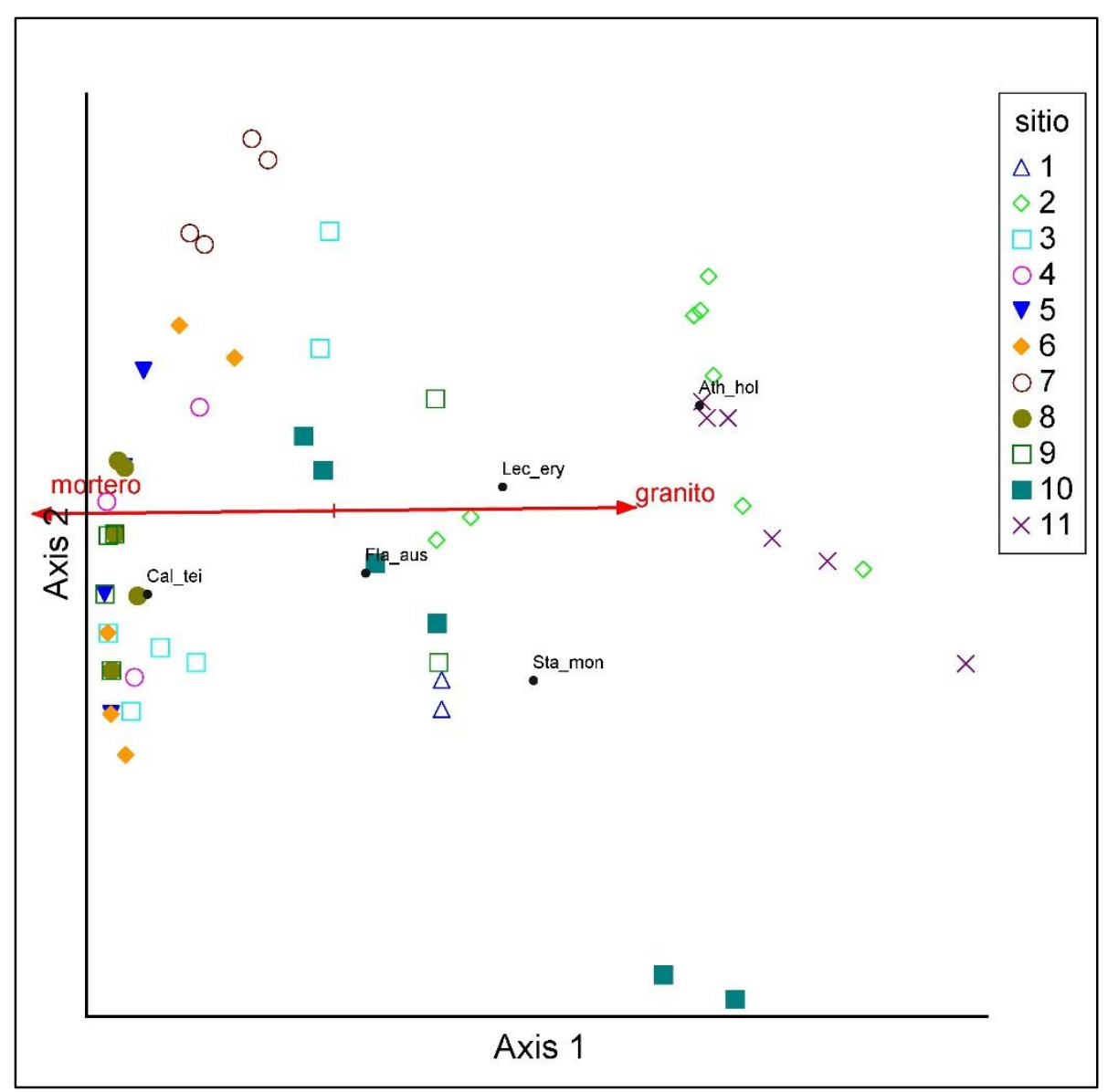

Figura V.4. Análisis NMS de la localidad Brandsen. Sitios 1- tumba 1; 2- tumba 2; 3- tumba 3; 4- tumba 4; 5- tumba 5; 6- tumba 6; 7- tumba 7; 8- tumba 8; 9- tumba 9; 10- tumba 10;11tumba 11. Referencias de especies de líquenes en Anexo II. Unidades de muestreo $n=67$.

\section{V.1.1.5. General Belgrano}

\section{Composición de especies}


Se encontraron 5 especies de las cuales todas presentaron morfología crustosa, de éstas, 2 son especies endolíticas y 3 epilíticas. De estas especies $F$. austrocitrina presenta las mayores cobertura y frecuencia seguida por $M$. dispersa (tabla V.13). Las especies F. austrocitrina, M. dispersa y $C$. teicholyta se encontraron en todos los sitios de muestreo, mientras que la especie Lecania erysibe solo se encontró sobre el sitio tumba 1. En todos los sitios la especie $F$. austrocitrina fue la que presentó mayor cobertura promedio (tabla V.14).

Tabla V.13. Especies encontradas en General Belgrano, cobertura (\%) promedio (Cob), frecuencia absoluta (Fre) y frecuencia porcentual (Fre \%) y tipo morfológico. Unidades de muestreo $\mathrm{n}=54$.

\begin{tabular}{lcccc}
\hline & Cob & Fre & Fre\% & Morfología \\
\hline Flavoplaca austrocitrina & 31,01 & 54 & 100 & Crustoso \\
Myriolecis dispersa & 8,33 & 44 & 81 & Crustoso \\
Lecania erysibe & 2,611 & 9 & 17 & Crustoso \\
Caloplaca teicholyta & 4,24 & 38 & 70 & Crustoso \\
Staurothele monosporoides & 6,94 & 27 & 50 & Crustoso \\
\hline
\end{tabular}

Tabla V.14. En la localidad de General Belgrano, cobertura (\%) promedio de especies por sitio de muestreo.

\begin{tabular}{lccc}
\hline & $\begin{array}{c}\text { Tumba 1 } \\
(\mathrm{n}=30)\end{array}$ & $\begin{array}{c}\text { Tumba 2 } \\
(\mathrm{n}=15)\end{array}$ & $\begin{array}{c}\text { Tumba 3 } \\
(\mathrm{n}=9)\end{array}$ \\
\hline Flavoplaca austrocitrina & 38,83 & 19,33 & 24,44 \\
Myriolecis dispersa & 5 & 18 & 3,33 \\
Caloplaca teicholyta & 4,47 & 5,93 & 0,67 \\
Staurothele monosporoides & 8,45 & 5,33 & 5,56 \\
Lecania erysibe & 4,70 & - & - \\
\hline
\end{tabular}

\section{$\underline{\text { Relación con las variables ambientales }}$}

Solo se registraron líquenes en las orientaciones NW y SE. La riqueza fue igual sobre ambas orientaciones y en todas las alturas, mientras que las 
mayores diversidad y equitatividad se encontraron en la orientación SE y a 1,5 m del suelo (altura 3) (tabla V.15).

Se realizó la prueba de Kruskal-Wallis usando las coberturas de las especies, entre las alturas, las orientaciones y la inclinación en todos los casos el resultado de la prueba fue que no existieron diferencias significativas ( $p>$ 0,05).

EI ISA para para la variable altura no mostro ninguna especie cuyo IV sea significativo, mientras que para la varible orientación se encontró que las especies $F$. austrocitrina para NW y $C$. teicholyta para SE presentaron IV significativos.

Tabla V.15. Riqueza (S), diversidad ( $\left.\mathrm{H}^{\prime}\right)$ y equitatividad $(\mathrm{J}$ ') total de la localidad General

Belgrano, sobre distintas orientaciones y alturas sobre el suelo.

\begin{tabular}{lccc}
\hline & S & H' & J' \\
\hline Altura 1 & 5 & 1,03 & 0,69 \\
Altura 2 & 5 & 1,26 & 0,78 \\
Altura 3 & 5 & 1,27 & 0,79 \\
NW & 4 & 0,54 & 0,39 \\
SE & 4 & 1,31 & 0,95 \\
Total & 5 & 1,23 & 0,76 \\
\hline
\end{tabular}

En el CCA (figura V.5) la variable altura 2 quedó afuera por la baja correlación que presentaban. Las variables SE y NW se presentaron una en contraposición sobre el eje 1. Las especies se separaron en 2 grupos, uno relacionado a la variable SE donde se encuentran las especies $M$. dispersa, $C$. teicholyta, S. monosporoides, mientras que $F$. austrocitrina y L. erysibe se han mostrado relacionadas a la variable NW siendo esta última especie el único lugar donde se la encontró. La mayoría de las unidades de muestreo se encuentran agrupadas alrededor de la variable altura $1(0,5 \mathrm{~m})$ donde la diversidad y la equitatividad son bajas con la excepción de las unidades de 
muestreo donde se encontró a $L$. erysibe, que se aprecian algo separadas del resto.

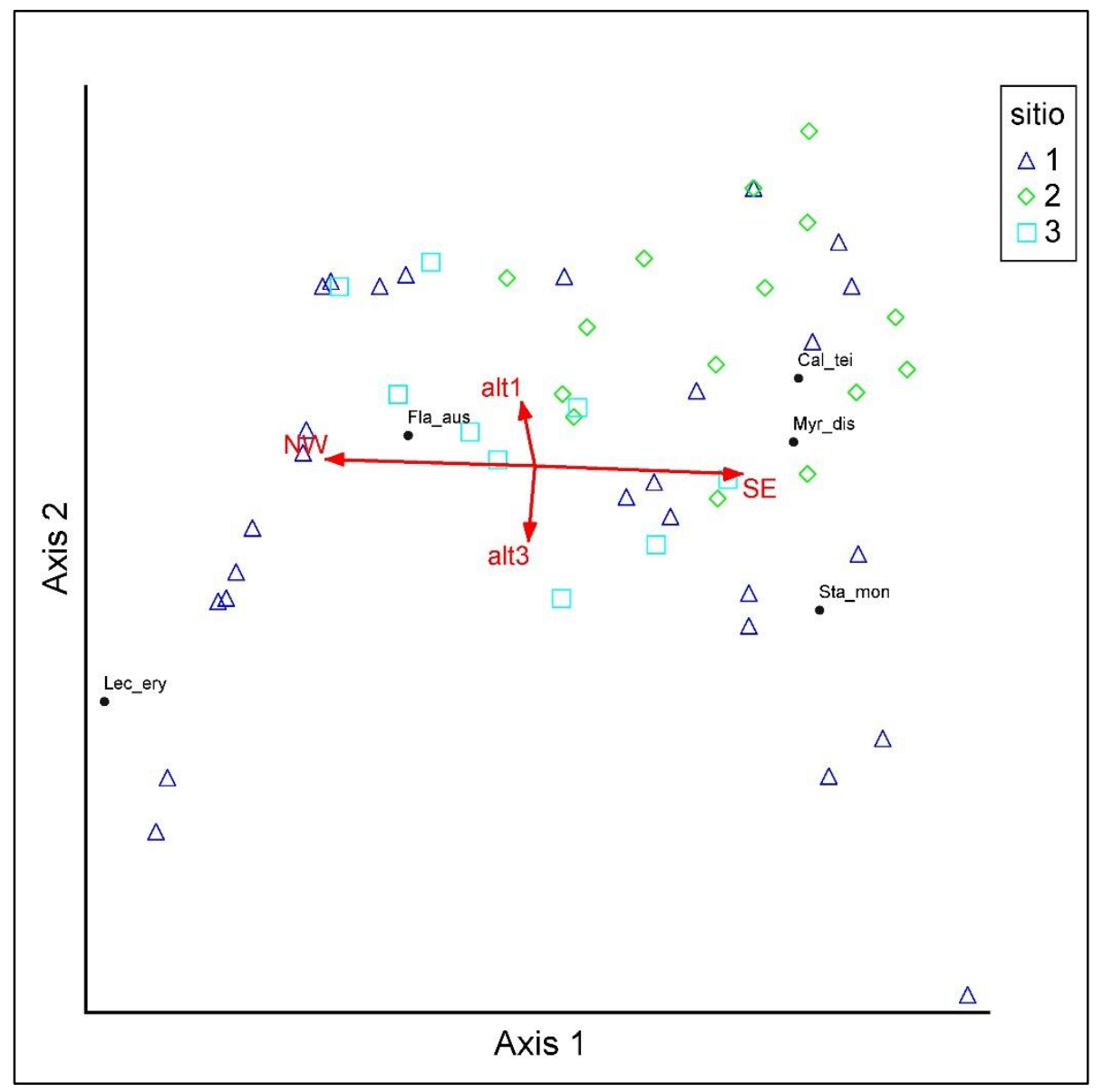

Figura V.5. Análisis de CCA en la localidad de General Belgrano. Sitios: 1- tumba 1; 2- tumba 2; 3- tumba 3. Referencias de especies de líquenes en Anexo II. Unidades de muestreo $n=54$.

\section{V.1.1.6. Azul}

\section{Composición de especies}

Se encontraron un total de 13 especies de las cuales 3 fueron foliosas y 10 crustosas, de éstas 5 fueron epíliticas y 5 endolíticas. La especie con mayor cobertura promedio y frecuencia fue $F$. austrocitrina, seguida por $C$. teicholyta (tabla V.16). De los sitios muestreados, los ubicados en el cementerio fueron 
los de mayor riqueza, mientras que los de la estación de trenes fueron los de menor riqueza. El cementerio, además, es el único lugar donde se encontraron especies foliosas, ya que en el resto se hallaron solo crustosas. F. austrocitrina fue la especie con mayor cobertura promedio, y junto con $M$. dispersa fueron las únicas compartidas por todos los sitios en la localidad de Azul (tabla V.17).

Tabla V.16. Especies encontradas en Azul, cobertura (\%) promedio (Cob), frecuencia absoluta (Fre), frecuencia porcentual (Fre \%) y tipo morfológico. Unidades de muestreo $\mathrm{n}=385$

\begin{tabular}{lcccc}
\hline & Cob & Fre & Fre \% & Morfología \\
\hline Flavoplaca austrocitrina & 36,68 & 327 & 84,94 & Crustoso \\
Candelariella aurella & 0,156 & 6 & 1,56 & Crustoso \\
Graphis anfractuosa & 0,052 & 2 & 0,52 & Crustoso \\
Myriolecis dispersa & 0,85 & 72 & 18,70 & Folioso \\
Lecania erysibe & 0,078 & 4 & 1,04 & Crustoso \\
Caloplaca teicholyta & 4,84 & 151 & 39,23 & Crustoso \\
Staurothele monosporoides & 3,21 & 54 & 14,03 & Crustoso \\
Crustoso sp. 4 & 0,003 & 1 & 0,26 & Crustoso \\
Oxneria fallax & 0,929 & 30 & 7,79 & Crustoso \\
Phaeophyscia choantha & 0,078 & 3 & 0,779 & Folioso \\
Lecanora sp.1 & 0,421 & 15 & 3,89 & Crustoso \\
Buellia sp.1 & 0,17 & 6 & 1,56 & Crustoso \\
Xanthoparmelia farinosa & 0,078 & 2 & 0,52 & Folioso \\
\hline
\end{tabular}

Tabla V.17. Cobertura relativa media (\%) de cada especie por sitio de muestreo, de la localidad de Azul.

\begin{tabular}{lcccc}
\hline & $\begin{array}{c}\text { Edificio } \\
(\mathrm{n}=18)\end{array}$ & $\begin{array}{c}\text { Costanera } \\
(\mathrm{n}=42)\end{array}$ & $\begin{array}{c}\text { Cementerio } \\
(\mathrm{n}=272)\end{array}$ & $\begin{array}{c}\text { Estación } \\
(\mathrm{n}=53)\end{array}$ \\
\hline Flavoplaca austrocitrina & 53,6 & 65 & 26,31 & 61,69 \\
Myriolecis dispersa & 1,44 & 1,33 & 0,88 & 0,094 \\
Candelariela aurella & 0,278 & 1,19 & 0,018 & - \\
Caloplaca teicholyta & - & 0,024 & 6,54 & 1,57 \\
Staurothele monosporoides & - & 3,12 & 4,06 & - \\
Oxneria fallax & - & - & 1,32 & - \\
Lecanora sp.1 & - & - & 0,59 & - \\
Buellia sp.1 & - & - & 0.24 & - \\
Phaeophyscia chloantha & - & - & 0.11 & - \\
Xanthoparmelia farinosa & - & - & 0.11 & - \\
Crustoso sp. 4 & - & - & 0,0037 & - \\
Lecania erysibe & - & 0,71 & - & - \\
& & $\sim$ & &
\end{tabular}


$\underline{\text { Relación con las variables ambientales }}$

La mayor riqueza se encontró en los muros de orientación vertical, sobre mortero de cemento, a $1 \mathrm{~m}$ del suelo (altura 2) y orientación NE. La diversidad fue mayor a 1,5 m del suelo (altura 3), inclinación vertical, sobre otros tipos de materiales y orientación SW. La equitatividad fue mayor en la altura 3, inclinación horizontal, sobre otros sustratos y en orientación SE (tabla V.18)

Se realizó la prueba de Kruskal-Wallis usando las coberturas de las especies, entre las alturas, las orientaciones, la inclinación y el tipo de material, en todos los casos el resultado de la prueba fue que no existía diferencia significativa $(p>0,05)$.

EI ISA para la variable sustrato mostró a las siguientes especies con valores de IV significativo: $F$. austrocitrina para mortero, $M$. dispersa para ladrillo, C. teicholyta para mortero 2 y $S$. monosporoides para granito. Para la variable orientación solo las especies $F$. austrocitrina para $\mathrm{N}$ y $C$. teicholyta para SE obtuvieron valores de IV significativos. En cuanto a la variable inclinación la única uq presento un IV significativo fue $F$. austrocitrina para horizontal.

Tabla V.18. Riqueza (S), diversidad (H') y equitatividad (J') total de la localidad Azul sobre distintas inclinaciones, orientaciones, materiales y alturas sobre el suelo. Unidades de muestreo $n=$ 385.

\begin{tabular}{lccc}
\hline & S & H' & J' \\
\hline Mortero & 9 & 0,51 & 0,23 \\
Ladrillo & 4 & 0,43 & 0,31 \\
Mortero2 & 3 & 0,87 & 0,79 \\
Granito & 7 & 1,22 & 0,63 \\
Horizontal & 6 & 0,783 & 0,437 \\
Vertical & 12 & 0,88 & 0,354 \\
Altura 1 & 9 & 0,904 & 0,411 \\
Altura 2 & 12 & 0,70 & 0,28
\end{tabular}




\begin{tabular}{lccc} 
Altura 3 & 11 & 0,99 & 0,42 \\
$\mathbf{N}$ & 2 & - & - \\
$\mathbf{N E}$ & 12 & 0,688 & 0,228 \\
$\mathbf{N W}$ & 5 & 0,938 & 0,582 \\
$\mathbf{E}$ & 4 & 0,08 & 0,05 \\
$\mathbf{S E}$ & 9 & 1,27 & 0,579 \\
$\mathbf{S W}$ & 6 & 0,99 & 0,552 \\
Total & 13 & 0,866 & 0,334 \\
\hline
\end{tabular}

En el análisis de CCA (figura V.6) sobre el eje 1 tuvieron mayor peso las variables relacionadas al tipo de sustrato, hacia el extremo negativo la variable mortero y hacia el positivo el granito. Sobre la variable mortero se agruparon las especies $F$. austrocitrina $C$. aurella, $P$. chloantha, crustoso sp. y L. erysibe. La variable granito se presentó asociada a las especies $X$. farinosa, $S$. monosporoides y Buellia sp. Sobre el sector negativo del eje 2 cobraron importancia las variables mortero2 (con conchilla) y la exposición SE que se asociaron a las especies C. teicholyta, Lecanora sp. y $G$. anfractuosa. La dirección contraria se asoció a la variable NE la cual no mostró especies asociadas de forma directa. La estructura del gráfico se dispuso en forma de "L" tanto los sitios como las especies, esta parece tener relación con los tipos de sustratos encontrados, donde el sector horizontal está asociado a la variable granito, la vertical a la variable mortero2 y la unión entre estas con la variable mortero. 


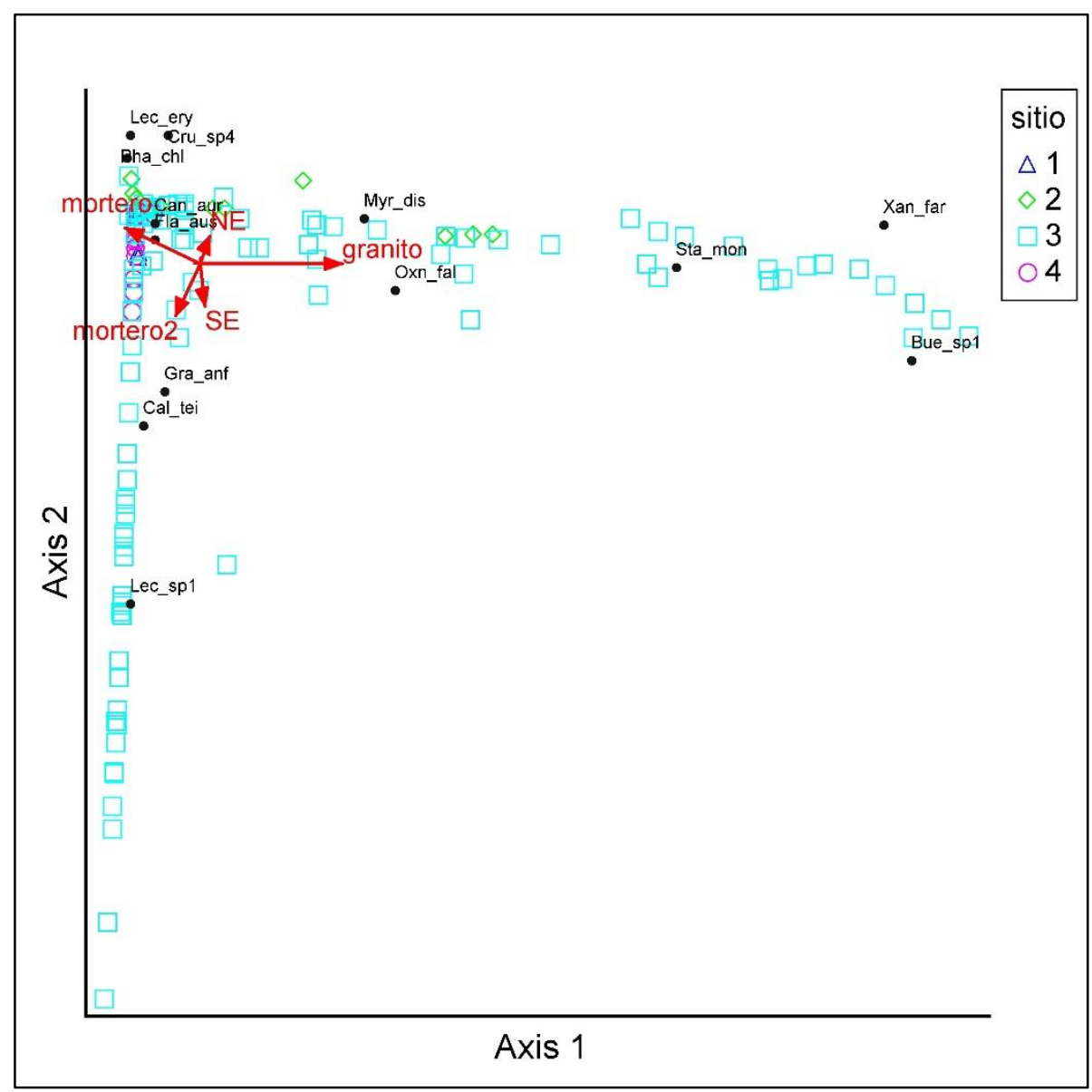

Figura V.6. Análisis de CCA, de las unidades de muestreo relevadas en la localidad de Azul en los sitios (1) edificio costanera; (2) costanera; (3) cementerio y (4) estación ferroviaria.

Referencias de especies de líquenes en Anexo II. Unidades de muestreo $n=385$.

\section{V.1.1.7. Tandil}

\section{Composición de especies}

Se encontraron un total de 16 especies: 4 foliosas y 12 crustosas, de estas últimas 4 fueron endolíticas y 8 epilíticas. La especie con mayor cobertura promedio fue $F$. austrocitrina seguida por $O$. fallax, mientras que la especie con mayor frecuencia fue $F$. austrocitrina seguida por $C$. teicholyta (tabla V.19). En el cementerio fue donde mayor riqueza se registró y solo compartió 4 especies ( $F$. autrocitrina, $M$. dispersa, Acarospora strigosa y $A$. holocarpa) con los sitios ubicados en la UNICEN. Las especies con la mayor 
cobertura en cada sitio fueron: $F$. austrocitrina en los edificios de la UNICEN y C. teicholyta en los del cementerio (tabla V.20).

Tabla V.19. Especies encontradas en Tandil, cobertura (\%) promedio (Cob), frecuencia absoluta (Fre), frecuencia porcentual (Fre \%) y tipo morfológico. Unidades de muestreo $\mathrm{n}=187$.

\begin{tabular}{lcccl}
\hline & Cob & Fre & Fre\% & Morfología \\
\hline Flavoplaca austrocitrina & 30,66 & 162 & 86,6 & Crustoso \\
Caloplaca teicholyta & 6,18 & 59 & 31,6 & Crustoso \\
Myriolecis dispersa & 1,53 & 46 & 24,6 & Crustoso \\
Dirinaria sp. & 1,32 & 16 & 8,6 & Folioso \\
Sarcogyne regularis & 0,65 & 23 & 12,3 & Crustoso \\
Acarospora strigata & 0,35 & 13 & 7,0 & Crustoso \\
Oxneria fallax & 0,31 & 13 & 7,0 & Folioso \\
Xanthoparmelia ulcerosa & 0,14 & 1 & 0,5 & Folioso \\
Monoblastia echinulospora & 0,05 & 6 & 3,2 & Crustoso \\
Athallia holocarpa & 0,05 & 10 & 5,3 & Crustoso \\
Rinodina bischoffii & 0,05 & 4 & 2,1 & Crustoso \\
Lecania erysibe & 0,05 & 5 & 2,7 & Crustoso \\
Phaeophyscia chloantha & 0,04 & 7 & 3,7 & Folioso \\
Myriolecis hagenii & 0,02 & 3 & 1,6 & Crustoso \\
Staurothele monosporoides & 0,01 & 1 & 0,5 & Crustoso \\
\hline
\end{tabular}

Tabla V.20. Cobertura relativa media (\%) de cada especie por sitio de muestreo, de la localidad Tandil

\begin{tabular}{lcc}
\hline & $\begin{array}{c}\text { Cementerio } \\
(\mathrm{n}=103)\end{array}$ & $\begin{array}{c}\text { UNICEN } \\
(\mathrm{n}=84)\end{array}$ \\
\hline Flavoplaca autrocitrina & 5,86 & 61,07 \\
Myriolecis dispersa & 0,33 & 3 \\
Acarospora strigata & 0,01 & 0,77 \\
Athallia holocarpa & 0,078 & 0,024 \\
Caloplaca teicholyta & 11,21 & - \\
Dirinaria sp. & 2,39 & - \\
Oxneria fallax & 0,56 & - \\
Xanthoparmelia ulcerosa & 0,25 & - \\
Rinodina bischoffii & 0,097 & - \\
Monoblastia echinulospora & 0,097 & - \\
Phaeophyscia chloantha & 0,068 & - \\
Staurothele monosporoides & 0,01 & -
\end{tabular}


Sarcogyne regularis

Lecania erysibe

Myriolecis hagenii
1,44

0,11

0,035

\section{$\underline{\text { Relación con las variables ambientales }}$}

La mayor riqueza fue encontrada en la orientación W, inclinación vertical, y a 1,5 (altura 3). La mayor diversidad se encontró en la orientación $\mathrm{N}$, inclinación vertical y altura 3. En cuanto a la equitatividad, ésta fue mayor en orientación $\mathrm{N}$ inclinación vertical y altura 1 . Las riqueza, diversidad y equitatividad fueron mayores sobre granito que sobre mortero (tabla V.21).

Se realizó la prueba de Kruskal-Wallis usando las coberturas de las especies, entre las alturas, las orientaciones, la inclinación y el tipo de material, en todos los casos el resultado de la prueba resultó en diferencias no significativas $(p>0,05)$.

EI ISA para la variable orientación motró que las siguientes especies presentaron IV significativos: Dirinaria sp. para $\mathrm{N}, X$. ulcerosa para W y $C$. teicholyta para E. Para la variable altura, las especies que mostraron IV significativos fueron M. echinulospora para altura 1 y $C$. teicholyta para altura 2. En cuanto a la variable sustrato se encontró que las especies que presentaron los mayores valores de IV significativos fueron $F$. austrocitrina para mortero y C. teicholyta para granito. Por otro lado para la variable inclinación se encontró que las especies Dirinaria sp. para vertical y $F$. austrocitrina para horizontal mostraron los mayores valores de IV significativos.

Tabla V.21. Riqueza (S), diversidad (H') y equitatividad (J') sobre distintos materiales, orientaciones, inclinaciones y alturas, de la localidad

Tandil.

\begin{tabular}{lccc}
\hline & S & H'$^{\prime}$ & J' \\
\hline Granito & 11 & 1,56 & 0,65 \\
Mortero & 9 & 0,71 & 0,33
\end{tabular}




\begin{tabular}{lccc} 
Horizontal & 7 & 0,355 & 0,183 \\
Vertical & 12 & 1,279 & 0,515 \\
Altura 1 & 9 & 1,26 & 0,573 \\
Altura 2 & 8 & 1,056 & 0,508 \\
Altura 3 & 12 & 1,421 & 0,572 \\
S & 4 & 0,67 & 0,48 \\
W & 12 & 1,252 & 0,504 \\
N & 7 & 1,395 & 0,719 \\
E & 3 & 0,209 & 0,19 \\
Total & 15 & 0,93 & 0,35 \\
\hline
\end{tabular}

El análisis de CCA (figura V.7) separó sobre el eje 1 las unidades de muestreo por el el tipo de sustrato, contraponiendo el mortero y el granito. El eje 2 presenta influencia sobre la mayoría de los cuadrados de muestreo, sobre este eje muestran mayor influencia las variables de orientaciones horizontal y vertical, acompañando a la variable vertical se encuentran las variables $S, E, N$ y alturas (1 y 2). En síntesis, en esta localidad podemos identificar 3 grupos en los cuales se acomodan las especies y los muestreos, uno relacionado a la variable horizontal con las especies $F$. austrocitrina, $S$. regularis, $M$. dispersa, $A$. strigata, $M$. hageni y $L$. erysibe, otro relacionado a la variable vertical con las especies $C$. teicholyta, $M$. echinulospora y $A$. holocarpa. El último grupo se asoció a la variable granito conformado por las especies $O$. fallax, $X$. ulcerosa, R. bischoffii, P. chloantha, Dirinaria sp. y S. monosporoides. 


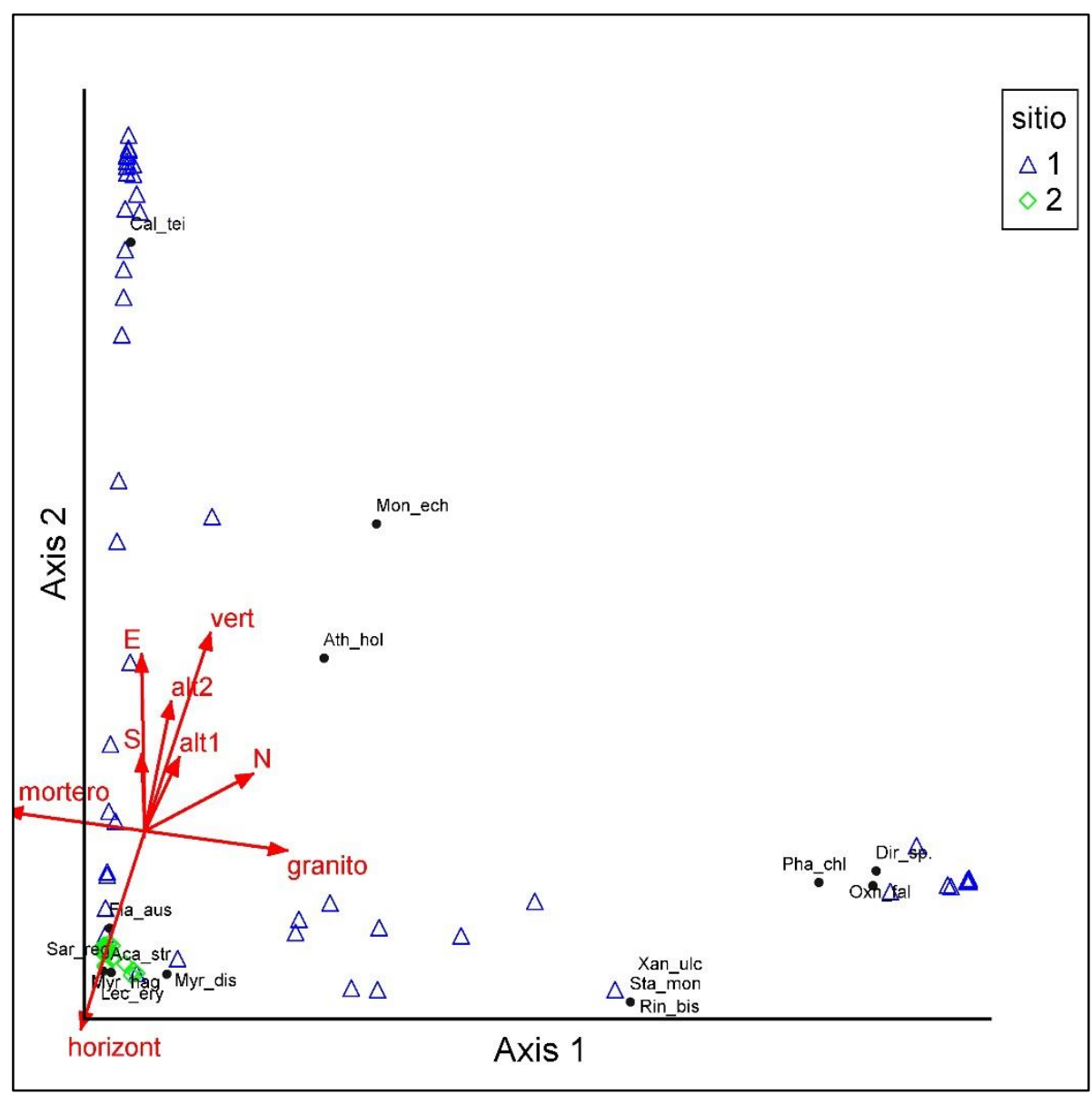

Figura V.7. Análisis de CCA de la localidad Tandil. Sitio 1- cementerio; 2- UNICEN. Referencias de especies de líquenes en Anexo II. Unidades de muestreo $n=187$.

\section{V.1.1.8. Saldungaray}

\section{Composición de especies}

Se encontraron un total de 9 especies de las cuales 2 fueron foliosas y 7 son crustosas, de estas 4 son epiliticas y 3 endoliticas. De las especies encontradas $F$. austrocitrina presentó las mayores cobertura y frecuencia seguida por $C$. teicholyta (tabla V.22). En cuanto a los sitios, las especies que se encontraron en todos fueron $M$. dispersa y $F$. austrocitrina, mientras que la especie $A$. altoandina solo fue encontrada en el sitio tumba 4 . La especie $F$. austrocitrina presentó la mayor cobertura en 2 de los 7 sitios, mientras que $C$. teicholyta alcanzó la mayor cobertura en estos 2 sitios (Tabla V. 23). 
Tabla V.22. Especies encontradas en Saldungaray, cobertura (\%) promedio (Cob), frecuencia absoluta (Fre), frecuencia porcentual (Fre \%) y tipo morfológico. Unidades de muestreo $n=145$.

\begin{tabular}{lcccc}
\hline & Cob & Fre & Fre\% & morfología \\
\hline Flavoplaca austrocitrina & 58,28 & 145 & 100 & Crustoso \\
Caloplaca teicholyta & 10,71 & 70 & 48,3 & Crustoso \\
Myriolecis dispersa & 2,06 & 45 & 29 & Crustoso \\
Staurothele monosporoides & 1,36 & 19 & 13,1 & Crustoso \\
Athallia holocarpa & 0,17 & 10 & 6,9 & Crustoso \\
Oxneria fallax & 0,08 & 8 & 5,5 & Folioso \\
Lecania erysibe & 0,08 & 6 & 4,1 & Crustoso \\
Acarospora altoandina & 0,07 & 6 & 4,1 & Crustoso \\
Physcia tribacina & 0,10 & 5 & 3,4 & Folioso \\
\hline
\end{tabular}

Tabla V.23. Cobertura relativa media (\%) de cada especie por sitio de muestreo, de la localidad Saldungaray.

\begin{tabular}{|c|c|c|c|c|c|c|c|}
\hline & $\begin{array}{c}\text { Bóveda1 } \\
(\mathrm{n}=39)\end{array}$ & $\begin{array}{c}\text { Bóveda2 } \\
(n=27)\end{array}$ & $\begin{array}{c}\text { Bóveda3 } \\
(n=36)\end{array}$ & $\begin{array}{c}\text { Tumba } 1 \\
(n=11)\end{array}$ & $\begin{array}{c}\text { Tumba } 2 \\
(n=10)\end{array}$ & $\begin{array}{c}\text { Tumba } 3 \\
(n=12)\end{array}$ & $\begin{array}{c}\text { Tumba } 4 \\
(n=10)\end{array}$ \\
\hline $\begin{array}{l}\text { Flavoplaca } \\
\text { austrocitrina }\end{array}$ & 70,4 & 73,2 & 74,4 & 7,36 & 22 & 26,3 & 43,5 \\
\hline Myriolecis dispersa & 0,23 & 0,85 & 0,25 & 1,55 & 6 & 0,08 & 18 \\
\hline Caloplaca teicholyta & 1,97 & 7,74 & 1,97 & 82,3 & 25,5 & 3 & \\
\hline $\begin{array}{l}\text { Physcia tribacina } \\
\text { Staurothele }\end{array}$ & 0,13 & 0,26 & - & - & 0,1 & - & 0,1 \\
\hline monosporoides & 0,18 & 0,74 & - & - & - & 14,2 & - \\
\hline Athallia holocarpa & 0,05 & - & 0,53 & - & - & 0,25 & - \\
\hline Lecania erysibe & 0,05 & - & 0,28 & - & - & - & - \\
\hline Acarospora altoandina & - & - & - & - & - & - & 1 \\
\hline
\end{tabular}

$\underline{\text { Relación con las variables ambientales }}$

La mayor riqueza se encontró en la inclinación vertical, sobre sustrato aglomerado y en la orientación $\mathrm{N}$; no hubo diferencias entre alturas. La diversidad y equitatividad fueron mayores en $0,5 \mathrm{~m}$ al suelo (alt 1 ), en los muros verticales de exposición $\mathrm{N}$ y en el sustrato aglomerado (tabla V.24). 
Se realizó la prueba de Kruskal-Wallis usando las coberturas de las especies, entre las alturas, las orientaciones, y la inclinación el tipo de material, en todos los casos el resultado de la prueba fue que no existía diferencia significativa $(p>0,05)$.

EI ISA para la variable altura dió como resultado a la especie $F$. austrocitrina para altura 3 con un IV significativo. Para la variable inclinación las especies $F$. austrocitrina para vertical y $C$. teicholyta para horizontal dieron IV significativos. En cuanto al sustrato se encontró que las especies que presentaron IV significativos fueron $F$. austrocitrina para mortero y $M$. dispersa para aglomerado.

Tabla V.24. Riqueza (S), diversidad $\left(H^{\prime}\right)$ y equitatividad

$\left(J^{\prime}\right)$ de la localidad Saldungaray, para inclinación, alturas y orientaciones. Unidades de muestreo $n=145$.

\begin{tabular}{lccc}
\hline & S & H' & J' \\
\hline Aglomerado & 7 & 1,02 & 0,52 \\
Mortero & 8 & 0,55 & 0,266 \\
Horizontal & 7 & 1,076 & 0,553 \\
Vertical & 8 & 0,269 & 0,129 \\
Altura 1 & 8 & 0,291 & 0,14 \\
Altura 2 & 8 & 0,249 & 0,1198 \\
Altura 3 & 8 & 0,265 & 0,128 \\
N & 7 & 0,344 & 0,177 \\
E & 4 & 0,08 & 0,059 \\
W & 6 & 0,151 & 0,216 \\
S & 6 & - & - \\
Total & 9 & 0,671 & 0,305 \\
\hline
\end{tabular}

Del análisis CCA (figura V.8) se aprecia una separación sobre el eje 1 por las variables Vertical y horizontal, mientras que sobre el eje 2 se separan por las variables tipo de sustrato (aglomerado y mortero). Las variables de altura y orientación están agrupadas junto con la variable vertical. Las especies se separaron en 3 grupos, uno relacionando a las especies $F$. austrocitrina, $L$. 
erysibe, P. tribacia, O. fallax y A. holocarpa cerca del centro de las variables ya que estas especies se encontraron en ambos sustratos y ambas inclinaciones, por otro lado se encuentra $C$. teicholyta relacionado a las variables horizontal y mortero donde en ambas consigó su mayor cobertura y por último otro grupo conformado por M. dispersa, S. monosporoides y A. altoandina relacionado a la variable aglomerado donde éstas mostraron su mayor porcentaje de cobertura.

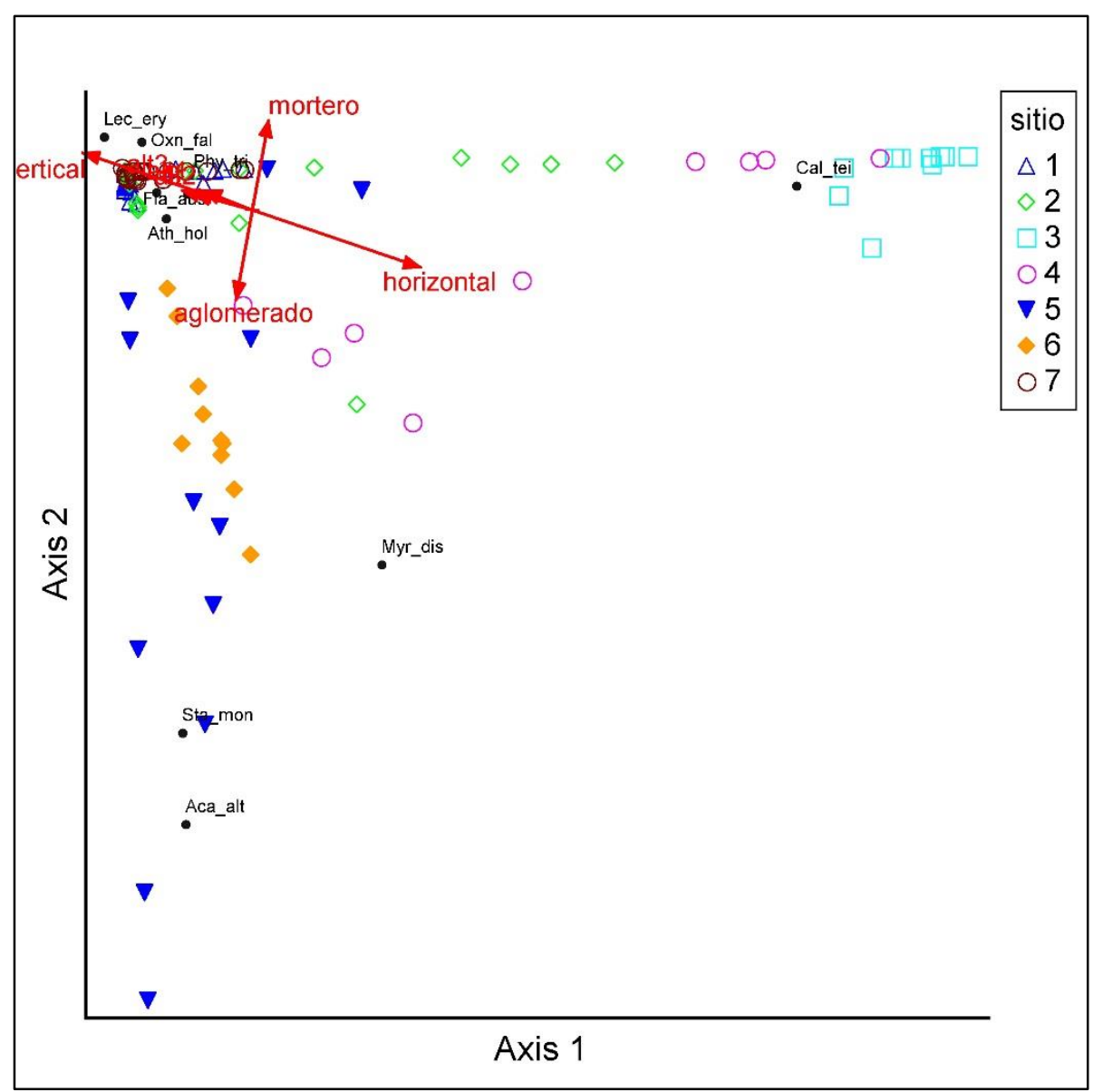

Figura V.8. Analisis CCA de la localidad de Saldungaray. Sitios: 1- Bóveda 1; 2- Bóveda 2; 3-

Tumba 1; 4- Tumba 2; 5- Tumba 3; 6- Tumba 4; 7-Bóveda 3. Referencias de especies de líquenes en Anexo II. Unidades de muestreo $n=145$.

\section{V.1.1.9. Parque Provincial Ernesto Tornquist}

\section{Composición de especies}


Se encontraron 4 especies de morfología crustosa (tabla V.25), entre las cuales $M$. dispersa es endolítica, mientras que las restantes son epilíticas; dentro de estas últimas Scytinium rogersii es gelatinosa. F. austrocitrina obtuvo las mayores coberturas y frecuencia (tabla V.26).

Tabla V.25. Especies encontradas sobre construcciones en el Parque Provincial Ernesto Tornquist, cobertura (\%) promedio (Cob), frecuencia absoluta (Fre), frecuencia porcentual (Fre \%) y tipo morfológico. Unidades de muestreo $\mathrm{n}=10$.

\begin{tabular}{lcccc}
\hline & Cob & Fre & Fre \% & Morfología \\
\hline Flavoplaca austrocitrina & 46 & 10 & 100 & Crustoso \\
Scytinium rogersii & 3 & 3 & 30 & Crustoso \\
Myriolecis dispersa & 6 & 7 & 70 & Crustoso \\
Staurothele monosporoides & 6,5 & 7 & 70 & Crustoso \\
\hline
\end{tabular}

Tabla V.26. Riqueza

(S), diversidad (H') y equitatividad (J') de construcciones en el

\begin{tabular}{cc}
\multicolumn{2}{c}{ PPET } \\
\hline & Total \\
\hline $\mathbf{S}$ & 4 \\
H'$^{\prime}$ & 0,83 \\
J' & 0,59 \\
\hline
\end{tabular}

\section{V.1.1.10. Tornquist}

\section{Composición de especies}

Se encontraron 5 especies de líquenes, 1 de morfología foliosa y 4 especies de morfología crustosa, de las cuales 2 eran endolíticas y 2 epilíticas. De todas las especies $F$. austrocitrina presentó las mayores coberturas y 
frecuencia (tabla V.27). La especie $F$. austrocitrina se encontró en todos los sitios, siendo además la que presentó mayor cobertura en todos, mientras que las restantes especies no alcanzaron ni el $5 \%$ de cobertura promedio y la especie A. holocarpa solo se encontró en 1 de los 6 sitios (tabla V.28).

Tabla V.27. Especies encontradas para Tornquist, cobertura (\%) promedio (Cob), frecuencia absoluta (Fre), frecuencia porcentual (Fre

\%) y tipo morfológico. Unidades de muestreo $n=166$.

\begin{tabular}{lcccc}
\hline & Cob & Fre & Fre\% & Morfología \\
\hline Flavoplaca austrocitrina & 45,9 & 166 & 100 & Crustoso \\
Physcia tribacia & 0,55 & 18 & 10,84 & Folioso \\
Myriolecis dispersa & 0,445 & 13 & 7,83 & Crustoso \\
Lecania erysibe & 0,138 & 5 & 3,01 & Crustoso \\
Athallia holocarpa & 0,102 & 5 & 3,01 & Crustoso \\
\hline
\end{tabular}

Tabla V.28. Porcentaje de cobertura de la localidad Tornquist, para los sitios relevados

\begin{tabular}{lccccc}
\hline & $\begin{array}{c}\text { Flavoplaca } \\
\text { austrocitrina }\end{array}$ & $\begin{array}{c}\text { Physcia } \\
\text { tribacia }\end{array}$ & $\begin{array}{c}\text { Myriolecis } \\
\text { dispersa }\end{array}$ & $\begin{array}{c}\text { Lecania } \\
\text { erysibe }\end{array}$ & $\begin{array}{c}\text { Athallia } \\
\text { holocarpa }\end{array}$ \\
\hline Bóveda 1 $(n=29)$ & 49,5 & 0,21 & - & - & - \\
Bóveda 2 $(n=24)$ & 55 & 3,42 & 0,04 & - & - \\
Bóveda 3 $(n=40)$ & 53,3 & - & - & - & - \\
Bóveda 4 $(n=33)$ & 28,9 & - & - & - & - \\
Bóveda 5 $(n=29)$ & 42,9 & 0,14 & 2,48 & 0,28 & - \\
Tumba $(n=11)$ & 48,6 & - & 0,09 & 1,36 & 1,55 \\
\hline
\end{tabular}

$\underline{\text { Relación con las variables ambientales }}$

La mayor riqueza se encontró en la orientación $\mathrm{S}$, siendo igual para todas las alturas e inclinaciones. La mayor diversidad y equitatividad se encontró en la altura 1, inclinación vertical y orientación S (tabla V.29).

La prueba de Kruskal-Wallis usando las coberturas de las especies, entre las alturas, las orientaciones, la inclinación y el tipo de material, resultó en todos los casos en la no existencia de diferencias significativas $(p>0,05)$. 
EI ISA para la variable orientación mostró que $M$. dispersa para $S$ obtuvo un IV significativo. En cuanto a la variable inclinación A. holocarpa para horizontal también presentó un IV significativo, mientras que para el resto de las variables no se encontraron especies con IV significativo.

Tabla V.29. Riqueza (S), diversidad ( $\left.\mathrm{H}^{\prime}\right)$ y equitatividad (J') en Tornquist sobre distintas orientaciones, materiales, inclinaciones y alturas.

\begin{tabular}{lccc}
\hline & S & H'$^{\prime}$ & J' \\
\hline Horizontal & 4 & 0,24 & 0,17 \\
Vertical & 4 & 0,096 & 0,069 \\
Altura 1 & 4 & 0,11 & 0,082 \\
Altura 2 & 4 & 0,098 & 0,071 \\
Altura 3 & 4 & 0,081 & 0,058 \\
N & 2 & - & - \\
E & 3 & - & - \\
W & 3 & 0,023 & 0,021 \\
S & 4 & 0,215 & 0,155 \\
Total & 5 & 0,11 & 0,069 \\
\hline
\end{tabular}

En el análisis de CCA (figura V.9) sobre el eje 1 se separaron las unidades de muestreo y las especies por el tipo de inclinacion, quedando de un lado las especies $A$. holocarpa y $L$. erysibe asociadas a la variable horizontal, por otro lado quedaron las unidades de muestreo y las especies $F$. austrocitrina, $P$. tribacia y $M$. dispersa asociadas a la variable vertical. En cuanto a el eje 2 solo se aprecia algo de influencia con la variable $S$ donde aparecen las especies $P$. tribacia y $M$. dispersa que fueron encontradas sobre esta orientación. Por lo que el análisis muestra 3 grupos uno asociado a la variable vertical, otro a la variable $S$ y otro a la variable horizontal, siendo este último el grupo que concentra la mayoría de las unidades de muestreo ya que la especie $F$. austrocitrina fue la dominante y en algunos casos la única especie encontrada. Las variables de altura y del resto de orientaciones no entraron dentro del análisis por su baja correlación. 


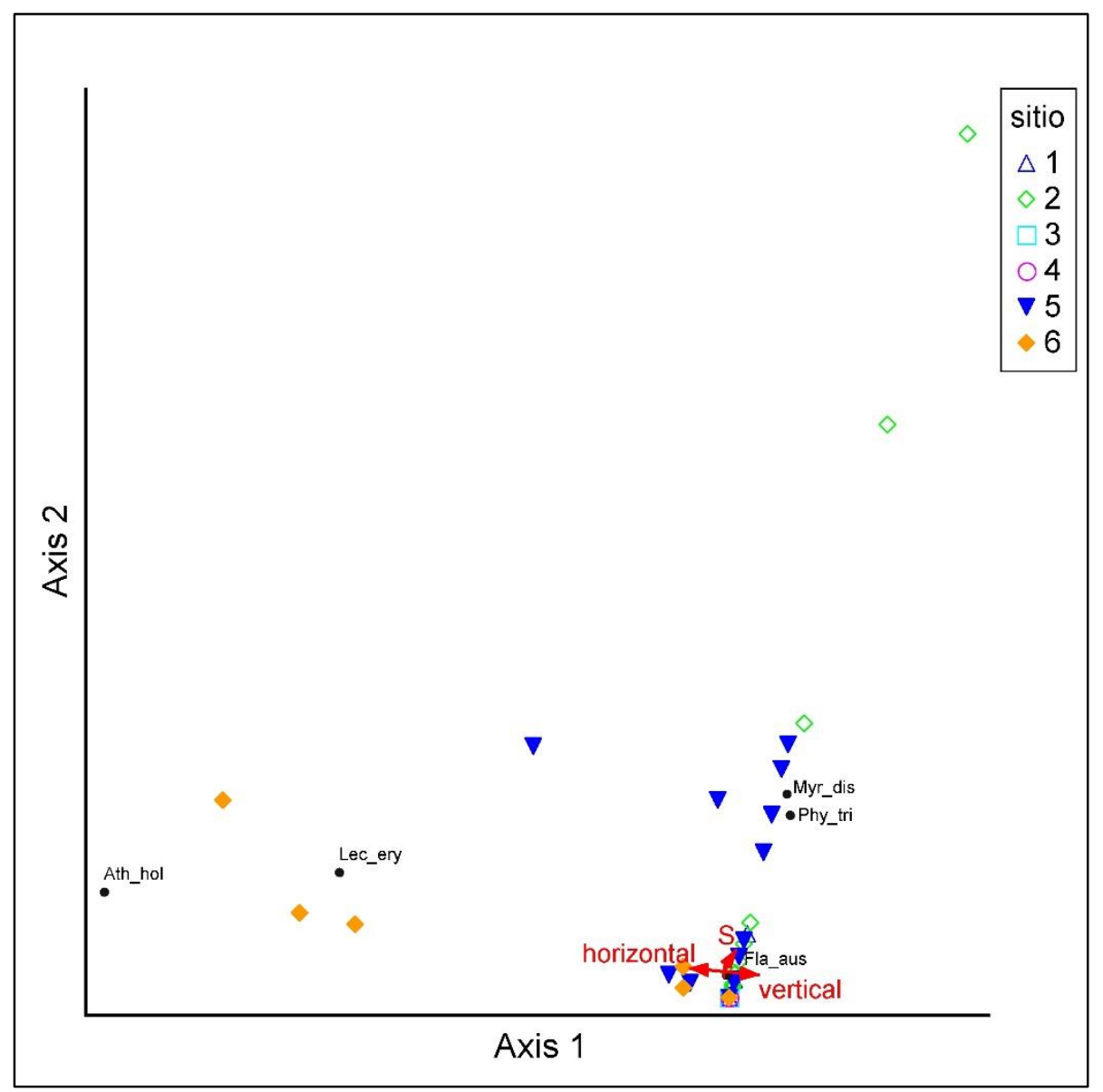

Figura V.9. Análisis CCA de la localidad de Tornquist. Sitios: 1-Bóveda 1; 2-Bóveda 2; 3Bóveda 3; 4-Bóveda 4; 5-Bóveda 5; 6-Tumba. Referencias de especies de líquenes en Anexo II. Unidades de muestreo $n=166$.

\section{V.1.1.11. Bahía Blanca}

\section{Composición de especies}

Se encontraron un total de 17 especies de las cuales 4 fueron foliosas y 13 crustosas; de éstas, 4 son endolíticas, 9 epilíticas de estas ultimas una presento una forma escuamulosa. De todas las especies $F$. austrocitrina fue la especie con mayor cobertura y frecuencia seguida por $A$. holocarpa (tabla v.30). De los sitios relevados, el cementerio presentó una mayor riqueza que el 
parque municipal y compartieron $42,8 \%$ de las especies. En ambos sitios se encontró que $F$. austrocitrina fue la especie con mayor cobertura (tabla V.31).

Tabla V.30. Especies encontradas en Bahía Blanca, cobertura (\%) promedio (Cob), frecuencia absoluta (Fre), frecuencia porcentual (Fre \%) y tipo morfológico. Unidades de muestreo $n=629$

\begin{tabular}{lcccc}
\hline & Cob & Fre & Fre \% & Morfología \\
\hline Flavoplaca austrocitrina & 27,15 & 599 & 94,93 & Crustoso \\
Athallia holocarpa & 2,87 & 134 & 21,24 & Crustoso \\
Phaeophyscia chloantha & 0,738 & 44 & 6,97 & Folioso \\
Endocarpon sp.2 & 0,019 & 4 & 0,63 & Escuamuloso \\
Candelaria concolor & 0,003 & 2 & 0,32 & Folioso \\
Crustoso sp. 5 & 0,006 & 4 & 0,63 & Crustoso \\
Caloplaca teicholyta & 0,011 & 3 & 0,48 & Crustoso \\
Staurothele monosporoides & 1,135 & 72 & 11,41 & Crustoso \\
Lecania ryaniana & 0,054 & 17 & 2,69 & Crustoso \\
Sarcogyne regularis & 0,383 & 35 & 5,55 & Crustoso \\
Schaereria sp. & 0,47 & 22 & 3,49 & Crustoso \\
Sarcogyne meriodinalis & 0,049 & 4 & 0,63 & Crustoso \\
Piccolia sp. & 0,033 & 12 & 1,90 & Crustoso \\
Candelariella aurella & 0,095 & 8 & 1,27 & Crustoso \\
\hline
\end{tabular}

Tabla V.31. Cobertura relativa media (\%) de cada especie por sitio de muestreo, de la localidad Bahía Blanca.

\begin{tabular}{lcc}
\hline & $\begin{array}{c}\text { Cementerio } \\
(\mathrm{n}=340)\end{array}$ & $\begin{array}{c}\text { Parque } \\
\text { Municipal } \\
(\mathrm{n}=289)\end{array}$ \\
\hline Flavoplaca austrocitrina & 25,76 & 28,79 \\
Athallia holocarpa & 2,58 & 3,22 \\
Phaeohyscia chloantha & 1,33 & 0,045 \\
Staurothele monosporoides & 0,10 & 2,35 \\
Lecania ryaniana & 0,035 & 0,076 \\
Sarcogyne regularis & 0,19 & 0,61 \\
Endocarpon sp. 2 & 0,035 & - \\
Candelaria concolor & 0,006 & - \\
Crustoso sp. 5 & 0,012 & - \\
Caloplaca teicholyta & 0,021 & - \\
Candelariella Concolor & 0,18 & - \\
Schaereria sp. & - & 1,024
\end{tabular}




\section{$\underline{\text { Relación con las variables ambientales }}$}

La mayor riqueza se produjo en muros horizontales, orientados al SE, a $0,5 \mathrm{~m}$ de altura 1 y cubiertos por lajas. La mayor diversidad y equitatividad se encontró en la inclinación horizontal, la orientación NE, altura 3 y material laja (tabla V.32).

Se realizó la prueba de Kruskal-Wallis usando las coberturas de las especies, entre las alturas, las orientaciones, la inclinación y el tipo de material, en todos los casos el resultado de la prueba fue que no existían diferencias significativas $(p>0,05)$.

EI ISA para la variable orientación dió como resultado a las especies $F$. austrocitrina para N, Endocarpon sp. para SE y $P$. chloantha para NE con valores de IV significativos. Para la variable inclinación las especies que presentaron valores de IV significativos fueron $A$. holocarpa para horizontal y $F$. austrocitrina para vertical. En cuanto al sustrato las especies que presentaron IV significativos fueron: $F$. austrocitrina para laja y $A$. holocarpa para aglomerado.

Tabla V.32. Riqueza (S), diversidad (H') y equitatividad (J') total de la localidad Bahía Blanca, sobre distintos materiales inclinaciones, orientaciones

y alturas sobre el suelo.

\begin{tabular}{lccc}
\hline & S & H' $^{\prime}$ & $\mathbf{J}^{\prime}$ \\
\hline Aglomerado & 3 & 0,28 & 0,26 \\
Mortero & 8 & 0,25 & 0,12 \\
Mármol & 1 & - & - \\
Laja & 10 & 0,78 & 0,34 \\
Horizontal & 14 & 1,52 & 0,58 \\
Vertical & 6 & 0,13 & 0,07 \\
Altura 1 & 6 & 0,14 & 0,08 \\
Altura 2 & 4 & 0,11 & 0,08 \\
Altura 3 & 4 & 0,14 & 0,098
\end{tabular}




\begin{tabular}{lccc}
$\mathbf{N}$ & 4 & 0,03 & 0,019 \\
$\mathbf{N E}$ & 3 & 0,46 & 0,42 \\
$\mathbf{N W}$ & 3 & 0,07 & 0,06 \\
$\mathbf{S E}$ & 6 & 0,19 & 0,10 \\
SW & 2 & - & - \\
Total & 14 & 0,71 & 0,27 \\
\hline
\end{tabular}

El análisis de CCA (figura V.10) separó sobre el eje 1 se las unidades de muestreo realizadas sobre aglomerado y horizontal, de las vertical y cemento. Sobre el eje 2 se separaron las muestras sobre sustratos horizontales delaja de las realizadas sobre aglomerado vertical. Las variables de altura y orientación no fueron representadas en el análisis por su bajo peso. En síntesis se pudieron observar tres grupos, uno asociado a las variables horizontal y laja conformado por las especies L. ryania, Piccolia sp., S. meridionalis, S. monosporoides, C. concolor, C. teicholyta, S. regularis y Schaereria sp. Otro grupo asociado a las variables horizontal y aglomerado conformado por las especies $A$. holocarpa y $C$. aurella. El último grupo se asoció a las variables vertical y cemento, relacionado a las especies $F$. austrocitrina, Endocarpon sp. y $P$. chloantha. 


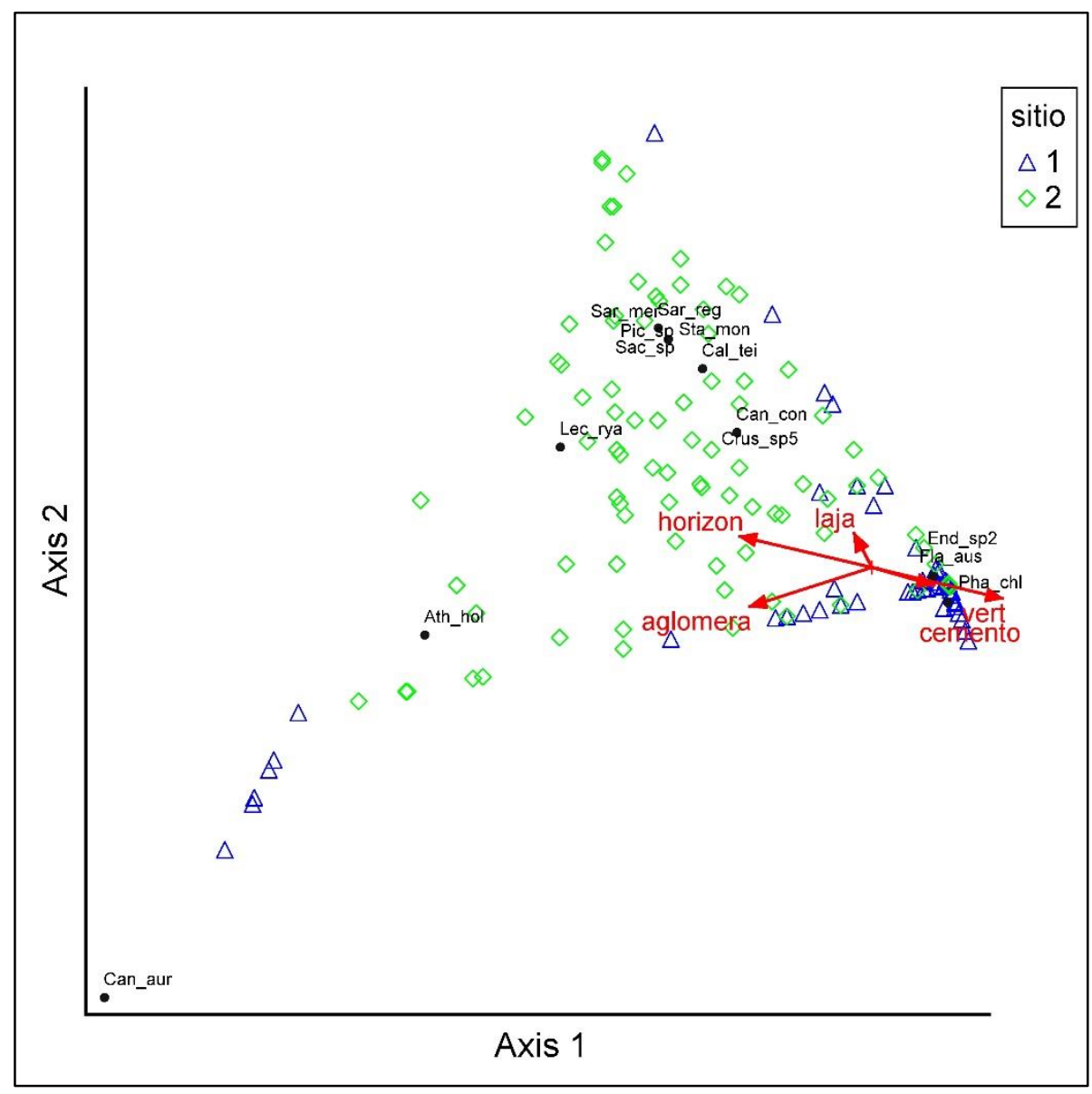

Figura V.10. Análisis de CCA de la localidad de Bahía Blanca. Sitios: 1) Cementerio 2) Parque de la Independencia. Referencias de especies de líquenes en Anexo II. Unidades de muestreo $n=629$.

\section{V.1.1.12. Carmen de Patagones}

\section{Composición de especies}

Se encontraron un total de 8 especies todas de morfología crustosa, de estas, 3 especies (S. regularis, M. dispersa y M. hageni) son endolíticas y las restantes 5 epilíticas. La especie con mayor cobertura y frecuencia fue $F$. austrocitrina, seguida por A. holocarpa (tabla V.33). De los tres sitios muestreados el murallón costero presentó la mayor riqueza mientras que la estación de ferrocarril la menor. Las especies $F$. austrocitrina, $A$. holocarpa y $M$. dispersa fueron encontradas en todos los sitios siendo la primera la que obtuvo la mayor cobertura en los tres sitios (tabla V.34). 
Tabla V.33. Especies encontradas en Carmen de Patagones, cobertura (\%) promedio (Cob), frecuencia absoluta (Fre), frecuencia porcentual (Fre \%) y tipo morfológico. Unidades de muestreo $n=196$.

\begin{tabular}{lcccc}
\hline & cob & Fre & Fre $\%$ & Morfología \\
\hline Flavoplaca austrocitrina & 31,1 & 184 & 93,9 & Crustoso \\
Caloplaca teicholyta & 5,17 & 44 & 22,45 & Crustoso \\
Myriolecis dispersa & 0,066 & 9 & 4,59 & Crustoso \\
Sarcogyne regularis & 0,11 & 5 & 2,55 & Crustoso \\
Staurothele monosporoides & 0,49 & 6 & 3,06 & Crustoso \\
Athallia holocarpa & 6,62 & 70 & 35,7 & Crustoso \\
Acarospora mendozana & 3,49 & 40 & 20,41 & Crustoso \\
Acarospora subcastanea & 1,02 & 17 & 8,67 & Crustoso \\
Myriolecis hagenii & 0,03 & 2 & 1,02 & Crustoso \\
\hline
\end{tabular}

Tabla V.34. Cobertura relativa media (\%) de cada especie por sitio de muestreo, de la localidad Carmen de Patagones.

\begin{tabular}{lccc}
\hline & $\begin{array}{c}\text { Murallón } \\
(\mathrm{n}=105)\end{array}$ & $\begin{array}{c}\text { Estación } \\
(\mathrm{n}=57)\end{array}$ & $\begin{array}{c}\text { Cementerio } \\
(\mathrm{n}=102)\end{array}$ \\
\hline Flavoplaca austrocitrina & 29,61 & 33,72 & 32,24 \\
Athallia holocarpa & 8,6 & 0,053 & 11,79 \\
Myriolecis dispersa & 0,03 & 0,018 & 0,27 \\
Acarospora mendozana & 6,5 & - & 0,03 \\
Caloplaca teicholyta & 9,7 & - & - \\
Staurothele monosporoides & 0,92 & - & - \\
Sarcogyne regularis & 0,21 & - & - \\
Myriolecis hagenii & 0,06 & - & - \\
Acarospora subcastanea & - & - & 5,91 \\
\hline
\end{tabular}

\section{$\underline{\text { Relación con las variables ambientales }}$}

La mayor riqueza se encontró en la inclinación horizontal y orientación sur; las tres alturas tuvieron la misma riqueza. La mayor diversidad y equitatividad se encontró en la inclinación horizontal, orientación sur y altura 2 (tabla V.35).

Se realizó la prueba de Kruskal-Wallis usando las coberturas de las especies, entre las alturas, las orientaciones, la inclinación y el tipo de material, 
en todos los casos el resultado fue que no existían diferencias significativas ( $p$ $>0,05)$.

EI ISA para la variable orientación dio como resultado que las especies C. teicholyta para S y M. dispersa para NW presentaron valores de IV significativos. En cuanto a la variable inclinación $A$. holocarpa para horizontal presento un IV significativo. Para la variable altura no se encontraron especies con IV significativos.

Tabla V.35. Riqueza, diversidad y equitatividad sobre distintas orientaciones, materiales, inclinaciones y alturas.

\begin{tabular}{lccc}
\hline & S & H' $^{\prime}$ & J' \\
\hline Horizontal & 9 & 1,503 & 0,684 \\
Vertical & 6 & 0,648 & 0,362 \\
Altura 1 & 5 & 0,584 & 0,363 \\
Altura 2 & 5 & 0,75 & 0,466 \\
Altura 3 & 5 & 0,503 & 0,313 \\
NW & 3 & 0,07 & 0,06 \\
S & 4 & 0,762 & 0,55 \\
SE & 2 & - & - \\
SW & 3 & - & - \\
Tootal & 9 & 1,147 & 0,522 \\
\hline
\end{tabular}

Sobre el eje 2 del análisis de CCA (figura V.11) se contrapusieron las muestras sobre sustrato horizontal con las variables $S$, vertical y alturas dividiendo a las unidades y a las especies por la inclinación a la que se encontraron. Sobre el eje 1 se encontró que las variables SE y SW tenían una misma dirección y no se encontró alguna variable contrapuesta a ésta, pero unidades de muestreo y especies se encontraron hacia esta otra dirección. De esta forma podemos reconocer un grupo asociado a la variable Horizontal conformado por las especies A. holocarpa, S. regularis, Acarospora mendozana, A. subcastanea y $M$. hagenii. Otro grupo más disperso separado por las variables de orientación, altura y vertical que a su vez se separa en dos, 
uno de estos conformado por las especies $S$. monosporoides y $C$. teicholyta, el cual no tiene una relación clara con variables sobre el eje 1, y otro grupo asociado a la variable SE y SW, conformado por las especies $F$. austrocitrina y M. dispersa.

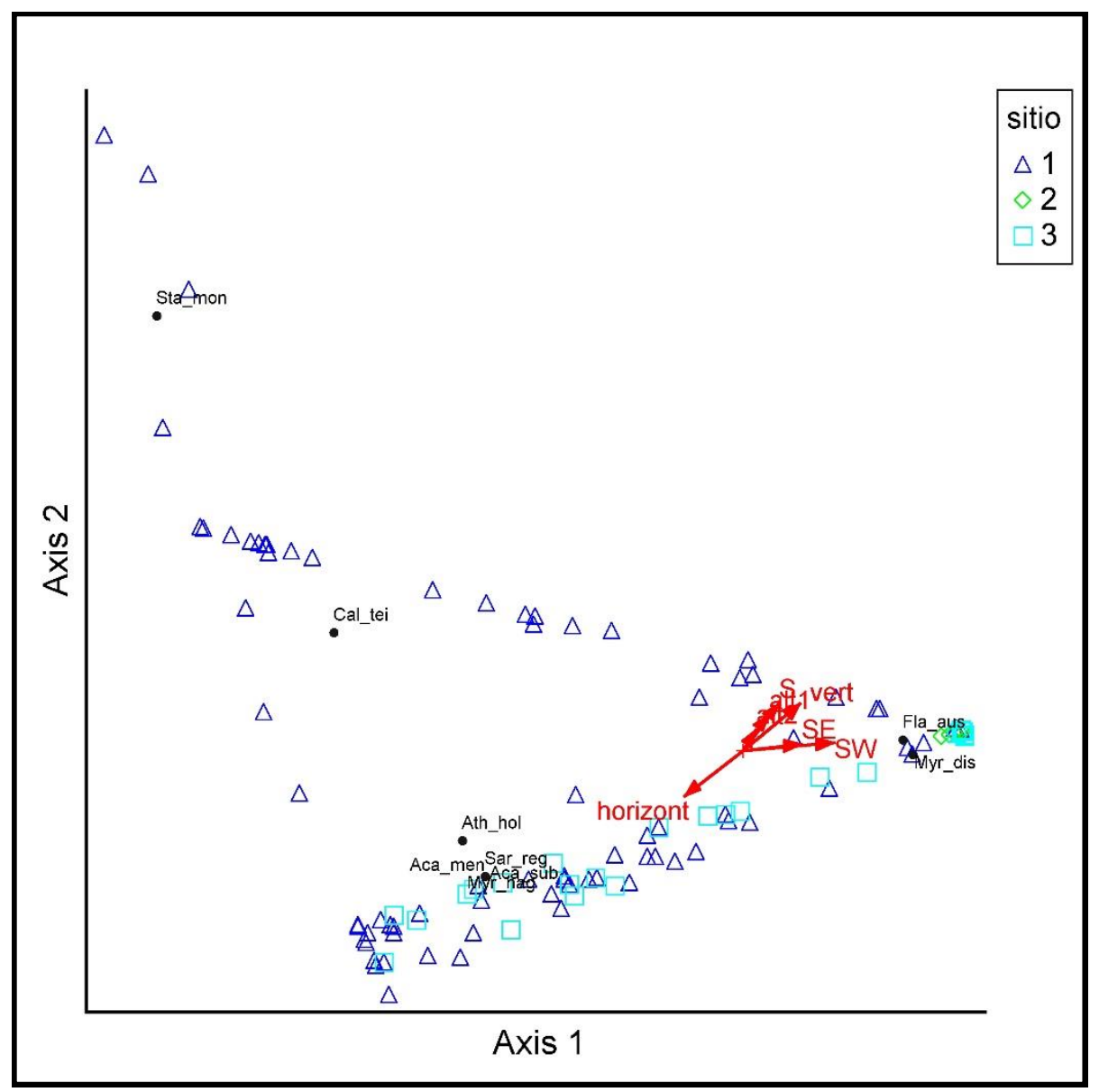

Figura V.11. Análisis de CCA de la localidad Carmen de Patagones. Sitios 1-murallon costero; 2-Estación de ferrocarril; 3-Cementerio. Referencias de especies de líquenes en Anexo II. Unidades de muestreo $n=196$.

\section{V.1.2. Liquenobiota de ambientes naturales}

\section{V.1.2.1. Reserva Natural de Uso Múltiple Isla Martín García (RNIMG)}

\section{Composición de especies}


En el arenal, sobre Sapium haematospermum, se encontraron 21 especies de las cuales 10 eran foliosas, 9 crustosas y 2 fruticulosas. Physcia erumpens presentó la mayor cobertura y Crespoa crozalsiana la mayor frecuencia (tabla V.36). En el sector de selva se encontraron 17 especies, donde Coenogonium isidigerum superó ampliamente al resto de las especies presentando una mayor cobertura y frecuencia (tabla V.37).

Tabla V.36. Especies encontradas para Isla Martín García, en el sitio del arenal porcentaje de cobertura media ( $\mathrm{Cob}$ ), frecuencia absoluta (Fre), frecuencia porcentual (Fre\%) y tipo morfológico. Unidades de muestreo $n=18$

\begin{tabular}{lcccc}
\hline & Cob & Fre & Fre\% & Morfotipo \\
\hline Physcia erumpens & 11,39 & 10 & 55,6 & Folioso \\
Parmotrema reticulatum & 11,11 & 12 & 66,7 & Folioso \\
Physcia alba & 9,72 & 11 & 61,1 & Folioso \\
Crespoa crozalsiana & 8,06 & 13 & 72,2 & Crustoso \\
Crustoso sp.6 & 6,39 & 7 & 38,9 & Crustoso \\
Chrysotrix candelaris & 5,83 & 7 & 38,9 & Folioso \\
Physcia stellaris & 5,28 & 6 & 33,3 & Folioso \\
Lecanora tropica & 4,72 & 6 & 33,3 & Crustoso \\
Parmotrema cetratum & 3,61 & 6 & 33,3 & Folioso \\
Teloschistes chrysophthalmus & 3,11 & 3 & 16,7 & Fruticoso \\
Buellia fraudans & 3,00 & 9 & 50,0 & Crustoso \\
Glyphis cicatricosa & 1,94 & 4 & 22,2 & Crustoso \\
Pyxine cocoes & 1,39 & 2 & 11,1 & Folioso \\
Lecanora helva & 1,17 & 4 & 22,2 & Crustoso \\
Ramalina celastri & 1,00 & 4 & 22,2 & Fruticoso \\
Flavoparmelia exornata & 0,83 & 3 & 16,7 & Folioso \\
Punctelia constantimotium & 0,83 & 3 & 16,7 & Folioso \\
Graphis sp. & 0,83 & 2 & 11,1 & Crustoso \\
Physcia aipolia & 0,83 & 2 & 11,1 & Folioso \\
Pyxine berteriana & 0,83 & 1 & 5,6 & Folioso \\
Hafellia parastata & 0,56 & 1 & 5,6 & Crustoso \\
\hline
\end{tabular}

Tabla V.37. Especies encontradas para Isla Martín García, en el sitio de selva marginal porcentaje de cobertura media ( $\mathrm{Cob}$ ), frecuencia absoluta (Fre), frecuencia porcentual (Fre\%) y tipo morfológico. Unidades de muestreo $n=168$ 


\begin{tabular}{lcccc}
\hline Coenogonium isidiigerum & 33,18 & 109 & 72,7 & Crustoso \\
Lepraria sp. & 12,62 & 38 & 25,3 & Crustoso \\
Malmidea leptoloma & 3,41 & 28 & 18,7 & Crustoso \\
Pyrenula pyrenuloides & 2,59 & 12 & 8 & Crustoso \\
Heterodermia comosa & 1,84 & 14 & 9,3 & Folioso \\
Bacidina pallidocarnea & 1,05 & 3 & 2 & Crustoso \\
Phaeophyscia chloantha & 1,02 & 5 & 3,3 & Folioso \\
Porina nucula & 0,35 & 5 & 3,3 & Crustoso \\
Graphis submarginata & 0,29 & 3 & 2 & Crustoso \\
Graphis geraënsis & 0,19 & 2 & 1,3 & Crustoso \\
Crustoso sp.7 & 0,11 & 3 & 2 & Crustoso \\
Graphis lineola & 0,1 & 2 & 1,3 & Crustoso \\
Physcia.subcinerea & 0,1 & 9 & 6 & Folioso \\
Punctelia hypoleucites & 0,07 & 1 & 0,66 & Folioso \\
Heterodermia diademata & 0,07 & 1 & 0,66 & Folioso \\
Physcia crispa & 0,04 & 2 & 1,33 & Folioso \\
Leptogium azureum & 0,03 & 9 & 6 & Gelatinoso \\
\hline
\end{tabular}

\section{Relación de las especies con las variables ambientales}

La riqueza total fue de 35 , de los sitios relevados el arenal presentó mayor riqueza, diversidad y equitatividad que el sector de selva (tabla V.38).

En el análisis de CCA (figura V.12) se aprecia sobre el eje 1 una separación entre 2 grupos, estos grupos están asociados a los 2 sitios de muestreo arenal y selva. Las variables $S$. haematospermum y valores de DAP bajos se asocian al sitio selva, mientras que el resto de los forófitos y valores altos de DAP se asocian al sitio selva. La proximidad de los cuadrados de muestreo en el sitio selva denota una alta homogeneidad en la comunidad de este sitio, que además presenta una mayor riqueza y no comparte ninguna especie con el sitio selva. El eje 2 no parece estar actuando sobre el sitio arenal, mientras que el el sitio selva sobre este eje se separa a las muestras tomadas sobre $O$. acutifolia, donde domina la especie Coenogonium isidiigerum, de las realizadas sobre el resto de los forófitos. No se observa que la altura sobre el tronco haya sido una variable de peso en la ordenación de los sitios. 
Tabla V.38. Riqueza (S), diversidad ( $\mathrm{H}^{\prime}$ ) y equitatividad

$\left(J^{\prime}\right)$ de los 2 sitios relevados en la reserva RNIMG

\begin{tabular}{lccc}
\hline & $\begin{array}{c}\text { Total } \\
\mathbf{N}=\mathbf{1 8 6}\end{array}$ & $\begin{array}{c}\text { Selva } \\
\mathbf{n}=\mathbf{1 6 8}\end{array}$ & $\begin{array}{c}\text { arenal } \\
\mathbf{n}=\mathbf{1 8}\end{array}$ \\
\hline $\mathbf{S}$ & 38 & 17 & 21 \\
$\mathbf{H}$, & 2,298 & 1,375 & 3 \\
$\mathbf{J}$ & 0,646 & 0,485 & 0,952 \\
\hline
\end{tabular}

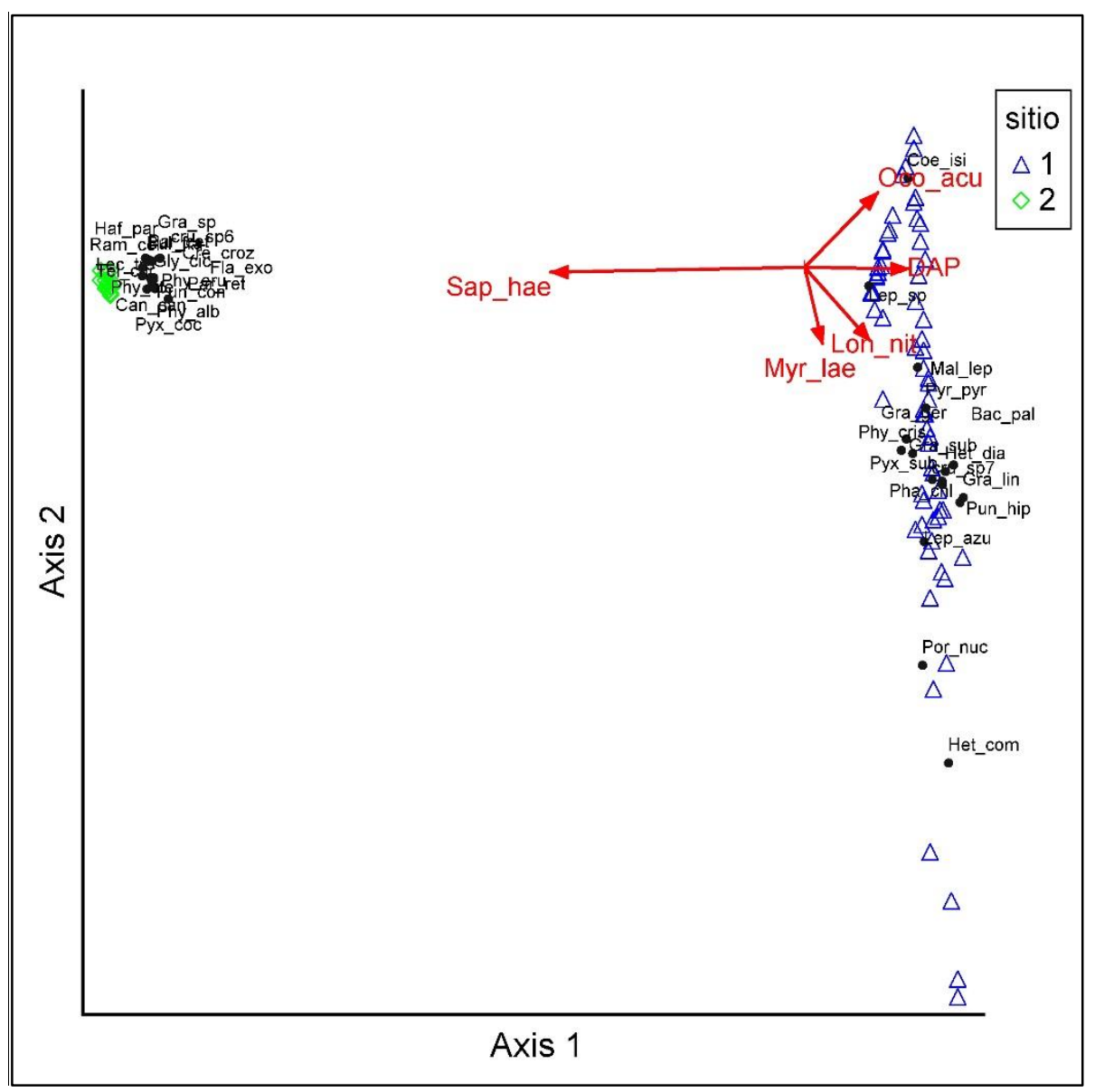

Figura V.12. Análisis de CCA de RNIMG. Sitio 1- selva marginal; 2- arenal. Las especies de líquenes (Anexo II) y de forófitos Sap_hae=Sapium haematospermun; Oco_acu=Ocotea acutifolia; Lon_nit=Lonchocarpus nitidus; Myr_lae= Myrsine laetevirens. Referencias de especies de líquenes en Anexo II. Unidades de muestreo $n=168$.

\section{V.1.2.2. Reserva Natural Integral Punta Lara (RNPL)}




\section{Composición de especies}

Se encontraron 25 especies de las cuales 8 fueron crustosas, 15 foliosas, 1 fruticosa y 1 filamentosa. Dos de las especies foliosas tienen un talo gelatinoso. La especie $P$. corallina presentó mayor cobertura y frecuencia que el resto (tabla V.39). La diversidad según el índice de Shannon fue de 2,58 y la equitatividad de 0,801 (tabla V.40).

Tabla V.39. Especies encontradas para RNPL, en el sector de selva marginal. Cobertura media (Cob), frecuencia absoluta (Fre), frecuencia porcentual (Fre\%) y tipo morfológico. Unidades de muestreo $n=93$.

\begin{tabular}{lcccc}
\hline & Cob & Fre & Fre\% & Morfología \\
\hline Phyllopsora corallina & 13,72 & 41 & 44,1 & Crustoso \\
Coenogonium pyrophthalmum & 11,77 & 36 & 38,7 & Crustoso \\
Lepraria sp. & 7,08 & 21 & 22,6 & Crustoso \\
Physcia ponsinci & 5,23 & 20 & 21,5 & Folioso \\
Leptogium cyanescens & 2,80 & 16 & 17,2 & Folioso \\
Pyrenula pyrenuloides & 2,15 & 11 & 11,8 & Crustoso \\
Heterodermia diademata & 2,04 & 7 & 7,5 & Folioso \\
Physcia albata & 1,75 & 17 & 18,3 & Folioso \\
Physcia undulata & 1,24 & 4 & 4,3 & Folioso \\
Physcia rolfii & 0,97 & 5 & 5,4 & Folioso \\
Heterodermia obscurata & 0,72 & 6 & 6,5 & Folioso \\
Pororina nucula & 0,71 & 5 & 5,4 & Crustoso \\
Phaeophyscia choantha & 0,59 & 2 & 2,2 & Folioso \\
Heterodermia speciosa & 0,59 & 5 & 5,4 & Folioso \\
Physcia alba & 0,59 & 3 & 3,2 & Folioso \\
Pertusaria sp.1 & 0,45 & 7 & 7,5 & Crustoso \\
Crustoso sp. 8 & 0,38 & 2 & 2,2 & Crustoso \\
Graphis lineola & 0,32 & 1 & 1,1 & Crustoso \\
Coenogonium interplexum & 0,32 & 4 & 4,3 & Filamentoso \\
Physcia erumpens & 0,22 & 1 & 1,1 & Folioso \\
Physcia stellaris & 0,11 & 1 & 1,1 & Folioso \\
Leptogium marginellum & 0,06 & 2 & 2,2 & Folioso \\
Physcia crispa & 0,05 & 1 & 1,1 & Folioso \\
Punctelia hypoleucites & 0,05 & 1 & 1,1 & Folioso \\
Ramalina celastri & 0,01 & 1 & 1,1 & Fruticoso \\
\hline
\end{tabular}




\begin{tabular}{|c|c|}
\hline & $\begin{array}{l}\text { ueza (S) } \\
\text { H') y } \\
\text { ) RNPL }\end{array}$ \\
\hline $\mathbf{S}$ & 25 \\
\hline$H^{\prime}$ & 2,58 \\
\hline $\mathbf{J}^{\prime}$ & 0,801 \\
\hline
\end{tabular}

\section{$\underline{\text { Relación de las especies con las variables ambientales }}$}

En el análisis de CCA (figura V.13) se verifica la importancia de los forófitos como variable de segregación de las unidades de muestreo. Sobre el eje 1 se diferenciaron 2 grupos uno asociado a Terminalia australis al que se asocian las especies de líquenes Physcia rolfii y Leptogium cyanescens, mientras que en el otro grupo tienen peso el resto de los forófitos y especies de líquenes. Este otro grupo se ordena sobre el eje 2 donde se separan en sus extremos las unidades de muestreo tomadas sobre Lonchocarpus nitidus y Ligustrum lucidum con especies de líquenes que se diferencian de las presentes sobre los forófitos Ocotea acutifolia y Pouteria salicifolia. 


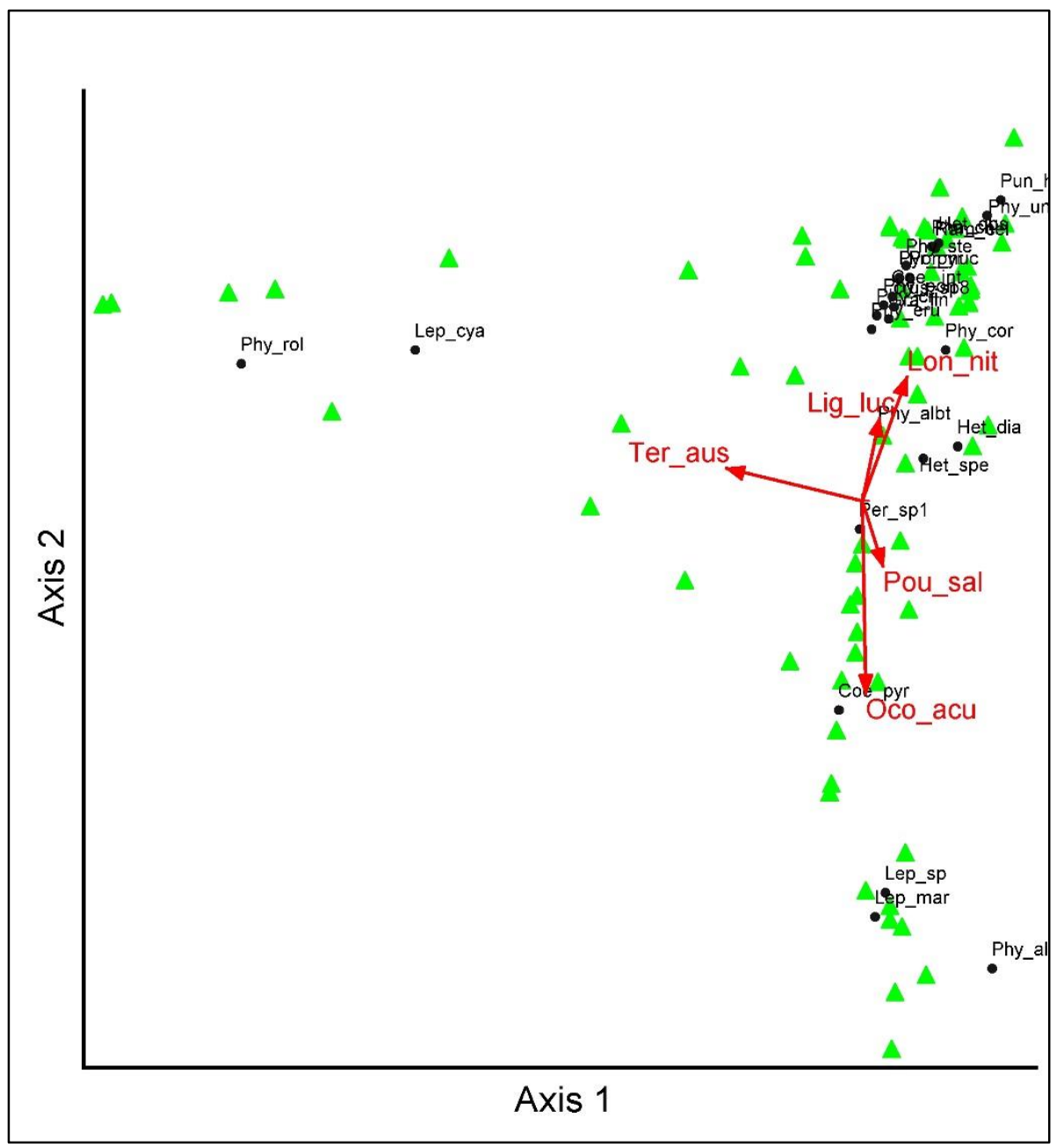

Figura V.13. Análisis de CCA de la reserva de Punta Lara. Forófitos: Lon_nit = Lonchocarpus nitidus; Pou_sal=Pouteria salicifolia; Oco_acu=Ocotea acutifolia; Ter_aus= Terminalia australis; Lig_luc= Ligustro lucidum. Referencias de especies de líquenes en Anexo II. Unidades de muestreo $n=93$.

\section{V.1.2.3. Sierras de Tandil (ST)}

\section{Composición de especies}

Se encontraron un total de 35 especies de las cuales 21 fueron crustosas, 12 foliosas y 2 fruticulosas. De estas especies Xanthoparmelia hypopsila fue la especie con mayor cobertura, mientras que Buellia spuria fue la especie con mayor frecuencia (tabla V.41). El índice de diversidad fue de 3,24 y contribuyó al mismo una alta equitabilidad de las especies que resultaron en un J de 0,9 (tabla V.42). 
Tabla V.41. Especies encontradas para ST, porcentaje de cobertura media (Cob), frecuencia absoluta (Fre), frecuencia porcentual (Fre\%) y tipo morfológico. Unidades de muestreo $n=57$.

\begin{tabular}{|c|c|c|c|c|}
\hline & Cob & Fre & Fre\% & Morfotipo \\
\hline Xanthoparmelia hypopsila & 16,88 & 33 & 57,63 & Folioso \\
\hline Buellia spuria & 11,53 & 41 & 69,49 & Crustoso \\
\hline Xanthoparmelia microspora & 7,288 & 15 & 25,42 & Folioso \\
\hline Aspicilia sp.1 & 5,259 & 15 & 25,42 & Crustoso \\
\hline Catillaria chalybaeoides & 4,93 & 21 & 35,59 & Crustoso \\
\hline Acarospora lorentzii & 2,93 & 12 & 20,339 & Crustoso \\
\hline Pertusaria patagónica & 2,42 & 5 & 8,47 & Crustoso \\
\hline Aspicilia sp. 2 & 2,32 & 9 & 15,25 & Crustoso \\
\hline Parmotrema fistulatum & 2,20 & 5 & 8,47 & Folioso \\
\hline Caloplaca rugulosa & 1,98 & 15 & 25,42 & Crustoso \\
\hline Acarospora rhabarbarina & 1,88 & 4 & 6,78 & Crustoso \\
\hline Amandinea punctata & 1,69 & 4 & 6.78 & Crustoso \\
\hline Candelariella aurella & 1,47 & 11 & 18,64 & Crustoso \\
\hline Lecanora microcarpa & 1,27 & 5 & 8,47 & Crustoso \\
\hline Parmotrema tandilensis & 1,10 & 5 & 8,47 & Folioso \\
\hline Haematomma montevidensis & 1,10 & 3 & 5,08 & Crustoso \\
\hline Parmotrema cetratum & 0,847 & 2 & 3,39 & Folioso \\
\hline Parmotrema reticulatum & 0,678 & 2 & 3,39 & Folioso \\
\hline Punctelia semansiana & 0,593 & 3 & 5,08 & Folioso \\
\hline Rhizocarpon disporum & 0,593 & 2 & 3,39 & Crustoso \\
\hline Flavoparmelia papillosa & 0,559 & 2 & 3,39 & Folioso \\
\hline Usnea amblyoclada & 0,508 & 5 & 8,47 & Fruticoso \\
\hline Punctelia colombiana & 0,508 & 1 & 1,69 & Folioso \\
\hline Crustoso sp.9 & 0,508 & 1 & 1,69 & Crustoso \\
\hline Brownliella cinabarinna & 0,4922 & 5 & 8,47 & Crustoso \\
\hline Usnea densirostra & 0,441 & 4 & 6,78 & Fruticoso \\
\hline Xanthoparmelia wrigthiana & 0,424 & 1 & 1,69 & Folioso \\
\hline Diploschistes cinereocaesius & 0,339 & 1 & 1,69 & Crustoso \\
\hline Candelaria concolor & 0,254 & 2 & 3,39 & Folioso \\
\hline Caloplaca xanthobola & 0,254 & 2 & 3,39 & Crustoso \\
\hline Flavoplaca austrocitrina & 0,203 & 3 & 5,08 & Crustoso \\
\hline Amandinea sp. & 0,169 & 1 & 1,69 & Crustoso \\
\hline Lecanora sp.2 & 0,169 & 1 & 1,69 & Crustoso \\
\hline Cladia aggregata & 0,085 & 1 & 1,69 & Fruticoso \\
\hline Umbilicaria krempelhuberi & 0,0169 & 1 & 1,69 & Folioso \\
\hline
\end{tabular}


Tabla V.42. Riqueza (S), diversidad $\left(\mathrm{H}^{\prime}\right)$ y equitatividad ( $J$ ') en las Sierras de tandil

\begin{tabular}{cc}
\hline $\mathbf{S}$ & 35 \\
$\mathbf{H}^{\prime}$ & 3,24 \\
$\mathbf{J}$ & 0,903 \\
\hline
\end{tabular}

Relación de las especies con las variables ambientales

El análisis de PCA (figura V.14), puso de manifiesto la separación de las especies en 2 grupos desde el centroide, hacia la izquierda algunas pocas unidades de muestreo ubicadas sobre faldeos al N, con mayor \% de rocosidad faldeos. Mientras que en el otro extremo se agrupa la mayoría de las muestras con especies que no presentarían preferencia por las variables usadas en el análisis. El segundo eje divide en 2 al primer grupo, uno de estos conformado íntegramente por las especies crustosas F. austrocitrina, Aspicilia sp. 6, crustoso sp. 9, Pertusaria patagonica y $C$. xanthobola y el otro grupo formado en su mayoría por las especies foliosas Parmotrema tandilensis, P. fistulatum, Umbilicaria kremperhuberi, Punctelia colombiana, Xanthoparmelia hypopsila, Candelaria concolor y $P$. reticulata, las especies crustosas Amandinea sp. y Lecanora microcarpa, y la especie fruticosa Cladia agregata. Las variables de pendiente y tipo de roca no fueron tenidas en cuenta por el análisis por su bajo peso. 


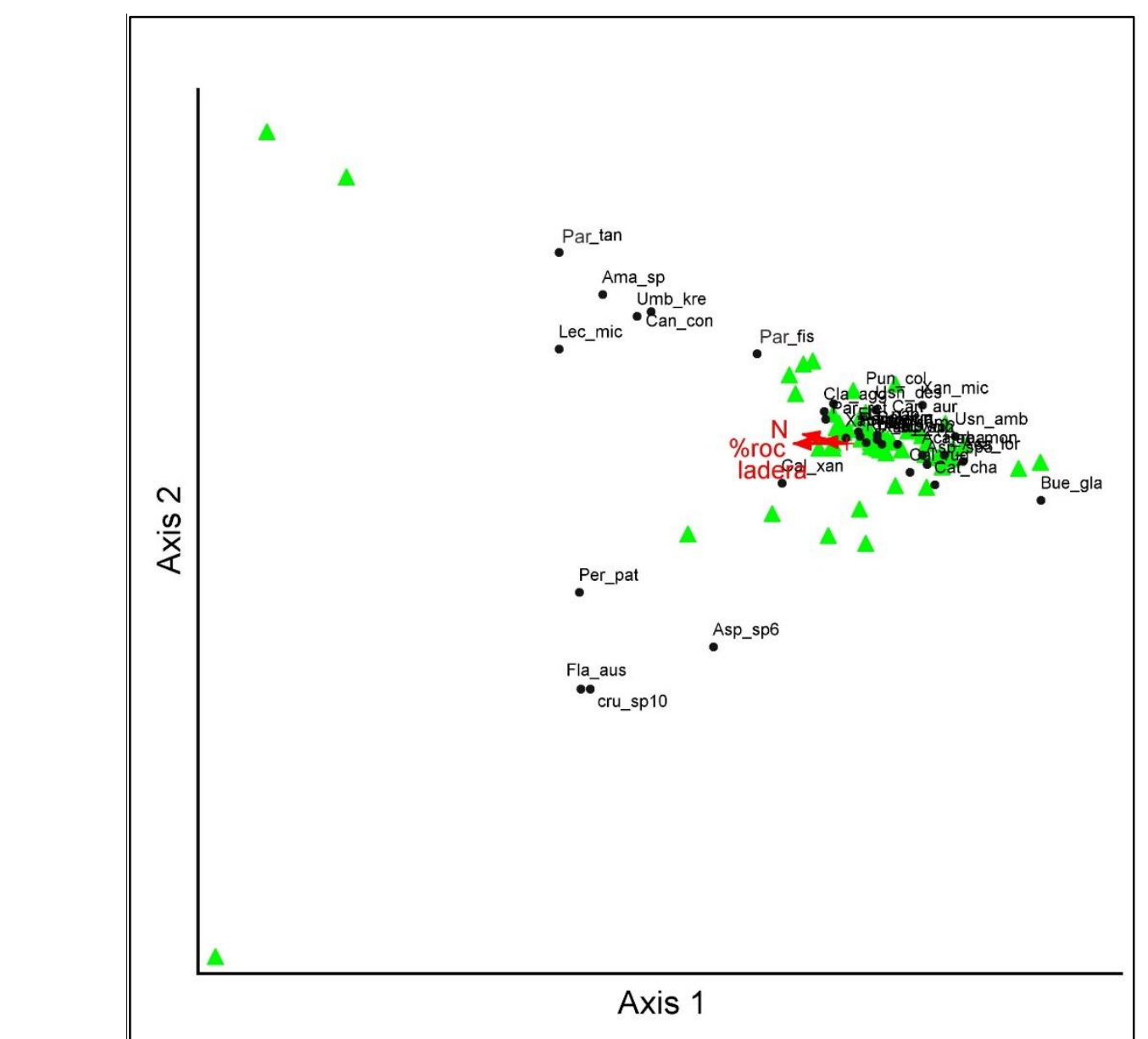

Figura V.14. Análisis de PCA de las Sierras de Tandil. Referencias de especies de líquenes en Anexo II. Unidades de muestreo $\mathrm{n}=57$

\section{V.1.2.4. Parque Provincial Ernesto Tornquist (PPET)}

\section{Composición de especies}

Se encontraron un total de 68 especies, de las cuales 36 especies fueron de morfología crustosa, 29 especies fueron de morfología foliosa, 5 especies de morfología fruticosa y 1 mixta (tabla V.43). De estas Buellia spuria presentó una mayor frecuencia encontrándola en el $65,9 \%$ de las unidades muestrales pero con coberturas relativamente bajas (13\%); Aspicilia sp. 1, con frecuencia del $48,9 \%$, fue la especie con mayor cobertura promedio $(48,69 \%)$. La diversidad fue de 2,99, con valores relativamente elevados de riqueza (71) y equitatividad $(0,7)$ (Tabla V.44). 
Tabla V.43. Especies encontradas para PPET, porcentaje de cobertura media (Cob), frecuencia absoluta (Fre), frecuencia porcentual (Fre\%) y tipo morfológico. $n=175$.

\begin{tabular}{|c|c|c|c|c|}
\hline & Cob & Fre & Fre\% & Morfología \\
\hline Buellia spuria & 13,32 & 116 & 65,9 & Crustoso \\
\hline Aspicilia sp. 3 & 48,69 & 86 & 48,9 & Crustoso \\
\hline Aspicilia sp. 4 & 8,89 & 73 & 41,5 & Crustoso \\
\hline Caloplaca rugulosum & 3,98 & 66 & 37,5 & Crustoso \\
\hline Umbilicaria krempelhuberi & 2,48 & 59 & 33,5 & Folioso \\
\hline Pertusaria patagonica & 5,92 & 47 & 26,7 & Crustoso \\
\hline Acarospora lorentzii & 2,82 & 46 & 26,1 & Crustoso \\
\hline Rhizocarpon disporum & 5,03 & 42 & 23,9 & Crustoso \\
\hline Usnea amblyoclada & 2,69 & 37 & 21 & Fruticoso \\
\hline Acarospora rhabarbarina & 1,01 & 35 & 19,9 & Crustoso \\
\hline Xanthoparmelia farinosa & 2,76 & 35 & 19,9 & Folioso \\
\hline Candelariella aurella & 0,60 & 32 & 18,2 & Crustoso \\
\hline Xanthoparmelia hypopsila & 3,10 & 29 & 16,5 & Folioso \\
\hline Brownliella cinnabarina & 1,85 & 24 & 13,6 & Crustoso \\
\hline Caloplaca xanthobola & 0,83 & 22 & 12,5 & Crustoso \\
\hline Punctelia semansiana & 1,65 & 19 & 10,8 & Folioso \\
\hline Catilaria chalybaeoides & 1,85 & 18 & 10,2 & Crustoso \\
\hline Rhizocarpon geographicum & 0,99 & 17 & 9,7 & Crustoso \\
\hline Lecanora farinacea & 2,4 & 14 & 7,9 & Crustoso \\
\hline Usnea fastuosa & 0,77 & 11 & 6,3 & Fruticoso \\
\hline Rhizocarpon reductum & 0,97 & 9 & 5,1 & Crustoso \\
\hline Physcia tribacia & 0,54 & 8 & 4,5 & Folioso \\
\hline Amandinea punctata & 0,68 & 8 & 4,5 & Crustoso \\
\hline Flavoparmelia papillosa & 23,22 & 8 & 4,5 & Folioso \\
\hline Xanthoparmelia microspora & 0,65 & 7 & 3,9 & Folioso \\
\hline Flavoplaca austrocitrina & 0,21 & 7 & 3,9 & Crustoso \\
\hline Ochrolechia sp.1 & 1,11 & 7 & 3,9 & Crustoso \\
\hline Acarospora fuscata & 0,17 & 6 & 3,4 & Crustoso \\
\hline Xanthoparmelia saxeti & 0,49 & 6 & 3,4 & Folioso \\
\hline Flavoparmelia haysonii & 0,34 & 6 & 3,4 & Folioso \\
\hline Usnea densirostra & 0,60 & 6 & 3,4 & Fruticoso \\
\hline Candelaria fibrosa & 0,15 & 6 & 3,4 & Crustoso \\
\hline Lecidella carpathica & 0,40 & 6 & 3,4 & Crustoso \\
\hline Aspilicia sp. 5 & 6,39 & 6 & 3,4 & Crustoso \\
\hline Xanthoparmelia rupicola & 0,26 & 5 & 2,8 & Folioso \\
\hline Caloplaca puiggarii & 0,63 & 4 & 2,3 & Crustoso \\
\hline Physcia undulata & 0,28 & 4 & 2,3 & Folioso \\
\hline Psora icterica & 0,31 & 4 & 2,3 & Crustoso \\
\hline Umbilicaria haplocarpa & 0,09 & 4 & 2,3 & Folioso \\
\hline Haematomma montevidense & 0,54 & 4 & 2,3 & Crustoso \\
\hline Xanthoparmelia scabrosa & 0,65 & 3 & 1,7 & Folioso \\
\hline Xanthoparmelia wrightiana & 0,07 & 3 & 1,7 & Folioso \\
\hline Punctelia colombiana & 0,43 & 3 & 1,7 & Folioso \\
\hline
\end{tabular}




\begin{tabular}{lllll} 
Physcia convexella & 0,11 & 3 & 1,7 & Folioso \\
Punctelia perreticulata & 0,65 & 3 & 1,7 & Folioso \\
Parmotrema tandilensis & 0,23 & 3 & 1,7 & Folioso \\
Xanthoparmelia squamans & 0,17 & 3 & 1,7 & Folioso \\
Punctelia punctilla & 0,11 & 2 & 1,1 & Folioso \\
Parmotrema cetratum & 0,17 & 2 & 1,1 & Folioso \\
Usnea exigua & 0,26 & 2 & 1,1 & Fruticoso \\
Scytinium rogersii & 0,09 & 2 & 1,1 & Crustoso \\
Hypotrachyna dactylifera & 0,03 & 1 & 0,6 & Folioso \\
Physcia cinerea & 0,03 & 1 & 0,6 & Folioso \\
Huneckia pollinii & 0,11 & 1 & 0,6 & Folioso \\
Heterodermia squamulosa & 0,06 & 1 & 0,6 & Folioso \\
Cladonia pyxidata & 0,03 & 1 & 0,6 & Mixto \\
Parmotrema consors & 0,11 & 1 & 0,6 & Folioso \\
Punctelia subpraesignis & 0,03 & 1 & 0,6 & Folioso \\
Dermatocarpon sp. & 0,06 & 1 & 0,6 & Crustoso \\
Rhizocarpon superficiale & 0,06 & 1 & 0,6 & Crustoso \\
Parmotrema eciliatum & 0,03 & 1 & 0,6 & Folioso \\
Peltula omphaliza & 0,03 & 1 & 0,6 & Crustoso \\
Crustoso sp. 9 & 0,06 & 1 & 0,6 & Crustoso \\
Staurothele monosporoides & 0,03 & 1 & 0,6 & Crustoso \\
Halecania australis & 0,06 & 1 & 0,6 & Crustoso \\
Carbonea latypizodes & 0,06 & 1 & 0,6 & Crustoso \\
Pertusaria sp. 2 & 0,2 & 1 & 0,6 & Crustoso \\
Aspicilia sp.6 & 0,03 & 1 & 0,6 & Crustoso \\
\hline
\end{tabular}

Tabla V.44. Riqueza (S), diversidad $\left(H^{\prime}\right)$ y equitatividad (J') en el

\begin{tabular}{lc}
\multicolumn{2}{c}{ PPET } \\
\hline $\mathbf{S}$ & 68 \\
$\mathbf{H}^{\prime}$ & 2,99 \\
$\mathbf{J}$ & 0,71 \\
\hline
\end{tabular}

\section{$\underline{\text { Relación de las especies con variables ambientales }}$}

En el análisis de CCA (figura V.15) muestra 3 grupos definidos, sobre el eje 1 separa en un grupo a los muestreos de la cimas al W que tienen especies particulares. El eje 2 separa en un grupo a los muestreos ubicados al SW, con 
pocas unidades de muestreos, con especies particulares de esta orientación. Sobre este mismo eje se forma otro grupo relacionando a la mayoría de los muestreos con la orientación $S$ y sobre los faldeos, este tercer grupo es el más rico en especies. La variable pendiente quedo fuera del análisis por falta de peso.

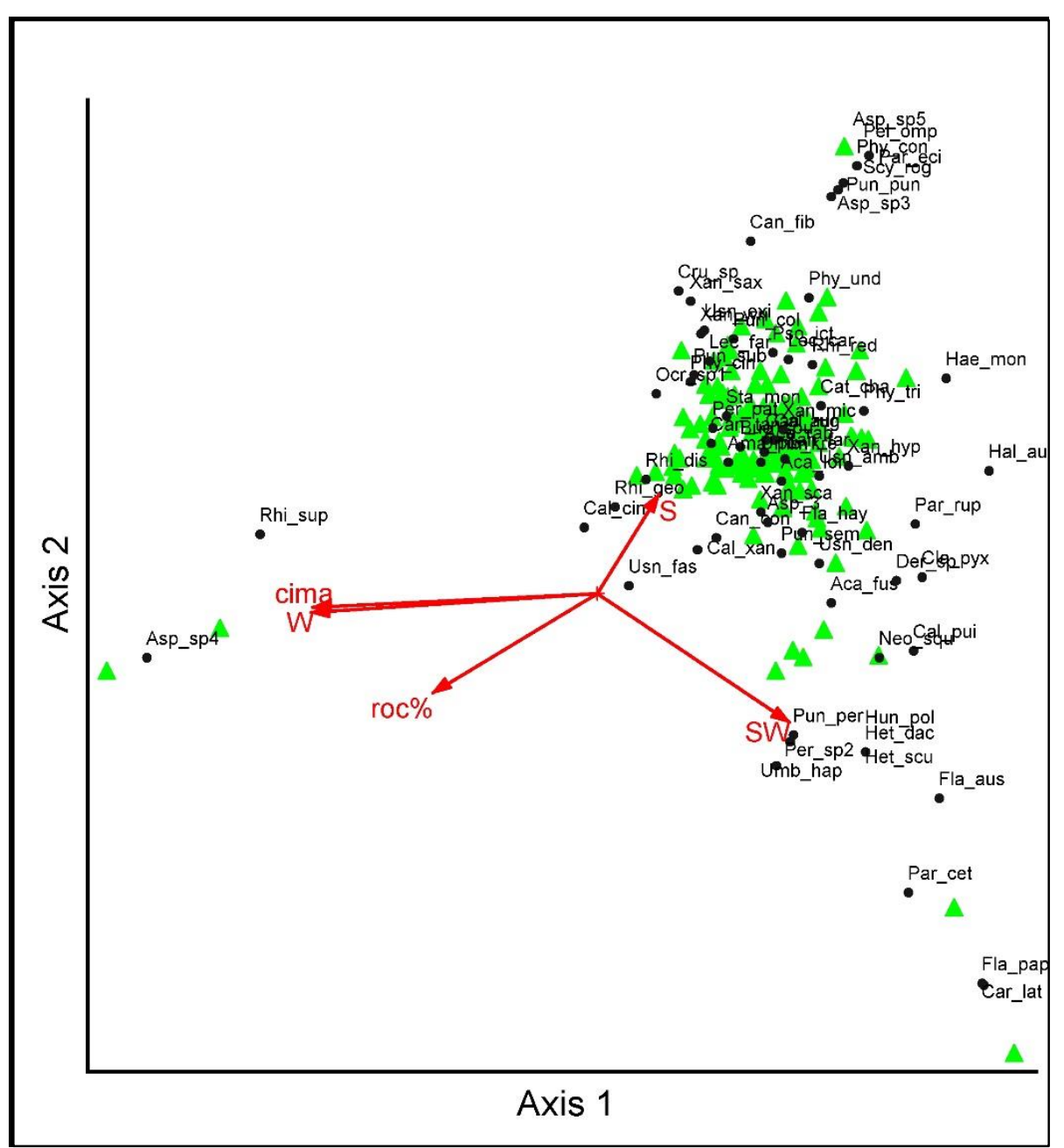

Figura V.15. Análisis de CCA del Parque Provincial Ernesto Tornquist. Referencias de especies de líquenes en Anexo II. Unidades de muestreo $n=175$

\section{V.2. Análisis regional}

Para la provincia de Buenos Aires en esta tesis se registraron tanto en ambientes naturales como en ambientes urbanos un total de 132 especies, las 
cuales se agrupan en 25 familias, todas ellas pertenecientes a la división Ascomycota. De estas la familia Parmeliaceae constituyó el $25 \%$ del total de especies, la familia Physciaceae el $17 \%$ y Teloschistaceae el $9 \%$, mientras que las restantes no superaron el $8 \%$ (figura V.16).

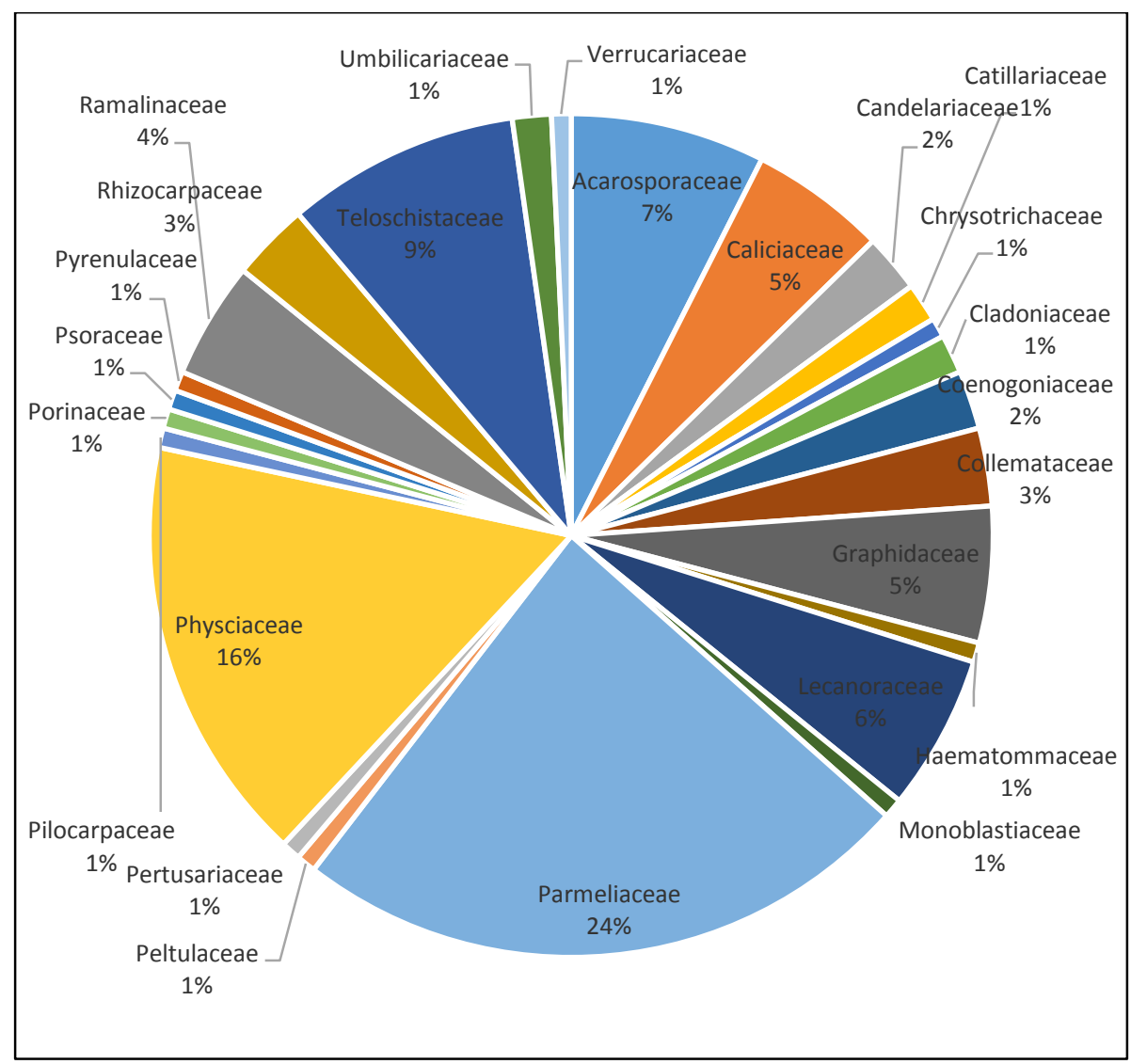

Figura V.16. Porcentaje de especies $(n=132)$ por familia en la provincia de Buenos Aires.

El análisis conjunto mediante un PCA (figura V.17) de todos los datos de cobertura promedio por especie estimados para las 16 localidades descriptas, tanto de ambientes urbanos como de naturales, puso en evidencia que la diferenciaron de los sitios se realiza fundamentalmente por el tipo de sustrato sobre el que se asientan los líquenes. En el mismo se pudieron reconocer 3 grupos, cada uno asociado a un tipo de sustrato diferente. Estas agrupaciones podrían corresponderse así a 3 asociaciones o comunidades: murícolas en ambientes urbanos, saxícolas sobre roquedales serranos y corticícolas en selvas y ambientes ribereños. 
Los sitios urbanos conforman un grupo consolidado que se diferencia claramente de las asociaciones naturales constituidas sobre roquedales en los sistemas serranos de Tandilia y Ventania y sobre cortezas de árboles en la ribera paranoplatense. De las localidades naturales, las más cercanas en el análisis, y por consiguiente las que tienen algún grado de relación con las urbanas son ST y RNPL.

De estas 3 comunidades la comunidad de roquedales presentó la mayor riqueza, seguida por la comunidad de los árboles y por último la urbana. En cuanto a la diversidad y la equitatividad se encontró que la comunidad que presentó mayores valores fue la de los árboles, seguida por la de los roquedales y con los valores más bajos la comunidad urbana (tabla V.45). Se realizó el ISA para todas las especies usando como variable cualitativa el tipo de sustrato, para las especies de ambiente urbano las especies que presentaron un IV significativo fueron: $F$. austrocitrina $(\mathrm{IV}=99,3), \quad S$. monosporoides (IV=91,2) y M. dispersa $(\mathrm{IV}=83,3)$. 


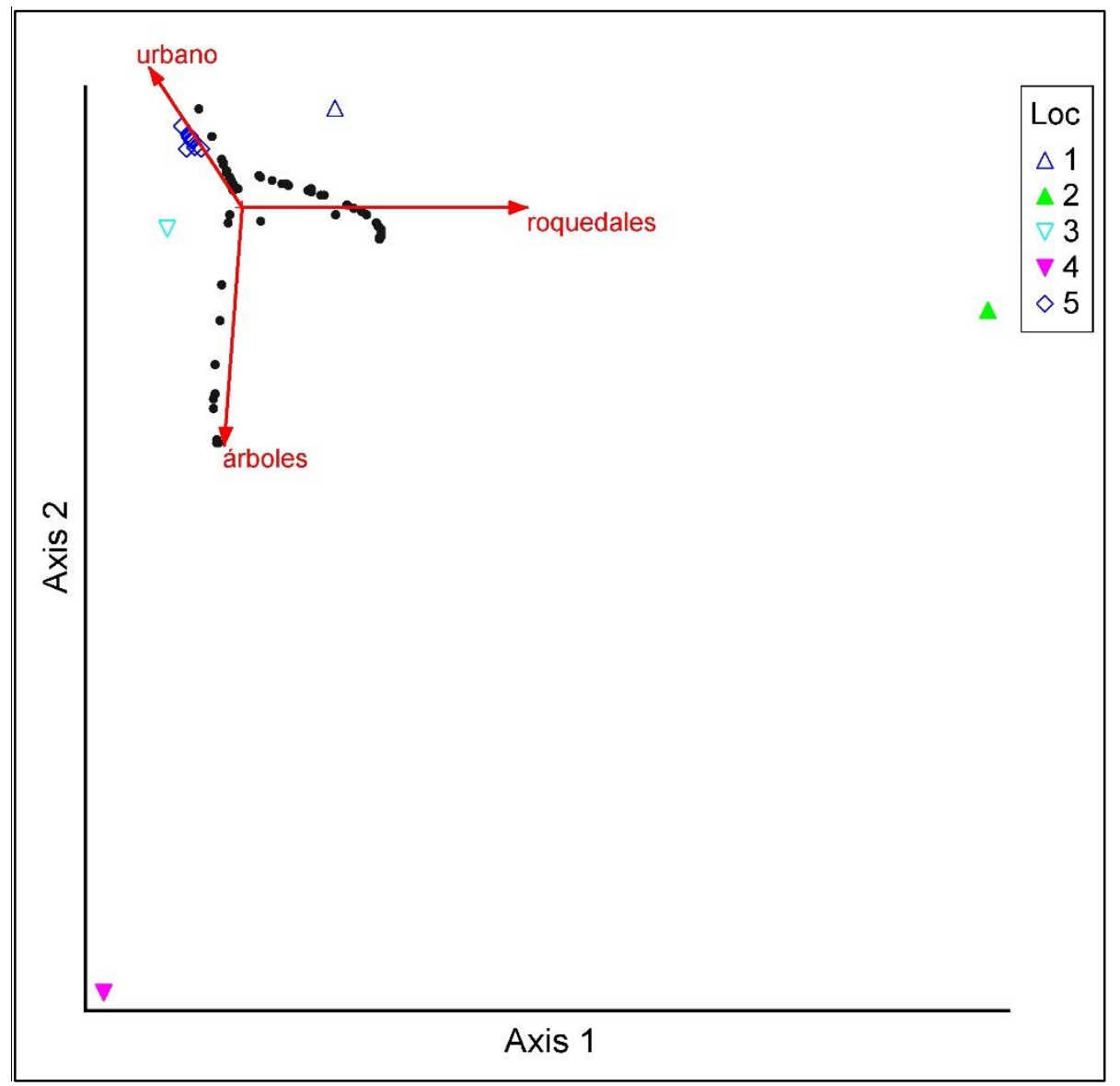

Figura V.17. Analisis de PCA. Especies (puntos negros). Localidades: 1- Sierras de Tandil, $2-$ Parque Provincial E. Tornquist, 3-Reserva Natural Punta Lara, 4- Reserva Natatural Isla Martín García, 5-Localidades urbanas urbanos. Total de localidades usadas $n=16$.

Tabla V.45. Riqueza (S), diversidad (H') y equitatividad $\left(\mathrm{J}^{\prime}\right)$ de las comunidades de líquenes de la provincia de Buenos Aires. $\mathrm{n}=171$

\begin{tabular}{cccc} 
& urbano & roquedales & árboles \\
\hline $\mathbf{S}$ & 48 & 80 & 53 \\
$\mathbf{H}$ & 1,04 & 3,36 & 3,4 \\
$\mathbf{J}$ & 0,27 & 0,76 & 0,87 \\
\hline
\end{tabular}

Se comparó mediante índices de similitud (Jaccard) y disimilitud (Cody) la biota liquénica que ocupa sustratos nativos y antrópicos. En el índice de Cody, los valores más altos y por lo tanto de mayor diferencia fueron entre Ensenada y el PPET, mientras que los más bajos son entre Ensenada y la 
RNPL. El índice de Jaccard (lj) mostró que la biota liquénica de las reservas de Punta Lara y Martín García solo tuvieron alguna similitud con la de Ensenada y que no existe ningún tipo de relación con el resto de las localidades analizadas. Por otro lado el valor más alto y por lo tanto, las localidades más similares fueron Ensenada y la Reserva Natural de Punta Lara, aunque con valores muy bajos $(0,1)$ (tabla V.46).

Tabla V.46. Índices de Cody ( $\beta$ ) y de Jaccard (lj), entre las localidades de muestreo de líquenes sobre sustratos naturales y las localidades correspondientes a ciudades con muestreos sobre sustratos antrópicos. Reserva Natural de Punta Lara (RNPL) y en la Reserva Natural Isla Martín García (RNIMG) y saxícola en las Sierras de Tandilia (ST) y en el Parque Provincial E. Tornquist (PPET). En negrita se destacan los valores más altos para cada índice.

\begin{tabular}{l|cc|cc|cc|cc} 
& \multicolumn{2}{|c}{$\mathbf{R N P L}$} & \multicolumn{2}{c}{$\mathbf{R N M G}$} & \multicolumn{2}{c|}{$\mathbf{S T}$} & \multicolumn{2}{c}{ PPET } \\
& $\boldsymbol{\beta}$ & $\mathbf{j}$ & $\boldsymbol{\beta}$ & $\mathbf{j}$ & $\boldsymbol{\beta}$ & $\mathbf{j}$ & $\mathbf{B}$ & $\mathbf{~ j j}$ \\
\hline Martin García & 32,5 & 0,015 & 30,5 & 0,032 & 41 & 0,024 & 51 & 0,029 \\
Ensenada & 25,5 & $\mathbf{0 , 1 8}$ & 29,5 & $\mathbf{0 , 0 7 5}$ & $\mathbf{4 3}$ & 0,033 & $\mathbf{5 4}$ & 0,027 \\
La Plata & 32 & 0 & 31 & 0 & 39,5 & 0,024 & 49,5 & 0,029 \\
Brandsen & 28,5 & 0 & 27,5 & 0 & 37 & 0,013 & 47 & 0,032 \\
General Belgrano & 28,5 & 0 & 27,5 & 0 & 37 & 0,013 & 47 & 0,021 \\
Azul & 32,5 & 0 & 31,5 & 0 & 40 & 0,024 & 49 & 0,039 \\
Tandil & 34 & 0 & 33 & 0 & 40,5 & $\mathbf{0 , 0 3 6}$ & 51,5 & 0,038 \\
Saldungaray & 32,5 & 0 & 31,5 & 0 & 41 & 0,012 & 49 & 0,039 \\
Ventana & 28 & 0 & 27 & 0 & 36,5 & 0,014 & 45,5 & 0,032 \\
Tornquist & 28,5 & 0 & 27,5 & 0 & 37 & 0,013 & 41 & 0,032 \\
Bahía Blanca & $\mathbf{3 4 , 5}$ & 0 & $\mathbf{3 3 , 5}$ & 0 & 41 & 0,035 & 50 & $\mathbf{0 , 0 4 8}$ \\
Carmen de Patagones & 30 & 0 & 29 & 0 & 38,5 & 0,013 & 48,5 & 0,031 \\
\hline
\end{tabular}

\section{V.3. La comunidad de líquenes urbanos}

En cuanto al ambiente urbano (figuras $V .18,19,20$ ) se refiere se encontraron un total de 48 especies las cuales se agruparon en 14 familias, de estas la familia Parmeliaceae presentó el $17 \%$ de las especies, las familias Teloschistaceae, Acarosporaceae y Physciaceae total sumaron un $13 \%$ de las especies (figura V.21). 
Capítulo V: Resultados
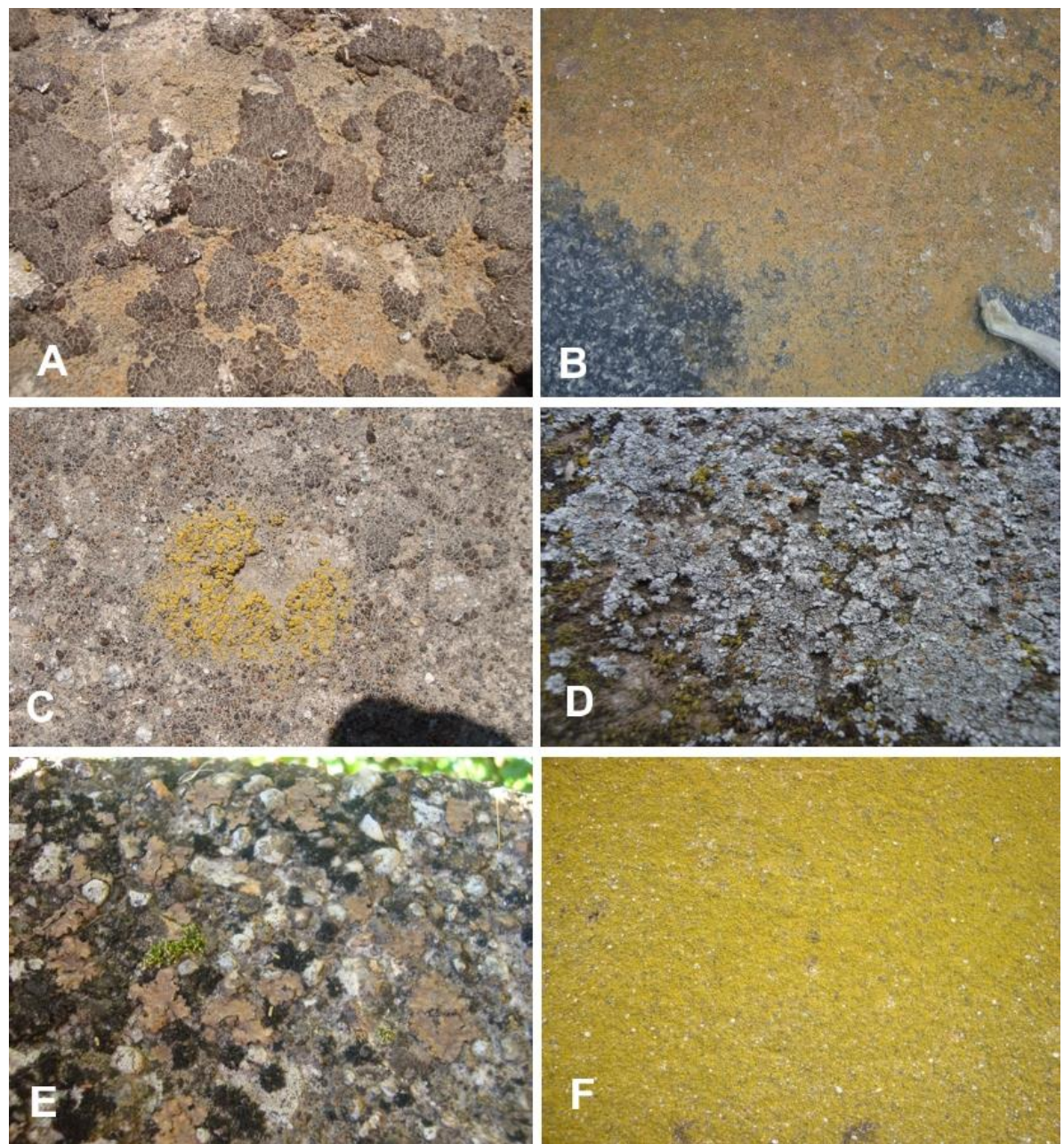

Figura V. 18. Especies urbanas. A) Acarospora mendozana; B) Athalia holocarpa; C) Candelariella aurella; D) Caloplaca teicholyta; E) Endocarpon sp.; F) Flavoplaca austrocitrina 


\section{Capítulo V: Resultados}
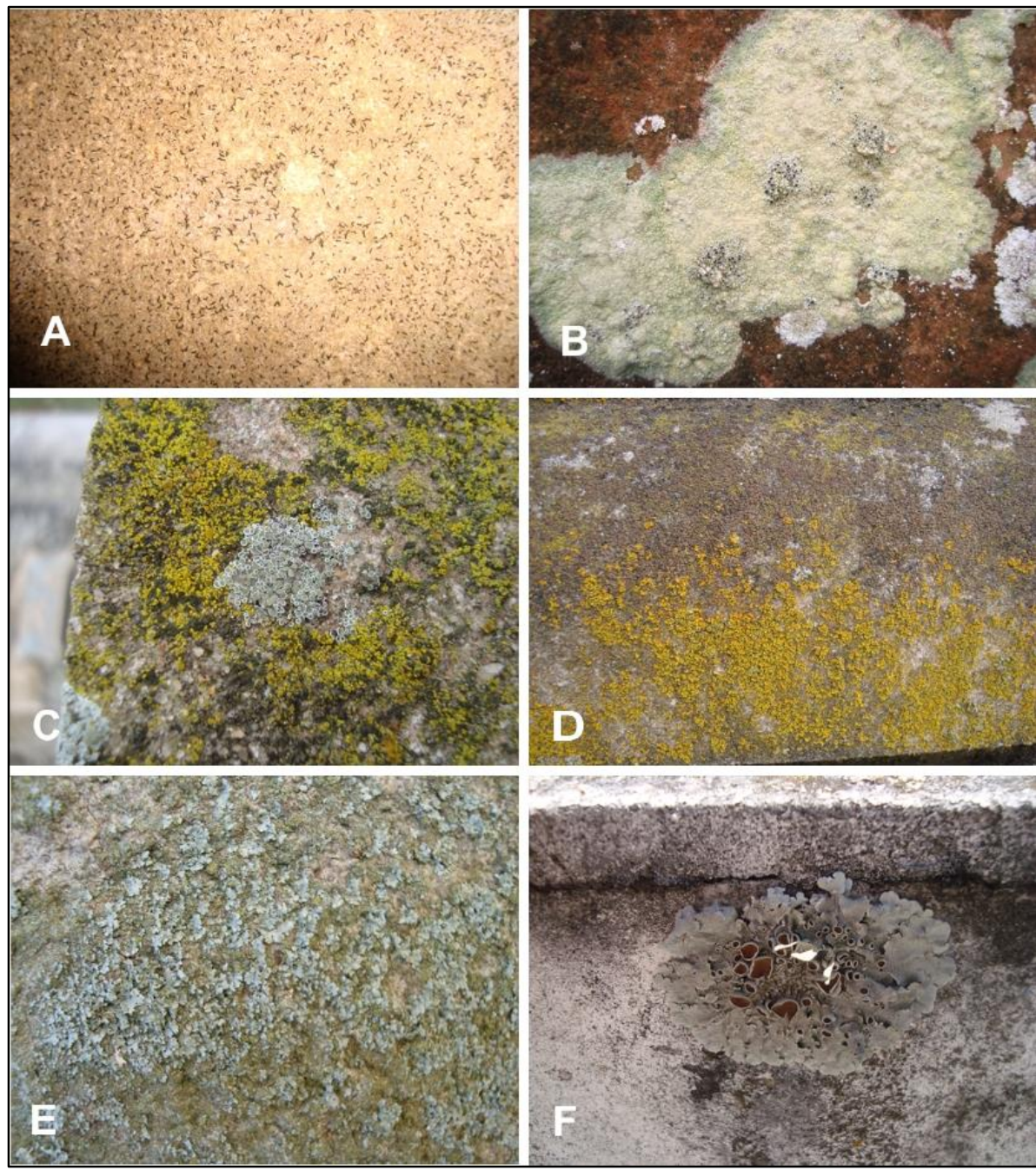

Figura V. 19. Especies urbanas. $\mathrm{A}=$ Graphis virescens $\mathrm{B}=$ Lecanora sp. $\mathrm{C}=$ Myrilecis dispersa; $\mathrm{D}=$ Oxneria fallax y Staurothele monosporoides; $\mathrm{E}=$ Physcia tribacia; $\mathrm{F}=$ Punctelia subpraesignis. 


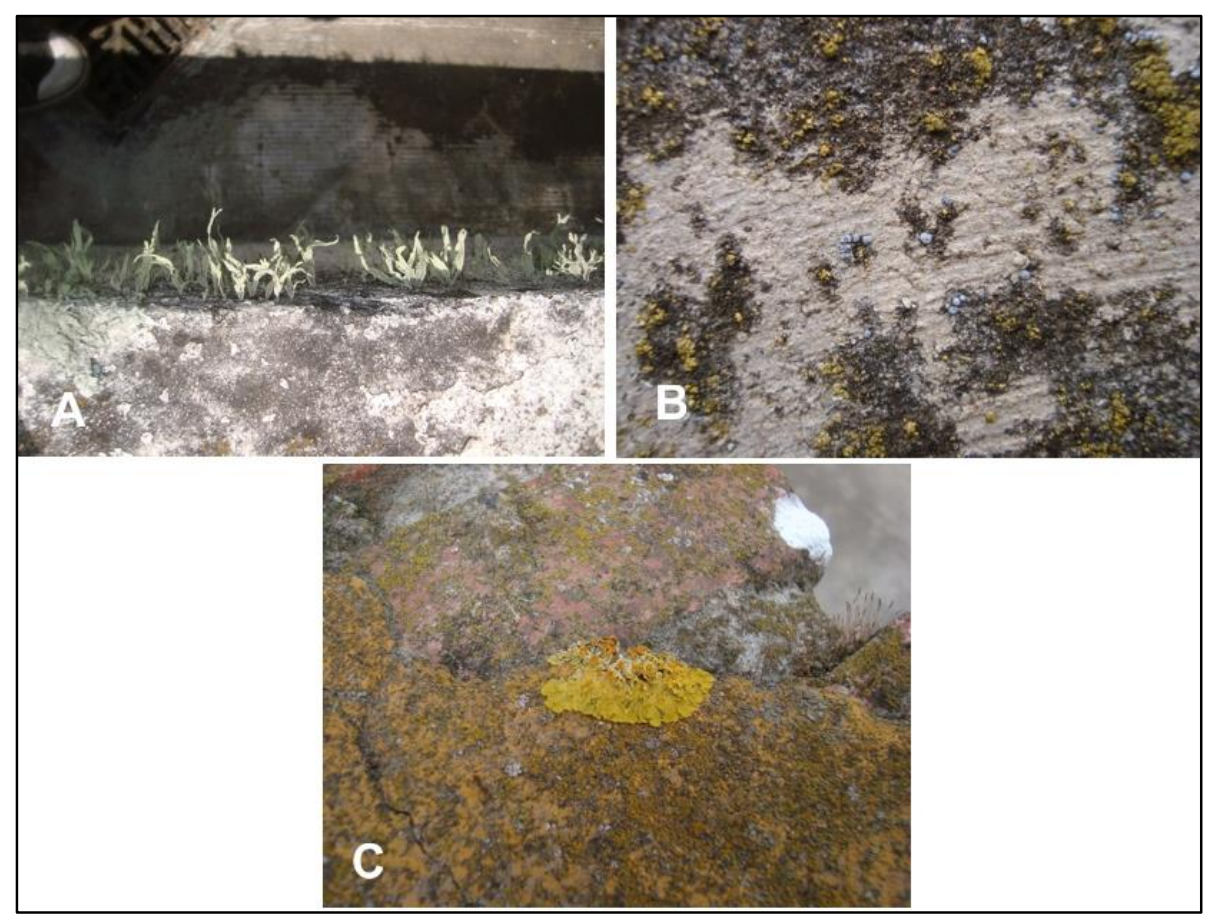

Figura V. 20. Especies urbanas. $\mathrm{A}=$ Ramalina celastri; $\mathrm{B}=$ Sarcogyne regularis; $\mathrm{C}=$ Xathoria parietina.

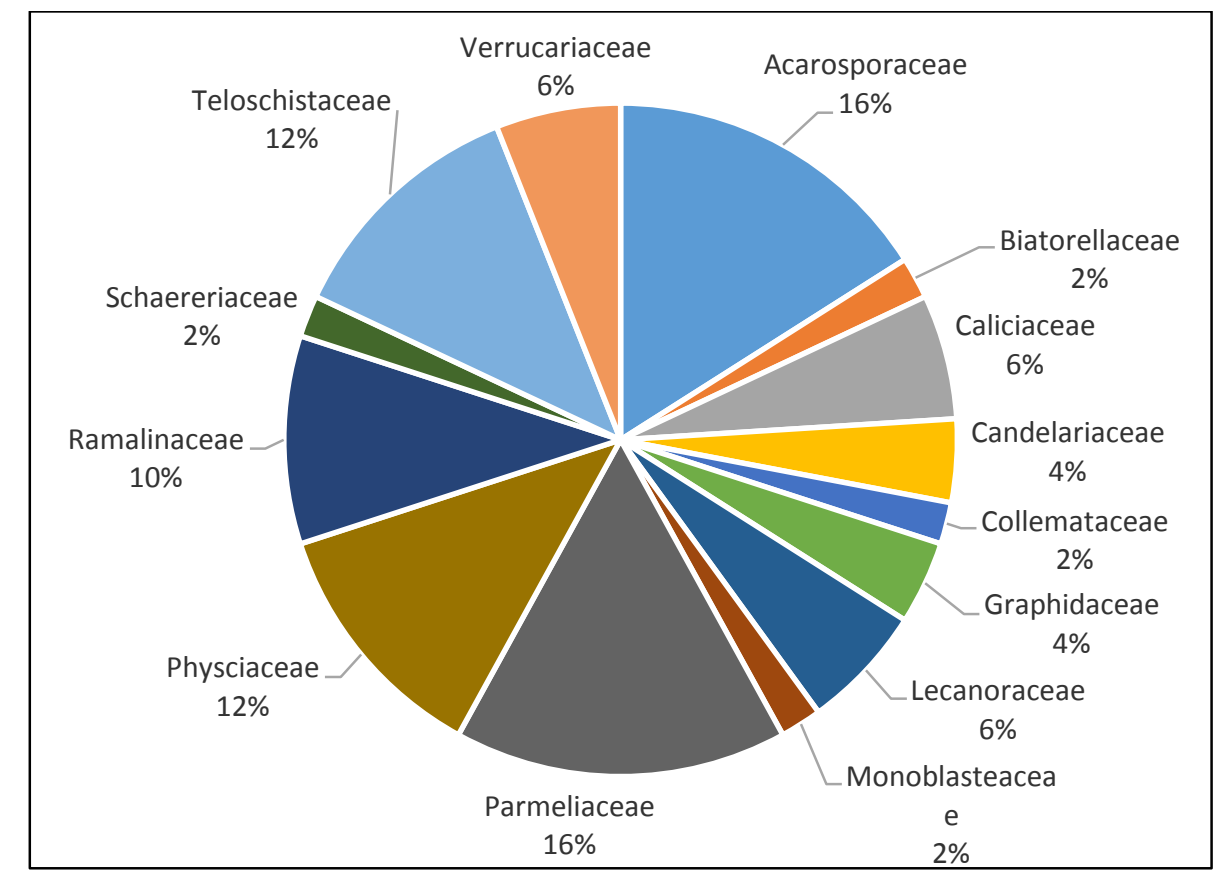

Figura V.21. Porcentaje las especies $(n=48)$ encontradas en ambientes urbanos de la provincia de Buenos Aires por familia. 
De las 48 especies encontradas sobre edificios en la provincia de Buenos Aires solo una, F. austrocitrina, apareció en el 100\% de las localidades de muestreo, de las restantes especies el 8,33\% se registraron entre el 91 al $75 \%$ de las localidades; el $16,7 \%$ de las especies tuvo una frecuencia del 74 al $25 \%$ de las localidades; el $10,4 \%$ de las especies se encontró entre el 24 y el $10 \%$ de las localidades y el $66,6 \%$ de las especies estuvo presente en menos del $10 \%$ de las localidades muestreadas (figura V.22). En cuanto a los morfotipos presentes, se encontró que el $58 \%$ eran especies crustosas, el $33 \%$ foliosas, el $7 \%$ fruticulosas y el $2 \%$ gelatinosas (figura V.23). 
Capítulo V: Resultados

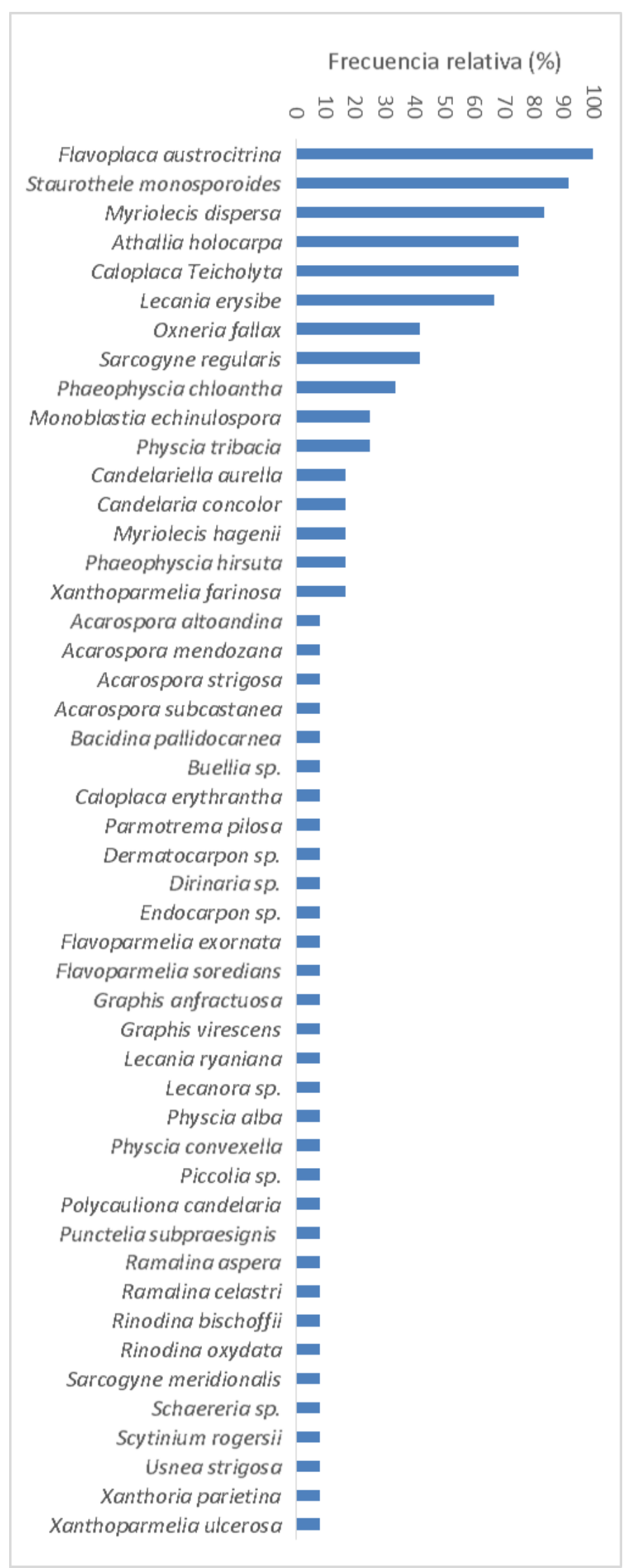

Figura V.22. Frecuencia relativa (\%) de las especies de líquenes registradas en las localidades de muestreo urbanas. 


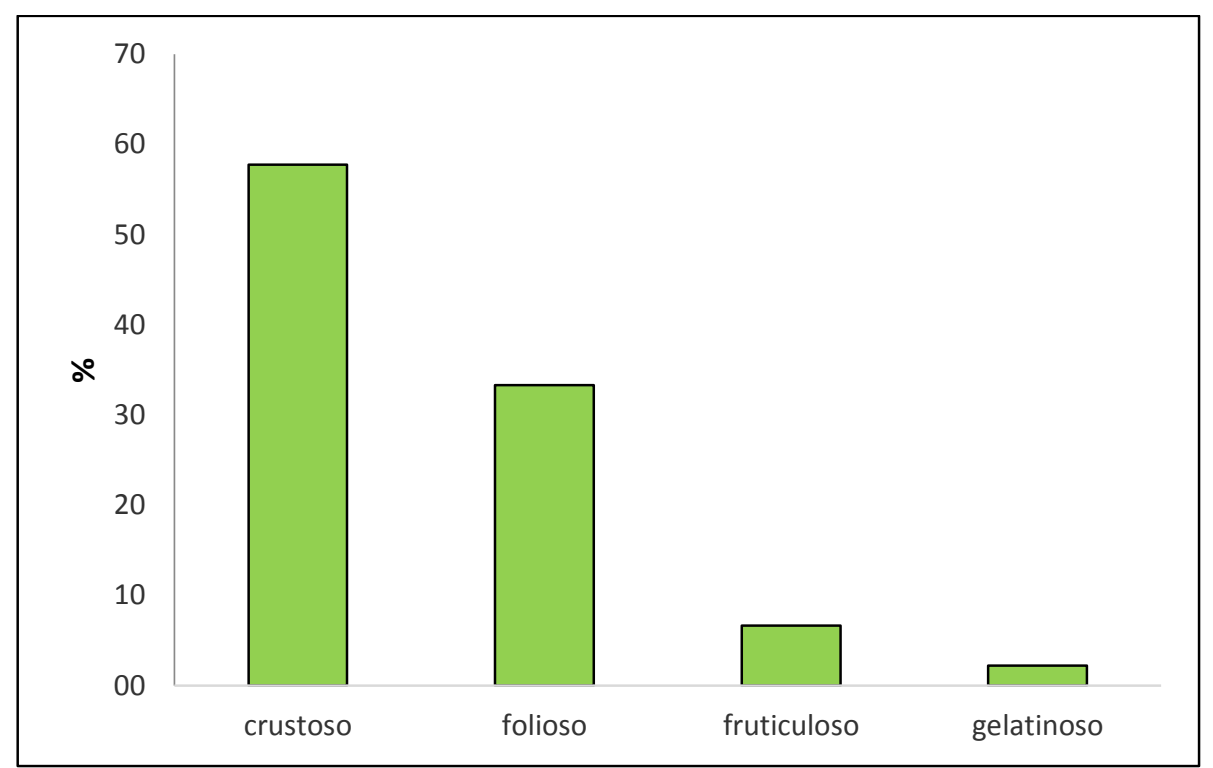

Figura V.23. Porcentaje de los morfotipos presentes de las especies encontradas creciendo sobre sustrato antrópico.

El análisis de NMS (figura V.24) se realizó solo con las especies de ambientes urbanos. En el centro del gráfico aparecen las especies representativas de la mayoría de las localidades ( $F$ : austrocitrina, $C$. teicholyta, M. dispersa, S. monosporoides y A. holocarpa). Sobre el eje 1 se separó la localidad Ensenada en base a un conjunto de especies exclusivas de este sitio que además solo fueron encontradas sobre el sustrato pintura, aunque se trata de especies primariamente corticícolas. Sobre el eje 2 se separó en el extremo inferior la localidad Bahía Blanca, en base a un conjunto de especies exclusivas que fueron encontradas sobre el sustrato laja, con la excepción de Phaeophyscia chloantha que también se encontró sobre mortero y laja. El resto de las especies de líquenes se agrupan según su presencia en las localidades sin observar ningún patrón distinguible. 


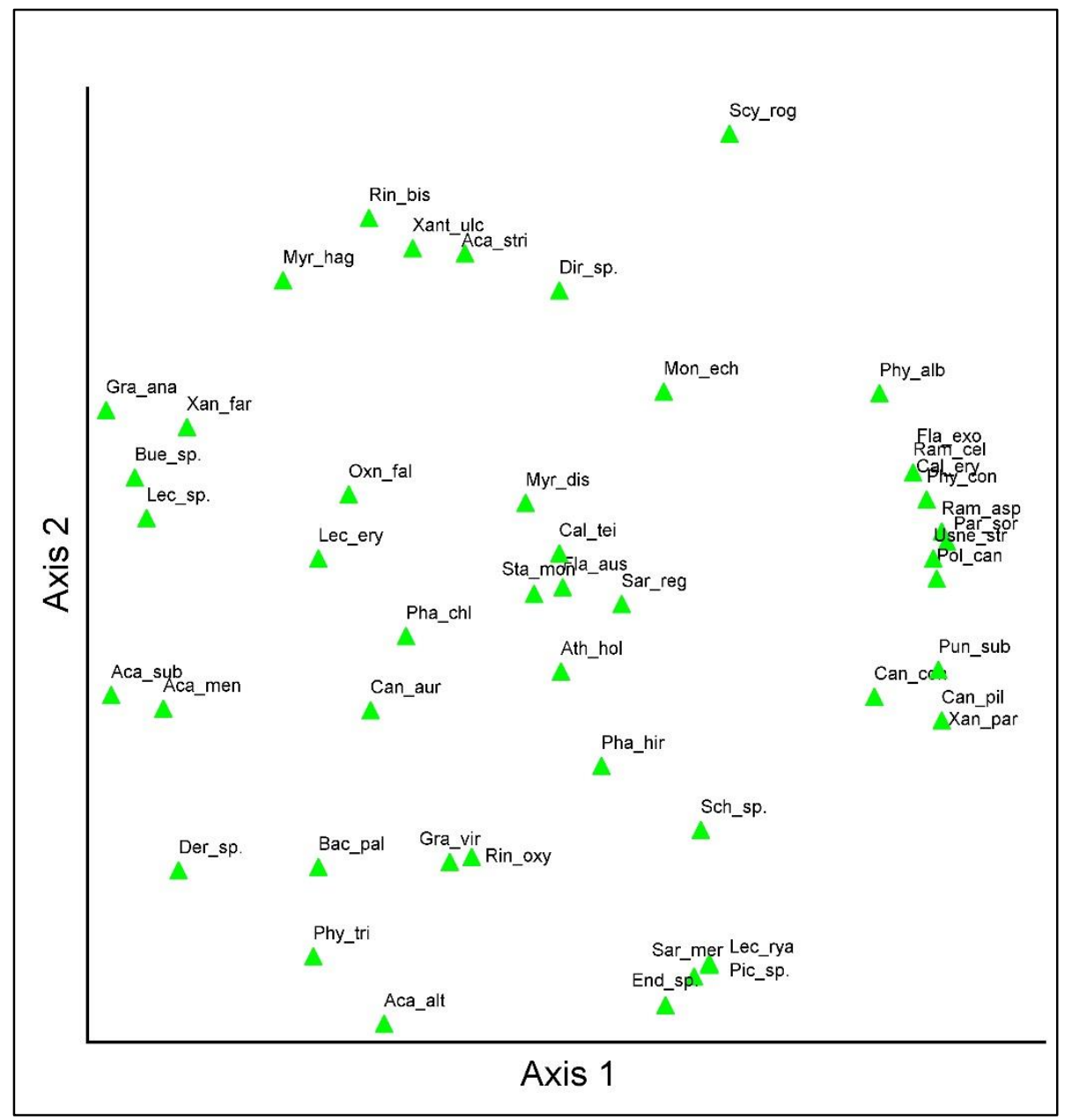

Figura V.24. Analisis NMS de las coberturas medias de cada especie por localidad. Referencias de especies de líquenes en Anexo II. Unidades de muestreo $\mathrm{n}=132$.

Se realizó un listado de las citas previas para Argentina (sobre sustrato natural) de cada especie urbana registrada en este estudio, mediante un análisis de la bibliografía (Rosato \& Scutari, 2000; Calvelo \& Liberatore, 2002; Knudsen et al., 2008; de la Rosa et al., 2011; Rodríguez, 2011). La comunidad urbana está compuesta por un $63 \%$ de especies saxícolas, $21 \%$ de especies corticícolas y un $16 \%$ de especies que pueden estar en ambos sustratos. En cuanto a su distribución, se encontró que el 12,2\% de las especies no habían sido citadas para Argentina previamente, y el 29,3\% fueron citadas para el país pero no para la provincia de Buenos Aires (tabla V.47). 
Tabla V.47. Especies urbanas de la provincia de Buenos Aires, el sustrato sobre el cual fueron encontradas y su distribución para Argentina.

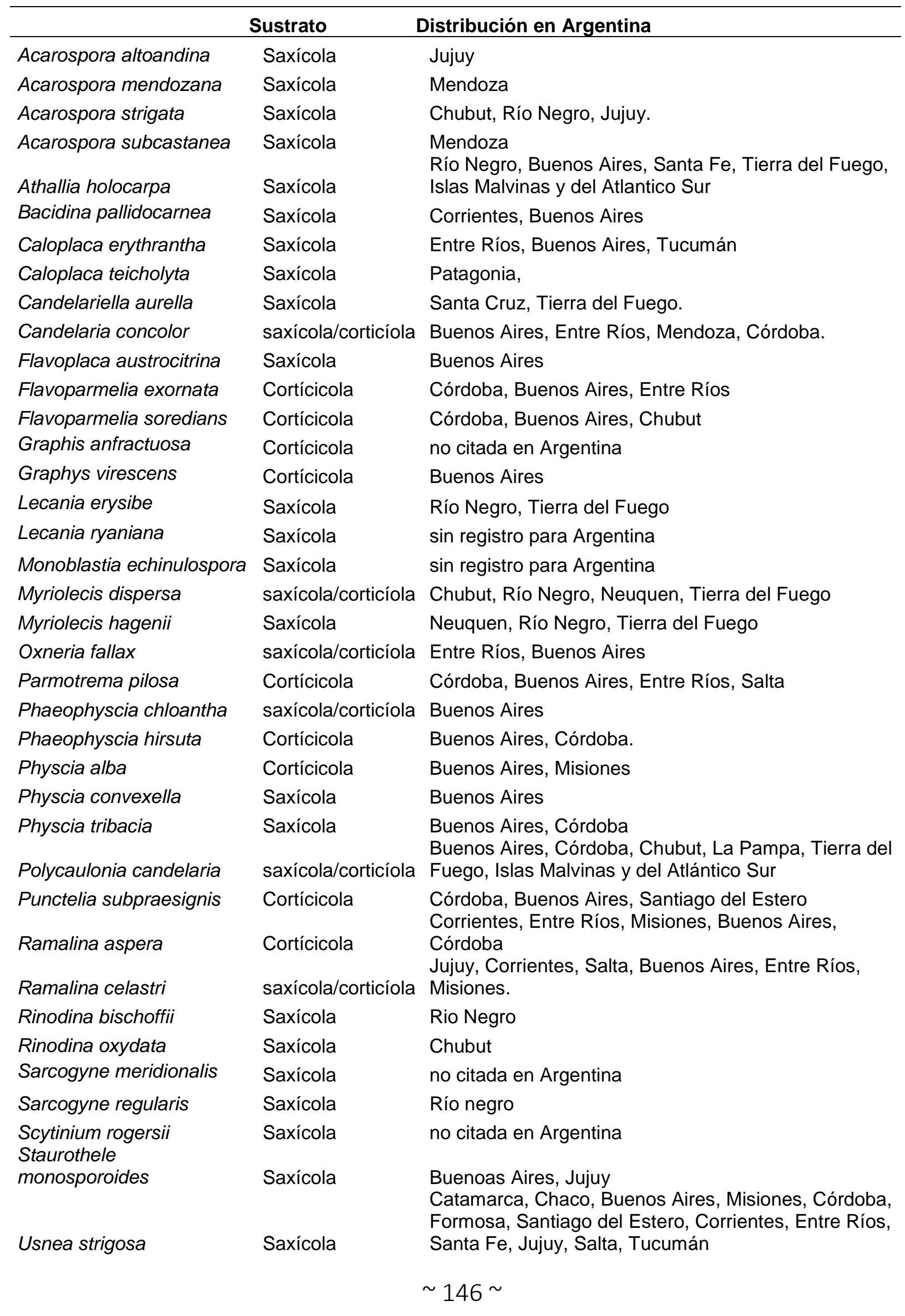




\begin{tabular}{lll} 
Xanthoparmelia farinosa & Saxícola & $\begin{array}{l}\text { Buenos Aires, Catamarca, Chubut, Córdoba, Jujuy, La } \\
\text { Rioja, Mendoza, Salta, San Juan } \\
\text { Buenos Aires, Catamarca, Chubut, Jujuy, La Rioja, }\end{array}$ \\
$\begin{array}{ll}\text { Xanthoparmelia ulcerosa } \\
\text { Xanthoria parietina }\end{array}$ & $\begin{array}{l}\text { Saxícola } \\
\text { Saxícola }\end{array}$ & $\begin{array}{l}\text { Mendoza, Misiones, Neuquen. } \\
\text { Buenos Aires, Chubut, Córdoba, Tucumán }\end{array}$ \\
\hline
\end{tabular}

Al comparar las afinidades entre la composición específica de las distintas localidades urbanas, se observó que el índice de Cody (1975) presentó valores en general bajos que denotan poca diferencia entre ellos. Las localidades con los valores más altos y por consiguiente con mayor diferencia entre sí, fueron Ensenada con Martín García, y Azul con Ensenada, mientras que los que tuvieron menores diferencias fueron General Belgrano y Brandsen, Tornquist y Brandsen, Ventana y Brandsen, Ventana y General Belgrano. El índice de Jaccard, que varía entre 0 y 1 , presentó valores bajos de similitud para la mayoría de las localidades: el par con un índice más bajo fue Bahía Blanca - Ventana, mientras que el valor más alto y por lo tanto más similar fue entre Tornquist y Brandsen (tabla V.48).

Tabla V.48. Índices comparativos entre sitios. En la parte inferior índice de Jaccard y en cursiva índice de Cody. En negrita se destacan los valores más altos para cada índice.

\begin{tabular}{ccccccccccccc}
\hline & MG & En & LP & Br & GB & Az & Ta & Sa & To & Ve & BB & CP \\
\hline MG & - & $\mathbf{1 3}$ & 7,5 & 6 & 6 & 9 & 8 & 5 & 5 & 6,5 & 10,5 & 9 \\
En & 0,16 & - & 10,5 & 9 & 9 & $\mathbf{1 2}$ & 11 & 10 & 10 & 9,5 & $\mathbf{1 1 , 5}$ & 9 \\
LP & 0,29 & 0,22 & - & 3,5 & 3,5 & 4,5 & 3,5 & 3,5 & 4,5 & 5 & 7 & 4,5 \\
Br & 0,25 & 0,18 & 0,42 & - & 1 & 5 & 5 & 2 & 1 & 1,5 & 5,5 & 3 \\
GB & 0,25 & 0,18 & 0,42 & 0,67 & - & 4 & 5 & 2 & 2 & 1,5 & 6,5 & 3 \\
Az & 0,22 & 0,17 & 0,47 & 0,29 & 0,38 & - & 7 & 5 & 6 & 5,5 & 9,5 & 7 \\
Ta & 0,30 & 0,24 & $\mathbf{0 , 5 9}$ & 0,33 & 0,33 & 0,33 & - & 5 & 6 & 6,5 & 8,5 & 5 \\
Sa & 0,41 & 0,20 & 0,50 & $\mathbf{0 , 5 6}$ & $\mathbf{0 , 5 6}$ & 0,38 & 0,41 & - & 2 & 3,5 & 6,5 & 4 \\
To & 0,33 & 0,13 & 0,31 & $\mathbf{0 , 6 7}$ & 0,43 & 0,20 & 0,25 & $\mathbf{0 , 5 6}$ & - & 2,5 & 7,5 & 4 \\
Ve & 0,19 & 0,14 & 0,23 & $\mathbf{0 , 5 0}$ & $\mathbf{0 , 5 0}$ & 0,21 & 0,19 & 0,30 & 0,29 & - & 8 & 3,5 \\
BB & 0,16 & 0,21 & 0,30 & 0,27 & 0,19 & 0,17 & 0,26 & 0,28 & 0,12 & 0,059 & - & 6,5 \\
CP & 0,14 & 0,25 & 0,40 & 0,40 & 0,40 & 0,22 & 0,41 & 0,38 & 0,27 & 0,3 & 0,28 & - \\
\hline
\end{tabular}


Del análisis de los componentes de la diversidad entre las las distintas ciudades analizadas (figura V.25) se observó que Ensenada presentó la riqueza más alta mientras que la más baja fue registrada sobre los muros muestreados en el PPET. La diversidad obtuvo el valor mayor en Isla Martín García, mediante la prueba de significancia de diversidad se comprobó que esta localidad no presentaba diferencias significativas con las localidades de La Plata, Ensenada, Bahía Blanca y Tandil, teniendo diferencias significativas con el resto de las localidades $(p<0,05)$. En cambio el menor valor de diversidad se encontró en la localidad de Tornquist, el cual presentó diferencia significativa con el resto de las localidades $(p<0,05)$.

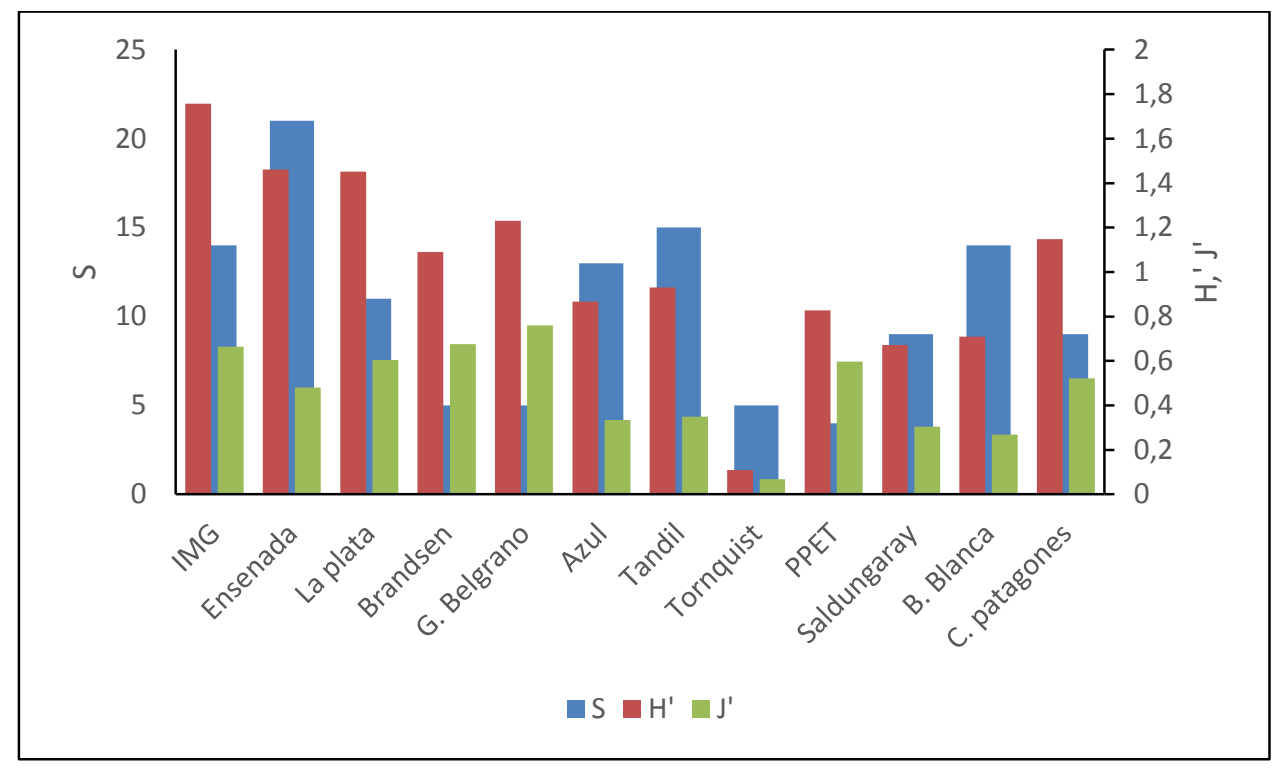

Figura V.25. Riqueza (S), diversidad $\left(\mathrm{H}^{\prime}\right)$ y equitatividad $\left(\mathrm{J}^{\prime}\right)$ de todas las localidades relevadas

\section{3.1. Análisis de la variabilidad geográfica}

En la figura V.26, se realizó un dendrograma de dos vías, en el cual se realizó un cruzamiento entre las especies y las localidades muestreados en ambientes urbanos. En cuanto a las especies, la única que se encontró en todos los sitios es $F$. austrocitrina, seguida por $M$. dispersa que solo estuvo ausente de Brandsen. F. austrocitrina, M. dispersa, S. monosporoides, L. 
erysibe y $C$. teicholyta conformaron un grupo muy relacionado. Unidas a éstas se encuentran $A$. holocarpa y $S$. regularis que se relacionaron estrechamente entre si, externo a este grupo se encuentra la especie $O$. fallax. Las restantes en su mayoría se encuentran agrupadas con las otras especies, muchas de ellas aparecieron en una sola localidad. Unidos a este grupo aparecen grupos de especies con pocas presencias y únicos para una sola localidad, como las especies corticícolas que se encontraron en Ensenada o las especies que se encontraron sobre laja en Bahía Blanca.

En tanto las localidades no parece encontrarse un patrón que esté asociado a un gradiente latitudinal, sino que se agrupan con respecto a las especies que muestran en común y son separadas por las diferencias que presentan. Localidades próximas muestran en algunos casos una relación fuerte como Brandsen y General Belgrano (distancia $75 \mathrm{~km}$ ), en otros casos localidades muy distantes muestran relaciones fuertes como La Plata $y$ Saldungaray (distancia $496 \mathrm{~km}$ ) y en otros casos localidades cercanas no muestran relaciones como Tornquist y Saldungaray (distancia $41 \mathrm{~km}$ ).

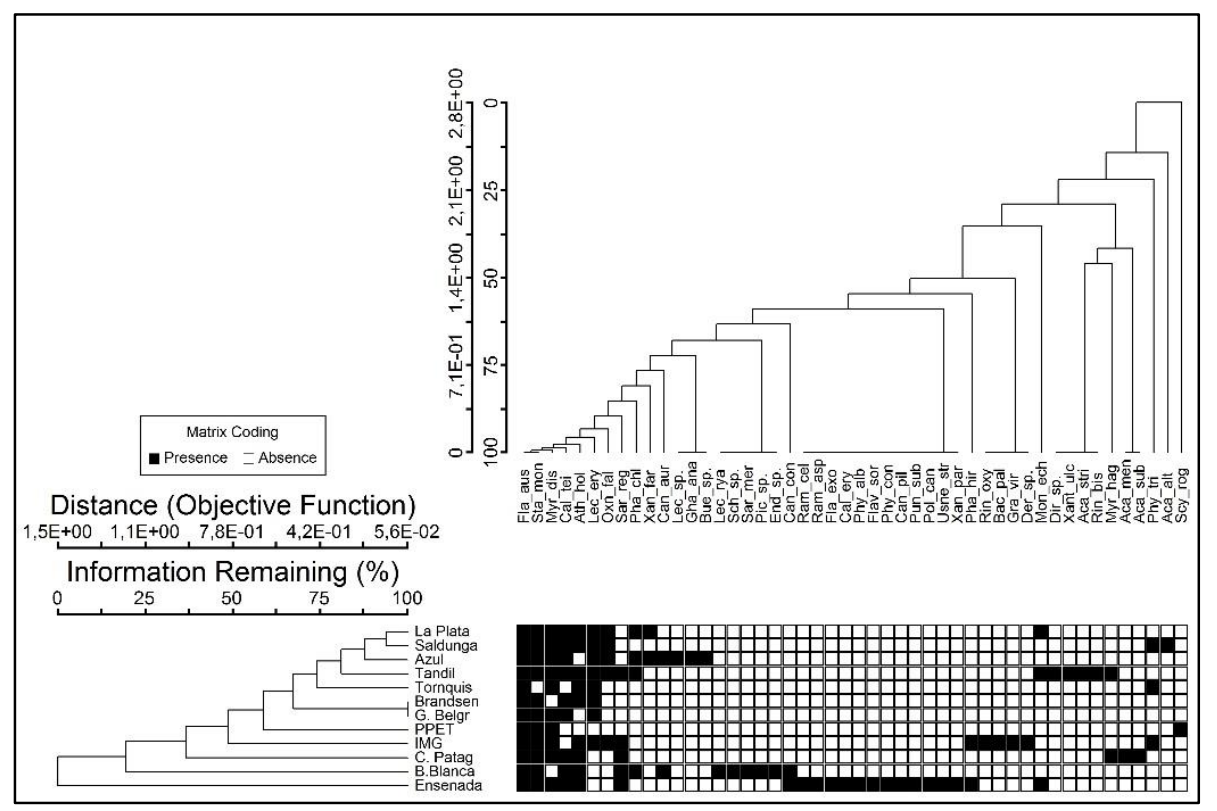

Figura V.26. Análisis Cluster de dos vías, entre las localidades con sustrato antrópico y especies de líquenes encontradas. Localidades 
Se realizó un análisis de las variables climáticas de cada localidad en las que se relevaron sustratos antrópicos. En el análisis de PCoA -Principal Coordinates Analysis- (figura V.27) se apreciaron 3 grupos de localidades, un grupo conformado por las localidades de Isla Martín García, Ensenada, General Belgrano, Azul, Tandil, La Plata, Brandsen; otro grupo conformado por PPET, Tornquist, Saldungaray, Bahía Blanca y alejado de estos dos grupos la localidad de Carmen de Patagones. Esta última localidad se separó del resto por su baja precipitación teniendo un clima más árido que el resto, mientras que el resto de las localidades comparten cierta semejanza en sus climas, y se agrupan principalmente en función de la precipitación mínima formando un gradiente desde la localidad con mayor valor (Isla Martín García) hasta la de menor (Bahía Blanca). Este mismo gradiente no concuerda con el agrupamiento de localidades y especies de la figura V.26. 


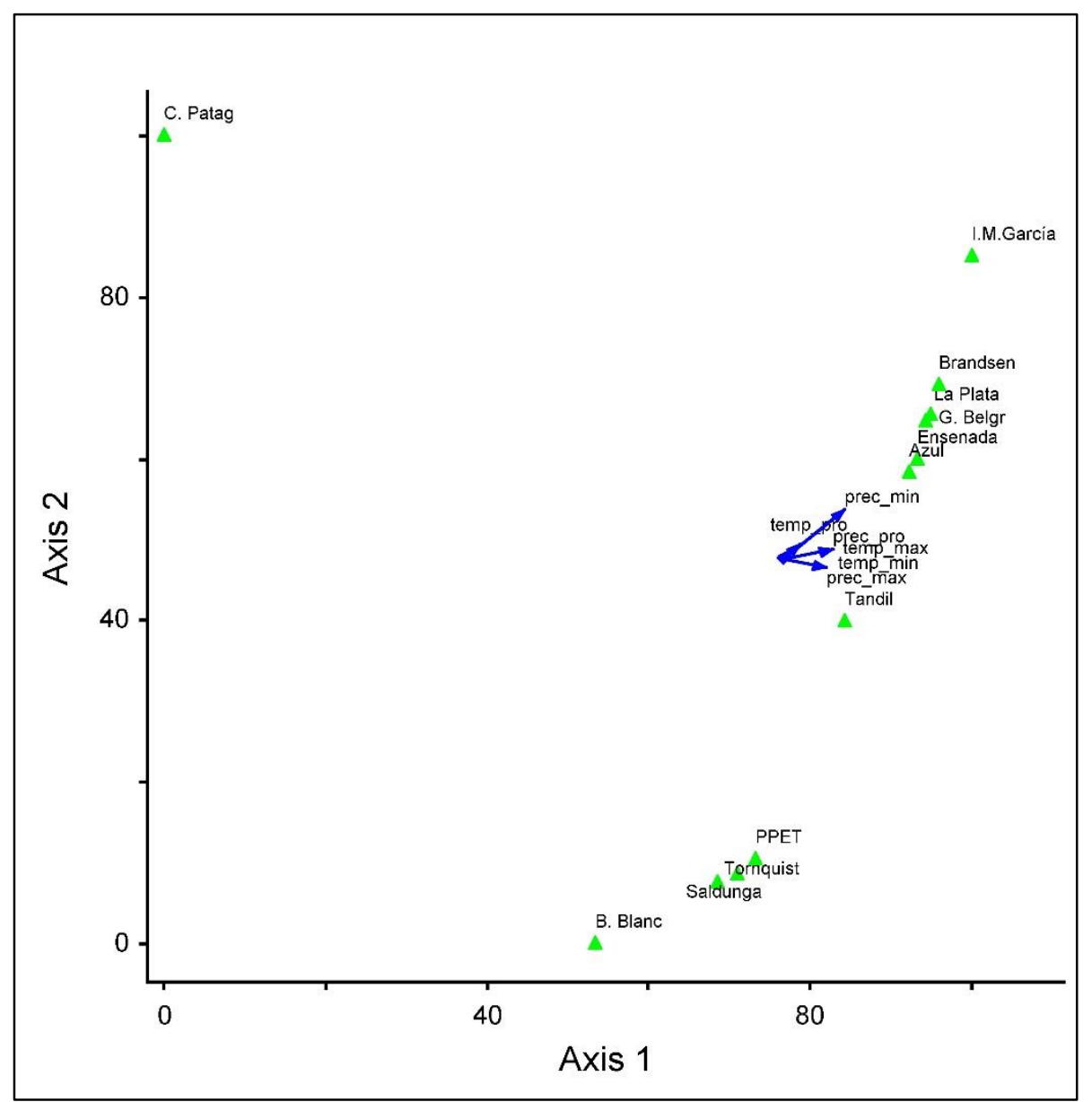

Figura V.27. Análisis de PCoA (Principal Coordinates Analisis) entre especies presentes por localidad en conjunto con las variables ambientales. Variables: temp_pro: temperatura promedio anual; prec_prom= precipitación promedio anual; temp_min= temperatura mínima anual; temp_max=temperatura máxima anual; prec_min=precipitación minima anual; prec_max=precipitación máxima anual.

\section{V.3.2. Preferencias ambientales de las especies urbanas}

El sustrato que presentó mayor riqueza de especies fue el mortero (24) seguido de la pintura (20) y el granito (16). En cuanto a la inclinación la horizontal presentó una mayor riqueza (40) que la vertical (25), dentro de la vertical la altura 3 presentó una mayor riqueza (22) seguida por la altura 2 (20) y la altura 1 (19). En cuanto a las orientaciones se encontró mayor riqueza al W (15), seguida por el E, SE y N (13). 
A 50 y $150 \mathrm{~cm}$ sobre el suelo (alturas 1 y 3) $F$. austrocitrina se encontró como especie dominante en todas las localidades con la excepción de Tandil donde $C$. teicholyta fue la dominante. Por otro lado sobre $1 \mathrm{~m}$ sobre el suelo (altura 2) F. austrocitrina fue la especie con mayor cobertura en el $100 \%$ de las ciudades muestreadas. En cuanto a las preferencias de altura sobre el suelo se encontró que solo las alturas 1 y 3 presentaron especies exclusivas, el 10,52\% y $13,63 \%$ respectivamente. Las orientaciones $\mathrm{W}, \mathrm{NE}, \mathrm{NW}$ y $\mathrm{S}$ presentaron exclusividad para el $20 \%, 16,67 \%, 12,5 \%$ y $10 \%$ de las especies respectivamente; las restantes orientaciones no presentaron especies exclusivas. La prueba de Kruskal-Wallis no mostró diferencias significativas entre las 3 alturas tomadas y la presencia de especies $(p>0,05)$.

Flavoplaca austrocitrina también fue la especie dominante sobre los sustratos de posición horizontal en el $70 \%$ de los casos, en tanto que $C$. teicholyta y $A$. holocarpa lo fueron en un 20 y $10 \%$ respectivamente. El $60 \%$ de las especies encontradas sobre sustratos horizontales solo se encontraron creciendo bajo esta condición, mientras que sobre sustratos verticales el $32 \%$ fueron exclusivas de esta inclinación (tabla V.49). El test de $T$ no mostró diferencias significativas entre las 2 inclinaciones y la presencia de especies $(p$ $>0,05)$.

En relación a la exposición $F$. austrocitrina fue la especie con mayor cobertura en el $100 \%$ de los sitios SE, SW, W, E y NW muestreados, no así sobre la orientación $\mathrm{N}$ en que fue dominante en el $83 \%$ de los sitios, mientras que Dirinaria $s p$. lo fue en el $17 \%$ restante. Sobre la orientación $S F$. austrocitrina dominó en el $60 \%$ de los casos, mientras que C. teicholyta y $G$. virescens dominaron en el $20 \%$ de los sitios. Sobre la orientación NE $F$. austrocitrina dominó en el $75 \%$ de los sitios y S. monosporoides en el $25 \%$ (tabla V.50). La prueba de Kruskal-Wallis no mostró diferencias significativas entre las orientaciones tomadas y la presencia de especies $(p>0,05)$.

Respecto a las preferencias a los materiales de sustrato, sobre mortero F. austrocitrina fue la especie con mayor cobertura en el $91,6 \%$ de los casos, mientras que en el $8,2 \%$ restante lo fue $C$. teicholyta. Sobre granito se encontraron en 3 localidades 3 especies distintas, en Brandsen fue C. teicholyta, en Tandil Dirinaria sp. y en Azul S. monosporoides. Sobre mármol se 
encontró a $A$. holocarpa en Isla Martín García y $F$. austrocitrina en Bahía Blanca. Sobre aglomerado se encontró a $F$. austrocitrina en Saldungaray y $A$. holocarpa en Bahía Blanca. Flavoplaca austrocitrina fue la especie dominante sobre laja que solo se encontró en Bahía Blanca y, también sobre ladrillo y mortero 2 (con conchilla) (tabla V.51). De todas las especies encontradas el $52,08 \%$ crecieron sobre un solo tipo de sustrato, mientras que el $47,92 \%$ se observaron en al menos 2 tipos de sustratos. El sustrato pintura presentó el $52 \%$ de las especies exclusivas, el mortero el $20 \%$, el granito y la laja el $12 \%$, el aglomerado $4 \%$. El mortero con conchilla (mortero 2) y el ladrillo no presentaron exclusividades. La prueba de Kruskal-Wallis mostró diferencias significativas entre los sustratos y la presencia de especies $(p<0,05)$. El sustrato que mostró diferencias significativas con el resto fue el mortero, que presentó una mayor cantidad de presencias de especies. Los restantes sustratos no mostraron diferencias entre sí mostrando una menor riqueza. 
Capítulo V: Resultados

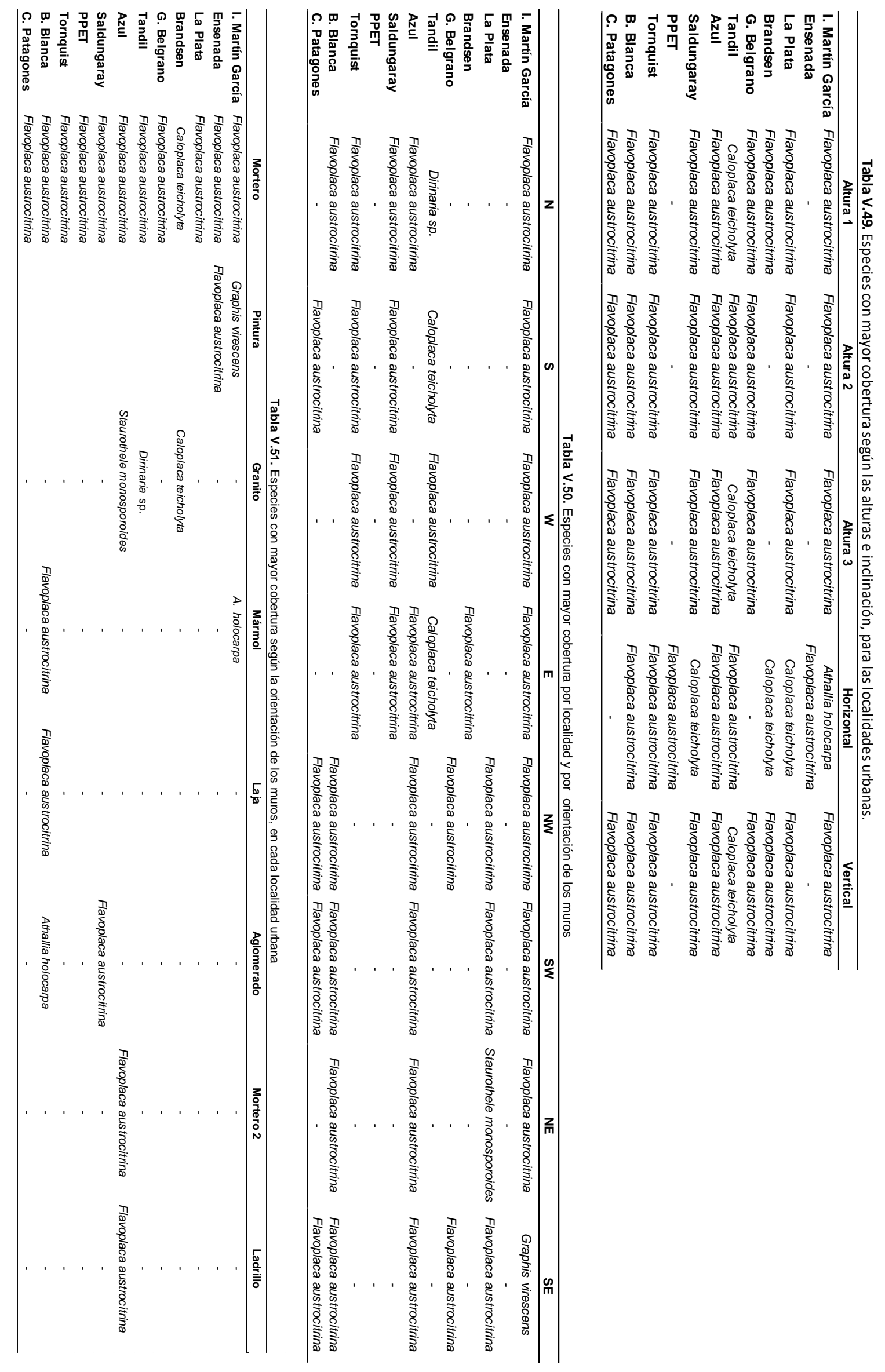




\section{V.3.3. Procesos vinculados a la colonización V.3.3.1. Fuentes de colonización}

Para establecer posibles fuentes de colonización de líquenes hacia el sustrato edilicio se realizó la comparación de la composición de líquenes de las comunidades urbanas de cada localidad con la de los sustratos naturales más próximos a cada una de ellas (árboles o roquedales) donde crecen los líquenes nativos. Del análisis del número de especies citadas previamente (y registradas en este estudio) para cada localidad surgió que las áreas naturales tuvieron una riqueza mucho mayor que la que pudo ser encontrada en áreas urbanas. Se han citado 50 especies para RNIMG (García \& Rosato, 2015), 52 especies para RNPL (García \& Rosato, 2013), 71 para ST (Lavornia et al., 2016) y 93 para PPET (Osorio, 1987). El 83,3\% de las localidades urbanas cuyos muestreos se realizaron sobre sustrato antrópico no compartieron ninguna especie con las áreas naturales boscosas. El 16,7\% restante sí compartió al menos una especie con las áreas naturales arboladas (Ensenada y Martín García), en ambos casos Ensenada fue el sitio que compartió más especies con los ambientes naturales próximos; con la RNPL compartió 11 especies mientras que con la RNIMG compartió 6 . En cambio el $100 \%$ de los sitios compartieron al menos una especie con las áreas naturales con roquedales, las localidades de Azul y Bahía Blanca fueron las que compartieron más especies con PPET, un total de 4 y Ensenada, Bahía Blanca y Tandil compartieron un total de 3 especies con ST, siendo estas las que compartieron más especies. (tabla V.52).

Tabla V.52. Especies de líquenes compartidos entre las localidades muestreadas con sustrato antrópico y con sustrato natural. Reserva Natural de Punta Lara (RNPL) y en la Reserva Natural Isla Martín García (RNIMG) y saxícola en las Sierras de Tandilia (ST) y en el Parque Provincial E. Tornquist (PPET).

\begin{tabular}{lllll}
\hline \multirow{2}{*}{$\begin{array}{l}\text { Ciudades, } \\
\text { poblados }\end{array}$} & RNPL & \multicolumn{4}{c}{ Ambientes naturales } \\
\cline { 2 - 5 } Martín & R. hirsuta & $\begin{array}{l}\text { B. pallidocarnea } \\
\text { G.virescens }\end{array}$ & $\begin{array}{l}\text { F. austrocitrina } \\
\text { P. chloantha }\end{array}$ & $\begin{array}{l}\text { F. austrocitrina } \\
\text { P. tribacina } \\
\text { S. monosporoides }\end{array}$ \\
\hline
\end{tabular}




\begin{tabular}{|c|c|c|c|c|}
\hline Ensenada & $\begin{array}{l}\text { C. concolor } \\
\text { C. erythrantha } \\
\text { C. pilosa } \\
\text { P. convexella } \\
\text { P. alba } \\
\text { P. hirsuta } \\
\text { P. subpraesignis } \\
\text { R. aspera } \\
\text { R. celastri } \\
\text { U. strigosa } \\
\text { X. candelaria }\end{array}$ & $\begin{array}{l}\text { C. concolor } \\
\text { F. exornata } \\
\text { P. alba } \\
\text { R. celastri } \\
\text { R. aspera } \\
\text { U. strigosa }\end{array}$ & $\begin{array}{l}\text { F. austrocitrina } \\
\text { R. celastri } \\
X . \text { parietina }\end{array}$ & $\begin{array}{l}\text { F. austrocitrina } \\
\text { P. subpraensis } \\
\text { S. monosporides }\end{array}$ \\
\hline La Plata & - & - & $\begin{array}{l}F \text {. austrocitrina } \\
P \text {. choantha }\end{array}$ & $\begin{array}{l}F . \text { austrocitrina } \\
\text { S. monosporoides } \\
X . \text { farinosa }\end{array}$ \\
\hline Brandsen & - & - & F. austrocitrina & $\begin{array}{l}\text { F. austrocitrina } \\
\text { S. monosporoides }\end{array}$ \\
\hline $\begin{array}{l}\text { General } \\
\text { Belgrano }\end{array}$ & - & - & F. austrocitrina & $\begin{array}{l}\text { F. austrocitrina } \\
\text { S. monosporoides }\end{array}$ \\
\hline Azul & - & - & $\begin{array}{l}\text { F. austrocitrina } \\
\text { P. choantha }\end{array}$ & $\begin{array}{l}F . \text { austrocitrina } \\
\text { S. monosporoides } \\
\text { C. aurella } \\
X . \text { farinosa }\end{array}$ \\
\hline Tandil & - & - & $\begin{array}{l}F . \text { austrocitrina } \\
P . \text { chloantha } \\
X . \text { ulcerosa }\end{array}$ & $\begin{array}{l}F . \text { austrocitrina } \\
\text { S. monosporoides } \\
X . \text { ulcerosa }\end{array}$ \\
\hline Saldungaray & - & - & F. austrocitrina & $\begin{array}{l}\text { F. austrocitrina } \\
\text { P. tribacina } \\
\text { S. monosporoides }\end{array}$ \\
\hline Ventana & - & - & F. austrocitrina & $\begin{array}{l}F . \text { austrocitrina } \\
\text { Sc. rogersii } \\
\text { S. monosporoides }\end{array}$ \\
\hline Tornquist & - & - & F. austrocitrina & $\begin{array}{l}\text { F. austrocitrina } \\
\text { P. tribacina }\end{array}$ \\
\hline $\begin{array}{l}\text { Bahía } \\
\text { Blanca }\end{array}$ & - & - & $\begin{array}{l}\text { C. concolor } \\
\text { F. austrocitrina } \\
\text { P. chloantha }\end{array}$ & $\begin{array}{l}\text { C. aurella } \\
\text { C. concolor } \\
\text { F. austrocitrina } \\
\text { S. monosporoides }\end{array}$ \\
\hline $\begin{array}{l}\text { Carmen de } \\
\text { Patagones }\end{array}$ & - & - & F. austrocitrina & $\begin{array}{l}\text { F. austrocitrina } \\
\text { S. monosporoides }\end{array}$ \\
\hline
\end{tabular}

\section{V.3.3.2. Colonización de sustratos}

En el mes de agosto de 2014 se realizó la eliminación de la cubierta liquénica mediante la limpieza realizada sobre superficies de muros para analizar la colonización. Se realizaron observaciones periódicas hasta que se detectó la presencia de líquenes (enero 2017) y cuando los hubo se realizaron dos muestreos de seguimiento, durante los que se registró la cobertura de las especies.

La comunidad original, que podría ser considerada la situación "clímax" o de referencia para las tres situaciones analizadas previa a la limpieza de los 
muros verticales de exposición NE, muros verticales de exposición SW y muros horizontales se muestra en la tabla V.53.

En la primer observación (enero de 2017), a los 28 meses de efectuada la limpieza de líquenes de los muros se encontró que el $77,78 \%$ de los parches presentaron alguna señal de colonización, siendo en su mayoría algunas areolas dispersas o soredios, F. austrocitrina estuvo en el $100 \%$ de los parches colonizados, en uno de ellos acompañada por $S$. monosporoides y $C$. teicholyta. Ya a los 31 meses (abril de 2017) se encontró que el 66,67\% de los parches presentaron señales de colonización, al igual que en la observación anterior $F$. austrocitrina estuvo en el $100 \%$ de los parches, mientras que $C$. teicholyta en el 66,66\% y $A$. holocarpa en el 16,6\%, en esta observación no se encontró presencia de $S$. monosporoides.

Las especies aumentaron la cobertura que presentaban en comparación con la primer observación destacando en este caso el aumento desde un $<1 \%$ a un $10 \%$ de la superficie de $F$. austrocitrina. Cabe aclarar que en ninguna de las observaciones realizadas se encontraron estructuras reproductivas sexuales (figura V. 28).

Tabla V.53. Cobertura porcentual promedio de los parches previos a la limpieza (agosto 2014).

\begin{tabular}{lccc}
\hline & NE & SW & Horizontal \\
\hline Caloplaca teicholyta & 8,3 & 21 & 42,5 \\
Flavoplaca austrocitrina & 25 & 68,3 & 9 \\
Staurothele monosporoides & 1,7 & 7,7 & 2,5 \\
Lecania erysibe & - & - & 3,75 \\
Athalia holocarpa & - & - & 0,25 \\
\hline
\end{tabular}




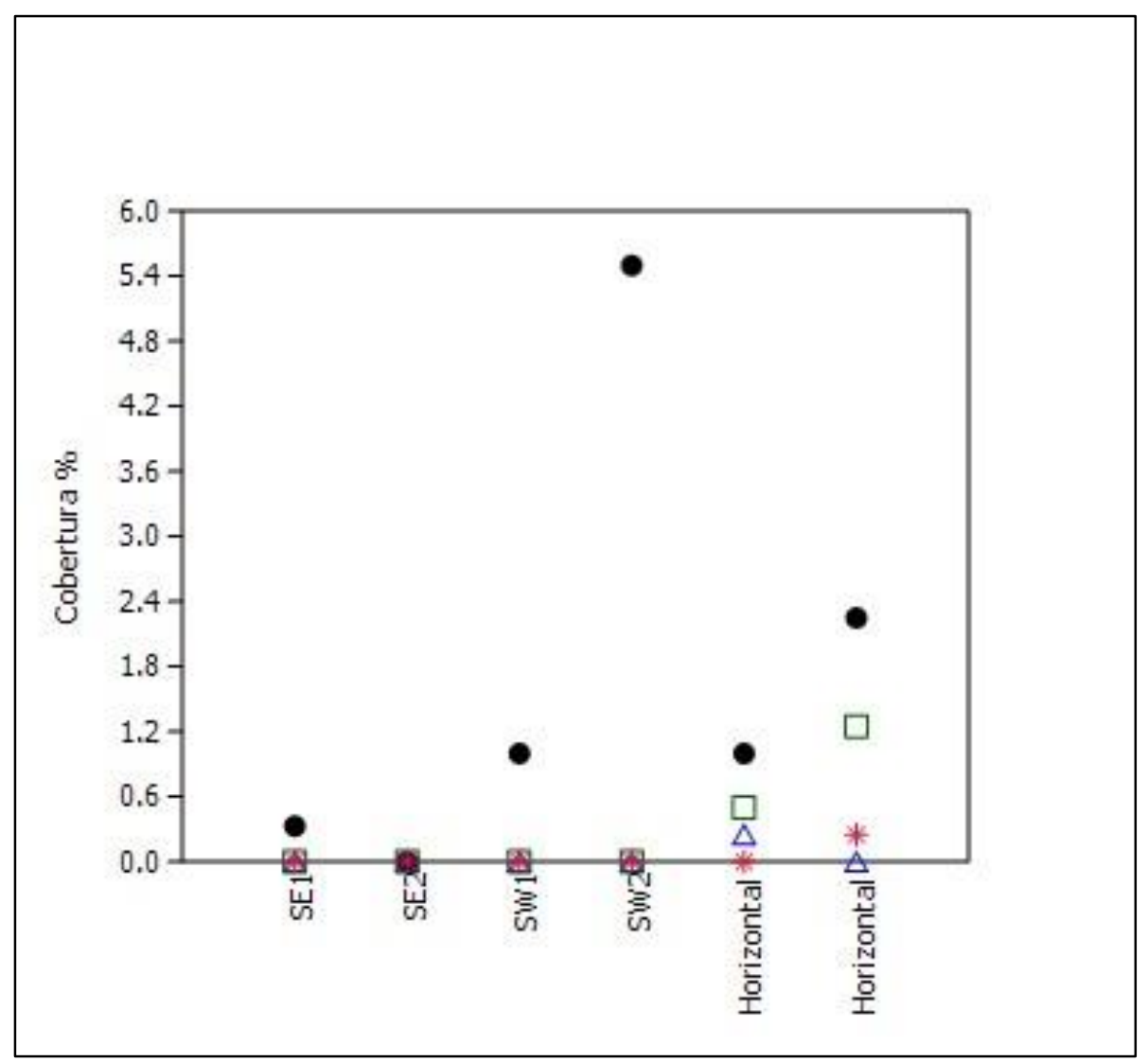

Figura V.28. Cobertura promedio de las especies Flavoplaca austrocitrina (punto) Caloplaca teicholyta (cuadrado), Athallia holocarpa (asterisco) y Staurothele monosporoides (triangulo) sobre sustrato de mortero. SE 1, al SW 1 y horizontal. 1: primera medición (enero 2017); SE 2, al SW 2 y horizontal 2: segunda medición (abril 2017).

\section{V.3.3.3. Competencia interespecífica}

Se realizó un ensayo, que constituyó un caso de estudio para comprender preliminarmente los fenómenos de competencia que ocurren en el seno de comunidades murícolas. En el caso analizado, una comunidad sobre un sustrato horizontal de 70 años de antigüedad, el biotipo liquénico dominante y único, fue el crustoso, la riqueza total de la comunidad fue de 8 especies de las cuales 4 fueron epilíticas (su talo se desarrolla sobre el sustrato) y 4 endolíticas (su talo se desarrolla dentro del sustrato).

La cobertura total promedio de la comunidad fue de $83 \pm 8,6 \%$ de todas las especies encontradas dos especies epilíticas fueron dominantes, $F$. 
austrocitrina y C. teicholyta, con coberturas medias de 46 y $26,5 \%$ respectivamente. Ambas, al igual que $S$. monosporoides, se registraron en casi la totalidad de las unidades de muestreo. Las restantes especies $C$. aurella, $A$. holocarpa, L. erysibe, M. dispersa y M. echinulospora presentaron frecuencias $\leq 50 \%$ y coberturas $\leq 1 \%$.

Todos los contactos registrados (figura V. 29) incluyeron almenos alguna de las dos especies dominantes, con la excepción de una ocasión en que $C$. aurella creció sobre S. monosporoides (figura. V.30). Siendo que solo las interacciones entre las dos especies dominantes presentaron un número significativo para analizar, se realizó el test de Kruskal-Wallis entre las tres posibles interacciones (victoria (+), derrota (-) y empate (II)) y se constató que fueran significativamente diferentes $(p<0,05)$. En el $8,75 \%$ de los casos se observa sobrecrecimiento $(+)$ de $F$. austrocitrina sobre $C$. teicholyta; en el $9,80 \%$ se produce la situación inversa (-) y por último el $81,45 \%$ de los casos ninguna de las especies sobrecrece a la otra sino que se detiene su crecimiento (\|). Mediante el test pos hoc de Bonferroni Dunn mostró que la condición de empate fue significativamente diferente $(p<0,05)$ a las situaciones de victoria y de derrota. La situación de sobrecrecimiento de una sobre otra (victoria-derrota), no mostraron diferencias significativas ( $p>0,05)$. No se consideraron los contactos entre individuos de la misma especie debido a que al producirse el contacto los talos se fusionan no pudiendo diferenciar individuos. El contacto de las dominantes con cualquiera de las otras especies siempre determinó una victoria, a excepción de un solo caso en que $C$. aurella y S. monosporoides crecieron sobre $C$. teicholyta. 


\section{Capítulo V: Resultados}

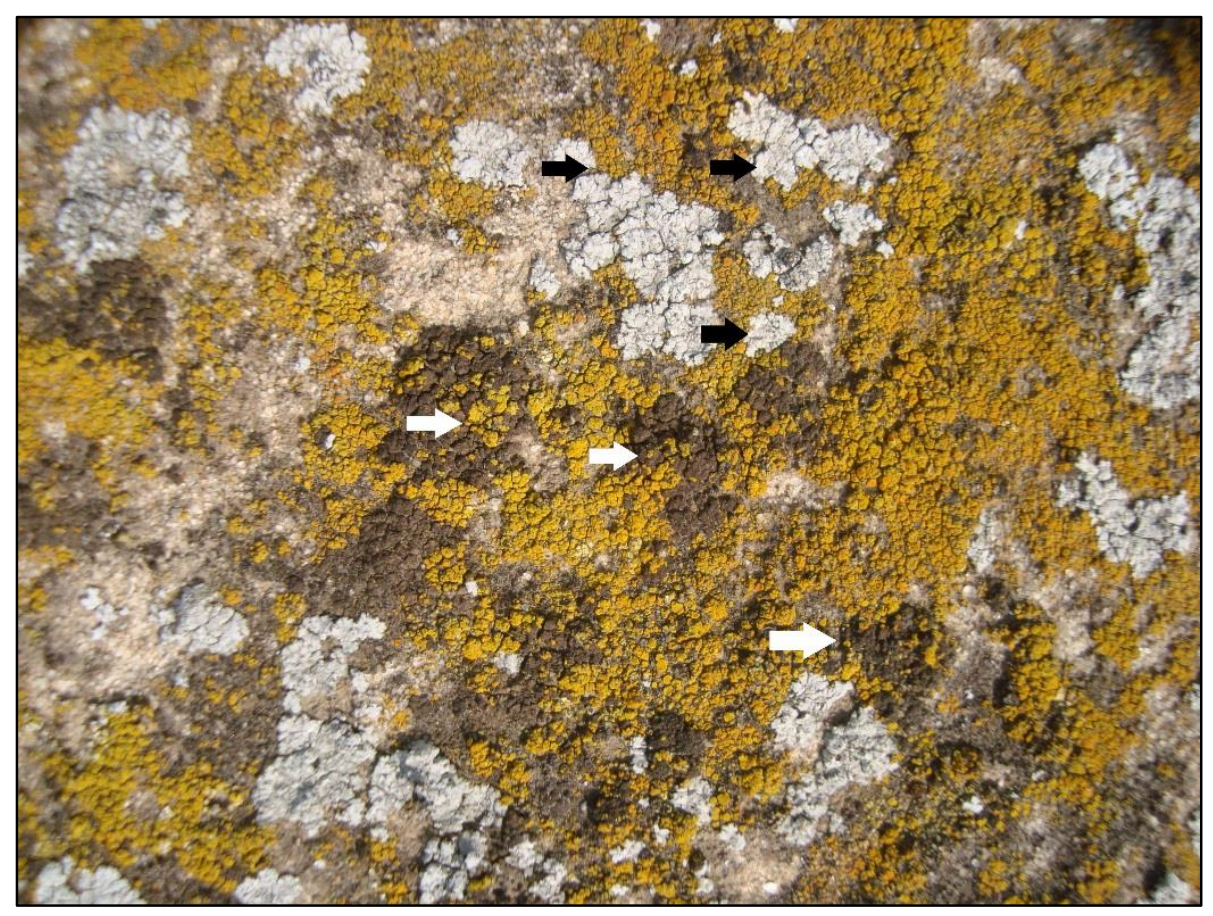

Figura V.29. Flechas blancas, sobrecrecimiento de Flavoplaca austrocitrina, sobre Staurothele monosporoides; Flechas negras contacto entre F. austrocitrina y Caloplaca teicholyta. 


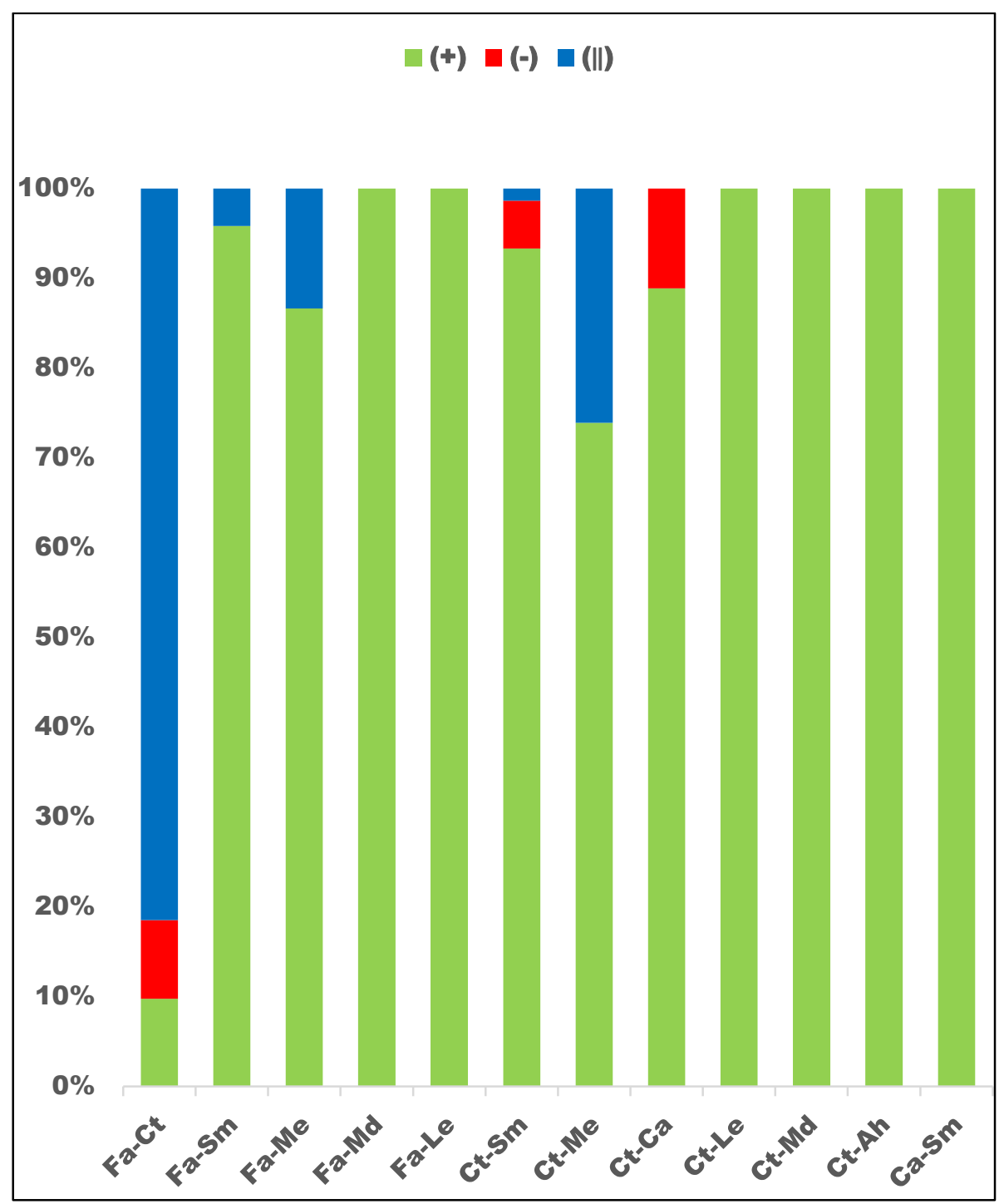

Figura V.30. Importancia relativa de las situaciones de victoria (+), derrota (-) y empate (II)), que se produjeron al contactarse dos especies de líquenes dentro de una comunidad murícola en la localidad de La Plata. $(\mathrm{n}=1294)$. $\mathrm{Ct}=$ Caloplaca teicholyta; $\mathrm{Fa}=$ Flavoplaca austrocitrina; $\mathrm{Ca}=$ Candelariella aurella; $\mathrm{Sm}=$ Staurothele monosporoides; $\mathrm{Me}=$ Monoblastia echinulospora.; $\mathrm{Le}=$ Lecania erysibe; $\mathrm{Md}=$ Myriolecis dispersa. $\mathrm{Ah}=$ Athallia holocarpa. 


\section{DISCUSIÓN}

Los sustratos rocosos (naturales o antrópicos) propician un ambiente extremo para la vida caracterizado por un alto flujo solar, temperaturas extremas, una rápida fluctuación de los niveles de evaporación de agua, y prolongados períodos de desecación (Hall \& Andre, 2001; Viles, 2005). Los hábitats rocosos se caracterizan por una alta variabilidad ambiental que ocurre en escalas espaciales muy pequeñas, lo que conduce a una alta variación en el microclima y otras condiciones físicas (Larson et al. 2000). Los muros se consideran a menudo hábitats más extremos aún, con fluctuaciones térmicas mayores debido a sus dimensiones más pequeñas, además tienen menos variabilidad de microhábitats por la regularidad de su superficie (Láníková \& Lososová, 2009). Por esta razón son pocas las formas de vidas capaces de colonizar este tipo de sustrato, los líquenes por ejemplo han podido explotar este espacio cuyas condiciones no favorece la colonización de otros organismos. En comparación con las zonas rurales, los hábitats urbanos suelen ser más parecidos a las islas: a menudo representan etapas sucesionales tempranas y son más fácilmente invadidos por especies exóticas, características que resultan de la intensa influencia humana en los paisajes urbanos (Niemelä, 1999). Como consecuencia esto trae asociado una biota que es capaz de vivir bajo estas condiciones con su propia dinámica, que puede ser diferente a la que presentan en ambientes naturales, las urbes pasan así a constituir sistemas que difiere de los alrededores, por lo que resulta necesario el conocimiento de la biota que allí se desarrolla.

Las familias con mayor cantidad de representantes sobre los muros fueron Parmeliaceae, Physciaceae, Teloschistaceae y Acarosporaceae, coincidentemente las primeras tres son las familias con mayor número de especies en Argentina (Calvelo \& Liberatore, 2002). Para la provincia de Buenos Aires la riqueza registrada fue de 48 líquenes creciendo sobre muros, siendo Ensenada la localidad que presentó la mayor riqueza, con 21 especies, en comparación con los ambientes naturales de la provincia ésta puede ser considerada baja (Osorio 1987; García \& Rosato, 2012, 2014; Lavornia et al. 2016) y se ajusta a la hipótesis de Larson et al. (2000) quien postula para 
plantas vasculares, que los ambientes naturales con más superficies heterogéneas son hábitats más variables y que albergan relativamente una biota más rica en especies que los muros. Al compararlo con lo observado por Purvis (2000), Weber \& Büdel (2001), Matwiejuk (2004) y Sparrius et al. (2007) para ciudades europeas encontramos que la riqueza de la provincia es baja, ya que estos autores en algunos casos nombran cientos de especies por localidad. Esto podría deberse a que la antigüedad de las construcciones europeas supera en gran medida a la antigüedad de las construcciones locales, siendo algunas de origen medieval. También podría deberse a frecuentes acciones de limpieza para mantener una estética de las estructuras edilicias (Seaward, 2015); esta hipótesis es razonable, porque se ha observado que algunas construcciones de la provincia de Buenos Aires se hidrolavan o son limpiadas con lavandina (obs. pers.). También se encontraron otros casos de riquezas especificas similares: Laso (2001) quien encontró 52 especies para Salamanca (España), o incluso más bajas como en Estambul (Turquía) con solo 16 especies sobre estructuras centenarias (Çobanoğlu, 2008). En estos casos parece ser que la antigüedad no fue un factor de importancia y es posible que otros factores no especificados tengan un mayor peso.

Aquí la morfología más recurrente sobre muros ha sido la crustosa, al igual como ha sido observado por varios autores (Purvis, 2000; Laso, 2001; Weber \& Büdel, 2001; Matwiejuk, 2004; Sparrius et al., 2007; Çobanoğlu, 2008), lo que generalmente es asociado a ambientes extremos porque ya que la pérdida de agua se limita solamente a la corteza superior de la especie y además pueden aprovechar el flujo superficial de agua que pasa sobre ellos para absorberla, aunque existen excepciones (Lakatos et al., 2006; Büdeland \&. Scheidegger, 2008). Dentro de los líquenes crustosos fueron encontradas 8 especies endolíticas, lo que es considerada una estrategia de adaptación para ambientes extremos (Matthes et al., 2001; Tretiach, 1995), aunque también ha sido considerado como una estrategia para escapar de la competencia que se da sobre la superficie (Kidron, 2000). En este estudio se observó que las especies con mayores coberturas y frecuencias ( $F$. austrocitrina y $C$. teicholyta) también han mostrado ser fuertes competidoras, por lo que la presencia de líquenes endolíticos tal vez se deba a esta estrategia para evitar la 
competencia creciendo por debajo de la superficie, y no solo como adaptación a las condiciones ambientales.

Las especies que tuvieron las mayores coberturas y frecuencias, $F$. austrocitrina, $C$. teicholyta y $A$. holocarpa, pertenecen a una de las familias con mayor número de representantes, Teloschistaceae, y al grupo de Caloplaca s.l. Las especies de este grupo presentan en sus cortezas el pigmento parietina que les permite continuar realizando fotosíntesis bajo condiciones de alta exposición solar. Así las especies de Caloplaca s.l., son características de ambientes altamente insolados y en algunos casos son los únicos líquenes saxícolas presentes en ambientes desérticos extremos (Barkman, 1958; Rundel, 1978).

Los sitios urbanos presentaron varias especies en común, pero solo $F$. austrocitrina fue la única especie presente en el $100 \%$ de las localidades muestreadas, que en el 90 y $83 \%$ de los casos estuvo acompañada por $M$. dispersa, S. monosporoides y $C$. teicholyta. Estas especies comparten características similares entre sí, presentan una morfología crustosa, son especies con una preferencia por sitios áridos, habitan sitios que van desde sombreados a muy insolados y poseen una gran tolerancia a los lugares eutrofizados y contaminados aunque también se los puede encontrar en ambientes con bajos valores de estas características (Nimis \& Martellos, 2017), por ello podemos considerarlas especies generalistas y con un amplio rango de tolerancia.

Dentro de los materiales encontrados, el mortero de cemento fue el tipo de sustrato más frecuente en todas las localidades donde se realizaron muestreos en Buenos Aires, probablemente por su menor costo y versatilidad (Traversa, 2011). Otros materiales colonizados por líquenes, como granito, aglomerado, laja y mármol, no fueron encontrados en todos los sitios y algunos fueron raros, encontrados solo en un sitio, esto se debe probablemente a la funcionalidad de cada material, a las modas, a la disponibilidad del material y al poder adquisitivo de los propietarios.

El mortero fue el sustrato sobre el que se encontró mayor riqueza; como se ha mencionado es considerado un material con una alta bioreceptividad (Guillitte \& Dresen, 1995; Miller et al. 2012) lo que también parece ser válido 
para el caso de los líquenes. El resto de los materiales han presentado una menor riqueza, y en algunos casos se encontraron especies exclusivas de estos materiales (como el caso de la laja), aunque al contar con registros de una sola localidad no es posible concluir si estas especies son exclusivas del material o de la localidad. Matwiejuk (2008) ha señalado que la liquenobiota en hábitats urbanos se caracteriza por una baja dependencia del sustrato, por una baja variedad de morfotipos del talo, y por poblaciones con alto número de individuos y bajo número de especies. Para éste caso de estudio se encontraron similitudes con éste postulado, siendo que se ha observado que en la liquenobiota de la provincia existen especies dominantes y ampliamente distribuidas, las cuales no tienen una preferencia por un tipo particular de sustrato, ya que se las ha encontrado en más de uno.

La mayoría de los trabajos que analizan líquenes de ambientes urbanos, proponen a las especies como primariamente saxícolas y secundariamente urbanas o murícolas, por la similitud entre los materiales de construcción y las rocas naturales estas especies pueden colonizarlas sin mayores dificultades (Brodo, 1966; Woodell, 1979; Larson et al., 2000; Aptroot \& James, 2002; Duchoslav, 2002). En este estudio, las especies saxícolas serranas nativas aparecieron en todos los sitios urbanos sin importar su distancia a éstos, aunque muchas especies no se han encontrado en estas localidades. Por otra parte, en la localidad que mostró la mayor riqueza específica -Ensenada- se encontraron sobre muros 9 especies que son primariamente corticícolas (García \& Rosato, 2013) y en Isla Martín García 2 especies también primariamente corticícolas (García \& Rosato, 2015). En ambos casos, sustratos que presentaban en parte un revestimiento de pintura látex sintético fueron los que coincidieron con la presencia de estos líquenes corticícolas, por lo que este tipo de sustrato estaría presentando características que favorecen la colonización de líquenes que llegan desde los ambientes selváticos circundantes próximos, probablemente asemejando algunas características de las cortezas. Éstas especies corticícolas fueron dependientes del tipo de sustrato, ya que solo aparecieron sobre muros que poseían pintura.

En cuanto a la variable que contempla la inclinación de la superficie, se ha establecido que esta tiene un efecto en la relación con el agua y la dinámica 
hídrica sobre el sustrato. Las superficies verticales son solo mojadas por lluvias copiosas y/o combinadas con fuerte viento, mientras que las superficies inclinadas retienen más humedad, las horizontales siempre se mojan con las lluvias y permanecen húmedas por más tiempo (Laso, 2001; Duchoslav, 2002; Simonová, 2008a,b). Por otra parte hay que tener en cuenta que los muros son diseñados para ser impermeables, ya que de otra forma su vida útil sería menor y las superficies regulares no ayudarían a la acumulación de humedad. Sin embargo, aunque varios autores defienden esta afirmación no se han encontrado mediciones que la corroboren. Por otro lado Cristensen (2004) agrega que en las zonas de bajo escurrimiento de agua se acumulan nutrientes que favorecen el desarrollo de líquenes, mientras que en las zonas de alto escurrimiento éstos son escasos, tal es así que se produce una diferencia entre las especies de ambos lugares con diferentes necesidades, principalmente de nitrógeno. La riqueza para este caso de estudio fue mayor sobre la inclinación horizontal, aunque no fue significativa comparada con la inclinación vertical, incluso en algunos sitios se pudo encontrar mayor riqueza y diversidad sobre muros verticales que sobre los horizontales, esto contradice a las resultados encontrados por Laso (2001) quien considera a los muros horizontales un ambiente más favorable para el desarrollo de las especies. La altura sobre los muros verticales, está en relación a esto, ya que se ha considerado que en sectores más cercanos al suelo se encontrarían ambientes más favorables por el salpicado del agua al golpear contra el suelo y por posibles infiltraciones de agua, en este estudio encontramos una leve mayoría de frecuencia de las especies sobre la altura $50 \mathrm{~cm}$ desde el suelo (altura 1) y en algunos casos se encontró que ésta tuvo la mayor riqueza y diversidad, aunque no presentó una diferencia significativa comparada con las otras alturas, incluso en la mayoría de las localidades no se encontraron preferencias de especies mediante el ISA. En ambos casos si bien la mayor disponibilidad de agua podría estar teniendo un pequeño efecto, como ya se ha mencionado los líquenes que se encuentran sobre los muros están adaptados a ambientes secos por lo que la disponibilidad de agua no debería ser un factor que aumente considerablemente la riqueza de especies, posiblemente la cantidad de agua que un muro horizontal puede retener no debe ser suficiente para sacarla de 
esta categoría de ambiente xérico ya que en algún momento siempre alcanzaría condiciones altamente desecantes.

En relación a la orientación los muros verticales, no se encontraron diferencias significativas en la frecuencia y riqueza de líquenes entre las orientaciones, tampoco se encontraron preferencias de especies mediante el ISA, siendo que algunas especies mostraron preferencias en una localidad pero esta no se repitió en otras. Esto podría deberse a que en las construcciones no suelen tener otras estructuras que impidan la llegada de luz, además que la regularidad de sus superficies permite que los mismos muros siempre estén expuestos. No obstante se observó una leve diferencia con una mayor frecuencia de especies en la orientación SE y en algunos sitios fue donde ocurrió la mayor riqueza de todas las orientaciones. Si bien para la mayoría de las especies no se ha encontrado referencias sobre su ecología algunas de éstas como F. austrocitrina, C. teicholyta, M. dispersa, S. regularis, O. fallax y A. holocarpa, según Nimis \& Martellos (2017) para Italia muestran preferencia por los sitios bien expuestos aunque también pueden ser encontrados en ambientes más umbríos lo que muestra una gran tolerancia de estas especies. Estas especies podrían verse favorecidas por la exposición SE, donde existe esa leve tendencia de mayor riqueza, pero al ser especies con una amplia tolerancia también pueden colonizar los sitios con menor exposición solar.

Otro aspecto a tener en cuenta es que sobre una superficie vertical la instalación de propágulos vegetativos presenta una mayor dificultad, ya que la gravedad como así también el agua que escurre produce el arrastre de los mismos (Seaward, 1979; Armstrong, 1988). Armstrong (1980) sugiere que los sitios de escorrentía son lugares donde es habitual encontrar propágulos de líquenes, para esto los propágulos necesitan llegar a "sitios seguros", con condiciones que permitan su instalación y crecimiento, como superficies irregulares y porosas, si lo consideramos desde el punto de vista del material la bioreceptividad del material estaría ligada a la irregularidad de su superficie. En nuestro caso el mortero de cemento presenta una superficie rugosa, y su porosidad permite mantener humedad, pero por otro lado el otro tipo de sustrato donde se registró la mayor riqueza mostró características contrarias 
siendo una capa de pintura lisa e impermeable. Este sustrato, cuyas características son contrarias al mortero, estaría permitiendo la instalación de otras especies con otros requerimientos, y en el caso analizado coincide con la mayor proximidad de una fuente de propágulos, al menos en los casos de sustrato con pinturas las especies corticícolas tuvieron mayor riqueza que las especies saxícolas.

Laso (2001) suma otro factor que influye sobre la biodiversidad de los líquenes urbanos, este es la presencia de la contaminación atmosférica. Algunas localidades de muestreo de esta tesis (La Plata, Tandil, Bahía Blanca), son grandes urbes y se han relevado estructuras edilicias aledañas a caminos transitados y posiblemente con mayor cantidad de contaminantes. Si bien no se ha analizado la correspondencia entre la presencia de contaminantes y las especies de líquenes urbanos, informalmente no parecen estar siendo afectados por la contaminacion, ya que se han encontrado las mismas especies en las grandes urbes y en lugares rurales, por lo que o al menos podríamos decir que los líquenes urbanos presentarían una resistencia a la contaminación.

Brodo (1966) en su trabajo para New York postula a la especie $M$. dispersa, como la mejor de las especies ciudad-tolerante, observando que podía crecer sobre mortero. Si bien esta especie también se encuentra en la provincia de Buenos Aires y es una de las que presenta mayor frecuencia, es ampliamente superada en frecuencia y cobertura por $F$. austrocitrina y $C$. teicholyta.

Si bien se han encontrado muchas especies de líquenes, F. austrocitrina es la especie que se ha visto más favorecida por la aparición de estos nuevos sustratos, y se ha adaptado perfectamente a variadas situaciones de exposición de luz, apareciendo sobre todas las orientaciones, como así también distintos materiales e inclinaciones, similar a lo observado para la especie Caloplaca saxicola por Weber \& Büdel (2001) en Alemania. El análisis de competencia interespecífica ha puesto de manifiesto que $F$. austrocitrina es una muy buena competidora e impide que otras especies puedan colonizar la superficie, además, coloniza el sustrato vacante de forma rápida expandiéndose antes de que otras especies puedan hacerlo (García et al. 
2015). Esta situación generalmente no ocurre en sustratos como rocas o árboles donde es raro encontrar que una sola especie domine de tal manera sobre el resto (Llimona \& Egea, 1985; Egea \& Llimona, 1987); solo se han encontrado situaciones similares en comunidades corticícolas de selvas de Brasil (Cáceres et al., 2007) y en bosques húmedos de China (Li et al. 2015). Si bien el análisis de competencia se ha llevado a cabo en una sola localidad de muestreo, es de esperar que en todas ellas se siga un patrón similar ya que las especies dominantes siempre fueron las mismas.

Pocos autores se han referido al origen, en relación a la fuentes de colonización de los líquenes urbanos, dado que la mayoría considera que las especies murícolas son saxícolas (Aptroot \& James, 2002). En este caso pudimos observar que en Buenos Aires, la cercanía a ambientes boscosos puede favorecer la aparición de especies corticícolas si estas encuentran el sustrato adecuado como en este caso una superficie con pintura. Las especies saxícolas que están presentes sobre los muros, podrían tener su origen en los sistemas serranos de Tandilia y Ventania, y se habrían dispersado desde estos puntos hasta colonizar los muros. Aunque la mayoría de las especies no han sido encontradas, en un ambiente natural como el caso de $C$. teicholyta, una de las especies con mayor cobertura, que no se ha encontrado en las zonas serranas, está citada para Argentina pero no se especifica el lugar (Calvelo \& Liberatore, 2002), algo similar fue notado por Carballal et. al (2001) quien comenta que las especies que encontró sobre mortero no se encontraban en las serranías de Galicia. Por sus características es posible que se pueda encontrar en las sierras, pero es probable que se encuentre con muy baja frecuencia y que por este motivo no ha sido observada. Este cambio en el comportamiento de las especies saxícolas sobre los muros, podría deberse a que sobre los roquedales se está observando el nicho realizado de la especie, mientras que sobre los muros se observa el nicho fundamental, o al menos algo más cercano a este. Por otro lado es posible que algunas de las especies que no han sido encontradas también existan en las serranías de los alrededores de la provincia por lo que podrían estar llegando sus propágulos

Como ya es conocido las estructuras de reproducción sexual presentan una mayor dispersión por su pequeño tamaño (esporas) y son arrastradas por 
el viento, mientras que las estructuras de reproducción asexual tendrían importancia a corta distancia en la colonización local (Hedenås et al., 2003; Ellis \& Coppins 2007). Esto tiene sentido ya que las especies que están ampliamente distribuidas a lo largo de la transecta presentan reproducción sexual. Las especies urbanas que también se han encontrado en roquedales han podido transportarse $357 \mathrm{~km}$ de Tandil a IMG, $508 \mathrm{~km}$ de Tandil a Carmen de Patagones, $306 \mathrm{~km}$ de PPET a Carmen de Patagones y 545 de PPET a IMG, desde las zonas serranas hasta las urbanas más alejadas. Esto evidencia una gran capacidad de dispersión posiblemente por corrientes de aire, pero también es posible que una vez colonizado un ambiente urbano, desde éste se dispersen los propágulos usando localidades intermedias. También hay que considerar la posibilidad, que al transportar materiales de construcción y los materiales con que se realiza el cemento en Buenos Aires provenientes de rocas extraídas del Sistema de Tandilia, se estén dispersando propágulos aumentando la dispersión que naturalmente tendrían por los factores ambientales, como ya ha sido observado por otros autores (Huiskes et al., 2014). También hay que tener en cuenta que los propágulos vegetativos están probablemente menos adaptados para persistir en condiciones adversas, siendo las esporas sexuales más exitosas para la colonización en estas condiciones (Nimis \& Martellos, 2003; Nascimbene et al., 2017). La biota murícola de la provincia de Buenos Aires tiene su origen gracias a la colonización por parte de especies saxícolas en gran medida y un sector pequeño por especies corticícolas cercanas a las zonas de arbolado nativo.

Armestro y Contreras (1981) observaron que si bien existía una gran migración de propágulos a nuevos sustratos no todos eran capaces de desarrollarse y formar talos reproductivos. Lo que concuerda con lo observado luego de la remoción de los líquenes del muro, donde entre la primera medición y la segunda se produjo una disminución de los parches colonizados. Esto podría haber sido causado por un herbívoro (e.g. caracoles) aunque no se observaron marcas en los alrededores del parche, otra posibilidad es una combinación entre viento y lluvia, la cual podría haber arrastrado estos pequeños talos que por su pequeño tamaño aún podrían no haber estados bien fijados al sustrato. 
Mediante la remoción de las especies sobre el muro se pudo observar que en el proceso de colonización, $F$. austrocitrina fue la primer especie que apareció y logró crecer con una velocidad mayor que las restantes. Posiblemente siendo una especie que posse estructuras de reproducción vegetativa (soredios) presenta una ventaja ya que estas son más eficaces para la colonización de nuevos hábitats, debido a que las esporas son incapaces de germinar y desarrollarse hasta que se produce el contacto con el fotobionte por lo que estas pueden morir o quedar un tiempo en el sustrato hasta formar la simbiosis (Hale, 1974; Bowler \& Rundel, 1975). Las especies observadas en los sectores limpiados no variaron de las encontradas en los sectores no alterados, esto difiere en la concepción clásica de la sucesión y de los modelos propuestos por Connell \& Slatyer (1977) -facilitación, tolerancia e inhibicióndonde se esperaría que las especies que se encontraron sobre el sustrato más antiguo (70 años) fueran las especies tardías. Vale aclarar que esta concepción de sucesión está planteada para especies con una mayor velocidad de crecimiento, por lo que existe la posibilidad de que en los muros antiguos esté presente aún una etapa seral temprana y que el reemplazo de especies necesite una mayor cantidad de tiempo, que según Topham (1977) significaría el reemplazo de las especies crustosas por foliosas en la secuencia sucesional dadas las ventajas competitivas de las foliosas. Aunque Armestro y Contreras (1981) sugieren que las comunidades de líquenes saxícolas son muy estables y raramente se dan eventos de extinción, al igual que Sparrius et al. (2007) quien observo que las especies pioneras se mantenían en la comunidad al pasar los años. Por lo que no necesariamente la sucesión sugerida por Tophan (1977) sea el único camino, sino que el camino de la sucesión dependerá de las especies de líquenes y de las condiciones ambientales por lo que la sucesión de especies podría llegar a ser única para cada sitio. Por el momento no se puede asegurar que los muros antiguos estén inalterados, de modo que no es posible asegurar cómo serían las etapas tardías o la posible comunidad clímax. Pero viendo que a lo largo de la provincia los patrones de las especies se han mantenido similares es difícil no suponer que las especies colonizadoras como F. austrocitrina, $C$ teicholyta, S. monosporoides y $M$ dispersa se mantendrán a lo largo del tiempo. 
Las especies $F$. austrocitrina y $C$. teicholyta mostraron una estrategia de sobrecrecimiento (Crowley et al., 2005) sobre las restantes especies. Por lo que no solo serían especies colonizadoras de sustratos vacíos, sino que mostrarían una habilidad competitiva mayor frente a otras especies de líquenes. Esto les conferiría características tanto de estrategas $r$ como $K$ (Begon et al., 2006), por lo que se propone a estas especies como estrategas intermedias. La mayor cobertura correspondió a $F$. austrocitrina cuyo crecimiento irregular, con alta cantidad de apotecios y talo cubierto por soredios (Rosato \& Arup, 2010), le permitiría colonizar rápidamente el sustrato. En cambio $C$. teicholyta presentó un crecimiento radial, una escasa cantidad de apotecios y ausencia de estructuras de reproducción asexual, lo que podría determinar tasas más lentas de colonización del sustrato. Topham (1977) y posteriormente Rogers (1990) sugieren que las especies con propágulos vegetativos de mayor tamaño (isidios) tienden a ser más competitivas con una estrategia de tipo $K$, mientras que las que cuentan con propágulos pequeños (soredios o esporas) tienden a ser tolerantes al estrés o ruderales, relacionados a una estrategia de tipo $r$. De las especies encontradas todas presentaron apotecios y por consiguiente esporas, pero solo $F$. austrocitrina además de esporas también posee soredios. Siguiendo la clasificación de Roger (1990) todas las especies encontradas sobre el muro entrarían en la categoría ruderal o tolerantes al estrés.

Según los mecanismos propuestos por Crowley et al. (2005) podríamos asumir que la capacidad de expansión está más desarrollada en $F$. austrocitrina que en $C$. teicholyta, mientras que en la capacidad de sobrecrecimiento están igualadas. Por ello era de esperar que la condición de empate entre las especies dominantes fuera la más habitual, tal como lo corroboraron los datos obtenidos, además de coincidir con lo observado para otras especies crustosas por Pentecost (1980). El mecanismo por el cual los líquenes crustosos dejan de crecer cuando sus talos se encuentran, no ha sido estudiado aquí, pero es un tema que está en discusión actualmente (Armstrong \& Welch, 2007). La competencia interespecífica puede ser interpretada como una relación que resulta por la limitación de uno o varios recursos y de la interacción entre los nichos ecológicos de las especies (Begon et al., 2006). 
Estudios descriptivos y experimentales sobre comunidades de líquenes han provisto evidencia de que la competencia condiciona la distribución de las especies, determina la estructura de las comunidades y es un factor clave dentro de la sucesión (Barkman, 1958; James et al., 1977; Armstrong, 1982; Oksanen, 1984; Woolhouse et al., 1985). Se ha sugerido que esta interacción puede aumentar o disminuir a causa del estrés ambiental a que estén sometidas (Bertness \& Callaway, 1994), pero Matthew et al. (2010) demostraron que esta afirmación es válida para plantas vasculares, pero no para comunidades de líquenes y musgos. En este caso particular podemos agrupar a las especies murícolas por su aptitudes competitivas en dos grupos, uno de estos con una capacidad competitiva alta formado por las especies $F$. austrocitrina y $C$. teicholyta y un grupo con una baja capacidad competitiva conformado por S. monosporoides, C. aurella, M. dispersa, L. erysibe y $M$. echinulospora. La convivencia de múltiples especies se debe a que las especies con mayor habilidad competitiva no pueden ocupar todos los sitios al mismo tiempo, dejando espacios para que otras especies puedan ocuparlos (Tilman \& Kareiva, 1997). Además, el desplazamiento local nunca es permanente por lo que, cuando los mejores competidores mueren por senescencia, factores ambientales, o factores bióticos (Seaward, 2008), los sitios quedarán disponibles creándose ventanas para ser colonizadas por competidores menos hábiles (Armstrong, 1982). Cáceres et al. (2007) proponen que el alto número de especies raras en los bosques brasileños es una estrategia de baja densidad de población y alta dispersión espacial, para escapar de la competencia de los líquenes dominantes, similar a lo que ha podido apreciar sobre los muros donde dos especies dominan competitivamente al resto, mientras que las otras especies se mantienen en la comunidad pero con un bajo número.

Las especies pueden comportarse de diferentes maneras al encontrarse en distintos ambientes, como fue observado por Antoine y Mccune (2004) en especies de Lobaria. Los autores realizaron trasplantes desde los troncos (donde naturalmente se encuentran) a las ramas (donde nunca se encuentran) observando que su desarrollo era mayor sobre las ramas que sobre los troncos. Según estos resultados, interpretan que sobre los troncos se expresa 
solo su nicho realizado y que su nicho fundamental es más amplio y que la razón por la que no se encuentran sobre las ramas es por exclusión competitiva con especies de Usnea. En el caso de $F$. austrocitrina se la ha encontrado sobre las sierras conviviendo con una gran cantidad de especies y presentado baja cobertura, mientras que sobre los muros es muy frecuente y dominante. Por lo que es posible que la competencia entre las especies de los roquedales por el espacio sea muy ardua, y $F$. austrocitrina podría ser superada por otras. Por el contrario sobre los muros no hay tal cantidad de especies y la competencia sería menor, además, como se ha visto, dentro de las especies de muros es una competidora fuerte. También esta situación podría estar poniendo en evidencia la necesidad de tiempos sucesionales muy largos para llegar a las situaciones "climax", y a que las construcciones en Buenos Aires no tienen la antigüedad requerida para superar las primeras etapas serales de estas comunidades saxícolas.

Varios autores como Weber \& Büdel (2001), Matwiejuk (2004), Sparrius et al. (2007) y Martin et al. (2011), han descripto la liquenobiota que existe sobre morteros de cemento en Europa, y consideran que las especies que los habitan (e.g. Flavoplaca citrina) tienden a ser comunes y muy extendidas, y no les prestan mayor importancia aunque ellas exhiben una amplia distribución a lo largo de todo este continente (e.g. España, Polonia, Italia, Alemania, Holanda). Se encontró un patrón similar para la provincia de Buenos Aires en este caso para la especie $F$. austrocitrina que es similar morfológicamente a la anterior, incluso en Argentina ha sido incluso confundida con esta (Rosato \& Arup, 2010). Esta especie ha extendido su rango de dispersión a todos los sustratos relevados, y probablemente su límite de distribución sea por causas macroclimáticas, como se ha encontrado para otras especies (García \& Biganzoli en prep).

No se encontró un gradiente latitudinal en cuanto a la riqueza y en cuanto a la diversidad se apreció un sutil patrón, con el mayor valor en la localidad del extremo N (Isla Martín García) y una disminución progresiva hacia el S, con la excepción de la localidad del extremo S (Carmen de Patagones) donde la misma aumenta levemente disonando con el resto de las localidades. Este aumento en la diversidad podría deberse a que a esta localidad, que es la 
única con clima seco, es posible que este clima cause un cambio en la cobertura y frecuencia de las especies con respecto a las localidades con clima húmedo, y esto contribuyera al aumento tanto de la equitatividad como del índice $H^{\prime}$. El análisis de la presencia de especies por localidad refuerza la no existencia de un patrón entre la liquenobiota con respecto a un gradiente latitudinal. En cambio ese gradiente si se puede observar cuando se analizó solo las variables climáticas. Si bien el cambio de especies con respecto a la latitud es conocido para muchos organismos, los líquenes no parecen seguir esta tendencia, Holt et al., (2015) demostró que los líquenes no responden a patrones latitudinales a grandes escalas ya que sobre ellos resultan de mayor importancia los factores locales, el micro clima, las características del sustrato y las posibilidades de dispersión de cada especie tendrían un papel importante (Werth et al., 2005; Giordani, 2006). La presencia de las algas necesarias para la formación de la simbiosis es también un factor que condiciona la presencia (Marini et al., 2011).

Los líquenes han mostrado poder adaptarse a los ambientes urbanos, como ha sido observado por otros autores (Fałtynowicz, 1994; Kozik 1994; Aptroot \& James, 2002) las construcciones artificiales crearon condiciones favorables para que los líquenes saxícolas se dispersen a zonas anteriormente inaccesibles para ellos debido a la falta de sustratos naturales. En el caso de los líquenes de la provincia de Buenos Aires, los líquenes se restringirían a las zonas con sustratos naturales tales como las zonas serranas y las selvas de la rivera platense (Cabrera, 1971), pero no se los encontraría en las zonas de pastizal que ocupan la mayor parte de la provincia. En este caso dentro de las zonas de pastizal las construcciones antrópicas han creado un ambiente propicio para el crecimiento de algunos líquenes, los cuales se han vistos favorecidos por estas estructuras y por consiguiente han aumentado su área de distribución. 


\section{CONCLUSIONES}

-Las comunidades urbanas constituyen ensambles de especies que se diferenciaron de las comunidades de sustratos no antrópicos por la composición de especies y por la abundancia de las mismas. Por lo que se rechaza la hipótesis 1.

-La comunidad urbana presenta una fisonomía crustosa con predominancia de especies crustosas, en menor medida especies foliosas y raramente fruticulosas.

-El ambiente urbano se caracteriza por presentar una baja riqueza y especies con una dominancia marcada.

-En la provincia de Buenos Aires existe una comunidad urbana definida por las especies F. austrocitrina, C. teicholyta, M. dispersa, A. holocarpa, S. monosporoides como componentes comunes, acompañados por las especies $S$. regularis, Mo. echinulospora y $M$. haguenii, y después un gran grupo de especies que presentaron presencias esporádicas.

-La mayor riqueza se observó sobre el mortero de cemento, siendo éste el sustrato con mayor biorreceptividad para las especies de líquenes, mientras que no se encontraron deferencias significativas en cuanto a las alturas, inclinaciones y orientaciones. Son especies generalistas y con una amplia tolerancia. Por lo que se rechaza la hipótesis 2.

-No existe diferencias latitudinales entre la liquenobiota de ambientes urbanos. Existen diferencias entre las localidades dadas por el tipo de sustrato que existe entre ellas y por las posibilidades de dispersión de cada especie. Por lo que se rechaza la hipótesis 3 .

-Las especies pioneras no son reemplazadas, sino que son capaces de competir por el espacio que ocupan, y se mantienen a lo largo del tiempo. Esta competencia por el espacio es una fuerza que estructura a la comunidad de líquenes murícolas. Por lo que se rechaza la hipótesis 4. 
-Las construcciones humanas han permitido que los líquenes "escapen" de las zonas serranas en las que estaban confinados y se expandan hasta donde sus preferencias ambientales se lo permitan.

Con ésta tesis se ha buscado contribuir al conocimiento de la ecología de líquenes urbanos, aunque han quedado temas en los que es necesario ahondar. Dentro de estos podemos pensar a futuro posibles investigaciones, tales como analizar de forma profunda las comunidades que se encuentran sobre los sustratos naturales (roquedales y bosque). Se propone expandir las experiencias realizadas a otros sustratos, comprobar si la competencia y la colonización suceden en un mismo patrón sobre otros sustratos antrópicos y también sobre sustratos naturales; delinear los límites de la distribución de las especies urbanas y los factores que la condicionan más allá de la provincia de Buenos Aires, como así también continuar con la observación los parches en los que se realizó la limpieza, pensando en escalas mayores de tiempo que las contempladas para ésta tesis. 


\section{Bibliografia}

Adler, M.T. (1988). La familia Parmeliaceae (Liquenes, Ascomycotina) en la Provincia de Buenos Aires: estudio taxonómico y florístico. Tesis, Facultad de Ciencias Exactas y Naturales, Universidad Nacional de Buenos Aires.

Adler, M.T. (1992). Clave de los géneros y las especies de Parmeliaceae (Lichenes, Ascomycotina) de la Provincia de Buenos Aires (Argentina). Bol. Soc. Argent. Bot. 28: 11-17.

Anstett, D. (2009). The influence of wind and light exposure on the extent of lichen coverage in an alpine environment. JULS. 4(1): 38-41.

Antoine, M.E. \& McCune, B. (2004). Contrasting Fundamental and Realized Ecological Niches with Epiphytic Lichen Transplants in an Old-Growth Pseudotsuga Forest. Bryologist. 107(2):163-172.

Aptroot, A.; Herk, C.M. van; Dobben, H.F. van; Boom, P.P.G. van den; Brand, A.M., \& Spier, L. (1998). Bedreigde en kwetsbare korstmossen in Nederland, Buxbaumiella. 46: 1-101.

Aptroot, A. \& James, P.W. (2002). Monitoring lichens on monuments. In: Nimis, P.L.; Scheidegger, C. \& Wolseley, P.A. (eds.) Monitoring with LichensMonitoring Lichens. 239-253. Netherlands. Springer.

Aptroot, A.; Mercado, J.A.; Pena B.; Caceres, M.E.S.; Coca, L.F.; Forno, M.D.; Feuerestein, S.C.; Herrera-Campos, M.A.; Joshi,S. Kirika, P.M., Karichak, E.; Lumbsch, H.T.; Gonzales, R.M.; Moncada, B.; Nelsen, M.P.; Perez, E.P.; Scharnagl, K.; Medina, E.S.; Ayabaca, A.Y. \& Lücking, R. (2014). Rapid assessment of the diversity of vehiculicolous lichens on a thirty years old Ford Bronco truck in central Puerto Rico. Fungi. 7(2/3): 22-27.

Aptroot A. \& Seaward M.R.D. (2003). Freshwater lichens. Fungal Diversity Research Series, 10: 101-110.

Ariño, X.; Ortega-Calve, J.J.; Gomez-Bolea, A. \& Saiz-Jimenez C. (1995). Lichen colonization of the Roman pavement at Baelo Claudia (Cadiz, Spain): biodeterioration vs. bioprotection. Sci Total Environ. 167: 353-363. 
Ariño, X.; Gomez-Bolea, A. \& Saint Jimenez C. (1997). Lichens on ancient mortars. Int. Biodeterior. Biodegradation. 40(2-4): 217-224.

Armesto, J.J. \& Contreras, L.C. (1981). Saxicolous Lichen Communities: Nonequilibrium Systems?. Am. Nat. 118: 597-604.

Armstrong, R.A. (1982). Competition between three saxicolous species of Parmelia (Lichens). New. Phytol. 90:67-72.

Armstrong, R.A. (1984). The influence of bird droppings and uric acid on the radial growth of five species of saxicolous lichens. Environ. Exp. Bot. 24(1): 9599.

Armstrong, R.A. (1988). Substrate colonization, growth, and competition. In: Galun, M. (ed.). Handbook of Lichenology. 3-16. Boca Raton. CRC Press.

Armstrong, R.A. (1991). Competitive interactions between four foliose lichens on north and south facing rock surfaces. Environ. Exp. Bot. 31: 51-58.

Armstrong, R.A. (2002). The effect of rock surface aspect on growth, size structure and competition in the lichen Rhizocarpon geographicum. Environ. Exp. Bot. 48: 187-194.

Armstrong, R.A. \& Smith, S.N. (1997). Factors associated with degeneration of the thallus centre in foliose lichens. Symbiosis. 22: 293-302.

Armstrong, R.A. \& Welch, A.R. (2007). Competition in lichen communities. Symbiosis. 43:1-12.

Arturi, M. (2005). Situación ambiental en la Ecorregión del Espinal. En: Brown, A., Martinez Ortiz U., Acerbi M. \& Corcuera J. (Eds.) La Situación Ambiental Argentina. 41-46. Buenos Aires. Fundación Vida Silvestre Argentina.

Ascaso, C. \& Wierzchos, J. (1994). Structural aspects of the lichen-rock interface using back-scattered electron imaging. Botanica Acta. 107: 251-256.

Bailey, R.H. (1966). Studies on the dispersal of lichen soredia. Biol. J. Linn. Soc. Lond. 59: 479-490.

Bailey, R.H. (1976). Ecological aspects of dispersal and establishment in lichens. In: Brown D.H., Hawksworth D.L. \& Bailey R.H. (ed.) Lichenology: Progress and Problems, New York: Academic Press. 215-247. 
Barkman, J.J. (1958). Phytosociology and Ecology of Cryptogamic Epiphytes. Assen: Van Gorcum. 628pp.

Barreno, E. (1998). Hongos Simbiontes. Botánica. España. McGraw-Hill. 309335.

Barreno, E. \& Rico, V.J. (1984). Sobre la biología de los líquenes. I. Anatomía, morfología y estructuras vegetativas. Anales de biología, Murcia, 1. Sección especial 1.

Begon, M.; Townsend, C.R. \& Harper, J.L. (2006). Ecology, from individuals to ecosystems. 4th ed. Blackwell Publishing. Ltd. U.K. 755 pp.

Bellinzoni, A.M., Caneva, G. \& Ricci, S. (2003). Ecological trends in travertine colonisation by pioneer algae and plant communities. Int. Biodeter. Biodegradation. 51: 203-210.

Belyea, L.R. \& Lancaster, J. (1999). Assembly rules within a contingent ecology. Oikos. 86: 402-416.

Belnap, J. \& Lange, O.L. (2003). Biological Soil Crusts: Structure, Function, and Management: Ecological Studies. Berlin. Springer.479 pp.

Bermúdez de Castro, F.; Müller, A. \& Schmitz M.F. (1990). Líquenes fijadores de nitrógeno atmosférico. Ecología. 4: 131-141.

Bertness, M.D. \& Callaway, R.M. (1994). Positive interactions in communities. Trends Ecol Evol. 9:191-193

Bonfil Batalla, G. (1997). Nuestro patrimonio cultural: un laberinto de significados". En: E. Florescano (coord.). El patrimonio nacional de México, tomo I. México, FCE.

Bowker, M.A. \& Maestre, F. (2012). Inferring local competition intensity from patch size distributions: a test using biological soil crusts. Oikos. 121: 19141922.

Bowker, M.A.; Soliveres, S. \& Maestre, F.A. (2010). Competition increases with abiotic stress and regulates the diversity of biological soil crusts. J Ecol. 98 : 551-560. 
Brightman, F.H. \& Seaward, M.R.D. (1977). Lichens of man-made substrates. In: M.R.D. Seaward (ed.). Lichen Ecology. 253-293.London. Academic Press.

Brodo, I.M. (1966). Lichen Growth and Cities: A Study on Long Island, New York. Bryologist. 69(4): 427-449.

Brunialti, G. \& Giordani, P. (2003). Variability of lichen diversity in a climatically heterogeneous area (Liguria, NW Italy). Lichenologist. 35: 55-69.

Burgos, J.J. (1968). El clima de la provincia de Buenos Aires en relación con la vegetación natural y el suelo. En: Cabrera A.L. (ed.) Flora de la provincia de Buenos Aires. Tomo IV, parte 1: 11-32.INTA, Col. Científica. Buenos Aires.

Buschbom, J. \& Kappen, L. (1998). The role of microclimate for the lichen vegetation pattern on rock surfaces in the subarctic. Sauteria 9:79-94.

Büdel, B. \& Scheidegger, C. (2008). Thallus morphology and anatomy. In: Nash, T.H. III (ed.). Lichen biology. 37-68. Cambridge. Cambridge University Press.

Bungartz, F.; Garvie, L.A.J. \&. Nash, T.H.III (2004). Anatomy of the endolithic Sonoran Desert lichen Verrucaria rubrocincta Breuss: implications for biodeterioration and biomineralization. Lichenologist. 36(1): 55-73.

Cabrera, A.L. (1971). Fitogeografía de la República Argentina. Bol. Soc. Argent. Bot. 14: 1-42.

Cabrera, A.L. (1976). Regiones fitogeográficas argentinas. Acme, Buenos Aires. Enciclopedia argentina de agricultura y jardinería. 85 pp.

Cabrera, A.L. \& Dawson, G. (1944). La selva marginal de Punta Lara. Revista del Museo de La Plata. Botánica. 5: 267-382.

Cabrera, A.L. \& Willink, A. (1980). Biogeografía de América Latina. OEA, Serie de Biología, monografía 13.

Cáceres, M.E.S. (2007). Corticolous crustose and microfoliose lichens of northeastern Brazil. Libri Botanici. 22:1-168.

Cáceres, M.; Lücking, R. \& Rambold, G. (2007). Phorophyte specificity and environmental parameters versus stochasticity as determinants for species 
composition of corticolous crustose lichen communities in the Atlantic rain forest of northeastern Brazil. Mycol. Progress. 6: 117-136.

Calatayud, V.; Barreno, E.; Atienza, V.; Sanz MJ. \& Fos, S. (1994). Análisis fitogeográfico de la flora liquénica de las rocas silíceas de la Sierra de Espadan (Castellón, España). Stvdia Botánica. 13: 155-161.

Carballal, R.; Paz-Bermúdez, G.; Sánchez-Biezmaa, M.J.; Prieto, B. (2001). Lichen colonization of coastal churches in Galicia: biodeterioration implications. Int. Biodeterior. Biodegradation. 47: 157-163

Carrera, F.M. \& Carreras, H.A. (2011). Efectos de la aplicación de glifosato sobre parámetros químico-fisiológicos en Usnea amblyoclada (Müll. Arg.) Zahlbr. Ecología Austral. 21:353-361.

Carter, N.E.A. \& Viles, H.A. (2003). Experimental investigations into the interactions between moisture, rock surface temperatures and an epilithic lichen cover in the bioprotection of limestone. Build Environ. 38: 1225-1234

Chaparro de Valencia, M. \& Ceballos, J.A. (2002). Hongos liquenizados. Universidad Nacional de Colombia. Colección textos. Primera edición.

Chaparro, M.A.E.; Lavornia, J.M.; Chaparro, M.A.E. \& Sinito, A.M. (2013). Biomonitors of urban air pollution: Magnetic studies and SEM observations of corticolous foliose and microfoliose lichens and their suitability for magnetic monitoring. Environ. Pollut. 172: 61-69.

Chen, J. \& Blume, H. (1999). Biotic weathering of rocks by lichens in Antarctica. Chinese journal of polar Science. 10: 25-32.

Chen, J., Blume, H. \& Beyer, L. (2000). Weathering of rocks induced by lichen colonization a review. Catena. 39: 121-146.

Chisholm, J.E., Jones, G.C. \& Purvis, O.W. (1987). Hydrated copper oxalate, moolootite, in lichens. Min. Mag. 51: 715-718.

Clements, F.E. (1916). Plant succession: an analysis of the development of vegetation (No. 242). Carnegie Institution of Washington.

Clements, F.E. (1928). Plant Succession and Indicators: A definitive edition of Plant Succession and Plant Indicators. The H. W. Wilson Company, New York. 
Cody, M.L. (1975). Toward a theory of continental species diversities: Bird distributions over Mediterranean habitat gradients. In: Cody \& Diamond (Eds.). Ecology and evolution of communities: 214-257. Harvard University Press, Cambridge.

Cooks, J. \& Otto, E. (1990). The weathering effects of the Lichen Lecidea aff. sarcogynoides Koerb. On Magaliesberg Quartzite. Earth Surf. Processes Landforms. 15: 491-500.

Costerton, J.W.; Lewandowski, Z.; Caldwell, D.E.; Korber, D.R. \& LappinScott, H.M. (1995). Microbial biofilms. Ann. Rev. Microbiol., 49: 711-745.

Coxson, D.S. \& Nadkarni, N.M. (1995). Ecological roles of epiphytes in nutrient cycles of forest ecosystems. In: Forest Canopies, ed. M.D. Lowman and N. M. Nadkarni, London: Academic Press. 495-543 pp.

Creveld, M. (1981). Epilithic Lichen Communities in the Alpine Zone of Southern Norway. Gantner Verlag K.G., Vaduz, 48-55.

Christensen, S.N. (2004). Epilithic lichen vegetation of corrugated asbestoscement roof tiles in the Copenhagen area. Graphis Scripta. 15: 7-13.

Culberson, C.F., Culberson, W.L. \& Johnson, A. (1981). A standardized TLC analysis of $\beta$-orcinol depsidones. Bryologist. 84 (1): 16-29.

Crowley, P.H.; Davis, H.M.; Ensminger, A.L.; Fuselier, L.C.; Jackson, J.K. \& McLetchie, D.N. (2005). A general model of local competition for space. Ecology Letters, 8: 176-188.

Czajkowski, J. \& Rosenfeld, E. (1992). Regionalización Bioclimática de la provincia de Buenos Aires. Actas $15^{\circ}$ Reunión de Trabajo de ASADES. $1^{\circ}$ Encuentro Nacional de la International Asociation for Solar Energy Education. Catamarca.

Dale, M.R.T. (1985). A geometric technique for evaluating lichen growth models using the boundaries of competing thalli. Lichenologist. 17:141-148.

Dalla Salda, L. (1999). Cratón del Río de la Plata. 1. Basamento granítico metamórfico de Tandilia y Martín García. Geología Argentina. Instituto de Geología y Recursos minerales. Anales. 29 (4): 97-106. 
De la Rosa, I.N.; Messuti, M.I. \& Śliwa, L. (2012). The Lecanora dispersa group (Lecanoraceae) in Argentina. Lichenologist. 44: 101-114.

De los Ríos, A.; Wierzchos, J.; Sancho, L.G.; Green, A. \& Ascaso, C. (2005). Ecology of endolithic lichens colonizing granite in continental Antarctica. Lichenologist. 37: 1-13.

Del Prado Millán, R. (2002). Estrategias de adaptación de líquenes a ambientes áridos. Tesis Doctoral. Universidad Complutense de Madrid.

Duchoslav, M. (2002). Flora and vegetation of stony walls in east Bohemia (Czech Republic). Preslia: 74:1-25.

Dufrêne, M. \& Legendre, P. (1997). Species assemblages and indicator species: the need for a flexible asymmetrical approach. Ecological Monographs. 67: 345-366.

Egea, J.M. (1985). Líquenes calcícolas y terrícolas de las Sierras de Pedro Ponce y Quípar (NW de Murcia, España). Anales de Biología 6. (Biología Vegetal, 1): 19-27.

Egea, J.M. \& Llimona, X. (1982). Los líquenes silícicolas de la sierra del Cabo de Palos; estudio florístico fitosociológico y ecológico. Acta Botánica Malacitana. 7: 11-38.

Egea, J.M. \& Llimona, X. (1987). Las comunidades de líquenes de las rocas silíceas no volcánicas del SE de España. Acta Botánica Barcinonensia. 36: 3123.

Egea, J.M. \& Llimona, X. (1994). La flore et la végétation lichéniques des laves acides du parc natural de la Sierra del Cabo de Gata (SE de l'Espagne) et des régions voisines. Bull. Soc. Linn. Provence. Homm. sci. a C. Clauzade. 45: 263281.

Egea, J.M. \& Llimona, X. (1997). Sobre la flora y vegetación liquénicas de las lavas básicas del sureste de España. Acta Botánica Malacitana. 22: 5-11.

Egler, F.E. 1954. Vegetation Science Concepts I. Intitial Floristic Composition, A Factor in Old-Field Vegetation Development. Vegetatio. 4: 412-417. 
Eick, M.J.; GrossI, P.R.; Golden, D.C.; Sparks, D.L. \& Ming, D.W. (1996a). Dissolution of a lunar simulant as affected by $\mathrm{pH}$ and organic anions. Geoderma. 74: 139-160.

Eick, M.J.; GrossI, P.R.; Golden, D.C.; Sparks, D.L. \& Ming, D.W. (1996b). Dissolution kinetics of a lunar glass simulant at $298 \mathrm{~K}$. The effect of $\mathrm{pH}$ and organic acids. Geochim. Cosmochim. Acta. 58: 4259-4279.

Ellis, C.J. \& Choppins, B.J. (2006). Contrasting functional traits maintain lichen epiphyte diversity in response to climate and autogenic succession. $J$. Biogeogr. 33: 1643-1656.

Ellis, C.J. \& Choppins, B.J. (2007). Reproductive strategy and the compositional dynamics of crustose lichen communities on aspen (Populus tremula L.) in Scotland. Lichenologist. 39(4): 377-391.

Ellis, C.J.; Crittenden, P.D. \& Scrimgeour, C.M., (2004). Soil as a potential source of nitrogen for mat-forming lichens. Can. J. Bot. 82: 145-149.

Erichsen, C.F.E. (1957). Flechtenflora van Nordwestdeutschland. Stuttgart.

EssI, F. \& Lambdon, P.W. (2009). Alien Bryophytes and Lichens of Europe. In: Handbook of Alien Species in Europe. (ed. DAISIE). Springer, Berlin. 399pp.

Estrabou, C. (2000). Patrones de distribución geográfica de Parmeliaceae sensu stricto (Ascomycetes liquenizados) en la provincia de Córdoba, Argentina. Nova Acta Científica Compostelana (Bioloxía). 10: 11-19.

Estrabou, C. (2007a). Líquenes sobre Monumentos Históricos de la ciudad de Córdoba. Revista Habitat. 86-88.

Estrabou, C. (2007b). Preferencia de forófito por los líquenes en el bosque chaqueño oriental. Bosque. 28 (1): 46-49.

Estrabou, C. \& García, L. (1995). Comunidades liquénicas cortícolas sobre Lithraea ternifolia en las Sierras Chicas de la provincia de Córdoba, Argentina. Bot. Complut. 20: 35-43.

Estrabou, C; Stiefkens, L.; Hadid, M.; Rodriguez J.M. \& A. Perez. (2005). Estudio comparativo de la comunidad liquénica en cuatro ecosistemas de la provincia de Córdoba. Bol. Soc. Argent. Bot. 40: 3-12. 
Evans, R.D. \& Johansen, J.R. (1999). Microbiotic crusts and ecosystem processes. Crit. Rev. Plan.t Sci. 18: 183-225.

Evju, M. \& Bruteig, I.E. (2013). Lichen community change over a 15-year time period: effects of climate and pollution. Lichenologist. 45 (1): 35-50.

Faguerland, M.W. \& Sandvik L. (2009). The Wilcoxon-Mann-Whitney test under scrutiny. Statist. Med. 28:1487-1497.

Fałtynowicz, W. (1994). Propozycja klasyfikacji porostów synantropijnych. Wprowadzenie do dyskusji. In: Kiszka, J. \& Piórecki, J. (eds.), Porosty apofityczne jako wynik antropopresji. Materiały z Sympozjum, Bolestraszyce, 49 wrzesień 1993. Arboretum Bolestraszyce 2: 21-30.

Ferraro, L.I. (1995). Comentarios sobre la distribución de los líquenes de las diferentes regiones fitogeográficas de la Provincia de Corrientes, nordeste de Argentina, América del sur. In: Daniels, F., Schulz, M. \& Peine, J. (eds). Contributions to Lichenology in honour of G. Follman. 403-413. Cologne. University of Cologne.

Fos, S.; Calatayud, A. \& Barreno, E. (2001). Diversidad liquénica asociada a fenómenos post-incendio en los alcornocales valenciano-castellonenses. Bot. Complut. 25: 103-113.

Frangi, J.L. (1973). Las comunidades vegetales de las sierras de Tandil, provincia de Buenos Aires. Tesis de doctorado. Facultad de Ciencias Naturales y Museo. UNLP.

Frangi, J.L. (1975). Sinopsis de las comunidades vegetales y el medio de las sierras del Tandil (provincia de Buenos Aires). Bol. Soc. Arg. Bot. 15 (4): 293-319. Fry, E.J. (1924). A suggested explanation of the mechanical action of lythophytic lichens on rocks shale. Ann. Bot. 38: 175-196.

Fry, E.J. (1927). The mechanical action of crustaceous lichens on substrata of shale, schist, gneiss, limestone and obsidian. Ann. Bot. 40: 437-460.

Galloway, D.J. (2008). Lichen biogeography. In: Nash T.H.III (ed.) Lichen biology. 315-335. Cambridge. Cambridge University Press. 
García, R. \& Rosato, V. (2013). Nuevas citas de líquenes para la Reserva Natural de Punta Lara, provincia de Buenos Aires, Argentina. Rev. Mus. Argentino Cienc. Nat. 15 (2): 169-174.

García, R. \& Rosato, V. (2015). Líquenes (Ascomycota liquenizados) de la Reserva Natural Isla Martín García. Nuevos registros para la provincia de Buenos Aires y para Argentina. Lilloa. 52 (1): 31-39.

García, R.; Correa, M. V. \& Rosato, V. (2015). Lichens growing on painted metal Plates. Journal of Basic and Applied Research International. 9 (1): 1-6.

García, R; Rosato, V. \& Kristensen, M.J. (2014). Análisis de las comunidades liquénicas presentes en construcciones edilicias de la ciudad de La Plata. Ciencia y tecnología de los Materiales. 4: 71-79.

Gargas, A.; de Priest, P.T.; Grube, M. \& Tehier, A. (1995). Multiple origins of lichen symbioses in fungi suggested by SSU rDNA phylogeny. Science. 268: 1492-1495.

Gaylarde, C.C. \& Morton, L.H.G. (1999). Deteriogenic biofilms on buildings and their control: a review. Biofouling. 14 (1): 59-74.

Geiser, L.H. \& Neitlich, P.N. (2007). Pollution and climate gradients in western Oregon and Washington indicated by epiphytic macrolichens. Environ. Pollut. 145: 203-218.

Giordani, P. (2006). Variables influencing the distribution of epiphytic lichens in heterogeneous areas: a case study for Liguria, NW Italy. J. Veg. Sci. 17:195206.

Gleason, H.A. (1926). The individualistic concept of the plant association. Bull. Torrey Bot. Club. 53: 7-26.

Gorbushina, A.A. (2007). Life on the rocks. Environ. Microbiol. 9: 1613-1631.

Green, T.G.A. (2009). Lichens in arctic, antarctic and alpine ecosystems. In: Ökologische Rolle der Flechten Rundgespräche der Kommissionfür Ökologie 36. BayerischeAkademie der Wissenschaften (Herausgeber), Verlag Dr. Friedrich Pfeil, München, pp 45-65. 
Greig-Smith, P. (1983). Quantitative Plant Ecology. University of California Press, California.

Guiamet, P.S.; Rosato, V.; Gómez de Saravia, S.; García, A.M. \& Moreno, D.A. (2012). Biofouling of crypts of historical and architectural interest at La Plata cemetery (Argentina). J. Cult. Herit. 13(3): 339-344.

Guillitte, O. (1995). Bioreceptivity: a new concept for building ecology studies. Sci. Total Environ. 167: 215-220.

Guillitte, O. \& Dreesenb, R. (1995). Laboratory chamber studies and petrographical analysis as bioreceptivity assessment tools of building materials. Sci. Total Environ. 167: 365-374.

Hale, M.E. (1974). The Biology of Lichens. 2nd edn. Edward Arnold. London. $181 \mathrm{pp}$.

Hauck, M. \& Wirth, V. (2010). Preference of lichens for shady habitats is correlated with intolerance to high nitrogen levels. Lichenologist 42(4): 475-484.

Hawkins, B.A. (2001). Ecology's oldest pattern? Trends Ecol. Evol. 16: 470.

Hedenås, H.; Bolyukh, V.O. \& Jonsson, B.G. (2003). Spatial distribution of epiphytes on Populus tremula in relation to dispersal mode. J. Veg. Sci. 14: 233-242.

Hernández Gallego, Y. \& Muñoz Reinoso, J.C. (2005). Líquenes psammófilos de Las Naves de Reserva Biológica de Doñana (Huelva). Mediterránea. 2(18): 8-23.

Hill, D. (2010). The vertical distribution on the lichen of de tower St. Stephens Church, Bath and the effect of scaffolding and air pollution. British Lichen Society Bulletin. 107: 84-94.

Hilmo, O. (1994). Distribution and succession of epiphytic lichens on Picea abies branches in a boreal forest, Central Norway. Lichenologist. 26:149-169.

Holmberg, E. (1972). Tandilia. Separata de Simposio Geología Regional Argentina. Edición del autor. Buenos Aires.

Holt, E.A.; Bradford, R. \& Garcia, I. (2015). Do lichens show latitudinal patterns of diversity?. Fungal Ecol. 15: 63-72. 
Honegger, R. (1993). Developmental biology of lichens. New Phytol. 125: 659677.

Honegger, R. (1997). Metabolic interactions at the mycobiont-photobiont interface in lichens. In: Carroll G.C. \& Tudzynski, P. (eds.) The Mycota, V part A. Plant relationships. 209-221. Springer. Berlin.

Honegger, R. (1998). The lichen symbiosis-what is so spectacular about it?. Lichenologist. 30: 193-212.

Huneck, S. \& Yoshimura, I. (1996) Identification of lichen substances. Springer, Berlin Heidelberg.

Hyvarinen, M. \& Crittenden, P.D. (1998a). Relationships between atmospheric nitrogen inputs and the vertical nitrogen and phosphorus concentration gradients in the lichen Cladonia portentosa. New Phytologist. 140: 519-530.

Hyvarinen, M. \& Crittenden, P.D. (1998b). Growth of the cushion forming lichen, Cladonia portentosa, at nitrogen-polluted and unpolluted heathland sites. Environ. Exp. Bot. 40: 67-76.

INDEC (2010). Censo 2010. http://www.sig.indec.gov.ar/censo2010/

Insarov, G. \& Insarova, I. (1995). The lichens of calcareous rocks in the Central Negev, Isr. J. Plant Sci. 43: 53-62.

James, P.W.; Hawksworth, D.L. \& Rose, F. (1977). Lichen communites in the British Isles: a preliminary conspectus. In: Seaward M.R.D. (ed.). Lichen Ecology. 295-414. England. Academic Press.

Johansson, S.; Li, Y. \& Wadsö, L. (2005). Biological organisms on building façades. Div. of Building Technology / Department of Civil and Architectural Engineering / Royal Institute of Technology, Brinellvägen 34, SE-100 44, Stockholm, Sweden.

Jones, D.; Wilson, M. J. \& Mchard, W. J. (1981). Lichen weathering of rockforming minerals: application of scanning electron microscopy and microprobe analysis. J Microsc. 124(1): 95-104. 
Jongman, R.H.G, ter Braak C.J.F. \& van Tongeren O.F.R. (1995). Data Analysis in Community and Landscape Ecology. Cambridge University Press, Cambridge.

Jørgensen, P.M. (1983). Distribution patterns of lichens in the Pacific region. Austral. J. Bot. 10: 43-66.

Jovan, S. \& McCune, B. (2004). Regional variation in epiphytic macrolichen communities in Northern and Central California forests. Bryologist. 107: 328-39.

Kachalkin, A.V.; Glushakova A.M. \& Pankratov A.T. (2017). Yeast Population of the Kindo Peninsula Lichens. Microbiology. 86(6): 786-792.

Kanda, H. \& Inoue, M. (1994). Ecological monitoring of moss and lichen vegetation in the Syowa station area, Antarctica. Symp. Polar Biol. 7: 221-231

Kappen, L. (1988). Ecophysiological relationships in different climatic regions. In: Galun, M. (ed.). Handbook of Lichenology. 37-100. Boca Raton: CRC Press.

Kappen, L. (2000). Some aspects of the great success of lichens in the Antarctica. Antarctic Science. 12: 314-324.

Kappen, L.; Lange, O.L.; Schulze, E.D.; Buschbom, U. \& Evenari, M. (1980). Ecophysiological investigations on lichens in the Negev Desert. VII. The influence of the habitat exposure on dew imbibition and photosynthetic productivity. Flora 169: 216-229.

Kappen, L. \& Valladares, F. (2007). Opportunistic growth and desiccation tolerance, the ecological success of poikilohydrous autotrophs. In: Pugnaire F, Valladares F (eds), Functional Plant Ecology. CRC Press, Boca Raton, Florida, pp. 7-65.

Kärnefelt, I. (1990). Evidence of a slow evolutionary change in the speciation of lichens. Bibl. Lichenol. 38: 291-306

Ketner-Oostra, R. \& Sýkora, K.V. (2000). Vegetation succession and lichen diversity on dry coastal calciumpoor dunes and the impact of management experiments. Journal of Coastal Conservation. 6: 191-206. 
Kidron, G.J. (2000). Dew moisture regime of endolithic and epilithic lichens inhabiting limestone cobbles and rock outcrops, Negev Highlands. Israel. Flora. 195: 145-153.

Kolbek, J. (1997). Plant communities on walls in the Czech Republicpreliminary notes. ZprávyČes Bot Společ 32 (Materiály 15):61-67.

Kottek, M.; Grieser, J.; Beck, C.; Rudolf, B. \& Rubel, F. (2006). World Map of the Köppen-Geiger climate classification updated. Meteorol. Z. 15: 259-263.

Kozik, R. (1994). Epilithic lichens on the monuments of cemeteries dating back to World War I in the Carpathian Foothills. In: Kiszka, J. \& J. Piórecki (eds). Apophytic lichens as result of anthropopressure. Materiały $z$ sympozjum Bolestraszyce, 4-9 wrzesień 1993, Arboretum Bolestraszyce 6:47-53.

Kristinsson, H. \& Heiðmarsson, S. (2009). Colonization of lichens on Surtsey 1970-2006. Surtsey Research. 12: 81-104.

Kristensen, M.J. (1992). Características microclimáticas de Sierra de la Ventana y su relación con la vegetación. Tesis doctoral. Facultad de Ciencias Naturales y Museo. UNLP.

Kristensen, M.J. \& Frangi, J.L. (1995). Mesoclimas de pastizales de la Sierra de la Ventana. Ecología Austral. 5: 55-64.

Kristensen, M.J. \& Frangi, J.L. (1996). Mesoclimas de roquedales de la Sierra de la Ventana. Ecología Austral. 6: 115-122.

Knudsen, K.; Elix, J.A. \& Reeb, V. (2011). A Preliminary Study of the Genera Acarospora and Pleopsidium in South America. Opuscula Philolichenum. 5: 122.

Lakatos, M.; Rascher, U. \& Büdel, B. (2006). Functional characteristics of corticolous lichens in the understory of a tropical lowland rain forest. New Phytol. 172: 679-695.

Láníková, D. \& Lososová, Z. (2009). Rocks and Walls: Natural VersusSecondary Habitats. Folia Geobot. 44: 263-280.

Larson, D.W.; Matthes, U. \& Kelly, P.E. (2000). Cliff ecology: pattern and process in cliff ecosystems. Cambridge. Cambridge University Press. 331 pp. 
Laso, M.B. (2001). Biodiversidad y colonización liquénica de algunos monumentos en la ciudad de Salamanca (España). Bot. Complut. 25: 93-102.

Laundon, J.R. (1967). A study of the lichen flora of London. Lichenologist. 3: 277-327.

Laundon, J.R. (1973). Urban lichen studies. In: Ferry, B.W.; Baddeley, M.S. \& Hawksworth, D.L. (eds.). Air Pollution and Lichens. 109-123. London. Athlone Press.

Lavornia, J.M. (2015). Las comunidades liquénicas de las sierras de Tandil (Buenos Aires) como bioindicadoras de la contaminación atmosférica. Tesis de doctorado. Facultad de Ciencias Naturales y Museo. UNLP.

Lavornia, J.M.; Kristensen, M.J. \& Rosato, V.G. (2016). Clave de identificación de líquenes saxícolas del Paisaje Protegido "La Poligonal" (Sistema De Tandilia, Buenos Aires). Rev. Mus. Argentino Cienc. Nat. 18(2): 107-115.

Lawrey, J.D. (1981). Evidence for Competitive Release in Simplified Saxicolous Lichen Communities. Amer. J. Bot. 68(8): 1066-1073.

Lázaro, R.; Cantón, Y.; Solé-Benet, A.; Bevan, J.; Alexander, R.; Sancho, L.G.; Puig de Fábregas, J. (2008). The influence of competition between lichen colonization and erosion on the evolution of soil surfaces in the Tabernas badlands (SE Spain) and its landscape effects. Geomorphology.102: 252-266.

Lahitte, H.B. \& Hurrel, J.A. (1994). Los Árboles de la Isla Martín García: árboles y arbustos arborescentes (nativos y naturalizados) de la Reserva Natural y Cultural Isla Martín García. CIC, La Plata, Argentina, pp 229.

Legendre, P. \& Legendre, L. (1998). Numerical Ecology. Elsevier Science BV, Amsterdam, pp 853.

Liberatore, S.; Garibotti, G. \& Calvelo, S. (2002). Phytogeography of Argentinean lichens. In: Llimona, X.; Lumbsch, H.T. \& Ott, S. (eds.): 221-234. Progress and Problems in Lichenology at the Turn of the Millenium. Bibliotheca Lichenologica. J. Cramer, Berlin, Stuttgart.

Lindsay, D.C. (1973). Probable introductions of lichens to South Georgia. Br. Antarct. Sur. Bull. 33-34: 169-172. 
Longton, R.E. (1988). Biology of Polar Bryophytes and Lichens. Cambridge: Cambridge University Press. 391 pp.

Lücking, R. (1998). "Plasticolous" Lichens in a tropical rain forest at la selva biological station. Costa Rica. Lichenologist. 30 (3): 287-291.

Lücking, R.; Archer, A.W. \& Aptroot, A. (2009). A worldwide key to the genus Graphis (Ostropales: Graphidaceae). Lichenologist 41: 363-452.

Lücking, R.; Wirth, V.; Ferraro, L.I. \& Cáceres, M.E.S. (2003). Foliicolous lichens from Valdivian temperate rain forest of Chile and Argentina: evidence of an austral element, with the description of seven new taxa. Glob. Ecol. Biogeogr. 12: 21-36.

Lumbsch, H.T. \& Elix, J.A. (2004). Lecanora. Flora of Australia 56A: 12-62.

Magnusson, A.H. (1929). A monograph of the genus Acarospora. Kungl. Svenska Vetenskapsakad. Handl. 7: 1-400.

Magurran, A.E. (1988). Ecological Diversity and Its Measurement. Princeton University Press. $179 \mathrm{pp}$.

Magurran, A.E. (2013). Ecological diversity and its measurement. Springer Science \& Business Media. $179 \mathrm{pp}$.

Malme, G.O.A. (1927). Buelliae Itineris Regnelliani Primi. Arkiv för Botanik 21A (14): 1-42.

Matwiejuk, A. (2008). Lichens of the Jewish cemetery in Białystok (northeastern Poland). Botanika-Steciana. 12: 111-116.

Marbach, B. (2000). Corticole und lignicole Arten der Flechtengattung Buelliasensu lato in den Subtropen und Tropen. Bibl. Lichenol. 74: 1-381.

Marini, L.; Nascimbene, J. \& Nimis, P.L. (2011). Large-scale patterns of epiphytic lichen species richness: Photobiont-dependent response to climate and forest structure. Sci. Total Environ. 409: 4381-4386.

Margalef, R. (1963). On certain unifying principles in ecology. Am. Nat.97: 357374.

Margalef, R. (1997). Our Biosphere. In: Kinne, O. (ed.). Excellence in Ecology.Oldendorf, Germany. Ecology Institute. 194 pp. 
Martins, S.M. (2006). Estudo da comunidade liquenizada epífita em Dodonaea viscosa L. na restinga. do Parque Estadual de Itapuã, Viamão, RS. Tese (Doutorado) - Instituto de Botânica da Secretaria de Estado do Meio Ambiente.

Martin, L.; Randlane, T. \& Martin, J. (2011). Lichens and their substrate preferences on the Pakri Peninsula (Northwest Estonia). Folia Cryptog. Estonica, Fasc. 48: 45-58.

Marton, K. \& Galun, M. (1981). The cyanophilous lichen population of the Arava Valley and the Judean Desert (Israel). Israel Journal of Botany 30: 125155.

Matteucci, S.D. \& Colma, A. (1982). Metodología para el estudio de la vegetación. Monografía 23, OEA. Washington, D.C. 168 pp.

McCune, B. (1997). Influence of noisy environmental data on canonical correspondence analysis. Ecology. 78: 2617-23

Mccune, B. (2012). Caloplaca in Pacific Northwest.

http://bmccune.weebly.com/uploads/2/4/5/6/24567979/caloplaca.pdf

Mccune, B. \& Grace, J.B. (2002). Analysis of ecological comunities. MJM software desing. $300 \mathrm{pp}$.

McKinney, M.L. \& Lockwood, J.L. (1999). Biotic homogenization: a few winners replacing many losers in the next mass extinction. Trends Ecol. Evol. 14: 450-453.

Medina, E.S.; Lücking, R. \& Rojas A.B. (2012). Especificidad de forófito y preferencias microambientales de los líquenes cortícolas en cinco forófitos del bosque premontano de finca Zíngara, Cali, Colombia. Rev. Biol. Trop. 60(2): 843-856.

Messuti, M.I. \& de la Rosa, I.N. (2009). Notes on the genus Haematomma (Ascomycota, Lecanoraceae) in Argentina. Darwiniana. 47(2): 297-308.

Messuti, M.I. \& Vobis, G. (2002). Orden Pertusariales. En: Guarrera S.A.; Gamundi de Amos I.J. \& Materi, C.M. (eds.). Flora criptogámica de Tierra del Fuego. Buenos Aires, Argentina.Fundación para la Educación. 106 pp. 
Miller, A.Z.; Dionísio, A.; Laiz L.; Macedo, M.F. \& Saiz-Jimenez, C. (2009). The influence of inherent properties of building limestones on their bioreceptivity to phototrophic microorganisms. Annals of Microbiology. 59(4): 705-713.

Miñarro, F.; Beade M. \& Bilenca D. (2006). Las áreas valiosas de pastizal, un paso hacia una visión ecorregional de la conservación de los pastizales pampeanos. En: Brown, A.; Martinez Ortiz, U.; Acerbi M. \& Corcuera J. (eds.) La Situación Ambiental Argentina. 269-263. Buenos Aires. Fundación Vida Silvestre Argentina.

Mohammadi, P. \& Krumbein, W.E. (2008). Biodeterioration of ancient stone materials from the Persepolis monuments (Iran). Aerobiologia. 24: 27-33.

Molina Moreno, J.R. \& Probanza, A. (1992). Pautas de distribución de biocenosis liquénicas epifíticas de un robledal de Somosierra (Madrid). Bot. Complutensis. 17: 65-78.

Monna, F.; Bouchaou, L.; Rambeau, C.; Losno, R.; Bruguie, O.; Dongarrà, G.; Black; S.\& Chateau, C. (2012). Lichens used as monitors of atmospheric pollution around Agadir (Southwestern Morocco) - a case study predating leadfree gasoline. Water Air Soil Pollut. 223: 1263-1274.

Motiejûnaitë, J. (2005). Effect of land-use on lichen diversity in the transboundary region of Lithuania and northeastern Poland. Ekologija. 3: 34-43.

Moreno, C.E. (2001). Métodos para medir la biodiversidad. M\&T-Manuales y Tesis SEA, vol.1. Zaragoza. $84 \mathrm{pp}$.

Moberg, R. (1990). The lichen genus Physcia in Central and South America. Nord. J. Bot. 10(3): 319-342.

Nascimbene, J.; Mayrhofer H.; Dainese, M. \& Bilovitz, P.O. (2017). Assembly patterns of soil-dwelling lichens after glacier retreat in the European Alps. J. Biogeogr. 44(6): 1393-1404.

Nascimbene, J.; Salvadori, O. \& Nimis, P.L. (2009). Monitoring lichen recolonization on a restored calcareous statue. Sci. Total Environ. 407(2): 4202426. 
Nash, T.H.III (2008). Nitrogen, its metabolism and potential contribution to ecosystems. In: Nash, T.H. III (ed.). Lichen biology. 215-229. Cambridge. Cambridge University Press.

Niemelä, J. (2002). Is there a need for a theory of urban ecology?. Urban Ecosystems. 3: 57-65.

Nimis, P.L. (2001). Artistic and historical monuments: threatened ecosystems, In: The Frontiers of Life. sect.2: Man and the Environment, S. Diego, Ca, Academic Press, pp. 557-569.

Nimis, P.L. \& Martellos, S. (2017). ITALIC - The Information System on Italian Lichens. Version 5.0. University of Trieste, Dept. of Biology, (http://dryades.units.it/italic)

Nimis, P.L. \& Salvadori, O. (1997). La crescita dei licheni sui monumenti di un parco. Uno studio pilota a Villa Manin. Restauro delle sculture lapidee nel parco di Villa Manin a Passariano. II viale delle Erme, vol. 4. Quaderni di studi e Ricerche del Centro Regionale di restauro dei beni culturali; $109-42$.

Nimis, P.L. \& Martellos, S. (2003). On the ecology of sorediate lichens in Italy. Bibliotheca Lichenologica. 86: 393-406

Nimis, P.L. \& Monte, M. (1988). Lichens and monuments. Stud. Geobot. 8: 1133.

Nimis, P.L., Monte, M. \& Tretiach, M. (1987). Flora e vegetazione lichenica di aree archeologiche del Lazio. Stud. Geobot. 7: 3-161.

Nguyen, K.; Chollet-Krugler, M.; Gouault, N. \& Tomasi, S. (2013). UVprotectant metabolites from lichens and their symbiotic partners. Nat. Prod. Rep. 30: 1490-1508.

Odum, E.P. \& Barrett, G.W. (2008). Fundamentos de Ecología. Cengage Learning.

Oksanen, J. (1984). Interspecific contact and association in sand dune vegetation dominated by bryophytes and lichens. Ann. Bot. Fenn. 21: 189-199.

Orwin, J. (1970). Lichen succession on recently deposited rock surfaces. New Zeal. J. Bot. 8 (4): 452-477. 
Osorio, H.S. (1968). Contributions to the Lichen Flora of Argentina - I. Some lichens from the Province of Buenos Aires. Bryologist. 71 (3): 285-286.

Osorio, H.S. (1976). Contribution to the Lichen Flora of Argentina VIII. Lichens from Punta Lara, Buenos Aires Province. Bryologist. 79 (3): 358-360.

Osorio, H.S. (1977a). Apuntes de liquenología y clave para los géneros de líquenes de los alrededores de Buenos Aires. Notas Botánicas, Sociedad Argentina de Botánica. 1: 1-36.

Osorio, H.S. (1977b). Contribution to the Lichen Flora of Argentina X. Lichens from Santa Catalina, Buenos Aires Province. Bryologist. 80 (2): 363-364.

Osorio, H.S. (1980). Contribution to the Lichen Flora of Argentina XII. New or additional records from Buenos Aires Province. Bryologist. 83 (2): 219-220.

Osorio, H.S. (1987). Contribution to the Lichen Flora of Argentina. XVI. Lichens from Sierra de la Ventana, Buenos Aires Province. Comunicaciones Botánicas del Museo de Historia Natural de Montevideo. 4(78): 1-11.

Osorio, H.S. \& D'esposito, F.R. (1979). Contribution to the Lichen Flora of Argentina XI. Lichens from Cabo San Antonio, Buenos Aires Province. Mycotaxon. 8 (1): 239-242.

Osorio, H.S. \& Ranta, P. (1985). Contribution to the Lichen Flora of Argentina. XV. Maritime lichens from Mar del Plata, Buenos Aires Province. Comunicaciones Botánicas del Museo de Historia Natural de Montevideo. 4(69): 1-4.

Osyczka, P. (2010). Alien lichens unintentionally transported to the "Arctowski" station (South Shetlands, Antarctica). Polar Biol. 33: 1067-1073.

Ozenda, P. \& Clauzade, G. (1970). Les Lichens. Étude biologique et flore illustreé. Masson et Cie, Paris.

Palmer, M.W. (1993). Putting things in even better order: the advantages of canonical correspondence analysis. Ecology. 74:2215-30.

Palmer, M.W. (2004). Ordination Methods - an overview. http://www.monitor2manage.com.au/userdata/downloads/p_/Ordination\%20Met hods\%20-\%20an\%200verview.pdf 
Pentecost, A. (1980). Aspects of competition in saxicolous lichen communities. Lichenologist 12:135-144.

Pernaut, C. \& Casal, S.M. (2005). El Patrimonio arquitectónico contemporáneo de Buenos Aires. Contemporary architectural heritage in Buenos Aires. Documento de Trabajo № 138, Universidad de Belgrano.

Perelman, S.B.; Batista W.B. \& León, R.J.C. (2005). El estudio de la heterogeneidad de la vegetación. Fitosociología y técnicas relacionadas. En: Oesterheld, Aguiar, Ghersa \& Paruelo (eds.). La heterogeneidad de la vegetación de los agroecosistemas. Un homenaje a Rolando León: 321-350. Buenos Aires.Editorial Facultad de Agronomía.

Pickett, S.T.A.; Cadenasso, M.L.; Grove, J.M.; Nilon, C.H.; Pouyat, R.V.; Zipperer, W.C. \& Costanza R. (2008). Urban Ecological Systems: Linking Terrestrial Ecological, Physical, and Socioeconomic Components of Metropolitan Areas. In: Marzluff, J.M.; Shulenberger, E.; Endlicher, W.; Alberti, M.; Bradley, G.; Ryan, C.; Simon, U. \& ZumBrunnen, C. (eds.). Urban ecology. 99-123. NewYork. Springer.

Piergentili, D. (1947). Contribución al conocimiento de los líquenes de los alrededores de La Plata. Tesis, Facultad de Ciencias Naturales y Museo. Universidad Nacional de La Plata.

Poelt, J. (1969). Bestimmungschlüssel der europäischen Flechten. Cramer, Lehre.

Prieto, B.; Rivas, T. \& Silva, B. (1999). Environmental factors affecting the distribution of lichens on granitic monuments in the Iberian Peninsula. The Lichenologist. 31(3): 291-305.

Prieto Lamas, B.; Rivas Brae, M.T. \& Silva Hermo, B.M. (1995). Colonization by lichens of granite churches in Galicia northwest Spain. Sci. Total Environ. 167: 343-351.

Prieto, B.; Rivas, T.M. \& Silva, B. (1994). Colonization by lichens of granite dolmens in Galicia NW Spain. Int. Biodeterior. Biodegrad. 34: 47-60.

Purvis, O .W. (2000). Lichens. London. British Museum of Natural History. 112 pp. 
Purvis, O.W. \& Halls, C. (1996). A review of lichens in metal-enriched environments. Lichenologist. 28: 671-681.

Quiroga, G.; Estrabou, C. \& Rodríguez, J.M. (2008). Lichen community response to different management situations in Cerro Colorado protected forest (Córdoba, Argentina). LAZAROA. 29: 131-138.

Rambold, G. \& Triebel, D. (1992). The inter-lecanoralean associations. Bibl. Lichenol. 48: 3-201.

Rambold, G.; Davydov, E.; Elix, J.A., Nash III, T.H.; Scheidegger, C. \& Zedda, L. (2001). LIAS light - A Database for Rapid Identification of Lichens. liaslight.lias.net/.

Ribichich, A.M. (2002). El modelo clásico de la fitogeografía de Argentina: un análisis crítico. Interciencia. 27(12): 669-675.

Rivas-Plata, E.; Lücking, R.; Aptroot, A.; Sipman, H.J.M.; Chaves-Chaves, J.L.; Umaña-Tenorio, L. \& Lizano, D. (2006). A first assessment of the Ticolichen biodiversity inventory in Costa Rica: the genus Coenogonium (Ostropales: Coenogoniaceae), with a world-wide key and checklist and a phenotype-based cladistic analysis. Fungal Diversity. 23: 255-321.

Rodríguez, J.M. (2011). El género Usnea (Ascomycetes liquenizados) en Argentina: estudio sistemático y biogeográfico. Tesis doctoral, Facultad de Ciencias Exactas, Físicas y Naturales, Universidad Nacional de Córdoba.

Rodríguez, J.M.; Estrabou, C.; Fenoglio, R.; Robbiati, F.; Salas, M.C., \& Quiroga, G. (2009). Recuperación post-fuego de la comunidad de líquenes epífitos en la provincia de Córdoba, Argentina. Acta Bot. Bras. 23(3): 854-859.

Rojas-Fernández, J.A.; Balza-Quintero, A.; Marcano, V.; Rojas, P.A; DávilaVera, D.; Peña-Contreras, Z.; Mendoza-Briceño, R.V. \& Palacios-Prü, E. (2008). Metabolitos secundarios de líquenes de la zona nival de la Sierra Nevada de Mérida-Venezuela y su papel en la absorción de la radiación ultravioleta. Anales del Jardín Botánico de Madrid. 65(1): 59-72.

Rogers, R.W. (1977). Lichens of hot arid and semi-arid lands. In: M.D.R. Seaward (ed.). Lichen Ecology. 211-252. England, London. Academic Press. 
Rogers, R.W. (1990). Ecological strategies of lichens. Lichenologist 22:149162.

Rosato, V.G. (2003). Lichens found on "La Postera" bridge across Salado River, Chascomús (Buenos Aires province). Conference on Microbial Impact on Building Materials. Lisbon, Portugal.

Rosato, V.G. (2006). Diversity and distribution of lichens on mortar and concrete in Buenos Aires province, Argentina. Darwiniana. 44 (1): 89-97.

Rosato, V.G. \& Arup, U. (2010). Caloplaca austrocitrina (Teloschistaceae) new for South America, based on molecular and morphological studies. Bryologist. $113(1): 1-5$.

Rosato, V. G. \& García, R. A. (2012). El índice de peligrosidad de las plantas y su aplicación a edificios del patrimonio de la plata. VIII CINPAR 2012 (Congreso Internacional de Patologías y Restauración de Estructuras), La Plata, 4 al 6 de junio de 2012

Rosato, V. \& García, R. (2014). Clave de líquenes creciendo sobre cemento y hormigón en la provincia de Buenos Aires, Argentina. Glalia. 6(1): 1-14.

Rosato, V.G.; García, R. \& Viera Barreto, J. (2009). Análisis de cobertura de Caloplaca austrocitrina en las paredes de la Catedral de la Inmaculada Concepción de La Plata. 1er. Congreso Iberoamericano y VIII Jornada "Técnicas de Restauración y Conservación del Patrimonio". La Plata, Buenos Aires, Argentina.

Rosato, V.G.; Lofeudo, R.; Ilorio, F. \& García, R. (2016). Ensayos de dos sustancias hidrorrepelentes en ladrillos: ¿demoran el crecimiento de biofilmes? El caso de la catedral de La Plata, provincia de Buenos Aires, Argentina. En: Rosato, V.G. (ed.). Deterioro biológico de materiales y técnicas para su limpieza y preservación. 55-59. CICBA, Argentina.

Rosato, V.G. \& Scutari, N.C. (2001). On the presence of Ramalina complanata (Ramalinaceae, Lichenized Ascomycotina) and allied species in Arentina. Mycotaxon. 74(1): 141-151. 
Ruchty, A; Rosso, A.L. \& McCune, B. (2001). Changes in epiphyte communities as the shrub, Acer circinatum, develops and ages. Bryologist. 104: 272-281.

Rundel, P.W. (1978). The Ecological Role of Secondary Lichen Substances. Biochem. Syst. Ecol. 6: 157-170.

Saiz-Jiménez, C. \& Ariño, X. (1995). Colonización biológica y deterioro de morteros por organismos fotótrofos. Materiales de construcción. 45(240): 5-16.

Sánchez, R.; Mattus, M. \& Zulaica, L. (1999). Compartimentación Ecológica y Ambiental del Partido de Tandil (Provincia de Buenos Aires). En Ambiental '99: 338-346. San Juan.

Sancho, L.G.; de la Torre, R.; Horneck, G.; Ascaso, C.; de los Ríos, A.; Pintado, A.; Wierzchos, J. \& Schuster, M. (2007). Lichens survive in space: Results from 2005 LICHENS experiment. Astrobiology. 7: 443-454.

Schroeter, B. \& Sancho, L.G. (1996). Lichens Growing on Glass in Antarctica. Lichenologist. 28 (4): 385-390.

Scutari, N.C. \& Theinhardt, N.I. (2001). Identificacion of urban lichens in the field: a case study for Buenos Aires city (Argentina). Mycotaxon. 80: 427-445.

Scutari, N.C. (1992a). Los géneros foliosos y fruticosos de Physciaceae, Candelariaceae y Teloschistaceae (Ascomicotina liquenizados) de la provincia de Buenos Aires. Tesis Doctoral, Facultad de Ciencias Exactas y Naturales, Universidad de Buenos Aires.

Scutari, N.C. (1992b). Estudios sobre Pyxinaceae foliosas (Lecanorales, Ascomycotina) de la Argentina IV: Clave de los géneros y las especies de la Provincia de Buenos Aires. Bol. Soc. Argent. Bot. 28: 169-173.

Scutari, N.C. (1995a). Los macrolíquenes de Buenos Aires, I: Dirinaria, Heterodermia e Hyperphyscia (Physciaceae, Ascomycotina). Darwiniana. 33: 149-176.

Scutari, N.C. (1995b). Los macrolíquenes de Buenos Aires, II: Phaeophyscia, Physcia y Pyxine (Physciaceae, Ascomycotina). Darwiniana. 33: 211-231. 
Seaward, M.R.D. (1979). Lower plants and the urban landscape. Urban Ecology. 4: 217-225.

Seaward, M.R.D. (1997). Urban deserts bloom: a lichen renaissance. Bibl. Lichenol. 67: 297-309.

Seaward, M.R.D. (2008). Environmental role of lichens. In: T.H. Nash III (ed.). Lichen biology. 274-295. Cambridge, Cambridge University Press.

Seaward, M.R.D. \& Coppins, B.J. (2004). Lichens and hypertrophication. Bibl. Lichenol. 88: 561-572.

Seaward, M.R.D.; Diacobini, C.; Giuliani, M.R. \& Roccardi, A. (1989). The role of lichens in the biodeterioration of ancient monuments with particular reference to Central Italy. Int. Biodeterior. 25: 49-55.

Sempé, M.C. \& Flores, B.O. (2011). El cementerio de La Plata y su contexto histórico. Municipalidad de La Plata.

Sheskin, D.J. (2003). Handbook of Parametric and Nonparametric Statistical Procedures. Boca Raton, United States CRC Press. 1926 pp.

Signorini, M.A., (1996). L'Indice di Pericolosita': un contributo del botanico al controllo della vegetazione infestante nelle aree monumentali. Informatore Botanico Italiano. 28: 7-14.

Simonová, D. (2008a). Alien flora on walls in southern and western Moravia (Czech Republic). In: Tokarska-Guzik, B., Brock, J.H., Brundu, G.; Child, L, Daehler, C.C. \& Pyšek, P. (eds). Plant invasions: human perception, ecological impacts and management. 317-332. Leiden. Backhuys Publishers.

Simonová, D. (2008b). Rostlinná společenstva zdí na jižní a západní Moravě (Plant communities on walls in southern and western Moravia). Príroda: 26:6583.

Sipman, H. \& Aptroot, A. (2001). Where are the missing lichens? Mycological Research. 105: 1433-1439.

Słaby A. \& Lisowska M. (2012). Epiphytic lichen recolonization in the centre of Cracow (Southern Poland) as a result of air quality improvement. Pol. J. Ecol. 60(2): 225-240. 
Sosa-Escalante, J. (2004). Valoración y seguimiento de la biodiversidad: implicaciones en conservación y manejo. Departamento de Zoología, Facultad de Medicina Veterinaria y Zootecnia, Universidad Autónoma de Yucatán. Mérida, México.

Sota, J.D.; Lugo, M.V.; Iloro, F.H. \& Traversa, L.P. (2004). Investigaciones y estudios sobre revoques simil piedra. III Jornada de Técnicas de Reparación y Conservación del Patrimonio.

Souza-Egipsy, V. \& García Sancho, L. (2001). Descripciones del micro clima en dos comunidades del SE semiárido de la Península Iberica. Ninbus. 7-8: 187-212.

Sparrius, L.B.; Aptroot, A. \& van Herk, K. (2007). Diversity and ecology of lichens on churches in the Netherlands. Nova Hedwigia. 85: 299-316.

Spegazzini, C. (1896). Contribución al estudio de la flora de la Sierra de la Ventana. Talleres de Publicaciones del Museo. La Plata. 1-8.

Spegazzini, C. (1901). Stipeae platenses. Anales del Museo de Historia Natural de Montevideo. 4: 1-173.

Spribille, T., et al. (2016) Basidiomycete yeasts in the cortex of ascomycete macrolichens. Science. 353(6298): 488-492.

St. Clair, L.L. \& Seaward M.D. (2004). Biodeterioration of Rock Substrata by Lichens: Progress and Problems. In: St. Clair, L.L. \& Seaward, M.D. (eds.). Biodeterioration of Stone Surfaces. 1-8. Kluwer Academic Publishers, The Netherlands.

Stone, D.F. (1989). Epiphytic succession on Quercus garryana branches in the Willamette Valley of western Oregon. Bryologist. 92:81-94.

Szczepańska, K.; Pruchniewicz, D. \& Kossowska, M. (2015). Modeling the potential distribution of three lichens of the Xanthoparmelia pulla group (Parmeliaceae, Ascomycota) in Central Europe. Acta Soc. Bot. Pol. 84 (4): 431438.

Tehler, A. \& Wedin, M. (2008). Systematics of lichenized fungi. In: Nash, T.H. III (ed.). Lichen biology. 336-341. Cambridge. Cambridge University Press, England. 
Tilman, D. \& Kareiva, P. (1997). Spatial Ecology: The role of space in population dynamics and interspecific interactions. Monographs in Population Biology 30. Princeton University Press, Princeton. 416 pp.

Topham, P.B. (1977). Colonization, growth, succession and competition. In: M.D.R. Seaward (ed.). Lichen Ecology. 31-68. London. Academic Press.

Traversa, L.P. (2010). Patrimonio religioso en colonias, pueblos y localidades de la provincia de Buenos Aires. Anales LEMIT serie 3, año 1.

Traversa, L.P. (2011). Determinación de la composición de morteros endurecidos de cal, híbridos y de cemento pórtland. II Congreso Iberoamericano y X Jornada de Técnicas de Reparación y Conservación del Patrimonio.

Traversa, L.P.; Di Maio, A. \& Longoni, R. (2003). Puesta en valor de algunas construcciones del ing. Salamone. II Jornada de Técnicas de Reparación y Conservación del Patrimonio. La Plata.

Traversa, L.P.: Coelho Dos Santos, G. \& Iloro, F.H. (2013). Estudio del mortero de revestimiento de un estanque de una mansión patrimonial de fines del siglo XIX. XI Jornada de Técnicas de Reparación y Conservación del Patrimonio.

Traversa, L.P.; lloro, F.H. \& Marquez, S. (2007). Relevamiento del patrimonio religioso católico en colonias, pueblos y localidades de la provincia de Buenos Aires. VI Jornada de Técnicas de Restauración y Conservación del Patrimonio.

Traversa, L.P.; lloro, F.H. \& Marquez, S. (2011). Determinación de la composición de morteros de la envolvente del Museo de Ciencias Naturales de la ciudad de La Plata. Ciencia y Tecnología de los Materiales 1: 63-74.

Tretiach, M. (1995). Ecophysiology of calcicolous endolithic lichens: progress and problems. G. Bot. Ital. 129: 159-184.

Urzì, C.; De Leo, F.; Salamonee, P. \& Criseo, G. (2001). Airborne fungal spores colonising marbles exposed in the terrace of Mesina Museum, Sicily. Aerobiologia. 17: 11-7. 
Van Herk, C.M.; Aptroot, A. \& van Dobben, H.F. (2002). Long-term monitoring in the Netherlands suggests that lichens respond to global warming. Lichenologist. 34: 141-154.

Viglizzo, E.F., Frank, F.C. \& Carreño, L.V (2006). La situación ambiental en las ecorregiones Pampa y Campos y Malezales. En: Brown, A., Martinez Ortiz U., Acerbi M. \& Corcuera J. (Eds.) La Situación Ambiental Argentina. 263-269. Buenos Aires. Fundación Vida Silvestre Argentina.

Weber, B. \& Büdel, B. (2001). Mapping and analysis of distribution patterns of lichens on rural medieval churches in north-eastern Germany. Lichenologist. 33(3): 231-249.

Welch, A.R. (2002). The effect of anthropogenic nutrient addition on the growth and competitive ability of Parmelia caperata, Parmelia reddenda, Parmelia saxatilis, and Xanthoria parietina in Cornwall. PhD Thesis, The Open University, UK.

Wessels, D.C.J. \& Schoeman, B. (1988). Mechanism and rate of weathering of Clarens sandstone by an endolithic lichen. S. Afr. J. Sci. 84: 274-277.

Wierzchos, J. \& Ascaso, C. (1996). Morphological and chemical features of bioweathered granitic biotite induced by lichen activity. Clays Clay Miner. 44: 652-657.

Whittaker, R.H. (1972). Evolution and measurement of species diversity. Taxon. 21: 213-251.

White, F.J. \& James, P.W. (1985). A new guide to microchemical techniques for the identification of lichen substances. British Lichen Society Bulletin 57 (supplement): 1-41.

Wirth, V. (2001). Zeigerwerte von Flechten. Scripta Geobotanica. 18: 221-243.

Wilson, M. \& Shmida, A. (1984). Measuring beta diversity with presenceabsence data. J. Ecol. 72: 1055-1064.

Woolhouse, M.E.J.; Harmsen, R. \& Fahrig, L. (1985). On succession in a saxicolous lichen community. Lichenologist. 17 (2): 167-172. 
Zárate, M. \& Rabassa, J. (2005). Geomorfología de la provincia de Buenos Aires. En: de Barrio, R.; Etcheverry, R.; Caballé, M. \& Llambías, E. (eds.) Relatorio XVI Congreso Geológico Argentino. Geología y recursos Minerales de la provincia de Buenos Aires 119-138.

Zimmerman, D.W. (1987). Comparative power of Student T Test and MannWhitney $U$ Test for unequal sample sizes and variances. The Journal of Experimental Education. 55(3): 171-174. 


\section{ANEXO I. Recomendaciones para la conservación del patrimonio}

Si bien este no es el fin de ésta tesis no es posible obiar que los líquenes al crecer sobre construcciones humanas adquieren un valor por su implicancia en la conservación del patrimonio. Por este motivo la información que se encuentra en esta tesis podría ser usada para tales fines por lo que a continuación se compendian y discuten un conjunto de recomendaciones basadas en datos y bibliografía para contribuir a la conservación del patrimonio.

Los líquenes al crecer sobre las estructuras antrópicas también producen biodeterioro sobre las mismas, diferenciándose 3 tipos de efecto asociados a su desarrollo sobre las estructuras:

-Deterioro estético: es dado por organismos que solo se apoyan o crecen sobre sedimentos acumulados en la estructura, sin producir ningún tipo de efecto sobre el mismo, solo desmejoran la visual propia de la estructura.

-Deterioro mecánico: se lleva a cabo por estructuras que penetran el sustrato tales como raíces, hifas, rizines, que producen una presión sobre el material circundante a medida que estas estructuras crecen se ahondan en el sustrato. Esto puede llevar a la formación de desprendimientos, fisuras, y hasta problemas estructurales de grandes sectores

-Deterioro químico: es producido por las sustancias químicas que los organismos liberan para degradar el sustrato, poder obtener nutrientes y poder adherirse mejor a las superficies. Esto produce el desgaste del material, cambios en su textura y aspecto.

Típicamente, las medidas de control van desde la remoción mecánica hasta la aplicación de varios tipos de biocidas. Dado que muchas especies de líquenes son capaces de regenerarse a partir de fragmentos de talo, la eliminación mecánica de líquenes solo puede reducir temporalmente la cobertura de líquenes y causar daños físicos significativos a las superficies de las rocas. La aplicación de biocidas puede producir cambios en la dinámica de la comunidad, con especies sobrevivientes que explotan agresivamente el espacio vacio de otras especies, talos muertos persistentes, que se 
descomponen lentamente, y daños a las superficies del sustrato (St. Clair \& Seaward, 2004).

Ante esta situación, hay cuatro factores que deben considerarse atentamente para la correcta protección y restauración de estructuras: las especies, las causas de su crecimiento, el daño que produjeron y la velocidad de la colonización (Nimis, 2001). En algunos casos la presencia de los líquenes estará asociadas a una condición particular, por lo cual es necesario una correcta identificación de las especies en cuestión, como así también conocer las características de la misma nos permitirán conocer sus posibles preferencias y su velocidad de crecimiento. Un ejemplo es el caso de los líquenes nitrofíticos, donde eliminarlos sin identificar la fuente de compuestos de nitrógeno es poco efectivo ya que volverán a crecer mientras la fuente de nitrógeno continue. Si se debe a depósitos de guano, la población de aves debe ser sometida a control o se deben construir estructuras que impidan que las aves lleguen a los monumentos (Aptroot \& James, 2002).

Si el crecimiento de los agentes de biodeterioro se deriva de la disponibilidad de agua se pueden tomar medidas sencillas, tales como revestimientos o canalización y desviación del agua de lluvia, si un monumento está expuesto a la lluvia -o al agua de lluvia de las canaletas- (Aptroop \& James, 2002). Otra opción es la aplicación de algún recubrimiento que impermeabilice la superficie evitando que esta esté húmeda se crearía un ambiente aún más hostil lo que bajaría las posibilidades de la instalación algunas especies. La impermeabilización también causaría que el agua escurra arrastrando los propágulos que se pudieran adherir al muro. Aunque cabe señalar que si esto no se hace de manera rutinaria la colonización del muro vuelve a suceder al cabo de unos años, como ya se ha podido observar (Rosato et al., 2016).

Rosato y García (2012) evaluaron la posible peligrosidad de los líquenes mediante el índice de Signorini (1996) que tiene en cuenta las características morfológicas de los distintos organismos. En el caso de los líquenes, el mismo ha sido de valor 2, una peligrosidad baja y no representando peligro alguno para la estructura. En la provincia de Buenos Aires, la mayoría de los líquenes encontrados son de morfología crustosa y a su vez, son los de mayor cobertura 
sobre estas estructuras. De esto se desprende que el principal perjuicio seria estético, pero hay que considerar también que, en el caso de los morfotipos crustosos al tener una unión tan íntima con el sustrato, la eventual remoción puede causar mayor daño que el accionar del liquen. La presencia de propágulos puede ser un factor que favorezca una nueva colonización en un tiempo breve, por lo que previa a la remoción se debería aplicar un biocida que tampoco altere la superficie con el fin de eliminar la mayor parte de la materia orgánica y evitar la dispersión de isidios y soredios.

Teniendo lo anterior en mente antes de la intervención se debe evaluar la relación de costo beneficio, siendo que la remoción de los líquenes o las medidas necesarias para evitar la instalación de propagulos podrían traer aparejado un deterioro de la estructura que se pretende resguardar. En algunos casos las especies de líquenes en realidad podrían estar protegiendo la frágil estructura subyasente de los efectos físicos del ambiente, los cuales podrian ser más perjudiciales que la misma presencia de los líquenes (Camuffo, 1995; Carter \& Viles, 2003). Por lo que también es necesario entender la estructura afectada siendo que el muro de un edificio no se verá tan afectado como una escultura antigua con una gran cantidad de detalles. De realizar alguna acción de limpieza de los líquenes es necesaria la monitorización periódica para observar una posible recolonización después de la eliminación, como así también es necesario realizar pruebas previas para evaluar la eficacia del tratamiento sobre las especies. 


\section{ANEXO II. Diversidad de familias y especies de líquenes registrados}

Biota liquénica de la provincia de Buenos Aires registradas (bases de datos taxonómicas) y abreviaturas utilizadas en los análisis.

\begin{tabular}{|c|c|c|}
\hline Especie & Familia & abreviatura \\
\hline Acarospora altoandina H. Magn. & Acarosporaceae & Aca_alt \\
\hline Acarospora fuscata (Nyl.) Th. Fr. & Acarosporaceae & Aca_fus \\
\hline Acarospora lorentzii (Müll. Arg.) Hue & Acarosporaceae & Aca_lor \\
\hline Acarospora mendozana H. Magn. & Acarosporaceae & Aca_men \\
\hline Acarospora rhabarbarina Hue & Acarosporaceae & Aca_rha \\
\hline Acarospora strigata (Nyl.) Jatta & Acarosporaceae & Aca_str \\
\hline Acarospora subcastanea (Nyl.) Hue & Acarosporaceae & Aca_sub \\
\hline $\begin{array}{l}\text { Amandinea punctate (Hoffm.) Coppins \& } \\
\text { Scheid. }\end{array}$ & Caliciaceae & Ama_pun \\
\hline $\begin{array}{l}\text { Athallia holocarpa (Hoffm.) Arup, Frödén } \\
\text { \& Søchting }\end{array}$ & Teloschistaceae & Ath_hol \\
\hline $\begin{array}{l}\text { Bacidina pallidocarnea (Müll. Arg.) Vězda } \\
\text { Brownliella cinnabarina (Ach.) S.Y. }\end{array}$ & Ramalinaceae & Bac_pal \\
\hline $\begin{array}{l}\text { Kondr., Kärnefelt, A. Thell, Elix, J.Kim, } \\
\text { A.S.Kondr. \& J. S.Hur }\end{array}$ & Teloschistaceae & Bro_cin \\
\hline Buellia fraudans (Starbäck) Elix & Caliciaceae & Bue_fra \\
\hline Buellia spuria (Schaer.) Anzi & Caliciaceae & Bue_spu \\
\hline Caloplaca erythrantha (Tuck.) Zahlbr. & Teloschistaceae & Cal_ery \\
\hline Caloplaca puiggarii (Müll. Arg.) Zahlbr. & Teloschistaceae & Cal_pui \\
\hline Caloplaca rugulosa (Nyl.) Zahlbr. & Teloschistaceae & Cal_rug \\
\hline Caloplaca teicholyta (Ach.) J. Steiner & Teloschistaceae & Cal_tei \\
\hline Caloplaca xanthobola (Kremp.) Zahlbr. & Teloschistaceae & Cal_xan \\
\hline Candelaria concolor (Dicks.) Arnold & Candelariaceae & Can_con \\
\hline Candelaria fibrosa (Fr.) Müll. Arg. & Candelariaceae & Can_fib \\
\hline Candelariella aurella (Hoffm.) Zahlbr. & Candelariaceae & Can_aur \\
\hline $\begin{array}{l}\text { Carbonea latypizodes (Nyl.) Knoph \& } \\
\text { Rambold }\end{array}$ & Lecanoraceae & Car_lat \\
\hline Catillaria chalybaeoides Malme & Catillariaceae & Cat_cha \\
\hline Chrysothrix candelaris (L.) J.R. Laundon & Chrysotrichaceae & Chy_can \\
\hline Cladia aggregata (Sw.) Nyl. & Cladoniaceae & Cla_agr \\
\hline Cladonia pyxidata (L.) Hoffm. & Cladoniaceae & Cla_pyx \\
\hline Coenogonium interplexum Nyl. & Coenogoniaceae & Coe_int \\
\hline $\begin{array}{l}\text { Coenogonium isidiigerum (Vězda \& } \\
\text { Osorio) Lücking, Aptroot \& Sipman }\end{array}$ & Coenogoniaceae & Coe_isi \\
\hline $\begin{array}{l}\text { Coenogonium pyrophthalmum (Mont.) } \\
\text { Lücking, Aptroot \& Sipman }\end{array}$ & Coenogoniaceae & Coe_pyr \\
\hline $\begin{array}{l}\text { Crespoa crozalsiana (B. de Lesd. ex } \\
\text { Harm.) Lendemer \& B.P. Hodk. }\end{array}$ & Parmeliaceae & Cre_cro \\
\hline Diploschistes cinereocaesius (Sw.) Vain. & Graphidaceae & Dip_cin \\
\hline
\end{tabular}


Flavoparmelia exornata (Zahlbr.) Hale

Flavoparmelia haysonii (C.W. Dodge)

Hale

Flavoparmelia papillosa (Lynge ex

Gyeln.) Hale

Flavoparmelia soredians (Nyl.) Hale

Flavoplaca austrocitrina (Vondrák, Ríha,

Arup \& Søchting) Arup, Søchting \&

Frödén

Glyphis cicatricosa Ach

Graphis anfractuosa (Eschw.) Eschw.

Graphis geraensis Redinger

Graphis lineola Ach

Graphis submarginata Lücking

Graphys virescens Müll. Arg.

Haematomma montevidense (Räsänen)

Follmann \& Redón

Hafellia parastata (Nyl.) Kalb

Halecania australis Lumbsch

Heterodermia comosa (Eschw.) Follmann

\& Redón

Heterodermia diademata (Taylor) D.D.

Awasthi

Heterodermia obscurata (Nyl.) Trevis.

Heterodermia speciosa (Wulfen) Trevis.

Heterodermia squamulosa (Degel.) W. L.

Culb

Huneckia pollinii (A. Massal.) S.Y. Kondr.,

Kärnefelt, A. Thell, Elix, J. Kim, A.S.

Kondr. \& Hur

Hypotrachyna dactylifera (Vain.) Hale

Lecania erysibe (Ach.) Mudd.

Lecania ryaniana van den Boom

Lecanora farinacea Fée

Lecanora helva Stizenb

Lecanora microcarpa Nyl.

Lecanora tropica Zahlbr.

Lecidella carpathica Körb

Leptogium azureum (Sw.) Mont.

Leptogium cyanescens (Rabenh.) Körb.

Leptogium marginellum (Sw.) Gray

Malcomiella leptoloma (Müll. Arg.) Kalb \&

Lücking, in Kalb, Rivas Plata, Lücking \&

Lumbsch

Monoblastia echinulospora (Riddle) R.C.

Harris

Myriolecis dispersa (Pers.) Śliwa, Zhao

Xin \& Lumbsch

Myriolecis hagenii (Ach.) Śliwa, Zhao Xin
Parmeliaceae

Fla_exo

Parmeliaceae

Fla_hay

Parmeliaceae

Fla_pap

Parmeliaceae

Fla_sore

Teloschistaceae

Fla aus

Graphidaceae

Gly_cic

Graphidaceae

Gra_anf

Graphidaceae

Gra_ger

Graphidaceae

Gra_lin

Graphidaceae

Graphidaceae

Haematommaceae

Caliciaceae

Catillariaceae

Physciaceae

Physciaceae

Physciaceae

Physciaceae

Physciaceae

Physciaceae

Parmeliaceae

Lecanoraceae

Ramalinaceae

Lecanoraceae

Lecanoraceae

Lecanoraceae

Lecanoraceae

Lecanoraceae

Collemataceae

Collemataceae

Collemataceae

Pilocarpaceae

Monoblastiaceae

Lecanoraceae

Lecanoraceae
Mal_lep

Mon_ech

Myr_dis

Gra_sub

Gra vir

Hae_mon

Haf_par

Hal_aus

Het_com

Het_dia

Het_obs

Het_spe

Het_squ

Hun_pol

Hyp_dac

Lec_ery

Lec_rya

Lec_far

Lec hel

Lec_mic

Lec_tro

Lec_car

Lep_azu

Lep_cya

Lep_mar

Myr_hag 
\& Lumbsch

Oxneria fallax (Arnold) S.Y. Kondr. \&

Kärnefelt

Parmotrema cetratum (Ach.) Hale

Parmotrema consor (Nyl.) Blanco,

Crespo, Divakar, Elix \& Lumbsch

Parmotrema eciliatum (Nyl.) Hale

Parmotrema fistulatum (Taylor) $\mathrm{O}$.

Blanco, A. Crespo, Divakar, Elix \&

Lumbsch

Parmotrema pilosa (Stizenb.) Blanco,

Crespo, Divakar, Elix \& Lumbsch

Parmotrema reticulatum (Taylor) M.

Choisy

Parmotrema tandilensis (Adler \& Elix)

Blanco, Crespo, Divakar, Elix \& Lumbsch

Peltula omphaliza (Nyl.) Wetmore

Pertusaria patagónica Müll. Arg.

Phaeophyscia chloantha (Ach.) Moberg

Phaeophyscia hirsuta (Mereschk.) Essl.

Phyllopsora corallina (Eschw.) Müll. Arg

Physcia aipolia (Ehrh. ex Humb.) Fürnr.

Physcia alba (Fée) Müll. Arg.

Physcia albata (F. Wilson) Hale

Physcia cinerea Moberg

Physcia convexella Moberg

Physcia crispa Nyl.

Physcia erumpens Moberg

Physcia poncinsii Hue

Physcia rolfii Moberg

Physcia stellaris (L.) Nyl.

Physcia tribacia (Ach.) Nyl.

Physcia undulata Moberg

Polycauliona candelaria (L.) Frödén, Arup

\& Søchting

Porina nucula Ach.

Psora icterica (Mont.) Müll. Arg.

Punctelia colombiana Sérus.

Punctelia constantimontium Sérus

Punctelia hypoleucites (Nyl.) Krog

Punctelia perreticulata (Räsänen) G.

Wilh. \& Ladd

Punctelia punctilla (Hale) Krog

Punctelia semansiana (W.L. Culb. \& C.F.

Culb.) Krog

Punctelia subpraesignis (Nyl.) Krog

Pyrenula pyrenuloides (Mont.) R.C. Harris

Pyxine berteriana (Fée) Imshaug

Teloschistaceae

Parmeliaceae

Parmeliaceae

Parmeliaceae

Parmeliaceae

Parmeliaceae

Parmeliaceae

Parmeliaceae

Peltulaceae

Pertusariaceae

Physciaceae

Physciaceae

Ramalinaceae

Physciaceae

Physciaceae

Physciaceae

Physciaceae

Physciaceae

Physciaceae

Physciaceae

Physciaceae

Physciaceae

Physciaceae

Physciaceae

Physciaceae

Teloschistaceae

Poninaceae

Psoraceae

Parmeliaceae

Parmeliaceae

Parmeliaceae

Parmeliaceae

Parmeliaceae

Parmeliaceae

Parmeliaceae

Pyrenulaceae

Caliciaceae
Oxn_fal

Par_cet

Par_con

Par_eci

Par_fis

Par_pil

Par_ret

Par_tan

Pel_omp

Per_pat

Pha_chl

Pha_hir

Phy_cor

Phy_aip

Phy_alb

Phy_alba

Phy_cin

Phy_con

Phy_cri

Phy_eru

Phy_pon

Phy_rol

Phy_ste

Phy_tri

Phy_und

Pol_can

Por_nuc

Pso_ict

Pun_col

Pun_con

Pun_hyp

Pun_per

Pun_pun

Pun_sem

Pun_sub

Pyr_pyr

Pyx_ber 
Pyxine cocoes (Sw.) Nyl.

Pyxine subcinerea Stirt.

Ramalina aspera Räsänen

Ramalina celastri (Spreng.) Krog \&

Swinscow

Rhizocarpon disporum (Nägeli ex Hepp)

Müll. Arg.

Rhizocarpon geographicum (L.) DC.

Rhizocarpon reductum Th. Fr.

Rhizocarpon superficiale (Schaer.)

Malme

Rinodina oxydata (A. Massal.) A. Massal.

Sarcogyne meridionalis P.M. McCarthy \&

Kantvilas

Sarcogyne regularis Körb.

Scytinium rogersii (Verdon) Otálora, P.M. Jørg. \& Wedin

Staurothele monosporoide R. Sant.

Teloschistes chrysophthalmus (L.)

Norman ex Tuck.

Umbilicaria haplocarpa Nyl.

Umbilicaria krempelhuberi Müll. Arg.

Usnea amblyoclada (Müll. Arg.) Zahlbr.

Usnea densirostra Taylor

Usnea exigua J.M. Rodr. \& P. Clerc

Usnea fastuosa (Müll. Arg.) Zahlbr.

Usnea strigosa (Ach.) Pers.

Xanthoparmelia farinosa (Vain.) T.H.

Nash, Elix \& J. Johnst.

Xanthoparmelia hypopsila (Müll. Arg.)

Hale

Xanthoparmelia saxeti (Stizenb.) G Amo,

A. Crespo, Elix \& Lumbsch

Xanthoparmelia scabrosa (Taylor) Hale

Xanthoparmelia squamans (Stizenb.)

Blanco, Crespo, Divakar, Elix \& Lumbsch

Xanthoparmelia wrightiana T.H. Nash,

Elix \& J. Johnst.

Xanthoparmelia microspora (Müll. Arg.)

Hale

Xanthoparmelia rupicola (Lynge) Elix \& J.

Johnst

Xanthoria parietina (L.) Th. Fr.
Caliciaceae

Caliciaceae

Ramalinaceae

Ramalinaceae

Rhizocarpaceae

Rhizocarpaceae

Rhizocarpaceae

Rhizocarpaceae

Physciaceae

Acarosporaceae

Acarosporaceae

Collemataceae

Verrucariaceae

Teloschistaceae

Umbilicariaceae

Umbilicariaceae

Parmeliaceae

Parmeliaceae

Parmeliaceae

Parmeliaceae

Parmeliaceae

Parmeliaceae

Parmeliaceae

Parmeliaceae

Parmeliaceae

Parmeliaceae

Parmeliaceae

Parmeliaceae

Parmeliaceae

Teloschistaceae
Pyx_coc

Pyx_sub

Ram_asp

Ram_cel

Rhi_dis

Rhi_geo

Rhi_red

Rhi_sup

Rin_oxy

Sar_reg

Scy_rog

Sta_mon

Tel_chy

Umb_hap

Umb_kre

Usn_amb

Usn_den

Usn_exi

Usn_fas

Usn_str

Xan_far

Xan_hyp

Xan_sax

Xan_sca

Xan_squ

Xan_wri

Xan_mic

Xan_rup

Xan_par 